\title{
Indoor acids and bases
}

\section{Nazaroff, William W.; Weschler, Charles J.}

\section{Published in: \\ Indoor Air}

Link to article, DOI:

10.1111/ina.12670

Publication date:

2020

\section{Document Version}

Peer reviewed version

Link back to DTU Orbit

\section{Citation (APA):}

Nazaroff, W. W., \& Weschler, C. J. (2020). Indoor acids and bases. Indoor Air, 30(4), 559-644. https://doi.org/10.1111/ina.12670

\section{General rights}

Copyright and moral rights for the publications made accessible in the public portal are retained by the authors and/or other copyright owners and it is a condition of accessing publications that users recognise and abide by the legal requirements associated with these rights.

- Users may download and print one copy of any publication from the public portal for the purpose of private study or research.

- You may not further distribute the material or use it for any profit-making activity or commercial gain

- You may freely distribute the URL identifying the publication in the public portal

If you believe that this document breaches copyright please contact us providing details, and we will remove access to the work immediately and investigate your claim. 
PROF. WILLIAM W NAZAROFF (Orcid ID : 0000-0001-5645-3357)

DR. CHARLES J WESCHLER (Orcid ID : 0000-0002-9097-5850)

Article type : Invited Review

\section{Indoor acids and bases}

William W Nazaroff ${ }^{1}$ and Charles J. Weschler 2,3

${ }^{1}$ Department of Civil and Environmental Engineering, University of California, Berkeley, CA, USA

2 Environmental and Occupational Health Sciences Institute, Rutgers University, Piscataway, NJ, USA

${ }^{3}$ International Centre for Indoor Environment and Energy, Technical University of Denmark, Lyngby, Denmark

Correspondence: William W Nazaroff, Civil and Environmental Engineering Department, University of California, Berkeley, CA, USA.

Email: nazaroff@berkeley.edu

\section{Abstract} Numerous acids and bases influence indoor air quality. The most abundant of these species are $\mathrm{CO}_{2}$ (acidic) and $\mathrm{NH}_{3}$ (basic); building occupants are important sources. Other prominent inorganic acids are $\mathrm{HNO}_{3}, \mathrm{HONO}, \mathrm{SO}_{2}, \mathrm{H}_{2} \mathrm{SO}_{4}, \mathrm{HCl}$ and $\mathrm{HOCl}$. Prominent organic acids include formic, acetic and lactic; nicotine is a noteworthy organic base. Sources of $\mathrm{N}-_{-}, \mathrm{S}-$, and $\mathrm{Cl}$-containing acids can include ventilation from outdoors, indoor combustion, consumer product use, and chemical reactions. Organic acids are commonly more abundant indoors than outdoors, with indoor sources including occupants, wood, and cooking. Beyond $\mathrm{NH}_{3}$ and nicotine, other noteworthy bases include inorganic

This article has been accepted for publication and undergone full peer review but has not been through the copyediting, typesetting, pagination and proofreading process, which may lead to differences between this version and the Version of Record. Please cite this article as doi: $\underline{10.1111 / \text { INA.12670 }}$

This article is protected by copyright. All rights reserved 
and organic amines. Acids and bases partition indoors among the gas phase, airborne particles, bulk water, and surfaces; relevant thermodynamic parameters governing the partitioning are the aciddissociation constant $\left(p K_{\mathrm{a}}\right)$, Henry's law constant $\left(K_{\mathrm{H}}\right)$, and the octanol-air partition coefficient $\left(K_{\text {oa }}\right)$. Condensed-phase water strongly influences the fate of indoor acids and bases and is also a medium for chemical interactions. Indoor surfaces can be large reservoirs of acids and bases. This extensive review of the state of knowledge establishes a foundation for future inquiry to better understand the roles of acids and bases influencing human health, preservation of cultural artifacts, and protection of sensitive equipment.

\section{Practical Implications}

- Acids and bases are major components of indoor air, potentially influencing health risks, perceived air quality, and material damage.

- Buildings are partially protective when outdoor air is the dominant source, as is the case for sulfur dioxide and aerosol strong acidity.

- Human emissions lead to higher indoor than outdoor concentrations for carbon dioxide, ammonia, and a broad suite of organic acids, amines and amino acids.

- Wood emissions, cleaning with bleach and smoking lead to higher indoor than outdoor concentrations for formic and acetic acid, hypochlorous acid, and nicotine, respectively.

- In typical indoor environments, excepting $\mathrm{CO}_{2}$, the mass of acids and bases sorbed to surfaces and in condensed-phase water is commonly much larger than the co-occurring mass in air.

Keywords: Ammonia, Carbon dioxide, Chemistry, Sources, Surfaces, Water

\section{INTRODUCTION}

The chemical composition of indoor air influences its healthfulness as well as its suitability for preserving cultural artifacts and protecting sensitive electronic equipment. As measurement technologies have improved, our understanding of the complexity of indoor air has grown. A striking feature of the atmosphere in general and of indoor environments in particular is the steep increase in the number of chemical species of potential interest as the minimum quantifiable concentration 
diminishes. In the atmosphere, the number of chemical species present at a level of $0.1 \%$ or higher is only four: $\mathrm{N}_{2}, \mathrm{O}_{2}, \mathrm{Ar}$, and $\mathrm{H}_{2} \mathrm{O}$. Decreasing the minimum level of concern to one part per million adds only a few components, such as $\mathrm{CO}_{2}$ and $\mathrm{CH}_{4}$. However, when the threshold for concern is set at a part per billion or a part per trillion, the number of constituents rises to hundreds or thousands of species. These numerous species exhibit a broad range of chemical properties and pose diverse health-risk and material-damage concerns.

Even at relatively low fractional abundance, some chemical components may significantly influence the attributes of indoor air. Thinking about the vast number of molecules in a given macroscopic air volume can help to establish perspective. Consider, for example, that adults inhale an average of 15 $\mathrm{m}^{3}$ or about 600 moles of air daily. This daily quantity of inhaled air corresponds to almost $4 \times 10^{26}$ molecules. Even at the small fractional abundance of one part per trillion, the daily number of molecules of a trace species inhaled could be nearly 400 trillion.

In part because of the large number of compounds of potential interest, it is scientifically valuable to categorize species according to key properties. One prominent example is the grouping of organic compounds into categories based on volatility, i.e., very volatile organic compounds, volatile organic compounds, and semivolatile organic compounds. ${ }^{1}$ Such a grouping allows for more efficient identification and treatment of important physicochemical processes governing the sources, dynamic behavior, and fates of indoor-air constituents than would be possible using a purely chemical-by-chemical approach.

This review is concerned with two broad and interrelated categories of chemicals occurring in indoor environments: acids and bases. We are guided principally by the Brønsted-Lowry conceptualization, in which a key feature of an acid is its tendency to donate a proton when in aqueous solution; the key complementary feature of a base is to accept a proton. The review's scope is specifically restricted to compounds that can be found in indoor air, considering gaseous species and also species primarily associated with airborne particles. The review aims to be thorough but does not 
aspire to be comprehensive. We do intend to include all major classes of acids and bases that occur indoors with substantial exploration of specific examples within these major classes. The indoor environments of concern are those that are normally occupied and of the types in which people spend much time, including but not limited to residences, schools, and offices.

As much as possible, our review approach is strongly grounded in physical science and aims to be incisively critical. We synthesize and report measured concentrations. We are particularly interested in processes that govern such concentrations, including characterizing sources and associated emission rates; factors influencing the dynamic behavior; fates; and consequences. Depending on the relative abundance of condensed-phase water indoors and key physicochemical properties of the chemical compounds, aqueous-phase processes can strongly influence the airborne concentrations of acids and bases indoors as well as altering the $\mathrm{pH}$ of indoor water.

Although there is a deep and extensive history of interest in indoor acids (especially) and bases, until now there has not been a systematic and thorough review of the state-of-knowledge for these important chemical classes. As early as the 1850s, Max von Pettenkofer used indoor abundance of carbonic acid (as gaseous $\mathrm{CO}_{2}$ was then called) to determine the level of ventilation required to achieve good indoor air. $^{2}$ In the middle of the $20^{\text {th }}$ century, sulfur dioxide emerged as an important urban air pollutant, and studies were undertaken to better understand the extent of protection provided by being indoors. 3,4 Later, as urban and regional air pollution concerns began to focus on particulate matter, a specific interest emerged in the role of aerosol strong acidity as a potential cause of adverse health effects. Several studies were undertaken in the late 1980s and 1990s to better understand indoor concentrations and associated exposures of acidic aerosols. ${ }^{5,6}$ Long-term awareness that acidic pollutants can damage cultural and historic materials has been documented by Baer and Banks. ${ }^{7}$ Corrosion of metals in indoor environments in relation to acid gases and other pollutants was already studied in the early 1970 s. ${ }^{8,9}$

This article is protected by copyright. All rights reserved 
During the past decade, strong new research interest has emerged concerning indoor acids and bases. One dimension has been some evidence, although not yet conclusive, that exposure to excessive carbon dioxide levels indoors can impair cognitive performance. ${ }^{10}$ This concern is but one example of a broad array of issues regarding how occupants influence indoor air quality, including through the acidic and basic species they generate, such as the fatty acids in skin oils. ${ }^{11}$ Following parallel advances in outdoor atmospheric chemistry, a new area of focus indoors is the class of compounds that are water soluble organic gases, of which acids are a major subcategory. ${ }^{12}$ In addition, instruments that have advanced the study of outdoor atmospheric chemistry are now beginning to be applied indoors. Advanced technologies, such as high-resolution time-of-flight chemical ionization mass spectrometry (CIMS), aerosol mass spectrometry (AMS), and semivolatile thermal-desorption aerosol gas chromatography (SV-TAG) are permitting new aspects of indoor air quality to be probed, reflecting their capabilities for sensitive measurement with fast time response combined with strong levels of chemical specificity. Recently published studies with such instruments are providing new insights in many aspects of indoor air quality, including the sources, abundances, and dynamic behaviors of indoor acids and bases. ${ }^{13-15}$

The body of this review is divided into three main sections. The first considers water in indoor environments. An important topic in its own regard, only certain aspects of indoor water have been well-addressed in prior studies. For this review, it is an important subject because of the strong twoway interactions between condensed-phase water and airborne acids and bases: (a) acid and base uptake influence the $\mathrm{pH}$ of liquid water, a "master variable" of water chemistry; (b) partitioning into the condensed phase alters the airborne concentrations and fates of airborne acids and bases; and (c) condensed-phase water can serve as a large reservoir for acids and bases, buffering their airborne concentrations. Because of water's important role influencing indoor acids and bases, we review the state of knowledge across a range of physicochemical forms: water vapor, bulk liquid water, sorbed water, water in surface films, and water in suspended airborne particles.

This article is protected by copyright. All rights reserved 
The middle section of the article explicitly addresses indoor acids and bases. Acknowledging the richness of the subject and the diversity of the species involved, the material is presented in ten subsections, respectively addressing (1) carbon dioxide, (2) ammonia, (3) sulfur dioxide and sulfate, (4) nitric and nitrous acid, (5) hydrochloric and hypochlorous acid, (6) carboxylic acids, (7) other organic acids, (8) aerosol strong acidity, (9) amines and amino acids, and (10) nicotine.

The final core section of the report is concerned with the roles of indoor surfaces and surface materials influencing the dynamic behavior, fates and consequences of indoor acids and bases. A prominent feature that contrasts indoor air from outdoor air is the high surface-to-volume ratio indoors, amplifying the importance of surface interactions influencing indoor air quality. With respect to indoor acids and bases, this feature is pertinent, extending beyond the roles of surfaces as substrates for aqueous and organic films and sorbents for water.

\section{INDOOR WATER}

Water is centrally important to the concentrations, fates and consequences of indoor acids and bases. When a molecule of a gaseous acid (or base) dissolves into condensed-phase water, it can release (or accept) a proton, changing the $\mathrm{pH}$ of that water. The extent to which the acid or base undergoes a proton-exchange reaction depends on several key factors: (a) the $\mathrm{pH}$ of the aqueous phase, which is influenced by the abundance of that particular species; (b) the abundance and strengths of other acids and bases; (c) the amount of condensed-phase water; (d) the presence of other anions and cations (i.e., the ionic strength); and (e) the influences of solid substrates in contact with the water. The ionized form of the acid or base has negligible vapor pressure, and so will remain in the condensed phase while ionized. However, acid-base reactions are readily reversible, so a change in $\mathrm{pH}$ can lead to the reestablishment of the neutral form of the molecule, which may then return to the gas phase.

Indoor water occurs in multiple forms; only some of these are well characterized. Gaseous water is abundant and can play a role in gas-phase chemistry; however, in the context of indoor acids and

This article is protected by copyright. All rights reserved 
bases, it is more important as a source and sink for indoor water's condensed phases. As a condensed species, several forms of water are potentially important in acid-base processes: bulk liquid water, sorbed water, aqueous surface films, and particle-phase water. These different forms of condensed-phase water can influence indoor acids and bases in different ways. In this section of the review, we summarize the state of knowledge about indoor water vapor along with each of these main forms of condensed-phase water.

Water is an important component of indoor environmental quality for reasons that extend well beyond the concerns of acids and bases. Dampness and moisture are strongly related to adverse respiratory health symptoms and allergies. ${ }^{16}$ Influenza transmission may be influenced by humidity. ${ }^{17}$ Humidity may play a role in sensory perception of indoor environmental quality. ${ }^{18}$ Humidifiers are used to deliberately increase the water vapor content of indoor air; these have the potential to elevate pollutant exposures and health risks. ${ }^{19,20}$ In warm and humid climates, much of the energy for air conditioning is used to dehumidify ventilation air. ${ }^{21}$

The nature and abundance of indoor water varies among building types, across climate zones, and seasonally. In this section, we emphasize general principles and broadly relevant empirical evidence. When specificity is warranted, we consider conditions that are common in residences in the United States.

\section{1. $L^{*}$ metric}

To quantify the abundance of condensed phase water indoors, specifically in relation to indoor acids and bases, we introduce a metric for liquid water abundance, symbolized as $L^{*}$. This metric quantifies the abundance of condensed water as a volume fraction, with dimensions liters (L) of water per $\mathrm{m}^{3}$ of air. Since the density of water is $1.0 \mathrm{~kg} / \mathrm{L}$, the numerical value of $L^{*}$ can also be interpreted as the mass of condensed water per volume of the indoor environment, in units of $\mathrm{kg} \mathrm{m}^{-}$ 3.

This article is protected by copyright. All rights reserved 
To properly account for acid and base phase partitioning, the $L^{*}$ metric represents an equivalent volume fraction that is chemically equilibrated with indoor air. As such, contributions to $L^{*}$ may differ from the total abundance of condensed phase water. In cases in which liquid water is distributed in a thin surface layer, e.g. as condensation on a window pane, the equilibration time scale would be rapid and likely all liquid water would contribute fully to $L^{*}$. On the other hand, water volumes with smaller ratios of liquid-air interfacial area to the liquid volume, such as found in a toilet bowl or a sink trap, may not always be in equilibrium with room air with regards to aqueous partitioning of water-soluble gases. In this case, the contribution of such water to $L^{*}$ would generally be less than its total abundance. A complicating feature of the $L^{*}$ metric is that it can vary among different acids and gases. That variation arises because mass-transport limitations influencing the extent of equilibration differ among species, primarily because of different Henry's law constants and acid-dissociation constants.

As a preamble to the more extensive discussions to follow, it is worthwhile to consider bounding estimates for $L^{*}$ indoors. As a lower bound, consider a monolayer of water molecules, of thickness $0.25 \mathrm{~nm},{ }^{22}$ covering all interior surfaces. If the nominal surface/volume ratio is $3.5 \mathrm{~m}^{2}$ per $\mathrm{m}^{3},{ }^{23-25}$ then the volume of water in that monolayer per volume of interior air would be approximately $10^{-6} \mathrm{~L}$ per $\mathrm{m}^{3}$. For an upper bound, consider that in a bathroom it would be common to have $1 \mathrm{~L}$ of liquid water present in a toilet bowl. Having $1 \mathrm{~L}$ of liquid water that is chemically equilibrated with $10 \mathrm{~m}^{3}$ of room air would produce a value $L^{*}=0.1 \mathrm{~L} / \mathrm{m}^{3}$. Note that the range between these two limiting estimates, $10^{-6}$ to $0.1 \mathrm{~L} / \mathrm{m}^{3}$, spans five orders of magnitude. Table 1 presents estimated $L^{*}$ values for several indoor conditions.

\subsection{Water vapor}

Two commonly reported environmental parameters, temperature $(T)$ and relative humidity (RH), suffice to determine the mass concentration of water vapor in air. Air temperature uniquely

This article is protected by copyright. All rights reserved 
specifies the saturation vapor pressure of water $\left(P_{s}\right)$, which is related to the saturation mass concentration $\left(C_{s}\right)$ via the ideal gas law:

$$
C_{s}=\left(\frac{P_{s}}{R T}\right) \mathrm{MW}_{\mathrm{H} 20}
$$

Here, $R=8.31 \mathrm{~m}^{3} \mathrm{~Pa} \mathrm{~K}^{-1} \mathrm{~mol}^{-1}$ is the gas constant and $\mathrm{MW}_{\mathrm{H} 2 \mathrm{O}}=18 \mathrm{~g} / \mathrm{mol}$ is the molecular mass of water. Relative humidity links the actual mass concentration to the saturated mass concentration:

$$
C_{\mathrm{H} 2 \mathrm{O}}=\mathrm{RH} \times C_{\mathrm{s}}
$$

The saturation vapor pressure of water is reasonably approximated as a function of temperature using this equation: ${ }^{26}$

$$
P_{S}=1000 \times \exp \left(16.7-\frac{4060}{T-37}\right)
$$

In this expression, temperature is in kelvin (K) and the saturation vapor pressure is in pascal ( $\mathrm{Pa})$. To illustrate, consider the following typical indoor conditions. At $T=25^{\circ} \mathrm{C}=298 \mathrm{~K}$ and $\mathrm{RH}=50 \%$, the saturation vapor pressure estimated by equation (3) is $3.14 \times 10^{3} \mathrm{~Pa}$; from equation (1), the saturated mass concentration of water vapor is $22.8 \mathrm{~g} / \mathrm{m}^{3}$, and the prevailing mass concentration of water vapor indoors is $11.4 \mathrm{~g} / \mathrm{m}^{3}$. Were this abundance of water vapor to become fully condensed and equilibrated with indoor acids and bases, the corresponding effective liquid water content would be $L^{*}=11 \times 10^{-3} \mathrm{~L} / \mathrm{m}^{3}$, a value toward the upper end of the range of entries in Table 1 . Gaseous water is an abundant indoor-air species. In the calculations that follow in this section, we will use equation (3) as the basis for determining water's saturation vapor pressure.

In occupied spaces, indoor temperatures might vary between 15 and $30{ }^{\circ} \mathrm{C}$ and indoor relative humidity is commonly in the range $30-70 \% .{ }^{27}$ For illustrative purposes, consider these to be 
independent parameters. At $T=15^{\circ} \mathrm{C}(=288 \mathrm{~K}), C_{\mathrm{s}}=12.3 \mathrm{~g} / \mathrm{m}^{3}$; for the relative humidity range 30 $70 \%$, the corresponding mass concentration range of water vapor would be $3.7-8.6 \mathrm{~g} / \mathrm{m}^{3}$. At $T=30$ ${ }^{\circ} \mathrm{C}(=303 \mathrm{~K}), \mathrm{C}_{\mathrm{s}}=30.6 \mathrm{~g} / \mathrm{m}^{3}$; and so, the range $\mathrm{RH}=30-70 \%$ would correspond to water vapor concentrations of $9.2-21.4 \mathrm{~g} / \mathrm{m}^{3}$. Hence, across this span of normal indoor air conditions, the indoor water vapor concentration would be contained within about an order of magnitude range from $\sim 4$ $\mathrm{g} / \mathrm{m}^{3}$ at the low end up to $\sim 20 \mathrm{~g} / \mathrm{m}^{3}$ at the high end.

Of comparable importance to the scale of water vapor stocks indoors are the associated sources and sinks. Broadly, these may be sorted into three categories: supply and removal by means of ventilation; supply and removal through deliberate humidification and dehumidification; and adventitious phase change, via evaporation and condensation.

Ventilation acts as a source of water vapor by supplying it from outdoor air. Ventilation is simultaneously a sink through the removal of water vapor from indoor air. Whether the net effect of ventilation is a source or a sink clearly depends on the relative moisture content of outdoor versus indoor air. During winter, ventilation is commonly a net sink, removing water vapor from indoor air at a rate in excess of its supply from outdoors. The reverse commonly applies in the summer in humid environments when air-conditioning is in use: ventilation supplies more water vapor from outdoor air than is removed from indoor air. To avoid the confounding effect of expansion and contraction with temperature change, it is easiest to see the scale of the ventilation source and sink terms by expressing the water vapor content of an air parcel as a (mass) mixing ratio, i.e., the mass of water vapor per mass of dry air. Consider, for example, a home with volume of $350 \mathrm{~m}^{3}$. Let's assess the ventilation sink rate of water vapor for the following assumed heatingseason conditions: an air-exchange rate of $0.5 \mathrm{~h}^{-1}$, indoor air at $T=20^{\circ} \mathrm{C}$ with $\mathrm{RH}=50 \%$, and outdoor air at $T=0{ }^{\circ} \mathrm{C}$ with $\mathrm{RH}=50 \%$. Assume that the total air pressure is $1 \mathrm{~atm}=101 \mathrm{kPa}$. For these circumstances, the indoor water vapor concentration of $8.4 \mathrm{~g} / \mathrm{m}^{3}$ corresponds to a mixing ratio of $W_{\text {in }}=7.1 \mathrm{~g} / \mathrm{kg}$. The outdoor mass concentration of water vapor is $2.2 \mathrm{~g} / \mathrm{m}^{3}$, corresponding to a mixing ratio of $W_{\text {out }}=1.7 \mathrm{~g} / \mathrm{kg}$. The air-exchange rate of 0.5 per hour implies removal of $175 \mathrm{~m}^{3} / \mathrm{h}$ of 
indoor air for which the dry-air density is $1.19 \mathrm{~kg} / \mathrm{m}^{3}$. So, the dry-air ventilation rate is $1.19 \times 175=$ $208 \mathrm{~kg} / \mathrm{h}$, and, therefore, the net water removal rate associated with ventilation is $(7.1-1.7) \times 208=$ $1120 \mathrm{~g} / \mathrm{h}$. To summarize a key point: even though the $\mathrm{RH}$ is the same indoors and outdoors, the cold air has a much lower absolute humidity and so, for the humidity to be maintained at $50 \% \mathrm{RH}$ at the warmer condition indoors, $1.1 \mathrm{~kg} / \mathrm{h}$ of water vapor must be added to indoor air to replace the net removal attributable to ventilation.

During warm and humid summer conditions, the situation is reversed. Consider the same house conditions: $1 \mathrm{~atm}$ total air pressure, $350 \mathrm{~m}^{3}$ volume, and $0.5 \mathrm{~h}^{-1}$ air-exchange rate. Assume that indoor air is maintained at $25{ }^{\circ} \mathrm{C}$ with $50 \% \mathrm{RH}$ while the outdoor condition is $35{ }^{\circ} \mathrm{C}$ at $50 \% \mathrm{RH}$. The indoor mass concentration of water vapor is $11.4 \mathrm{~g} / \mathrm{m}^{3}$, which corresponds to a mixing ratio of $W_{\text {in }}=$ $9.8 \mathrm{~g} / \mathrm{kg}$. The outdoor mass concentration of water vapor is $20.3 \mathrm{~g} / \mathrm{m}^{3}$, which corresponds to a mixing ratio of $W_{\text {out }}=18.2 \mathrm{~g} / \mathrm{kg}$. The dry-air density indoors is $1.16 \mathrm{~kg} / \mathrm{m}^{3}$, so the dry-air ventilation rate is $204 \mathrm{~kg} / \mathrm{h}$ and, therefore, the net water supply rate associated with ventilation is (18.2-9.8) $\times$ $204=1710 \mathrm{~g} / \mathrm{h}$. Even though the RH is the same indoors and outdoors, the warmer outdoor air has a much higher absolute humidity. To maintain $50 \% \mathrm{RH}$ at the cooler condition indoors, about 1.7 $\mathrm{kg} / \mathrm{h}$ of water vapor must be removed through dehumidification to compensate for the net supply attributable to ventilation.

Available evidence provides clues about the extent to which residential air is deliberately humidified and dehumidified in the United States for $\mathrm{RH}$ control. With regards to humidification, the Residential Energy Consumption Survey (RECS)

(https://www.eia.gov/consumption/residential/data/2015/hc/php/hc6.1.php) reports that, for year 2015-2016, 24 million households (20\%) had a humidifier and 94 million households did not. Among the households with a humidifier, the most common responses to a question about the regularity of usage were "used less than 4 months [per year]" (10 million households) and "used 4 to 6 months" (also 10 million households). Sales data indicate that homes are more likely to be equipped with portable (room-scale) humidifiers as compared to whole-house units. Specifically, for year 2011, 
sales of portable humidifiers were estimated to be 8.0 million compared to 0.35 million whole-house humidification systems. ${ }^{28}$

Regarding deliberate dehumidification, The RECS data for year 2015-2016 indicate that 17 million US households (14\%) have a dehumidifier compared to 101 million that do not. Reported usage is about 6 million for each of two categories: "less than 4 months" and " 4 to 6 months" per year. About 2 million each report annual usage during "7 to 9 months" and "all 12 months." (https://www.eia.gov/consumption/residential/data/2015/hc/php/hc7.1.php)

Using an air conditioner would contribute to dehumidification in many US climates. Residential air conditioning is common in the United States: 103 of 118 million total households (87\%) report that they "use air-conditioning equipment." (https://www.eia.gov/consumption/residential/data/2015/hc/php/hc7.1.php). Compressor-based air conditioning using a refrigeration cycle cools indoor air by passing it over chilled metal surfaces. If the air being cooled is sufficiently humid, then water will condense on the heat-exchanger surfaces. During air-conditioner operation, such condensate would be in intimate contact with indoor air until it drains away.

Beyond air-conditioning, other types of adventitious phase-change would more commonly cause water to evaporate, increasing indoor water vapor (RH). TenWolde and Walker ${ }^{29}$ have summarized residential moisture design loads. Representative water vapor emission rates from all indoor sources were scaled according to the number of bedrooms in the household: $8 \mathrm{~kg} / \mathrm{d}(0.33 \mathrm{~kg} / \mathrm{h})$ for a onebedroom unit, $12 \mathrm{~kg} / \mathrm{d}(0.5 \mathrm{~kg} / \mathrm{h})$ for two bedrooms, $14 \mathrm{~kg} / \mathrm{d}(0.58 \mathrm{~kg} / \mathrm{h})$ for three, and an increment of $1 \mathrm{~kg} / \mathrm{d}$ for each additional bedroom. TenWolde and Pilon ${ }^{30}$ have reviewed the component contributions to interior water vapor generation. For direct human emissions, representing the sum of respiration and transpiration, they suggest a range of $0.8-1.7 \mathrm{~kg} / \mathrm{d}$ for an adult at rest. Personal emissions from children are assumed to scale in proportion to body weight. Each shower is estimated to emit in the range $0.2-0.8 \mathrm{~kg}$ of water vapor, depending on duration (in the range 3-15 
min). Cooking for a family of four releases $0.24 \mathrm{~kg} / \mathrm{meal}$ and dishwashing $0.25 \mathrm{~kg} / \mathrm{load}$ of dishes. For a family of four, a bottom-up estimate of daily interior emissions of water vapor might sum to about $5 \mathrm{~kg} / \mathrm{d}$ from personal emissions, $2 \mathrm{~kg} / \mathrm{d}$ from bathing, and $1 \mathrm{~kg} / \mathrm{d}$ from meals, or a total of about 8 $\mathrm{kg} / \mathrm{d}=330 \mathrm{~g} / \mathrm{h}$. The addition of $0.33-0.58 \mathrm{~kg} / \mathrm{h}$ of water vapor into a residence of $350-\mathrm{m}^{3}$ volume and an air-exchange rate of $0.5 \mathrm{~h}^{-1}$ would add a mass concentration increment of 1.9-3.3 g/m to the indoor air water vapor concentration. At $T=298 \mathrm{~K}$, the corresponding increase in indoor relative humidity would be $8-15 \%$. Consequently, for these not uncommon conditions, an RH of $50 \%$ in the absence of contributions from the occupants would be expected to increase to $58-65 \%$.

\subsection{Bulk condensed water}

This category includes all forms in contact with indoor air in which the water is sufficiently abundant to be visible. It also includes forms of water that are potentially visible, but normally hidden, such as in sink traps and toilet tanks.

We know of no quantitative accounting of the abundance of bulk condensed water in residences or other indoor environments. Direct inspection of spaces occupied by the authors, along with some reflection, suggests that quantities of bulk liquid water in residences might commonly be in the range 0.35-35 L. In the event that all such water was fully equilibrated with gaseous acids and bases, and if such an abundance were present in a $350 \mathrm{~m}^{3}$ residence, then the corresponding contribution to the liquid water volume ratio would be in the range $L^{*}=0.001-0.1 \mathrm{~L} \mathrm{~m}^{-3}$.

Although anecdotal and therefore not directly generalizable, it seems worthwhile to make a brief account of the bulk water observed at a moment in time in the home of one of the authors. In the kitchen, there is about $2 \mathrm{~L}$ of visible liquid water, divided among $1 \mathrm{~L}$ used to soak dried beans for an upcoming meal, $0.2 \mathrm{~L}$ in a teakettle, $0.1 \mathrm{~L}$ in a drinking glass, and $0.5 \mathrm{~L}$ in an automatic coffee maker. There are smaller amounts of water associated with washed breakfast dishes on a drying rack, dish towels, and the wetted surfaces of the kitchen sink. There is also $0.25 \mathrm{~L}$ of water in a P-trap beneath the kitchen sink. If $2 \mathrm{~L}$ of water were fully equilibrated with the kitchen volume of about 50

This article is protected by copyright. All rights reserved 
$\mathrm{m}^{3}$, the corresponding contribution to $L^{*}$ would be $0.04 \mathrm{~L} / \mathrm{m}^{3}$. Each of the two bathrooms in this house has a toilet with about $1 \mathrm{~L}$ of water in the bowl and $5 \mathrm{~L}$ of water in the tank that provides for flushing. Each bathroom has a sink and a shower. Each of these contains a P-trap connected to the drain. The toilet and two traps together hold $\sim 6.5 \mathrm{~L}$ of water, but only a fraction of this water is likely equilibrated with room air. The shower surfaces are periodically wetted, typically once or twice per day. The sink basins are also wetted periodically and more frequently than the shower stall surfaces. Fabrics associated with personal hygiene are also wetted periodically: bath towels, hand towels, and washcloths. While these are drying, the water they contain contributes to $L^{*}$.

Additional bulk water occurs episodically in this house. At meal times, water is used for food preparation, served for drinking, and utilized after meals for kitchen cleanup. During seasonal periods of rainy weather, wet shoes, clothes and umbrellas may be allowed to dry indoors. Water tends to condense on interior surfaces of windows on cold days following winter storms; such water may persist for hours before drying. During one post-storm event, the estimated abundance of condensed water on windows was $140 \mathrm{~g}$ distributed across $8.4 \mathrm{~m}^{2}$ of window surface; the estimated contribution to $L^{*}$ for the whole house volume of $350 \mathrm{~m}^{3}$ would be $4 \times 10^{-4} \mathrm{~L} / \mathrm{m}^{3}$.

Returning from this specific example to more general considerations, in addition to the stocks of bulk water, flows are expected to influence the concentrations and fates of indoor acids and bases. Acids and bases that dissolve in flowing water would be removed via associated drains. A recent study provides information about residential end uses of water in the United States. ${ }^{31}$ Based on survey methods, the average indoor water use per household was reported to be 520 L/day (138 gallons per household per day). For a typical US home volume of $500 \mathrm{~m}^{3}$, the overall average flow of potable water corresponds to about $1 \mathrm{~L} / \mathrm{m}^{3}$ per day, or $0.04 \mathrm{~L} / \mathrm{m}^{3}$ per hour. The five largest contributors (and the associated averages) were toilets (24\%), showers (20\%), faucets (19\%), clothes washer (17\%), and water leaks (12\%).

We have noted that ventilation in warm and humid conditions could necessitate the removal of about $1.7 \mathrm{~L} / \mathrm{h}$ of water for a $350-\mathrm{m}^{3}$ residence as a component of air conditioning. The associated 
flow rate of condensate would be $0.005 \mathrm{~L} / \mathrm{m}^{3}$ per hour, about an order of magnitude lower than the mean flow rate of water from metered uses in residences. To substantiate the estimate of $1.7 \mathrm{~L} / \mathrm{h}$, we cite results from two studies. In a home in North Carolina, Duncan et al. ${ }^{32}$ reported that "about $2.2 \pm 0.2 \mathrm{~L}$ of water vapor was condensed in the air conditioning system during each cooling cycle, approximately hourly." An unoccupied house in Fort Wayne, Indiana, with volume of $490 \mathrm{~m}^{3}$ had a mechanical ventilation rate of $119 \mathrm{~m}^{3} \mathrm{~h}^{-1} .^{33}$ The measured air conditioner condensate flow spanned a range up to $40 \mathrm{~L} / \mathrm{d}$, equivalent to $1.7 \mathrm{~L} / \mathrm{h}$.

\subsection{Sorbed water}

Large quantities of condensed-phase water are associated with the fibrous and porous materials that are prevalent indoors, including wood, gypsum board, and textiles. Some of this water could be in a form of sufficient accessibility and availability to influence the behavior of indoor airborne acids and bases. Of particular interest in this regard is water that is sufficiently abundant locally to behave chemically like bulk water and that is sufficiently proximate to indoor air to permit timely interaction with airborne species. These restrictions on chemical behavior and accessibility limit our ability to assess contributions to $L^{*}$. Here, we emphasize the state of knowledge about the abundance of solids-associated water and the materials with which it is associated. We caution that it is unknown to what extent the thermodynamic properties of sorbed water are similar to bulk water with regard to the partitioning of gaseous species and the proton-exchange reactions that are central to acidbase behavior.

Historically, the abundance of water associated with indoor materials has been of considerable research interest for three major purposes. First, the movement of moisture into and out of materials can contribute to structural damage. Among other specific concerns, the goal of preserving cultural artifacts benefits from maintaining stable humidity so as to limit mechanical stresses from moisture migration. ${ }^{34}$ Second, moisture and dampness problems that are associated with adverse respiratory symptoms and allergies can result from excessive water in building

This article is protected by copyright. All rights reserved 
materials. ${ }^{35}$ Third, the reversible storage of water by interior materials can serve to buffer indoor humidity and therefore potentially improve building energy performance. ${ }^{36}$

A key parameter to quantify the abundance of sorbed water is the moisture content. As commonly reported, the moisture content is a mass ratio: the mass of condensed water associated with the solid material per mass of solid material when dry. If a material is exposed to water vapor at a fixed relative humidity for sufficient duration, then the abundance of sorbed water will attain an equilibrium state in which there is no subsequent net gain or loss. The functional dependence of the equilibrium moisture content in relation to relative humidity is referred to as a sorption isotherm. As indicated by "isotherm," this functional dependence is assessed at a fixed temperature; sorption isotherms are temperature dependent. Figure 1 displays sorption isotherms for two common indoor materials: wood and gypsum board. An important point is displayed in this figure: a given mass of wood contains much more sorbed water at equilibrium than does gypsum board. At RH $=50 \%$ the equilibrium moisture content of wood $(9 \%)$ is almost $30 \times$ higher than that of gypsum board $(0.3 \%)$. However, even with its much lower capacity, the amount of sorbed water associated with gypsum board is substantial. Consider a room of dimensions $3 \times 4 \times 2.3 \mathrm{~m}$, for which the walls and ceiling are covered by gypsum board of thickness ${ }^{33} 13 \mathrm{~mm}$ and density $38690 \mathrm{~kg} \mathrm{~m}^{-3}$. In this room volume of $28 \mathrm{~m}^{3}$, the total area of walls plus ceiling is $44 \mathrm{~m}^{2}$, which would be covered with about $400 \mathrm{~kg}$ of gypsum board. At $0.33 \%$ equilibrium moisture content (for $\mathrm{RH}=50 \%$ ), the equilibrium mass of sorbed water would be $1.3 \mathrm{~kg}$. If this water contributed fully to $L^{*}$, it would add $0.05 \mathrm{~L} / \mathrm{m}^{3}$.

Table 2 presents equilibrium moisture content data for several common construction materials. A striking feature is the contrast between the moisture content of wood - a plant-based product - and the other materials, which are mineral-based. At $50 \% \mathrm{RH}$, the reported equilibrium moisture contents for wood span the range 8-11\%, whereas most of the mineral-based construction materials have moisture contents below $1 \%$.

This article is protected by copyright. All rights reserved 
Latex paint is a common finishing material for interior walls and ceiling. Van der Zanden and Goossens ${ }^{41}$ studied water sorption by latex paint; at $\mathrm{RH}=50 \%$, their mathematical relationship estimates $8.6 \mathrm{~g}$ of sorbed water per kg of paint. Consider again the example of a room with dimensions $3 \times 4 \times 2.3 \mathrm{~m}$, for which the walls and ceiling are covered by gypsum board finished by a $50-\mu \mathrm{m}$ thick latex paint layer, ${ }^{44}$ with a nominal assumed density of $1 \mathrm{~g} \mathrm{~cm}^{-3}$. The $2.2 \mathrm{~kg}$ of paint would have an equilibrium sorbed water content of $19 \mathrm{~g}$. If that water behaved thermodynamically like bulk water with regards to indoor acids and bases, then it would contribute about $7 \times 10^{-4} \mathrm{~L} / \mathrm{m}^{3}$ to $L^{*}$, almost three orders of magnitude above the lower-bound estimate for a water monolayer on all interior surfaces.

It is common for water sorption isotherms to exhibit hysteresis. Specifically, this means that the equilibrium moisture content depends not only on the relative humidity but also on the direction of approach. When an isotherm is measured using steps of progressively increasing humidity, the equilibrium moisture content attained at a specific humidity value is lower than when measured for a progressively decreasing humidity. The underlying reasons for this phenomenon are not fully understood. In a review of the physics of wood-water interactions, Engelund et al. ${ }^{45}$ stated that "no physically consistent model for sorption hysteresis has been put forward." Among the factors that could contribute to a hysteresis effect is that sorbed water can change the physical structure of the sorbent, e.g. by causing swelling. Such alteration can mean, for example, that at an any specific relative humidity, wood is a physically different sorbent if in the process of drying rather than in the process of taking up more water. A chemical process might also contribute if some part of water sorption involves dissolution of solids. A parallel example is observed in the efflorescence and deliquescence of particles as they are exposed to changing humidity conditions. ${ }^{46}$

Reversible sorption of water by building materials helps to buffer indoor humidity against change. The extent of buffering is influenced not only by equilibrium moisture capacities but also by the rates at which water vapor can be transported into and out of a material. A key parameter is the "moisture buffer value." As defined by Rode et al., ${ }^{47}$ "The practical moisture buffer value 
$\left(\mathrm{MBV}_{\text {practical }}\right)$ indicates the amount of water that is transported in or out of a material per open surface area, during a certain period of time, when it is subjected to variations in relative humidity of the surrounding air." In specific determination of $\mathrm{MBV}_{\text {practical, }}$ the repeated RH cycle comprises $8 \mathrm{~h}$ at $75 \% \mathrm{RH}$ followed by $16 \mathrm{~h}$ at $33 \% \mathrm{RH}$. This cycle is repeated until a consistent response is produced. Table 3 presents a summary of $\mathrm{MBV}_{\text {practical }}$ for several materials. ${ }^{47}$ If we consider a $3 \times 4 \times 2.3 \mathrm{~m}=28$ $\mathrm{m}^{3}$ room volume with $56 \mathrm{~m}^{2}$ of total interior surface, which possesses an average $\mathrm{MBV}_{\text {practical }}$ value of $0.7 \mathrm{~g} \mathrm{~m}^{-2}$ per \% RH (the mean of the values reported in Table 3), then a 24-h driving cycle varying between $33 \%$ and $75 \% \mathrm{RH}$ would be associated with an average net flux of $0.7 \times 56 \times(75-33) \times$ $(1 / 24)=69 \mathrm{~g} / \mathrm{h}$ of water into or out of the floor and wall materials. If this room had an air-exchange rate of $0.5 \mathrm{~h}^{-1}$ so that the ventilation flow rate was $14 \mathrm{~m}^{3} \mathrm{~h}^{-1}$, the associated water vapor mass concentration for average sorptive uptake and release would be $69 / 14=4.9 \mathrm{~g} \mathrm{~m}^{-3}$. The incremental change in relative humidity $(T=298 \mathrm{~K})$ corresponding to this concentration would be $21 \%$, a substantial fraction of the $42 \%$ change in $\mathrm{RH}$ in the driving cycle. The key message: reversible sorptive uptake of water by construction materials provides for substantial buffering of indoor humidity.

Large-scale surveys of indoor materials that would influence stocks and flows of sorbed water have not been undertaken. Svennberg and Wadsö ${ }^{48}$ reported the relative abundance of "surface materials exposed in dwellings" based on an inventory of 16 rooms in Swedish apartments. The resulting apportionment was 33\% wallpaper, $21 \%$ painted surface, $18 \%$ textile furnishings, $15 \%$ wood, $8 \%$ synthetic flooring, and $4 \%$ textile carpets. Woods and Winkler ${ }^{33}$ reported the major categories of surface areas for moisture-buffering materials in three unoccupied homes they studied. With volumes in the range $235-490 \mathrm{~m}^{3}$, the corresponding area/volume ratios were 1.23$1.29 \mathrm{~m}^{2} \mathrm{~m}^{-3}$ for drywall, $0.20-0.28 \mathrm{~m}^{2} \mathrm{~m}^{-3}$ for wood, and 0.27-0.36 $\mathrm{m}^{2} \mathrm{~m}^{-3}$ for carpet. The prevalence of indoor surface materials is further discussed in §4.3.

In US residences, fibrous materials would commonly be found in carpeting, draperies, upholstery, bedding covers, bath and kitchen towels, and clothing. There are no known published summaries of 
the amounts of fibrous materials present in indoor environments. Total quantities could easily exceed $100 \mathrm{~kg}$. For carpet alone, the mass of fibers could be in the range $1-2 \mathrm{~kg}$ per $\mathrm{m}^{2}$ of flooring area covered. ${ }^{49}$ Fibrous materials that are common and abundantly present indoors have substantial associated water. Table 4 summarizes empirical evidence. At $50 \% \mathrm{RH}$ and for equilibrium conditions, the amount of water associated with nylon is about $3 \%$; for cotton, the abundance of sorbed water is 4-7\%; and for wool, the observed range is about 9-13\%. A fully carpeted house with $150 \mathrm{~m}^{2}$ of floor area might have $150-300 \mathrm{~kg}$ of carpet fibers. If the primary material were nylon, then, at $50 \% \mathrm{RH}$, the equilibrium abundance of sorbed water could be in the range $4.5-9 \mathrm{~kg}$. If water sorbed to nylon carpet fibers contributed fully to $L^{*}$, then wall-to-wall carpet in a room with a $2.3 \mathrm{~m}$ height, equilibrated at $\mathrm{RH}=50 \%$, would add an increment to $L^{*}$ in the range $0.013-0.026 \mathrm{~L} / \mathrm{m}^{3}$.

An interesting feature of water sorption by fibrous materials is the chemical strength of the association. One can observe this feature empirically by comparing the nominal surface areas for sorption with water and $\mathrm{N}_{2}$ as the sorbates. Rowen and Blaine ${ }^{50}$ reported apparent surface areas on such a comparative basis. The specific surface areas for the two sorbates were comparable for titanium dioxide. However, for nylon $(145 \times)$ and for wool $(215 \times)$ specific surface areas were much larger for sorbing water as compared to $\mathrm{N}_{2}$.

With dynamically changing indoor humidity conditions, an important consideration for sorptive partitioning of water is the accessibility of fabrics. As one example, the magnitude of clothing worn by a person is $1 \mathrm{~kg} .{ }^{55}$ Closets and clothing cabinets contain tens to hundreds of $\mathrm{kg}$ of clothing. While being worn, clothing fibers are readily accessible to moisture and to gaseous acids and bases. While stored, however, limited rates of mass transfer might extend the equilibration time scale such that gaseous interactions are not responsive to rapid dynamic changes. The influence of long sorptive time scales associated with abundant fibrous materials has not been studied even with regards to water vapor buffering.

This article is protected by copyright. All rights reserved 
Another key consideration is the thermodynamic properties of the sorbed water. In particular, to what extent do volatile and semivolatile species partition into water that is sorbed to fibrous materials? Do the Henry's law constants developed for partitioning to bulk water have meaning, even as estimates, for the expected partitioning between gaseous and sorbed water? Can sorbed water serve as a proton acceptor for the case of an acid or as a proton donor for the case of a base? Are the respective $\mathrm{p} K_{\mathrm{a}}$ values, e.g. for acids in bulk water, reasonably predictive of acid behavior in sorbed water? We don't know the answers to these questions. Given the expected abundance of sorbed water indoors, research is warranted to answer them.

\subsection{Aqueous surface films}

Water may be sorbed at any of the interfaces between solid materials and indoor air. In relation to the forms of condensed water already discussed, this surface-sorbed water has small abundance. However, because the surface-sorbed water occurs in thin films, the equilibration time scales are rapid for species partitioning between the water film and air.

We acknowledge an overlap in classifying water in aqueous surface films as compared with sorbed water in indoor materials. Compare water for an impervious surface such as window glass to a porous sorbent such as gypsum board. Water molecules are not expected to penetrate materially into window glass; instead, condensed water is present as part of an invisible surface film along with other deposited materials, such as inorganic ions and organic compounds. ${ }^{56}$ For gypsum board, at equilibrium, sorbed water will be present throughout the bulk of the material (bulk-sorbed). Masstransfer limitations influence the degree to which water is present throughout the bulk of a porous material such as gypsum board, but would not strongly affect water's abundance in surface films. The distinction in this comparison between surface-sorbed water and bulk-sorbed water should be clear. But what then about sorptive water partitioning to textiles indoors, such as carpet, furniture fabrics, and window coverings? In this review, we have categorized such water as bulk-sorbed, in relation to the bulk properties of the fabrics. For materials like painted gypsum board or wood furniture, contributions to total condensed-phase water abundance occur from both the bulk

This article is protected by copyright. All rights reserved 
sorption throughout the material and from surface sorption in a film. Bulk sorption in such cases was discussed in the previous section. One should consider the possibility of additional water being present in surface films (surface-sorbed) on such permeable and porous materials. To date, the relevant literature about surface films, itself limited in scope and extent, focuses on impervious surfaces.

Important lessons about the adsorption of water on glass can be found in an early investigation by Razouk and Salem. ${ }^{57}$ They measured the sorption of water on glass wool, glass powder, and glass microspheres. For water-washed glass, they found that the "real surface is about two to three times greater than the geometric surface." They also found that "the amounts adsorbed at 0.20 and 0.80 relative pressures [i.e., at $\mathrm{RH}=20 \%$ and $80 \%$, respectively] correspond closely to one and two molecular layers (besides a firmly held monolayer)." Their experimental evidence was interpreted to support the view that, "water adsorbed by glass is made up of two parts: one part being readily removed by pumping and thus loosely held, the other part being held firmly and driven off only by heating at higher temperatures."

Water sorbed on a surface can be quantified in terms of monolayer equivalents. As suggested by the name, a monolayer corresponds to the quantity of water just sufficient to completely cover the surface at a thickness of a single molecule. A few clarifying points are needed. First, the idea of a monolayer is conceptually valuable, but not real. Sorption occurs in a patchy manner, with multiple layers of sorbed molecules occurring before a first layer is full. Second, isotherm data are often based on measurements of the mass of sorbed water per mass of sorbent. To convert to equivalent monolayers, basic information is needed about the geometry of sorbed water and about the specific surface area (SSA, $\mathrm{m}^{2} \mathrm{~g}^{-1}$ ) of sorbents. For sorbed water a nominal linear dimension can be obtained as the cube root of the effective volume occupied by a single water molecule. From this perspective, water at $18 \mathrm{~g} / \mathrm{mol}$ and $1.0 \mathrm{~g} \mathrm{~cm}^{-3}$ has a molecular-specific volume of $3.0 \times 10^{-23} \mathrm{~cm}^{3} \mathrm{molecule}^{-1}$, and the corresponding linear scale is the cube root, i.e. $0.31 \mathrm{~nm}$. Based on their literature review, McClellan and Harnsberger ${ }^{58}$ recommended $12.5 \AA^{2}\left(=0.125 \mathrm{~nm}^{2}\right)$ as the effective surface area 
occupied by adsorbed water molecules. The corresponding monolayer thickness to produce the proper molecular-specific volume would be $0.24 \mathrm{~nm}$. This finding is consistent with direct experimental measurements of water film thickness. ${ }^{22}$ We will adopt the following practice. When original sources quoted here report results in units of monolayers, then we will cite those results without amendment. (Some sources used different assumptions about effective surface area covered per molecule; other sources did not specify their assumptions.). When original sources report isotherm data in other terms, such as mass of water sorbed per mass of sorbent, we then convert these data to monolayer equivalents using a monolayer thickness of $0.24 \mathrm{~nm}$, based on the McClellan and Harnsberger recommendation. ${ }^{58}$ Another important detail is that the true surface area onto which sorption occurs often exceeds the nominal surface area, even for seemingly impervious materials such as glass. In cases in which we have computed monolayer equivalents, we use the specific surface areas measured by the BET method as reported in the original source (generally with $\mathrm{N}_{2}$ as the sorbate).

Studies of water sorption on the surfaces of different types of materials reveal two important points. First, at the ordinary relative humidity levels encountered indoors, it is common for the abundance of sorbed water to exceed a monolayer. Table 5 records the numbers of equivalent monolayers of sorbed water onto different types of surface materials, typically either pure minerals or mixtures of mineral origin. Among the entries, the median (interquartile ranges) are as follows: at 30\% $\mathrm{RH}-1.9$ (1.1-3.3) monolayers; at 50\% RH - 2.3 (1.8-4.8) monolayers; at 70\% RH - 3.8 (3.0-6.6) monolayers. It is noteworthy that that the results exhibit a fair degree of homogeneity despite the diverse minerals tested. These results also are in broad agreement with the information presented by Leygraf et al. ${ }^{59}$ concerning metal surfaces: "a number of metals are seen to be covered by water equivalent to 2-10 monolayers for relative humidities exceeding $40 \%$ at normal room temperatures." They also state, "The first layer of water has a high degree of ordering relative to the substrate because of its proximity to the solid surface. The second and third layers are more mobile with a higher degree of random orientation. Aqueous films thicker than three monolayers possess properties that are close to those of bulk water." Although the properties of surface water 
approach those of bulk water as the film thickness grows, the water film may also have properties (e.g., high ionic strength) that differ from bulk water so as to coexist at equilibrium with water vapor at relative humidities less than $100 \%$.

A second point is that the specific surface areas of these materials commonly are much greater than the superficial or apparent surface areas. For example, a sample of sand studied by Lin et al. ${ }^{65}$ had a specific surface area based on the BET test with $\mathrm{N}_{2}$ of $0.4 \mathrm{~m}^{2} \mathrm{~g}^{-1}$, a value $60 \times$ as large as the nominal surface area of equivalently sized solid spheres. Most of the additional surface area was associated with internal pores, even though the within-grain porosity was determined to be only $1.4 \%$. With the high internal surface area, at $50 \% \mathrm{RH}$, this sand sample had a sorbed water content of $1.1 \mathrm{mg}$ per $\mathrm{g}$ of sand.

The existence of a much higher internal surface area than the apparent or nominal surface poses difficulties for translating the isotherm-based information of the type displayed in Table 5 into information about the expected contribution of surface-sorbed water to $L^{*}$. Fundamentally, we lack adequate information about the effective true surface areas of mineral-type materials exposed indoors. Another complication in applying the data reported in Table 5 is that interior surfaces are commonly coated with films of organic materials that may alter the nature of water-surface interactions (see §4.4). Liu et al. ${ }^{69}$ were among the first to characterize such films on indoor window surfaces, and many subsequent studies support an inference that organic films are ubiquitous on indoor impervious surfaces. Wu et al. ${ }^{70}$ demonstrated that airborne exposure to "kitchen grime" caused different surfaces to exhibit comparable thermodynamic properties with respect to sorptive partitioning of phthalates. Weschler and Nazaroff ${ }^{56}$ and Eichler et al. ${ }^{71}$ have modeled film formation and growth.

A recent study provides new clues about sorbed water in indoor surface films. Schwartz-Narbonne and Donaldson ${ }^{72}$ exposed initially clean, gold-coated quartz crystals for periods of approximately two months in two occupied homes in Toronto. These crystals were oriented horizontally during the 
exposure period, so they would accumulate both settling dust as well as organic vapors. After the exposure period, the crystals were exposed to conditions in which the relative humidity could be controlled. The humidity was systematically varied "from $5 \%$ to $85 \%$ at a rate of $1 \%$ per minute." By measuring the change in oscillation frequency, the mass change associated with water uptake could be evaluated as a function of relative humidity. Unexposed crystals were also analyzed and these results were used for blank correction, so that only the uptake of water into the surface film was assessed. The detailed results, displayed in Figures 2-4 of the cited reference, show an irregular feature: the water mass associated with several exposed crystals did not rise monotonically with increasing RH. Nevertheless, among 12 samples for which results were reported, at $\mathrm{RH}=30 \%, 50 \%$, and $70 \%$, the mean \pm standard deviation of water surface densities was $0.15 \pm 0.09,0.42 \pm 0.26$, and $0.90 \pm 0.56 \mu \mathrm{g} \mathrm{cm}^{-2}$, respectively. The corresponding effective mean monolayer thicknesses of sorbed water would be 6,18 , and 38 , respectively. There was not a clear pattern of differences between pairs of rooms sampled at each site or between study sites. For an effective monolayer thickness of $0.24 \mathrm{~nm}, 18$ monolayers would correspond to an equivalent thickness of $4 \mathrm{~nm}$. By comparison, the experimental data on window film growth summarized in Weschler and Nazaroff ${ }^{56}$ show median and mean growth rates of $0.15 \mathrm{~nm} / \mathrm{d}$, so that an expected representative thickness of organic constituents after an exposure period of two months would be about $9 \mathrm{~nm}$, or about $2 \times$ the associated contribution from sorbed water at $50 \% \mathrm{RH}$.

An important point to highlight is that the Schwartz-Narbonne and Donaldson ${ }^{72}$ results are based on the nominal or superficial surface area of the sorbing substrate, in this case the gold-coated quartz crystal covered with an indoor-exposure acquired surface film. If the mean water surface density of $0.42 \mu \mathrm{gm}^{-2}\left(=4.2 \mathrm{mg} \mathrm{m}^{-2}\right)$ for $\mathrm{RH}=50 \%$ applied for the average exposed surface in an indoor environment with an overall surface-to-volume ratio $23-25$ of $3.5 \mathrm{~m}^{2} \mathrm{~m}^{-3}$, then (subject to the other caveats being satisfied) this water could contribute $1.5 \times 10^{-5} \mathrm{~L} \mathrm{~m}^{-3}$ to the indoor liquid water ratio, $L^{*}$.

This article is protected by copyright. All rights reserved 
Recent studies have investigated the properties of surface water in relation to the behavior of acids. Using silica as the substrate, Fang et al. ${ }^{73}$ showed that a surface-bound acid can deprotonate in the presence of sorbed water and that the degree of deprotonation is greater for a strong acid $\left(\mathrm{HNO}_{3}\right)$ than for a weak acid $(\mathrm{HCOOH})$. Wellen et al. ${ }^{74}$ investigated the behavior of octanoic (C8), nonanoic (C9), and decanoic (C10) acids. They found a reduction in the acidity of the species at the water-air interface. In contrast to the water/air interface, at the substrate/water interface Parashar et al. ${ }^{75}$ used a modeling approach to "show how the acidity of pyruvic acid at the quartz/water interface is increased by almost two units" (relative to the value in bulk water).

\subsection{Particle-phase water}

Liquid water can be a component of airborne particles. This feature is understood to be important in several atmospheric processes, including the roles of aerosols influencing climate, the phase partitioning of water-soluble organic compounds, and the formation of secondary organic aerosol. ${ }^{76}$ Liquid water in particles is prominent, even in the absence of clouds. "Liquid water is predicted to be the most abundant particle-phase species in the atmosphere, 2-3 times total aerosol dry mass globally." 77

Notwithstanding its influence on atmospheric physical and chemical processes, and despite its relative abundance compared to dry aerosol constituents, the condensed phase normally represents a small proportion of tropospheric water molecules. At a temperature of $20^{\circ} \mathrm{C}$ and relative humidity of $50 \%$, the mass concentration of water vapor is $8.4 \mathrm{~g} / \mathrm{m}^{3}$ (based on equations (1) and (3)). Outside of fog and clouds, the abundance of aerosol liquid water is commonly at least five orders of magnitude smaller, usually below $100 \mu \mathrm{g} / \mathrm{m}^{3}$. Meng et al. ${ }^{78}$ used thermodynamic modeling combined with extensive year 1987 measurements of aerosol chemical characterization to estimate the liquid water content of $\mathrm{PM}_{2.5}$ and $\mathrm{PM}_{10}$ for three urban sites near Los Angeles, California, considering separately winter and summer seasons. Using sampling durations of 4-7 $\mathrm{h}$, the median aerosol liquid water contents in $\mathrm{PM}_{10}$ were generally in the range 4-17 $\mathrm{\mu g} / \mathrm{m}^{3}$. (The exception was at Riverside in the summer, for which the median was $0.03 \mu \mathrm{g} / \mathrm{m}^{3}$.) The $90^{\text {th }}$ percentile values for $\mathrm{PM}_{10}$ 
by location and season ranged from $42 \mu \mathrm{g} / \mathrm{m}^{3}$ at Long Beach during summer to $143 \mu \mathrm{g} / \mathrm{m}^{3}$ at Long Beach during winter. Nguyen et al. ${ }^{76}$ applied thermodynamic modeling to estimate the aerosol liquid water (ALW) from aerosol mass spectrometry (AMS) data in several field campaigns. Note that the AMS mainly measures submicron particles and so would not capture completely the liquid water associated with $\mathrm{PM}_{2.5}$ or $\mathrm{PM}_{10}$. Nguyen et al. ${ }^{76}$ report that "campaign average ALW mass amounts are 12,11 , and $3 \mu \mathrm{g} / \mathrm{m}^{3}$ for urban, urban downwind, and rural sites, respectively." Parworth et al. ${ }^{79}$ reported an average of $19 \mu \mathrm{g} / \mathrm{m}^{3}$ for the water content associated with $\mathrm{PM}_{2.5}$ for wintertime conditions in Fresno, California. Diurnal variability produced lower values in the afternoon and higher values during overnight and early morning periods.

Indoors, recent studies are starting to provide some information about aerosol liquid water and its potential significance. Water-soluble organic compounds and indoor aqueous chemistry is highlighted in the work of Duncan et al. ${ }^{12}$ They made the important observation that "even a $1 \mathrm{~nm}$ water film on indoor surfaces, a film consistent with simple water adsorption, will provide more than 1000 times the volume of liquid water as is found in aerosols in outdoor air (assuming $3 \mu \mathrm{g} / \mathrm{m}^{3}$ of aerosol water)." Note that $3 \mu \mathrm{g} / \mathrm{m}^{3}$ of aerosol water, chemically equilibrated with air, provides a contribution to the liquid water content of only $L^{*}=3 \times 10^{-9} \mathrm{~L} \mathrm{~m}^{-3}$, considerably smaller than the range expected to prevail indoors or than the contributions of the other forms of water that we have highlighted in this review.

DeCarlo et al. ${ }^{14}$ inferred an important role for aerosol liquid water in their study of third-hand tobacco smoke. They made an interesting and potentially important observation regarding the role of heating, ventilation and air-conditioning (HVAC) systems influencing water in particles: "In the summertime, warm air with varying amounts of water content is brought into the building, mixed with recirculated air, and conditioned to cooler temperatures ... for the supply airstream. This process leads to deliquescence and significant uptake of water by aerosol particles, as RH values will increase to above $90 \%$ in the supply air .... Even with the subsequent decrease in $\mathrm{RH}$ of the rooms, all of the indoor aerosol will maintain the aqueous phase because the indoor RH does not drop low 
enough to drive off the water. ... In the wintertime, the temperature gradient is reversed with colder, drier outdoor air drawn into the HVAC system mixed with recirculating air and heated to temperatures approaching $38^{\circ} \mathrm{C} \ldots$. This process effectively effloresces the aerosol particles, drying them and resulting in the loss of the aqueous phase in the aerosol."

The first quantitative determination of aerosol liquid water indoors was recently reported by Avery et al. ${ }^{80}$ Their study site was a university classroom in Philadelphia, PA. They monitored chemical composition of submicron particles indoors and outdoors during both winter (with occupancy) and summer (unoccupied) periods, using aerosol mass spectrometry. Aerosol liquid water content was then computed using a thermodynamic model. A key finding was much higher abundance of aerosol liquid water outdoors than indoors, during both summer and winter periods. "Aerosol liquid water $(A L W)$ in winter has an average outdoor and indoor concentration ( \pm standard deviation) of $2.6 \pm 3.6$ $\mu \mathrm{g} \mathrm{m} \mathrm{m}^{-3}$ outdoors and only $0.11 \pm 0.06 \mu \mathrm{g} \mathrm{m}^{-3}$ indoors. In summer, the decrease in concentrations upon transport indoors is much smaller, and similar to aerosol species at $2.7 \pm 2.5 \mu \mathrm{g} \mathrm{m}^{-3}$ outdoors and $0.53 \pm 0.24$ indoors."

\subsection{Summary and outlook}

Water is an important constituent in indoor environments for many reasons. Among these are the partitioning and dynamic behavior of acids and bases. As reviewed in this section, water is manifest indoors in several forms: as water vapor, in bulk condensed liquid, sorbed to interior materials, in surface films, and in particulate matter. The abundance of water vapor is large, on the order of grams per $\mathrm{m}^{3}$, but the direct influence of water vapor on indoor acids and bases is small. Bulk condensed water can be as large in abundance as water vapor. Acids and bases can partition into bulk condensed water from the gas phase and undergo acid-base chemistry (i.e., proton-exchange reactions) therein. The thermodynamics of this system are generally well understood, but much of the bulk water may not become equilibrated owing to mass-transport limitations. Sorbed water can also be abundant indoors at a scale comparable to water vapor. As described by sorption isotherms, the abundance of sorbed water tends to increase monotonically with increasing relative humidity

This article is protected by copyright. All rights reserved 
under equilibrium conditions. However, equilibrium may not be consistently attained for water sorption in indoor environments. Furthermore, the properties of acids and bases in water sorbed to common indoor materials are largely not understood. Surface-film water and aerosol water are far less abundant than the other forms of indoor water; but, water in these forms is highly accessible to gaseous species. Hence, some important acid-base processes may be modulated to meaningful extents by water in these less abundant forms.

\section{ACIDS AND BASES}

In this major portion of the review, we describe the state of knowledge regarding specific acids and bases indoors, emphasizing species that can be airborne, either as gases or in the particle phase. We organize the material according to species or groups of species that share core chemical characteristics. We consider in separate subsections inorganic acids and organic acids. Among the inorganic gaseous acids, we discuss carbon dioxide (§3.1), sulfur oxides (§3.3), nitrogen oxides (§3.4), and chlorinated acids (§3.5). Particle-phase strong acidity is described in §3.8. Among the organic acids, we discuss $n$-alkanoic monocarboxylic acids (§3.6), as well as dicarboxylic, $n$-alkenoic acids, and several other organic acids (§3.7). The most important airborne basic species is ammonia; it is the subject of §3.2. Amine bases other than ammonia along with amino acids are the subjects of §3.9. Nicotine, an important indoor base resulting from tobacco smoking and vaping, is the topic of $\S 3.10$.

In reviewing the states-of-knowledge for acids and bases, we summarize information about indoor concentrations along with the sources and sinks that account for their abundance. We devote substantial attention to the key physicochemical properties that influence phase partitioning and fates indoors. We highlight key reasons for concerns about the presence of these species indoors, including possible effects on human health and wellbeing and also material damage concerns.

Two thermodynamic properties consistently influence indoor dynamic behavior of acids (and bases): the water-air partitioning coefficient and the propensity to donate (or accept) a proton in aqueous

This article is protected by copyright. All rights reserved 
solution. Another important attribute, especially for organic compounds, is the tendency to partition into condensed-phase weakly polar organic matter. These properties are quantified through the Henry's law constant, $K_{\mathrm{H}}$, the acidity (basicity) constant, $\mathrm{p} K_{\mathrm{a}}\left(\mathrm{p} K_{\mathrm{b}}\right)$, and the octanol-air partition coefficient, $K_{\text {oa }}$.

Consider, for example, an acidic species designated $\mathrm{HA}$, where $\mathrm{H}^{+}$represents the proton that can be liberated in the aqueous phase from the conjugate base, $A^{-}$. The partial pressure of the gaseous form of that species is designated as $P_{\text {HA }}$. Henry's law describes the equilibrium partitioning of the species between the gas phase and the aqueous phase:

$$
[\mathrm{HA}]=K_{\mathrm{H}} P_{\mathrm{HA}}
$$

Expressing $P_{\mathrm{HA}}$ in units of atmospheres and $[\mathrm{HA}]$ in moles per liter of water $(\mathrm{M})$, Henry's law constant has units of $\mathrm{M} \mathrm{atm}^{-1}$. We caution that for acids or bases that are extremely water soluble, it is difficult to accurately measure Henry's law constant; large values for $K_{\mathrm{H}}$ should be treated accordingly.

In the aqueous phase, the acid dissociates to an extent that depends upon the $\mathrm{pH}$ of water and on the strength of the acid. The acid dissociation reaction is written as follows:

$$
H A \Leftrightarrow H^{+}+A^{-}
$$

The equilibrium constant for this acid dissociation reaction can be expressed as

$$
K_{a}=\frac{\left[\mathrm{H}^{+}\right]\left[\mathrm{A}^{-}\right]}{[\mathrm{HA}]}
$$


In part because of its large range among different species, the acid dissociation constant, $K_{\mathrm{a}}$, is often reported in a logarithmic scale analogously to the $\mathrm{pH}$. Specifically,

$$
\mathrm{p} K_{\mathrm{a}}=-\log \left(K_{\mathrm{a}}\right)
$$

Taking the logarithm of both sides of equation (6), making appropriate substitutions, and rearranging, we find that

$$
\log [A-]-\log [H A]=p H-p K_{a}
$$

This equation expresses an important point: when the $\mathrm{pH}$ is greater than $\mathrm{p} K_{\mathrm{a}}$, then the aqueous acid is predominantly in the dissociated state $\left(\left[\mathrm{A}^{-}\right]>[\mathrm{HA}]\right)$. Conversely, when the $\mathrm{pH}$ is less than the $\mathrm{p} K_{\mathrm{a}}$ value, then the aqueous acid is predominantly in its undissociated state $\left([\mathrm{HA}]>\left[\mathrm{A}^{-}\right]\right)$. A significant feature is that only an undissociated acid can have a meaningful tendency to partition to the gas phase. Consequently, the tendency of an acid to lose a proton enhances its propensity to be found in the aqueous phase.

Values of Henry's law constants and acid dissociation constants span a remarkably large range among the acids reported to occur in indoor air. Figure 2 illustrates this point.

For a base, with example species designation $B$, the analogous aqueous reaction strength can be expressed as $K_{\mathrm{b}}$. The uptake of a proton by a base in aqueous solution can be written in a form parallel to reaction (5):

$$
\mathrm{B}+\mathrm{H}_{2} \mathrm{O} \Leftrightarrow \mathrm{BH}^{+}+\mathrm{OH}^{-}
$$

The equilibrium constant for this acid dissociation reaction can be expressed as

This article is protected by copyright. All rights reserved 


$$
K_{b}=\frac{\left[\mathrm{BH}^{+}\right]\left[\mathrm{OH}^{-}\right]}{[\mathrm{B}]}
$$

By analogy with the definition of the $\mathrm{p} K_{\mathrm{a}}$ for acids, we can write for bases

$$
\mathrm{p} K_{\mathrm{b}}=-\log \left(K_{\mathrm{b}}\right)
$$

As an alternative to expressing the strength of a base through its $\mathrm{p} K_{\mathrm{b}}$ value, one can also express the strength through the $\mathrm{p} K_{\mathrm{a}}$ value of its conjugate acid, $\mathrm{BH}^{+}$. The two $\mathrm{p} K$ values are linked through the dissociation constant for water:

$$
K_{\mathrm{w}}=\left[\mathrm{H}^{+}\right]\left[\mathrm{OH}^{-}\right]
$$

This temperature-dependent thermodynamic constant has a value $10^{-14} \mathrm{M}^{2}$ at $25^{\circ} \mathrm{C}$. The acid dissociation constant for $\mathrm{BH}^{+}$and the basicity constant for $\mathrm{B}$ are linked through this expression:

$$
\mathrm{p} K_{\mathrm{a}}+\mathrm{p} K_{\mathrm{b}}=\mathrm{p} K_{\mathrm{w}}=14
$$

We note here important simplifications that are applied throughout this review. In quantitative analyses, we assume (a) that the thermodynamic properties of bulk water apply to all aqueous phases; and (b) that corrections for high ionic strength can be neglected with regard to the thermodynamic constants of equilibrium reactions. These approximations are not expected to change the qualitative features described. The quantitative descriptions could be materially affected, especially for the portions of the aqueous phase indoors in which water is not so strongly dominant and/or ionic strengths are high, as would be expected for water in airborne particles, in surface films, and sorbed to indoor materials.

This article is protected by copyright. All rights reserved 
As a final topic for this introductory section, consider the equilibrium distribution of a volatile monoprotic acid among three phase states indoors: gaseous, aqueous but undissociated, and aqueous with dissociation. The system is defined by the temperature $T$ and by the volume ratio of equilibrated liquid water to indoor air, $L^{*}$. Two key thermodynamic properties of the acid are its Henry's law coefficient, $K_{\mathrm{H}}$, and its acid dissociation constant, $K_{\mathrm{a}}$.

Let the numbers of species molecules of the three states in an indoor space be represented, respectively, by $N_{\mathrm{g}}, N_{\mathrm{au}}$, and $N_{\mathrm{ad}}$, for the gas phase, the aqueous phase undissociated (e.g. as HA), and the aqueous phase dissociated (e.g., as $A^{-}$). The total number of molecules of interest then is

$$
N=N_{\mathrm{g}}+N_{\mathrm{au}}+N_{\mathrm{ad}}
$$

We seek to determine the fraction of the total in each state, i.e. $f_{\mathrm{g}}=N_{\mathrm{g}} / N, f_{\mathrm{au}}=N_{\mathrm{au}} / N$, and $f_{\mathrm{ad}}=$ $N_{\mathrm{ad}} / N$. Two independent parameters define the three fractions because they must clearly satisfy the $\operatorname{sum} f_{\mathrm{g}}+f_{\mathrm{au}}+f_{\mathrm{ad}}=1$.

Making appropriate substitutions for the equilibrium relationships and for the relationships between numbers of molecules and the concentration measures - partial pressure (for the gaseous species) and aqueous concentration (molarity, for the undissociated and dissociated condensed-phase states) - one can derive the following apportionment relationships.

$$
\begin{aligned}
& f_{g}=\frac{1}{1+R T L^{*} K_{H}\left(1+K_{a} /\left[H^{+}\right]\right)} \\
& f_{a u}=\frac{R T L^{*} K_{H}}{1+R T L^{*} K_{H}\left(1+K_{a} /\left[H^{+}\right]\right)}
\end{aligned}
$$




$$
f_{a d}=\frac{\operatorname{RTL}^{*} K_{H}\left(K_{a} /\left[H^{+}\right]\right)}{1+R T L^{*} K_{H}\left(1+K_{a} /\left[H^{+}\right]\right)}
$$

Here, $R$ represents the gas constant. With a value $R=0.082 \mathrm{~atm} \mathrm{~K}^{-1} \mathrm{M}^{-1}$, the combination $R T K_{\mathrm{H}}$ is the dimensionless water-air partition coefficient, $K_{\text {wa }}$. The equations demonstrate clearly and quantitatively that the phase apportionment depends on the two key thermodynamic parameters, $K_{\mathrm{H}}$ and $K_{\mathrm{a}}$, which, as we have seen, can span vast ranges (Figure 2 ). As expected, the apportionment is also influenced by the relative abundance of liquid water, $L^{*}$, which can itself vary across several orders of magnitude (see §2.1). As a final important point, the apportionment varies with the aqueous $\left[\mathrm{H}^{+}\right]$concentration, which, again, can vary by orders of magnitude as reflected by the common use of a logarithmic scale $(\mathrm{pH})$ to express the $\mathrm{H}^{+}$concentration. Through the influence of $\mathrm{pH}$, phase partitioning and therefore the fate of all indoor acids and bases can, in principle, be altered by all of the other acids and bases present in a given environment. This interdependence is one of the key reasons to consider indoor acids and bases holistically.

\subsection{Carbon dioxide}

Carbon dioxide is the fifth most prominent molecule in the earth's atmosphere, following $\mathrm{N}_{2}, \mathrm{O}_{2}, \mathrm{Ar}$, and $\mathrm{H}_{2} \mathrm{O}$. Its atmospheric abundance has risen from a preindustrial value of $280 \mathrm{ppm}$ to a current global average value of approximately 410 ppm. Largely because of fossil fuel combustion, atmospheric $\mathrm{CO}_{2}$ levels are continuing to rise at a rate of a few ppm per year.

Carbon dioxide is an important component of the photosynthesis and respiration processes at the foundation of life on earth. Plants create energy-rich organic molecules by combining carbon from $\mathrm{CO}_{2}$ with energy from sunlight. Humans (and other animals) eat carbon-based food, liberate energy from oxidation reactions, and, in the process, generate $\mathrm{CO}_{2}$, which is exhaled as a waste product.

This article is protected by copyright. All rights reserved 
Carbon dioxide levels in occupied indoor environments are elevated above the local outdoor level. Metabolic emissions from occupants are a primary indoor source. Unvented combustion of carbonaceous fuels, as in the use of natural gas as a cooking fuel, can also contribute to elevated indoor $\mathrm{CO}_{2}$ levels. Considering its dominant behavior, it is reasonable to model $\mathrm{CO}_{2}$ as being chemically inert indoors. By far, the major removal mechanism is ventilation. Active $\mathrm{CO}_{2}$ control by other means than ventilation is necessary in submarines and spacecraft and is being explored for additional applications. ${ }^{81}$ At present, such applications are restricted to a small, specialized set of indoor environments.

Persily and de Jonge ${ }^{82}$ reviewed the state of knowledge about metabolic production of $\mathrm{CO}_{2}$ by building occupants. In their Table 6, average $\mathrm{CO}_{2}$ generation rates are reported for different types of common indoor environments. These range from $0.0025 \mathrm{~L} / \mathrm{s}$ per person in a child's bedroom to $0.0055 \mathrm{~L} / \mathrm{s}$ per person in a lobby. The volumetric rates are based on assumed standard values of temperature $(273 \mathrm{~K})$ and pressure $(101 \mathrm{kPa})$. Corresponding $\mathrm{CO}_{2}$ mass emission rates are in the range 18 to $39 \mathrm{gCO}_{2} / \mathrm{h}$ per person. Figure 3 displays the steady-state indoor $\mathrm{CO}_{2}$ increment above the outdoor level considering only metabolically generated $\mathrm{CO}_{2}$ and accounting for removal only by means of ventilation.

Reported indoor concentrations of carbon dioxide vary from 400-500 ppm in sparsely occupied and highly ventilated buildings up to a few thousand ppm or more in densely occupied and/or poorly ventilated spaces. Concentrations above 1000 ppm occur commonly, in particular, in bedrooms, ${ }^{83}$ in classrooms, ${ }^{84}$ and in transportation microenvironments, including automobiles, ${ }^{85}$ buses, ${ }^{86}$ and aircraft cabins. ${ }^{87}$

Carbon dioxide levels have long been used as a measure of the adequacy of ventilation in occupied spaces. Recent research raises interesting and important questions about whether carbon dioxide is itself an indoor air pollutant that directly contributes to adverse effects for building occupants. ${ }^{10,88}$

This article is protected by copyright. All rights reserved 
Although only sparingly soluble, carbon dioxide's partitioning into water is important owing to its relatively high concentrations in air. Aqueous $\mathrm{CO}_{2}$ combines with water to form the weak diprotic acid, carbonic acid $\left(\mathrm{H}_{2} \mathrm{CO}_{3}\right)$. Acid-dissociation reactions liberate, from carbonic acid, the bicarbonate $\left(\mathrm{HCO}_{3}{ }^{-}\right)$and carbonate $\left(\mathrm{CO}_{3}{ }^{2-}\right)$ anions along with $\mathrm{H}^{+}$. Figure 4 displays the predicted equilibrium $\mathrm{pH}$ of liquid water that is otherwise pure except for its exposure to $\mathrm{CO}_{2}$. For $\mathrm{CO}_{2}$ levels rising from 400 to $4000 \mathrm{ppm}$, the $\mathrm{pH}$ would drop by half a unit, from 5.61 to 5.11 .

\subsection{Ammonia}

\subsubsection{Units of measure}

Ammonia $\left(\mathrm{NH}_{3}\right)$ levels are commonly reported in both mass concentration $\left(\mu \mathrm{g} / \mathrm{m}^{3}\right)$ and in mole fraction or mixing ratio (ppb). At an air pressure of $1 \mathrm{~atm}$ and a temperature of $298 \mathrm{~K}$, the conversion factor for $\mathrm{NH}_{3}$ is $1 \mathrm{ppb}=0.70 \mu \mathrm{g} / \mathrm{m}^{3}$. Some studies report airborne aerosol ammonium $\left(\mathrm{NH}_{4}{ }^{+}\right)$concentrations in units of $\mathrm{nmol} / \mathrm{m}^{3}$. Since the molecular mass of $\mathrm{NH}_{4}{ }^{+}$is $18 \mathrm{~g} / \mathrm{mol}$, an $\mathrm{NH}_{4}{ }^{+}$ concentration of $1 \mathrm{nmol} / \mathrm{m}^{3}$ is equivalent to $0.018 \mu \mathrm{g} / \mathrm{m}^{3}$. The mass concentration of $\mathrm{NH}_{4}{ }^{+}$is occasionally reported in units of $\mathrm{ng}-\mathrm{N} / \mathrm{m}^{3}$. Since $\mathrm{NH}_{4}{ }^{+}$has a molecular mass that is $1.29 \times$ the atomic mass of nitrogen, the unit conversion is $1000 \mathrm{ng}-\mathrm{N} / \mathrm{m}^{3}=1.29 \mu \mathrm{g} / \mathrm{m}^{3}$ of ammonium.

\subsubsection{Background}

Ammonia is the major neutralizer of atmospheric acidity. Its outdoor sources include soil emissions, fertilizers, livestock production, forest fires and biomass burning, industrial processes, light-duty motor vehicles equipped with three-way catalysts, and domestic emissions. ${ }^{90-94}$ Interestingly, domestic emissions (i.e., indoor sources) are estimated to have contributed $14 \%$ of total ammonia emissions in the South Coast Air Basin in 1974. ${ }^{91}$ Spengler et al. reported outdoor $\mathrm{NH}_{3}$ levels for 21 North American communities. ${ }^{95}$ Mean concentrations ranged from $0.1 \mathrm{ppb}$ to $5.8 \mathrm{ppb}$. The highest mean level was observed in Springdale, Arkansas, "a community with a high density of chicken farms." In general, farming communities tended to have higher levels (means $>1$ ppb) than other communities.

This article is protected by copyright. All rights reserved 
As is the case outdoors, ammonia is the dominant basic species in indoor air. Its principal indoor source is humans. Pets, when present, also emit ammonia. ${ }^{96}$ Other indoor sources include cooking, ${ }^{97}$ smoking, ${ }^{98-100}$ cleaning products, ${ }^{91,93}$ and concrete. ${ }^{101-103}$

\subsubsection{Human and other indoor emission sources}

Human ammonia emissions occur from breath, skin, flatulence, urine and feces; rates are highly variable among individuals. Over time, microbes transform urea in urine and feces to $\mathrm{NH}_{3}{ }^{104}$ hence, diapers and unflushed toilets also are $\mathrm{NH}_{3}$ sources. As reported in Lee and Longhurst, ${ }^{105}$ early estimates of human emission rates included $540 \mathrm{~g} \mathrm{NH}_{3}-\mathrm{N} \mathrm{y}^{-1}$ person ${ }^{-1}\left(75 \mathrm{mg} \mathrm{NH}_{3} \mathrm{~h}^{-1}\right) ; 106250 \mathrm{~g} \mathrm{NH}_{3}-\mathrm{N}$ $\mathrm{y}^{-1}$ person $^{-1}$ (35 mg NH $\mathrm{h}^{-1}$ ); ${ }^{91,107}$ and $1300 \mathrm{~g} \mathrm{NH}_{3}-\mathrm{N} \mathrm{y}^{-1}$ person-1 $\left(180 \mathrm{mg} \mathrm{NH}_{3} \mathrm{~h}^{-1}\right){ }^{108}$

Based on typical $\mathrm{NH}_{3}$ concentrations in blood (10-30 $\left.\mu \mathrm{M}\right)$, "alveolar blood-gas equilibration alone should lead to an $\mathrm{NH}_{3}$ level of 15-40 ppb in exhaled air."96 Special experimental techniques are required to disentangle breath emissions from skin emissions. Larson et al. ${ }^{109}$ concluded from a series of clever breath sampling experiments that the $\mathrm{NH}_{3}$ concentration in exhaled breath "is determined largely by the last segment of the respiratory tract traversed." When the last segment traversed was the mouth ( $n=16$ subjects), the exhaled concentration spanned the range $40-740 \mathrm{ppb}$ $\left(29-520 \mu \mathrm{g} / \mathrm{m}^{3}\right)$ with a central tendency of about $240 \mathrm{ppb}$; when it was the nose $(n=5)$, the exhaled concentration was $10-90 \mathrm{ppb}\left(7-62 \mu \mathrm{g} / \mathrm{m}^{3}\right)$ with a central tendency of $35 \mathrm{ppb}$. The higher level in the mouth was partially attributed to bacterial decomposition of urea in saliva. Norwood et al. ${ }^{110}$ studied the influence of different oral hygiene regimes on $\mathrm{NH}_{3}$ in exhaled breath. A distilled water rinse or tooth brushing followed by a water rinse had little effect on $\mathrm{NH}_{3}$ levels. In contrast, an acidic oral rinse reduced the concentration in exhaled breath by more than $90 \%$ in all volunteers; breath levels returned to $50 \%$ of initial value within an hour. The acidic rinse presumably lowers saliva $\mathrm{pH}$, increasing the ratio of $\mathrm{NH}_{4}{ }^{+} / \mathrm{NH}_{3}(\mathrm{aq})$ in saliva and thereby decreasing the fraction of $\mathrm{NH}_{3}$ that volatilizes to breath. Using a cavity ring-down spectrometer, Schmidt et al. ${ }^{111}$ measured concentrations of $\mathrm{NH}_{3}$ in breath exhaled through the nose and though the mouth of 20 healthy subjects. The median $\mathrm{NH}_{3}$ concentration was 34 ppb (range: 13-140 ppb) from the nose and 688 ppb

This article is protected by copyright. All rights reserved 
(range: 396-2130 ppb) from the mouth. The values for nose exhalation agree with those reported by Larson et al., while those for mouth exhalation are in better agreement with Norwood et al. Schmidt et al. observed that an acidic mouth rinse reduced the median level for nose- and mouth-breath to $21 \mathrm{ppb}$. Based on a review of the literature through 2014, Mochalski et al. ${ }^{112}$ estimated a breath emission rate of $91 \mathrm{nmol} \mathrm{m^{-1 } \text { person }}{ }^{-1}\left(0.093 \mathrm{mg} \mathrm{h}^{-1}\right.$ person $\left.{ }^{-1}\right)$, which corresponds to an average breath concentration of approximately $210 \mathrm{ppb}\left(150 \mu \mathrm{g} / \mathrm{m}^{3}\right)$ at a volumetric breathing rate of 15 $\mathrm{m}^{3} /$ day.

Schmidt et al. ${ }^{111}$ measured $\mathrm{NH}_{3}$ emissions from skin of 20 subjects. They reported a median $\mathrm{NH}_{3}$ emission rate of $0.3 \mathrm{ng} \mathrm{cm}^{-2} \mathrm{~min}^{-1}\left(0.18 \mathrm{mg} \mathrm{m}^{-2} \mathrm{~h}^{-1}\right)$ from the forearms of subjects who had washed their skin and tried to minimize sweating prior to measurements. In their review, Mochalski et al. ${ }^{112}$ estimated a total human skin emission rate of $514 \mathrm{nmol} \mathrm{min}^{-1}$ person ${ }^{-1}\left(0.52 \mathrm{mg} \mathrm{h}^{-1}\right.$ person $\left.{ }^{-1}\right)$. In subsequent experiments, Furukawa et al. ${ }^{113}$ reported a median emission rate of $270 \mathrm{ng} \mathrm{cm}^{-2} \mathrm{~h}^{-1}(2.7$ $\mathrm{mg} \mathrm{m}^{-2} \mathrm{~h}^{-1}$ ) from the forearms of five male and five female volunteers. This average value is 15 times larger than that reported by Schmidt et al. The larger emission rates may have been due to the sampling method, which entailed passive samplers that were sealed to the skin; sweating likely occurred during the 1-hour sampling period, enhancing $\mathrm{NH}_{3}$ emission. Furukawa et al. also measured emission rates at 12 other body locations and summed the emissions from different body locations to obtain whole-body emission rate estimates (excluding breathing). For males the range of these estimates spanned a factor three (3.8-12 $\left.\mathrm{mg} \mathrm{h}^{-1}\right)$; for females, somewhat lower values spanned a factor of two (2.9-5.6 $\left.\mathrm{mg} \mathrm{h}^{-1}\right)$. The average whole-body skin-emission rate of $\mathrm{NH}_{3}$, likely enhanced by the sampling method, was estimated to be $5.9 \pm 3.2 \mathrm{mg} \mathrm{h}^{-1}$, equivalent to $43 \pm 23 \mathrm{~g} \mathrm{NH}_{3}-\mathrm{N} \mathrm{y}^{-1}$ person1.

Recently, human ammonia emissions have been measured under a variety of conditions in carefully controlled chamber experiments. ${ }^{114}$ In eighteen experiments, most with two male and two female volunteers, $\mathrm{NH}_{3}$ emissions were quantified at different temperatures, relative humidities, fraction of exposed skin, and absence/presence of ozone. The investigators found a strong positive correlation

This article is protected by copyright. All rights reserved 
between $\mathrm{NH}_{3}$ emission rates and temperature. For fully clothed adults and seniors, the calculated emission rate was $0.41 \mathrm{mg} \mathrm{h}^{-1}$ person ${ }^{-1}$ at $25^{\circ} \mathrm{C}, 0.77 \mathrm{mg} \mathrm{h}^{-1}$ person ${ }^{-1}$ at $27^{\circ} \mathrm{C}$, and $1.4 \mathrm{mg} \mathrm{h}^{-1}$ person $^{-1}$ at $29^{\circ} \mathrm{C}$. Emission rates also increased with an increase in exposed skin. Relative humidity had only a moderate impact on emission rates, while ozone had no detectable influence. Although most of the experiments measured whole-body emission rates, a subset of experiments measured dermal and breath emissions separately. Dermal emission rates were found to be substantially larger than breath emission rates. Over the range of conditions studied, the measured $\mathrm{NH}_{3}$ emission rates ranged from 0.4 to $5.4 \mathrm{mg} \mathrm{h}^{-1}$ person-1. These values are much lower than the per person $\mathrm{NH}_{3}$ emission rates reported almost 30 years earlier in Table 4 of Lee and Longhurst. ${ }^{105}$ Based on current literature, we judge that the $\mathrm{NH}_{3}$ emission rate of a typical adult is dominated by emissions from skin, is influenced by temperature, sweating, fraction of exposed skin, and is commonly in the range

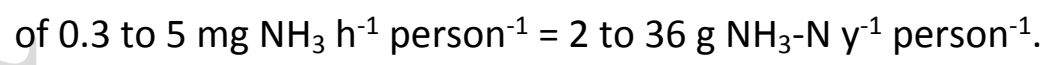

Humans also contribute to indoor $\mathrm{NH}_{3}$ levels via their skin squames (skin flakes). In mechanically ventilated buildings, squames can accumulate in HVAC systems. $\mathrm{Ng}$ et al. ${ }^{115}$ report the generation of $\mathrm{NH}_{3}$ and volatile fatty acids via bacteria acting on skin squames in air cooling units. Temperature was seen to have a pronounced effect on $\mathrm{NH}_{3}$ generation. Insufficient information was reported to quantitatively estimate an emission rate from this source under typical building conditions.

Concrete treated with urea-based antifreeze during mixing can be a substantial source of ammonia. Bai et al. ${ }^{101}$ measured $\mathrm{NH}_{3}$ emissions to vary with air-exchange rate in the range 1-6 $\mathrm{mg} \mathrm{m}^{-2} \mathrm{~h}^{-1}$ for samples prepared with about $1 \mathrm{~kg}$ of urea per $300 \mathrm{~kg}$ of concrete. The investigators estimated that, at typical ventilation rates, it would take more than ten years to exhaust the ammonia emanating from their concrete samples. They also made measurements in five undecorated apartments in a building that had been built four years earlier with concrete containing urea. The mean $\mathrm{NH}_{3}$ concentrations in the bedrooms and living rooms were approximately $5000 \mathrm{ppb}$ when windows and outside doors were closed and were slightly above $1000 \mathrm{ppb}$ when the apartments were ventilated. Lindgren ${ }^{116}$ measured ammonia levels between 3000 and 6000 ppb in a newly built Beijing office, 
reporting that additives in the concrete were the likely cause of the high values. Jang et al. ${ }^{103}$ examined how the organic content of the aggregate affected $\mathrm{NH}_{3}$ emissions from different cement mortars. The $\mathrm{NH}_{3}$ emitted from the aggregate increased with the mass fraction of organic matter in the aggregate. Due to the potential for $\mathrm{NH}_{3}$ emissions from concrete, Chinese buildings are often tested for ammonia.

While it is well known that environmental tobacco smoke (ETS) contains elevated levels of $\mathrm{NH}_{3},{ }^{98,99}$ direct measurements of the influence of smoking on indoor $\mathrm{NH}_{3}$ levels are scarce. Risner and Conner ${ }^{100}$ report a mean ammonia concentration of $107 \mu \mathrm{g} / \mathrm{m}^{3}(150 \mathrm{ppb})$ in a $28 \mathrm{~m}^{3}$ room in which four cigarettes had been smoked. No information was reported on occupancy or air-exchange rate. In addition to $\mathrm{NH}_{3}$ generated by the combustion of tobacco, $\mathrm{NH}_{3}$ in ETS can also be a consequence of the deliberate addition of ammonia-forming compounds to cigarettes. Ammonia increases the fraction of nicotine that is present in ETS as the free base in contrast to the protonated form. The free-base nicotine is more readily absorbed by the smoker. Pankow et al. ${ }^{117}$ have investigated the partitioning of nicotine between particles and the gas phase in ETS and mainstream smoke. See also $\S 3.10$.

\subsubsection{Indoor ammonia concentrations}

Indoor ammonia concentrations tend to be much larger than outdoor concentrations. Ampollini et al. ${ }^{97}$ have assembled an extensive summary of indoor ammonia measurements reported in the peer-reviewed literature. Table 6 summarizes indoor and outdoor ammonia concentrations measured in representative studies. Ammonia measurements indoors first appeared in the literature in the late 1980s and early 1990s. Sisovic et al. ${ }^{118}$ measured indoor $\mathrm{NH}_{3}$ levels multiple times (10-12 per office) in six offices spanning five buildings in Zagreb, Yugoslavia, during summer and winter. The mean summer concentration was $74 \mu \mathrm{g} / \mathrm{m}^{3}$ (106 ppb); the mean winter concentration was $67 \mathrm{\mu g} / \mathrm{m}^{3}$ (96 ppb). This outcome suggests substantially higher indoor $\mathrm{NH}_{3}$ emission rates in summer, since air-exchange rates were presumably lower in winter. Li and Harrison ${ }^{119}$ measured indoor and outdoor $\mathrm{NH}_{3}$ levels at University of Essex buildings. They found 
that indoor levels were 3.5 to 21 times the corresponding outdoor levels; indoor levels ranged from 7 to $48 \mu \mathrm{g} / \mathrm{m}^{3}$ (10-69 ppb) with a mean value of $20 \mu \mathrm{g} / \mathrm{m}^{3}$ (29 ppb). Atkins and Lee ${ }^{120}$ made repeated measurements in 10 British homes. The mean $\mathrm{NH}_{3}$ concentrations in kitchens, living rooms and bedrooms were 39, 37, and $32 \mu \mathrm{g} \mathrm{NH} \mathrm{NH}_{3} \mathrm{~N} / \mathrm{m}^{3}$, respectively (corresponding to 68, 64 and $55 \mathrm{ppb}$ ). During winter months, Tidy and Cape ${ }^{121}$ measured $\mathrm{NH}_{3}$ concentrations in houses and public buildings in Edinburgh. In private living rooms, $\mathrm{NH}_{3}$ levels ranged from 7 to $63 \mathrm{ppb}$ with higher values where smoking occurred. A similar range of values was found in public buildings.

More recently (2001-2009), researchers in Finland have measured $\mathrm{NH}_{3}$ concentrations in newly constructed apartments ( $68 \mathrm{ppb}$ mean $)^{122}$ and residences (60 ppb mean), ${ }^{123}$ as well as office buildings with indoor air problems (20 ppb geometric mean). ${ }^{124}$ In Prague, $\mathrm{NH}_{3}$ measurements were made at the historic National Library, which is naturally ventilated. During warmer months (JulySeptember) the monthly mean $\mathrm{NH}_{3}$ concentrations (12-15 ppb) were somewhat larger than those measured during cooler months of December-March (4-6 ppb). ${ }^{125}$ Researchers from Kumamoto University, ${ }^{126}$ using a novel automated flow-based ammonia gas analyzer, measured a mean $\mathrm{NH}_{3}$ concentration of $28 \mathrm{ppb}$ in their university laboratory.

The values reported in Table 6 are for occupied environments. Investigators from Lawrence Berkeley National Laboratory ${ }^{127}$ measured $\mathrm{NH}_{3}$ concentrations in an unoccupied home in Clovis, CA. During the months of October, December and January, the mean levels were 21, 17 and 15 ppb, respectively. These indoor values were only slightly larger than co-occurring outdoor values.

In more comprehensive multipollutant studies, Brauer et al., ${ }^{128}$ Liang and Waldman ${ }^{129}$ and Suh et al. ${ }^{130,131}$ measured indoor $\mathrm{NH}_{3}$ and examined its relationship to aerosol strong acidity. Brauer et al., sampling in Boston homes, found that $\mathrm{NH}_{3}$ concentrations were higher indoors than outdoors, with mean indoor $\mathrm{NH}_{3}$ concentrations of $8 \mathrm{ppb}$ in summer ( 6 homes) and $19 \mathrm{ppb}$ in winter (5 homes). ${ }^{128}$ In three New Jersey facilities, Liang and Waldman also found $\mathrm{NH}_{3}$ concentrations to be higher indoors than outdoors. In a daycare facility the mean $\mathrm{NH}_{3}$ concentration was $61 \mathrm{ppb}$; in a nursing

This article is protected by copyright. All rights reserved 
home, 56 ppb; and in a home for the elderly 31 ppb (day) and 29 ppb (night). ${ }^{129}$ For 24 homes in Uniontown, PA, Suh et al. reported a geometric mean indoor $\mathrm{NH}_{3}$ concentration of $22 \mathrm{ppb}$ (GSD = 1.7), much higher than the outdoor level of $0.3 \mathrm{ppb} .{ }^{130}$ In a study of 47 homes in State College, PA, Suh et al. obtained similar results: geometric mean $=20$ ppb; GSD = 2.2. ${ }^{131}$ As expected, indoor $\mathrm{NH}_{3}$ concentrations tended to be higher in residences with lower air-exchange rates, albeit with considerable scatter. In Connecticut and Virginia, Leaderer et al. ${ }^{132}$ measured $\mathrm{NH}_{3}$ levels, in addition to other inorganic species, in 58 homes in the summer and 223 homes in the winter. During the summer, mean $\mathrm{NH}_{3}$ levels were $32 \mathrm{ppb}$ in air-conditioned homes and $28 \mathrm{ppb}$ in homes without AC. During the winter, mean $\mathrm{NH}_{3}$ levels were $44 \mathrm{ppb}$ in homes with kerosene heaters and $38 \mathrm{ppb}$ in homes without. In 10 Albuquerque homes, known to have elevated levels of nitrogen dioxide, mean $\mathrm{NH}_{3}$ concentrations were 20 ppb. ${ }^{133}$

Recently, Ampollini et al. ${ }^{97}$ reported time-resolved $\mathrm{NH}_{3}$ concentrations, measured with a cavity ringdown spectrometer in a test house in Austin, Texas, during the HOMEChem campaign. ${ }^{134}$ During unoccupied periods, the mean $\mathrm{NH}_{3}$ concentration was $32 \mathrm{ppb}$, increasing when indoor temperature increased. During high-occupancy events, the mean concentration was $52 \mathrm{ppb}$. Levels rose to an average of $62 \mathrm{ppb}$ while cooking a turkey, and $73 \mathrm{ppb}$ while cleaning with an ammonia-based product. ${ }^{97}$ When the air conditioning cooling coil cycled on, the $\mathrm{NH}_{3}$ concentration dropped, qualitatively consistent with expectations for two influencing factors: dissolution of $\mathrm{NH}_{3}$ in water on coils and lower emission rates at lower temperatures. A half-hour of venting with outdoor air substantially reduced the indoor $\mathrm{NH}_{3}$ concentration, but it returned to its prior concentration in less than an hour after the venting ended. The return to concentrations before venting was confirmed during five separate venting periods on a day dedicated to such experiments. These results suggest the presence of a large reservoir of sorbed and/or dissolved $\mathrm{NH}_{3}$ associated with exposed indoor surfaces in the test house.

It is instructive to compare the values in Table 6 for indoor $\mathrm{NH}_{3}$ concentrations with calculated estimates based on whole-body emission rates. Assuming no loss of indoor $\mathrm{NH}_{3}$ other than by

This article is protected by copyright. All rights reserved 
ventilation and using Li et al.'s ${ }^{114}$ average whole-body emission rate at moderate temperatures of approximately $1 \mathrm{mg} \mathrm{h}^{-1}$ person-1 in a residence ventilated at $5 \mathrm{~L} \mathrm{~s}^{-1}$ person-1, the calculated $\mathrm{NH}_{3}$ concentration would be about $80 \mathrm{ppb}$. This is higher than all of the reported mean indoor concentrations in Table 6, suggesting that loss of $\mathrm{NH}_{3}$ from indoor air by processes other than ventilation (e.g., uptake to indoor surfaces) is an important fate. Deposition to indoor surfaces is supported by observations made after cleaning with an ammonia-based product in the HOMEChem experiments. ${ }^{97}$ After reaching its peak concentration, ammonia levels decreased at a rate substantially faster than the air-exchange rate.

In summary, in occupied buildings measured indoor $\mathrm{NH}_{3}(\mathrm{~g})$ concentrations are typically in the range 15-75 ppb and are much higher than outdoor concentrations. Indoor enhancement is consistent with strong $\mathrm{NH}_{3}$ emissions from occupants. Higher concentrations occur when other sources are present (e.g., smoking, cooking, or concrete with $\mathrm{N}$-containing organic additives).

\subsubsection{Indoor ammonium concentrations}

In bulk condensed water, in aqueous atmospheric aerosols, and in aqueous surface films, $\mathrm{NH}_{3}(\mathrm{aq})$ equilibrates with the ammonium ion $\left(\mathrm{NH}_{4}{ }^{+}\right)$. Outdoors, as $\mathrm{SO}_{2}$ is oxidized to $\mathrm{H}_{2} \mathrm{SO}_{4}$, gas-phase ammonia partially neutralizes $\mathrm{H}_{2} \mathrm{SO}_{4}$, forming ammonium salts, e.g., $\left(\mathrm{NH}_{4}\right)_{2} \mathrm{SO}_{4},\left(\mathrm{NH}_{4}\right) \mathrm{HSO}_{4}$, and $\left(\mathrm{NH}_{4}\right)_{3} \mathrm{H}\left(\mathrm{SO}_{4}\right)_{2}$. The dominant ammonium salt depends on the relative amounts of $\mathrm{NH}_{3}$ and $\mathrm{H}_{2} \mathrm{SO}_{4}$ and is also influenced by the presence of nitric acid. Ammonium sulfate salts are often the most abundant inorganic constituent of fine-mode particles. In regions with high levels of nitrogen oxides, aerosol ammonium nitrate $\left(\mathrm{NH}_{4} \mathrm{NO}_{3}\right)$ levels can approach or exceed those of ammonium sulfate salts.

Indoors, ammonium is a common counterion for sulfate, nitrate, and chloride salts present in airborne particles and settled dust. Indoor sources of ammonium include outdoor-to-indoor transport of particles and generation indoors by the reaction of ammonia with acidic species (e.g., $\mathrm{HCl}, \mathrm{HNO}_{3}$, and acidic sulfates). Many of the studies that have measured indoor ammonia

This article is protected by copyright. All rights reserved 
concentrations have also measured ammonium concentrations in indoor airborne particles, commonly reporting results in terms of nmol of ammonium per $\mathrm{m}^{3}$ of air. Table 7 summarizes such measurements in selected studies, contrasting indoor and outdoor values.

Sinclair et al. ${ }^{135-137}$ measured $\mathrm{NH}_{4}{ }^{+}$in fine- and coarse-mode indoor and outdoor particles for extended periods at sparsely occupied telephone switching (telco) offices in Wichita KS, Lubbock TX, Newark NJ and Neenah WI. Ammonium was present primarily in fine-mode particles. These offices were mechanically ventilated and HVAC systems contained particle filters, which removed some of the particles from the ventilation air. Consequently, the I/O ratios for fine-mode ammonium were low, ranging from 0.065 (Lubbock) to 0.20 (Wichita), depending on the removal efficiency of the filters at a given facility. ${ }^{135}$ The low $\mathrm{I} / \mathrm{O}$ ratios translate to low indoor $\mathrm{NH}_{4}{ }^{+}$concentrations in finemode particles, ranging from mean values of $0.13 \mu \mathrm{g} / \mathrm{m}^{3}\left(7 \mathrm{nmol} / \mathrm{m}^{3}\right)$ in Lubbock to $0.26 \mu \mathrm{g} / \mathrm{m}^{3}(14$ $\mathrm{nmol} / \mathrm{m}^{3}$ ) in Wichita. ${ }^{136} \mathrm{Li}$ and Harrison ${ }^{119}$ measured much higher ammonium levels in indoor aerosol particles in university buildings, finding a mean value of $2.44 \mathrm{\mu g} / \mathrm{m}^{3}\left(136 \mathrm{nmol} / \mathrm{m}^{3}\right)$ and an average I/O ratio of 0.96 . These higher values are reasonable, given that they were measured in a communal kitchen, coffee room, and corridors, whereas the measurements by Sinclair et al. were in offices with filtered ventilation air. Although Li and Harrison found no correlation between indoor and outdoor $\mathrm{NH}_{3}$ levels, they did find significant correlation between indoor and outdoor $\mathrm{NH}_{4}{ }^{+}$levels, indicating the importance of outdoor-to-indoor transport as a source of indoor particle-phase ammonium.

Based on measurements made in five Los Angeles area museums, Ligocki et al. ${ }^{138}$ observed that the indoor/outdoor ratios for $\mathrm{NH}_{4}{ }^{+}$in fine particles was always less than one and tended to be higher in summer compared to winter. A linear regression model indicated significant correlation between indoor and outdoor levels for fine-mode $\mathrm{NH}_{4}{ }^{+}$. The ion balances for the aerosol samples indicated that ammonium was primarily associated with sulfate in the summer and with nitrate in the winter.

This article is protected by copyright. All rights reserved 
In a study of Boston homes, Brauer et al. ${ }^{128}$ found that mean ammonium levels were higher in summer than in winter. In both seasons, the I/O ratio was close to unity. In the New Jersey institutional buildings sampled by Liang and Waldman, ${ }^{129} \mathrm{I} / \mathrm{O}$ ratios for fine-particle $\mathrm{NH}_{4}{ }^{+}$ranged from 0.44 to 1.1 , with median indoor concentrations in the range $73-117 \mathrm{nmol} / \mathrm{m}^{3}$. Suh et al. ${ }^{130}$ measured indoor and outdoor levels of fine-particle ammonium in the homes of 24 children in Uniontown, PA. The geometric mean concentrations were, respectively, $157 \mathrm{nmol} / \mathrm{m}^{3}$ indoors $(2.8$ $\mu \mathrm{g} / \mathrm{m}^{3}, n=91$ samples) and $139 \mathrm{nmol} / \mathrm{m}^{3}$ outdoors $\left(2.5 \mu \mathrm{g} / \mathrm{m}^{3}, n=44\right)$. In the Connecticut and Virginia homes sampled by Leaderer et al.,132 the average fine-particle ammonium concentrations in the summer were slightly smaller for air-conditioned homes, $78 \mathrm{nmol} / \mathrm{m}^{3}\left(1.4 \mu \mathrm{g} / \mathrm{m}^{3}, n=49\right)$ compared to homes without air conditioning, $97 \mathrm{nmol} / \mathrm{m}^{3}\left(1.7 \mu \mathrm{g} / \mathrm{m}^{3}, n=9\right)$, possibly due to lower air-exchange rates in the air-conditioned homes. During winter, homes with kerosene heaters had much higher fine-particle ammonium concentrations, $126 \mathrm{nmol} / \mathrm{m}^{3}\left(2.3 \mu \mathrm{g} / \mathrm{m}^{3}, n=74\right)$ than homes without, $9.4 \mathrm{nmol} / \mathrm{m}^{3}\left(0.2 \mu \mathrm{g} / \mathrm{m}^{3}, n=147\right)$. The average indoor concentration was about $2 \times$ the outdoor value during winter in kerosene-heater homes. The elevated $\mathrm{NH}_{4}{ }^{+}$levels in the keroseneheater homes were matched by elevated $\mathrm{SO}_{4}{ }^{2-}$ levels in these homes. This observation suggests that acidic $\mathrm{S}$ emissions from kerosene combustion were neutralized by $\mathrm{NH}_{3}(\mathrm{~g})$ emitted from occupants and other indoor sources to produce particle-phase ammonium sulfate.

Johnson et al. ${ }^{139}$ used an aerosol mass spectrometer (AMS) to make time-resolved measurements of ammonium levels in submicron particles both outdoors and inside a mixed-use laboratory at Drexel University. During mid-April sampling, the I/O ratio for ammonium (0.52) was slightly less than that for sulfate (0.60). Avery et al. ${ }^{80}$ made more comprehensive AMS measurements of outdoor and indoor atmospheric aerosols during winter and summer in a Drexel classroom. In both seasons, the indoor ammonium concentrations were low. Outdoor and indoor $\mathrm{NH}_{4}^{+}$levels averaged $0.63 \mu \mathrm{g} / \mathrm{m}^{3}$ $\left(35 \mathrm{nmol} / \mathrm{m}^{3}\right)$ and $0.07 \mu \mathrm{g} / \mathrm{m}^{3}\left(4 \mathrm{nmol} / \mathrm{m}^{3}\right)$, respectively, in the winter, and $0.44 \mu \mathrm{g} / \mathrm{m}^{3}\left(24 \mathrm{nmol} / \mathrm{m}^{3}\right)$ and $0.05 \mu \mathrm{g} / \mathrm{m}^{3}\left(3 \mathrm{nmol} / \mathrm{m}^{3}\right)$, respectively, in the summer. During winter and summer, the sulfate normalized $\mathrm{NH}_{4}{ }^{+}$concentration was much larger outdoors than indoors, indicating loss of ammonia from particles during outdoor to indoor transport. The sulfate-normalized indoor/outdoor ratio for 
$\mathrm{NH}_{4}{ }^{+}$tracked the sulfate-normalized outdoor $\mathrm{NH}_{4}{ }^{+}$concentration in summer, but not in winter. This observation is consistent with evidence suggesting that a larger fraction of the outdoor aerosol comprises $\mathrm{NH}_{4} \mathrm{NO}_{3}$ in the winter compared to the summer. In the summer, with higher temperatures favoring ammonia and nitric acid gas rather than condensed-phase ammonium nitrate, the ammonium is present in the outdoor aerosol particles primarily as sulfate salts.

Particles containing ammonium salts accumulate on indoor surfaces. The flux of particles to a surface can be estimated as the product of the airborne particle concentration and the particle deposition velocity. Actual measurements of accumulated ammonium salts on indoor surfaces are reported only in a few studies. ${ }^{135-137,140}$ Sinclair et al. ${ }^{135-137}$ measured accumulated ionic species on vertical and horizontal zinc and aluminum surfaces in mechanically ventilated telephone switching offices. Compared to other ionic species, the behavior of ammonium was complex. The zinc and aluminum surfaces, oriented both horizontally and vertically, quickly reached an $\mathrm{NH}_{4}{ }^{+}$surface accumulation beyond which there was little further increase. The authors speculated that an equilibration process might be occurring on these surfaces whereby, as additional ammonium salts deposited, there was a compensating loss of gaseous $\mathrm{NH}_{3}$ from the surface. Ligocki et al. ${ }^{140}$ measured deposition velocities of various ionic constituents of particles to vertical and upwardfacing horizontal surfaces in five California museums. The deposition velocities for sulfate, nitrate and chloride were much larger to horizontal surfaces than to vertical surfaces, as would be expected for particles influenced by gravitational setting. However, for ammonium, the deposition velocities were similar for both surface orientations. Furthermore, ammonium had the lowest deposition velocity among the measured ionic species. The authors speculated that ammonium may have been lost from collection surfaces in the form of gaseous ammonia during the long exposure time. These independent indications of ammonia loss from surface-accumulated ammonium in two different types of buildings using different experimental methods reinforce one another and encourage further investigation.

This article is protected by copyright. All rights reserved 
The vapor pressure of ammonia immediately above a saturated solution of an ammonium salt can be high. Saturated salt solutions can occur in aqueous surface films as the relative humidity decreases and the film loses water. Opila et al. ${ }^{141}$ calculated that, at $25^{\circ} \mathrm{C}$, the vapor pressure for $\mathrm{NH}_{3}(\mathrm{~g})$ is $4 \mathrm{~Pa}$ above a saturated $\mathrm{pH} 5.5$ solution of $\left(\mathrm{NH}_{4}\right)_{2} \mathrm{SO}_{4}$ and $0.1 \mathrm{~Pa}$ above a saturated $\mathrm{pH} 4.2$ solution of $\mathrm{NH}_{4} \mathrm{Cl}$.

\subsubsection{Ammonia's basicity and its role in indoor acid neutralization}

With a Henry's law constant of $K_{\mathrm{H}}=59 \mathrm{M} / \mathrm{atm},{ }^{142}$ ammonia is almost two thousand times more water-soluble than $\mathrm{CO}_{2}$ and about forty times more soluble than $\mathrm{SO}_{2}$. It is also the most prominent basic gas found in indoor air. The $\mathrm{p} K_{\mathrm{a}}$ of the ammonium ion is 9.24 at $25^{\circ} \mathrm{C} .{ }^{143} \mathrm{Ammonia}$ is more basic than $\mathrm{CO}_{2}$ is acidic. This fact, coupled with ammonia's much greater water solubility, means that the time to equilibrate with liquid water is greater $\mathrm{NH}_{3}$ than for $\mathrm{CO}_{2}$. The upper trace in Figure 5 shows the equilibrium $\mathrm{pH}$ of pure liquid water as a function of its exposure to gaseous ammonia (ppb), in the absence of any other acidic or basic species. However, in actual indoor (and outdoor) environments, carbon dioxide is always present. Figure 5 also has traces showing the equilibrium $\mathrm{pH}$ of liquid water as a function of gaseous ammonia when the $\mathrm{CO}_{2}$ concentration is either 400 or 1000 ppm. Ammonia's large water solubility, coupled with its moderate basicity, means that, molecule for molecule, ammonia has a much larger impact on the $\mathrm{pH}$ of condensed-phase water than does $\mathrm{CO}_{2}$. Specifically, only a small amount of $\mathrm{NH}_{3}(\mathrm{~g})$ is sufficient to neutralize the influence of $\mathrm{CO}_{2}$ when

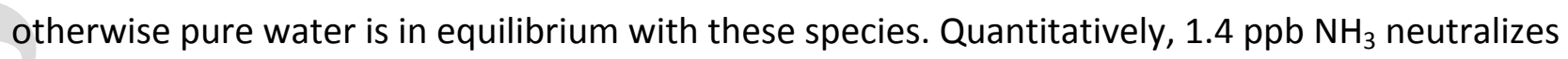
the influence of $100 \mathrm{ppm} \mathrm{CO}_{2}$.

Humans are primary sources for both $\mathrm{CO}_{2}$ and $\mathrm{NH}_{3}$ indoors. In occupied environments that are appropriately ventilated, $\mathrm{CO}_{2}(\mathrm{~g})$ is typically between 500 and $1000 \mathrm{ppm}$ and $\mathrm{NH}_{3}(\mathrm{~g})$ is typically between 15 and $75 \mathrm{ppb}$. Otherwise pure water in equilibrium with $\mathrm{NH}_{3}$ and $\mathrm{CO}_{2}$ over these concentration ranges has a $\mathrm{pH}$ that is surprisingly close to neutral. Calculated $\mathrm{pH}$ values at the four

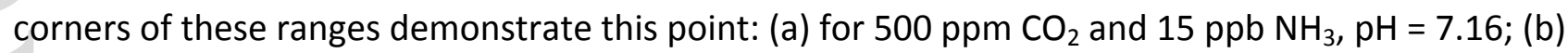
at 1000 ppm $\mathrm{CO}_{2}$ and 15 ppb NH $3, \mathrm{pH}=7.01$; (c) at 500 ppm $\mathrm{CO}_{2}$ and $75 \mathrm{ppb} \mathrm{NH}_{3}, \mathrm{pH}=7.51$; and (d) 
at $1000 \mathrm{ppm} \mathrm{CO}$ and $75 \mathrm{ppb} \mathrm{NH}, \mathrm{pH}=7.36$. In indoor environments, whenever the major determinant of carbon dioxide and ammonia concentrations is human occupancy, and under the assumption that these two species dominate acid-base influence, then condensed-phase water in equilibrium should have a close-to-neutral $\mathrm{pH}$. Of course, that outcome can be altered by the presence of other gaseous acids and bases.

Gaseous ammonia contributes to the neutralization of acids in airborne particles. Brauer et al. ${ }^{128}$ found that aerosol strong acidity $\left(\mathrm{H}^{+}\right)$was much lower indoors than outdoors, suggesting partial neutralization of acidic aerosol by indoor $\mathrm{NH}_{3}$. Liang and Waldman ${ }^{129}$ measured I/O ratios for aerosol strong acidity that were substantially lower than those for sulfate. They proceeded to use the ratio of these I/O values to estimate percent neutralization of indoor acidic aerosol and concluded, as had Brauer et al., that acidic aerosols transported indoors were partially neutralized by $\mathrm{NH}_{3}$. Suh et al. ${ }^{130}$ found that the indoor/outdoor ratio of geometric mean concentrations for ammonium was greater than unity (1.13), whereas, for sulfate, the ratio was less than unity (0.70). This finding is consistent with neutralization of acidic aerosol components by indoor ammonia. Suh et al. ${ }^{131}$ measured indoor aerosol acidity levels that were substantially lower than corresponding outdoor levels and attributed this difference to neutralization by indoor $\mathrm{NH}_{3}$. Indoor $\mathrm{NH}_{3}$ levels $>50 \mathrm{ppb}$ were calculated to be sufficient to completely neutralize $\mathrm{H}^{+}$in the sampled homes in State College, Pennsylvania.

Neutralization by ammonia of inhaled strongly acidic aerosols has also been reported. In an experiment with one subject, Larson et al. ${ }^{109}$ demonstrated that $\mathrm{NH}_{3}$ in the respiratory tract partially neutralized inhaled sulfuric acid aerosol. Sarangapani and Wexler ${ }^{144}$ developed a mathematical model to explore the neutralization of sulfate-containing aerosols by $\mathrm{NH}_{3}$ in the respiratory tract. The model predicts neutralization for particles smaller than $0.1 \mu \mathrm{m}$ diameter, but for particles larger than $1.0 \mu \mathrm{m}$ it predicts little neutralization. When the air inhaled is cool and humid, modeled neutralization is enhanced.

This article is protected by copyright. All rights reserved 
In indoor air, a potential source of secondary organic aerosols (SOA) is ozone reacting with terpenoids used to scent cleaning agents or air fresheners. ${ }^{145}$ Ammonia has been shown to influence the formation of secondary organic aerosols (SOA) generated by ozone-initiated chemistry. Na et al. ${ }^{146}$ used Teflon chamber experiments to examine the impact of ammonia on SOA resulting from $\mathrm{O}_{3}$ reacting with $\alpha$-pinene under both dry and humid conditions. They found "evidence that $\mathrm{NH}_{3}$ can interact with gas-phase organic acids forming condensable salts and thereby enhancing SOA formation." Huang et al. ${ }^{147}$ measured particle counts resulting from ozone reacting with three categories of household cleaning products in a series of chamber experiments conducted with $\mathrm{NH}_{3}$ absent or present. For a floor cleaner, the average maximum particle concentration was about $1.5 \times$ as large when $\mathrm{NH}_{3}$ was present. Even larger increases in SOA formation in the presence of $\mathrm{NH}_{3}$ were observed for experiments with a kitchen cleaner and dishwashing detergent. Furthermore, the consumption of $d$-limonene, a constituent of each cleaning agent, was greater in the presence of $\mathrm{NH}_{3}$. The authors speculate that additional condensable species were formed when $\mathrm{NH}_{3}$ reacted with volatile organic acids generated from ozone reactions with terpenoids in the cleaning agents. These findings were reinforced in a study by Niu et al. ${ }^{148}$ They observed that the peak particle number concentration resulting from ozone/d-limonene reaction was about $60 \%$ larger when $\mathrm{NH}_{3}$ was present compared with when it was absent. Furthermore, the evolution of the particle size distribution was influenced by $\mathrm{NH}_{3}$, with "burst" growth being more apparent in its presence. Interestingly, based on several biomarkers, the SOA formed in the presence of $\mathrm{NH}_{3}$ had a larger pulmonary inflammatory effect in mice.

When $\mathrm{NH}_{3}$ neutralizes an organic acid, an ammonium salt is formed. Upon heating, such ammonium salts may yield amides. ${ }^{149}$ The extent to which this process occurs indoors remains to be investigated.

\subsubsection{Ammonium nitrate dissociation indoors}

Ammonium nitrate is a common constituent of outdoor airborne particles, formed by the reaction between $\mathrm{NH}_{3}(\mathrm{~g})$ and $\mathrm{HNO}_{3}(\mathrm{~g})$. Equilibrium among these species is described by this relationship:

This article is protected by copyright. All rights reserved 


$$
\mathrm{NH}_{4} \mathrm{NO}_{3}(\mathrm{~s}) \leftrightarrow \mathrm{HNO}_{3}(\mathrm{~g})+\mathrm{NH}_{3}(\mathrm{~g})
$$

The dissociation constant for ammonium nitrate, $K_{\mathrm{AN}}$, equals the product of the gas-phase concentrations of $\mathrm{HNO}_{3}$ and $\mathrm{NH}_{3}$ under equilibrium conditions when all three species are present. This equilibrium constant varies with both temperature and relative humidity. At $25{ }^{\circ} \mathrm{C}, \mathrm{NH}_{4} \mathrm{NO}_{3}$ deliquesces at $62 \% \mathrm{RH}^{150}$ Above the deliquescence point, the equilibrium dissociation constant depends on the aqueous concentrations (or, more formally, the activities) of $\mathrm{HNO}_{3}$ and $\mathrm{NH}_{3},{ }^{151}$ with the high water-solubilities of $\mathrm{NH}_{4}{ }^{+}$and $\mathrm{NO}_{3}{ }^{-}$ions favoring dissociation of $\mathrm{NH}_{4} \mathrm{NO}_{3}$. If the relative humidity is less than that at which ammonium nitrate deliquesces, the temperature dependence of $K_{\mathrm{AN}}$, in units of $\mathrm{ppb}^{2}$, can be estimated using this equation: ${ }^{107}$

$$
\ln K_{\mathrm{AN}}=84.6-24220 / T-6.1 \ln (T / 298)
$$

Here, $T$ is the temperature, in kelvin. As quantified, $K_{\mathrm{AN}}$ is larger, and so dissociation is favored, at warmer temperatures. Values predicted from equation (19) are $7.7 \mathrm{ppb}^{2}$ at $20^{\circ} \mathrm{C}$ and $28 \mathrm{ppb}^{2}$ at 25 ${ }^{\circ} \mathrm{C}$. Above the deliquescence point, at $T=25^{\circ} \mathrm{C}$ and $\mathrm{RH}=62-85 \%, K_{A N}$ is in the approximate range $10-$ $30 \mathrm{ppb}^{2} .107$

In outdoor air, $\mathrm{HNO}_{3}(\mathrm{~g})$ and $\mathrm{NH}_{3}(\mathrm{~g})$ have been found at levels consistent with predictions for equilibrium partitioning with particulate $\mathrm{NH}_{4} \mathrm{NO}_{3} .{ }^{152}$ Such equilibrium conditions may not prevail indoors. Li and Harrison ${ }^{119}$ found, in the University of Essex buildings sampled, that the combined concentrations of nitric acid and ammonia were lower indoors than anticipated under equilibrium conditions. Presumably the findings reflect partial dissociation of ammonium nitrate coupled with loss of nitric acid to surfaces indoors. Similarly, for the three institutional buildings that they surveyed, Liang and Waldman ${ }^{129}$ found that the products of the measured gas-phase concentrations were in poor agreement with theory for half of the sampling periods. A contribution to this finding may be the difficulty of measuring indoor $\mathrm{HNO}_{3}(\mathrm{~g})$ at low levels. During summer sampling, indoor 
ammonium nitrate levels were higher in air-conditioned buildings than in naturally ventilated buildings, and the authors attributed this observation to the cooler temperatures in air-conditioned buildings, and hence lower values for $K_{\mathrm{AN}}$. In their study of California museums, Ligocki et al. ${ }^{138}$ found that the I/O ratio for fine-mode ammonium nitrate was smaller than that of other fine-mode species that they measured. They attributed their observation to either dissociation of ammonium nitrate as it was transported from outdoors to indoors or to dissociation occurring during indoor sampling. Suh et al. ${ }^{131}$ reported measured values for the product of airborne nitric acid and ammonia concentrations that they described as "comparable to the dissociation constant." However, Figure 4 in their paper indicates that a substantial proportion of the daytime values for the concentration product were below $3 \mathrm{ppb}^{2}$. Although corresponding temperatures are not reported, $3 \mathrm{ppb}^{2}$ appears lower than expected for equilibrium conditions at the indoor temperatures that should have prevailed during the sampling period (June-August) in State College, Pennsylvania.

At an unoccupied 134- $\mathrm{m}^{2}$ home in Clovis, California, Fischer et al. ${ }^{127}$ measured time-resolved outdoor and indoor concentrations of gas-phase $\mathrm{NH}_{3}, \mathrm{HONO}, \mathrm{HNO}_{3}$ and $\mathrm{SO}_{2}$. During the experiments, indoor activities that might produce these species were restricted. Although there were no known indoor sources, measured concentrations of indoor $\mathrm{NH}_{3}(\mathrm{~g})$ tended to be slightly higher than corresponding outdoor concentrations, possibly as a consequence of $\mathrm{NH}_{4} \mathrm{NO}_{3}$ dissociation. Yet the concentration of gaseous nitric acid indoors was always very low, suggesting that $\mathrm{HNO}_{3}(\mathrm{~g})$ was lost to indoor surfaces to a larger extent than $\mathrm{NH}_{3}(\mathrm{~g})$. During these same periods, Lunden et al. ${ }^{153}$ measured nitrate and sulfate levels in indoor and outdoor aerosol particles at the Clovis house. The measured I/O ratios for nitrate were much lower than the measured I/O ratios for sulfate, suggesting that ammonium nitrate dissociated when outdoor particles were transported indoors. Additionally, they found that the increases in indoor $\mathrm{NH}_{3}(\mathrm{~g})$ correlated with increases in the difference between outdoor and indoor aerosol nitrate levels, consistent with outdoor $\mathrm{NH}_{4} \mathrm{NO}_{3}$ serving as the indoor ammonia source. Their calculations indicated that the rate of "evaporation" of $\mathrm{NH}_{4} \mathrm{NO}_{3}$ varied substantially with temperature and with the concentrations of gas-phase $\mathrm{NH}_{3}$ and $\mathrm{HNO}_{3}$. The time scale for evaporation indicated that this removal mechanism for $\mathrm{NH}_{4} \mathrm{NO}_{3}$ would 
often be comparable to that for air exchange or deposition to indoor surfaces. A mass-balance model that included a term for the rate of $\mathrm{NH}_{4} \mathrm{NO}_{3}$ dissociation successfully modeled the levels of indoor $\mathrm{NH}_{4} \mathrm{NO}_{3}$ and $\mathrm{HNO}_{3}(\mathrm{~g})$ during the measurement periods. However, the authors were unable to successfully model the measured $\mathrm{NH}_{3}(\mathrm{~g})$ concentrations, and they concluded that modeling $\mathrm{NH}_{3}$ levels was more complicated. They were unable to calculate a single deposition velocity that could describe removal of $\mathrm{NH}_{3}(\mathrm{~g})$ by indoor surfaces. They did calculate a best-fit deposition velocity for $\mathrm{HNO}_{3}$; the value obtained, $0.56 \mathrm{~cm} / \mathrm{s}(20 \mathrm{~m} / \mathrm{h})$, was noted to be higher than the expected masstransport limit, an outcome that the authors suggested was a consequence of "problems encountered when measuring nitric acid concentration." 153

López-Aparicio et al. ${ }^{125}$ measured $\mathrm{NH}_{3}$ among other species outside and inside the Baroque Library Hall in the National Library in Prague from the beginning of July 2009 until the end of March 2010. The room where the indoor measurements were made was normally unoccupied and had no readily identified sources of $\mathrm{NH}_{3}$. During the months July-October, the l/O ratio for $\mathrm{NH}_{3}$ was larger than one (e.g., 2.3 in August), while during the months November-March, the I/O ratio was less than one (e.g., 0.69 in December). The researchers speculated that $\mathrm{NH}_{4} \mathrm{NO}_{3}$ dissociation was responsible for a fraction of the indoor $\mathrm{NH}_{3}$, and that this process made a larger contribution during the warmer months when $K_{\mathrm{AN}}$ was larger. This hypothesis was supported by the product of measured nitric acid and ammonia concentrations, which was smaller than that expected for equilibrium with $\mathrm{NH}_{4} \mathrm{NO}_{3}$ at the temperatures measured in the room. It should be noted that any contribution of $\mathrm{NH}_{4} \mathrm{NO}_{3}$ dissociation to indoor $\mathrm{NH}_{3}(\mathrm{~g})$ concentrations would be more difficult to observe in occupied settings, given typical $\mathrm{NH}_{3}$ emissions from human occupants.

Although the above cited studies have discussed the product of gaseous nitric acid and ammonia concentrations as a test of equilibrium between these gas-phase species and particulate $\mathrm{NH}_{4} \mathrm{NO}_{3}$, in indoor environments the mass of $\mathrm{NH}_{4} \mathrm{NO}_{3}$ accumulated on surfaces is anticipated to be much larger than the mass associated with indoor airborne particles. The complicating features of this additional compartment for ammonium and nitrate have not been fully incorporated into efforts to predict or

This article is protected by copyright. All rights reserved 
interpret indoor ammonia behavior. Nevertheless, the rapid loss of nitric acid to indoor surfaces, which is not matched by ammonia loss, is likely to result in products of the gas-phase species that are smaller than would be predicted for equilibrium with aerosol $\mathrm{NH}_{4} \mathrm{NO}_{3}$. Additional measurements of ammonium concentrations on indoor surfaces, coupled with measurements of gaseous nitric acid and ammonia, would contribute to better understanding of indoor ammonia chemistry.

\subsubsection{Ammonia's influence on other indoor processes}

By raising the $\mathrm{pH}$ of surface-associated aqueous films, ammonia has the potential to influence the partitioning of various species between the gas phase and indoor surfaces. In chamber experiments (RH 35-55\%), Webb et al. ${ }^{154}$ found that elevated ammonia levels ( 7 ppm in supply air) promoted the desorption of nicotine from nylon carpet, but not from painted gypsum board. In a more detailed subsequent series of studies, Ongwandee and colleagues examined the impact of $\mathrm{NH}_{3}$ and $\mathrm{CO}_{2}$ on the sorption of $\mathrm{N}$-containing organics to mineral and real-world surfaces. ${ }^{155-157}$ In the experiments most directly relevant to acids and bases in ordinary indoor environments, the investigators found that the sorption of nicotine to polyester curtain and to carpet increased as the $\mathrm{RH}$ increased. ${ }^{157}$ Ammonia at high levels (20 or 40 ppm) suppressed the sorption of nicotine to carpet at $50 \%$ and $90 \% \mathrm{RH}$ but not at $0 \% \mathrm{RH}$. We stress that the ammonia concentrations in these studies ${ }^{154,157}$ were much larger than those routinely observed indoors (Table 6). This point is particularly relevant for situations where $\mathrm{NH}_{3}$ appears to be competing with $\mathrm{N}$-containing basic organics for surface sites: the behavior at high concentrations may not be directly predictive of effects at much lower levels. Nonetheless, these studies illustrate different mechanisms, including $\mathrm{pH}$ modification, through which $\mathrm{NH}_{3}$ can influence the sorption of $\mathrm{N}$-containing organics to real room surfaces.

During the HOMEChem campaign, an ammonia cleaner (1-3\% $\mathrm{NH}_{3}$ by weight) was used on surfaces in the living room and kitchen of the test house either before or after mopping with a vinegar solution. ${ }^{158} \mathrm{~A}$ rapid decrease was observed in the gas-phase concentrations of acidic species (e.g., $\mathrm{HONO}, \mathrm{HNCO}$, and $\mathrm{HCOOH}$ ) when ammonia surface cleaning preceded vinegar mopping. 
A final note concerns the potential for ammonia to contribute to discoloration of interior surfaces. Updyke et al. ${ }^{159}$ demonstrated that when filter samples of secondary organic aerosol generated from both $\mathrm{O}_{3}$-initiated and $\mathrm{OH}$ reactions with biogenic and anthropogenic precursors were exposed to 100 ppb of $\mathrm{NH}_{3}$ in humid air, the samples changed from initially white to a red-brown color. The extent to which this browning occurred varied with the SOA precursors and ranged from no color change for SOA from isoprene to a strong color change for SOA derived from limonene. In the latter case, the light absorption coefficients for wavelengths $300-700 \mathrm{~nm}$ were comparable to values measured for brown carbon from biomass burning. The authors hypothesize that "browning" begins when $\mathrm{NH}_{3}$ reacts with a carbonyl group in SOA constituents forming hemiaminals that subsequently dehydrate into primary imines. Not only is such chemistry anticipated to occur indoors, but it may also occur on indoor surfaces soiled with SOA formed from reactions between ozone and terpenoids or sesquiterpenes. Such SOA may be close to colorless when first deposited on indoor surfaces, but over time, in the presence of $\mathrm{NH}_{3}$, the chemicals could become "brown," contributing to discoloration of lightly colored indoor surfaces.

\subsection{Sulfur dioxide and sulfate}

Sulfur dioxide and sulfate are prominent contributors to atmospheric acidity. The largest source of atmospheric $\mathrm{SO}_{2}$ is coal combustion. Sulfur, originating as a minor constituent of coal, is oxidized to $\mathrm{SO}_{2}$ when the fuel is burned. In the atmosphere, sulfur can be oxidized from +IV (as in $\mathrm{SO}_{2}$ ) to $+\mathrm{VI}$ (as in $\mathrm{H}_{2} \mathrm{SO}_{4}$ or $\mathrm{SO}_{4}{ }^{*}$ ). That oxidation process is an important factor in the acidifying influence of atmospheric sulfur for two reasons. First, whereas $\mathrm{SO}_{2}$ is moderately soluble in water, sulfuric acid is highly soluble and - in the atmosphere - is almost entirely found in the condensed phase. Second, although both acids are diprotic, sulfuric acid $\left(\mathrm{H}_{2} \mathrm{SO}_{4}\right)$ is a much stronger acid than is sulfurous acid $\left(\mathrm{H}_{2} \mathrm{SO}_{3}\right)$. Consequently, atom for atom, the conversion of $\mathrm{S}(\mathrm{IV})$ to $\mathrm{S}(\mathrm{VI})$ substantially increases the acidic potency of airborne S.

This article is protected by copyright. All rights reserved 
Sulfur dioxide and sulfate play important roles in the acid-base properties of indoor environments, too. In this subsection, we'll first consider $\mathrm{SO}_{2}$ and its related S(IV) species and then discuss sulfate and associated S(VI) compounds. We explore sources, dynamic behavior, and fates, especially considering the role affecting the $\mathrm{pH}$ of condensed-phase water indoors. The role of sulfate contributing to aerosol strong acidity is further considered in $\S 3.8$.

A note on units: In the literature, $\mathrm{SO}_{2}$ levels are commonly reported in both mass concentration units $\left(\mu \mathrm{g} / \mathrm{m}^{3}\right)$ and in mole fraction or mixing ratio units $(\mathrm{ppb})$. At an air pressure of $1 \mathrm{~atm}$ and a temperature of $298 \mathrm{~K}$, the conversion factor for $\mathrm{SO}_{2}$ is $1 \mathrm{ppb}=2.6 \mu \mathrm{g} / \mathrm{m}^{3}$. Some studies report airborne aerosol sulfate concentrations in units of $\mathrm{nmol} / \mathrm{m}^{3}$. Since the molecular mass of sulfate $\left(\mathrm{SO}_{4}{ }^{2}\right)$ is $96 \mathrm{~g} / \mathrm{mol}$, a molar sulfate concentration of $1 \mathrm{nmol} / \mathrm{m}^{3}$ is equivalent to $0.096 \mu \mathrm{g} / \mathrm{m}^{3}$. Finally, in some reports, the mass concentration of sulfate is reported in units of $\mathrm{ngS} / \mathrm{m}^{3}$. Sulfate has a molecular mass that is $3 \times$ the atomic mass of sulfur, and so an appropriate unit conversion is that $1000 \mathrm{ngS} / \mathrm{m}^{3}$ equals $3.0 \mu \mathrm{g} / \mathrm{m}^{3}$ of sulfate.

\subsubsection{Sulfur dioxide}

Sulfur dioxide is a respiratory irritant with a health based standard set for outdoor air in the United States at $75 \mathrm{ppb}$, based on a one-hour averaging period. That standard applies to the "3-year average of the $99^{\text {th }}$ percentile of the yearly distribution of 1-hour daily maximum concentrations." (https://www.epa.gov/so2-pollution/primary-national-ambient-air-quality-standard-naaqs-sulfurdioxide). The World Health Organization specifies a 24-h guideline value for $\mathrm{SO}_{2}$ at $20 \mu \mathrm{g} / \mathrm{m}^{3}$, which corresponds to 7.6 ppb (https://www.who.int/airpollution/publications/aqg2005/en/).

Over the past few decades, atmospheric levels of sulfur dioxide have declined in the United States ${ }^{160}$ (https://www.epa.gov/air-trends/sulfur-dioxide-trends) and in Europe ${ }^{161}$ owing in large part to reduced sulfur emissions from coal combustion. In 2018, the US national average $\mathrm{SO}_{2}$ concentration, as measured across a network of 287 outdoor air monitoring stations, was $14 \mathrm{ppb}$ (https://www.epa.gov/air-trends/sulfur-dioxide-trends). In India, $\mathrm{SO}_{2}$ emissions trended upwards 
between 1996 and 2010. ${ }^{162}$ In China, the temporal patterns of emission rates and concentrations have exhibited variability, with an overall decreasing trend emerging during the past several years. ${ }^{163}$ Over the past three decades, a slight reduction of ambient $\mathrm{SO}_{2}$ has been reported from a monitoring station in South Korea, ${ }^{164}$ with an overall mean $\mathrm{SO}_{2}$ abundance of 5.5 ppb for 14 y of sampling during the period 1987-2013. Global anthropogenic $\mathrm{SO}_{2}$ emissions are estimated to have increased between 2000 and 2006 with a declining trend subsequently, through $2011 .{ }^{165}$

The presence of $\mathrm{SO}_{2}$ in outdoor air constitutes a major source for $\mathrm{SO}_{2}$ in buildings, it being transported indoors along with ventilation air. In the absence of indoor emission sources, $\mathrm{SO}_{2}$ concentrations in buildings are observed to be lower than the corresponding outdoor concentrations. Table 8 presents a summary from one major US study, in 1977-1978, of measured $\mathrm{SO}_{2}$ levels in residences and outdoors in circumstances in which outdoor air was thought to be the most important indoor $\mathrm{SO}_{2}$ source. If an average $\mathrm{l} / \mathrm{O}$ ratio of 0.4 is assumed to prevail, then the average indoor $\mathrm{SO}_{2}$ concentration in the US in 2018 is estimated to have been approximately $6 \mathrm{ppb}$ $(=0.4 \times 14 \mathrm{ppb})$ for homes with no indoor sources of $\mathrm{SO}_{2}$.

Sulfur dioxide is emitted indoors when sulfur-containing fuels are burned and the combustion byproducts are released directly (or leak inadvertently) into the indoor space. One potentially important indoor emission source is unvented kerosene space heaters. Even though householdgrade kerosene is low in sulfur (the $1-\mathrm{K}$ grade must have less than $0.04 \% \mathrm{~S}$ by mass), ${ }^{167}$ unvented combustion of kerosene for space heating can have a discernible impact on indoor $\mathrm{SO}_{2}$ levels. For example, Leaderer et al. ${ }^{132}$ measured 24-h average $\mathrm{SO}_{2}$ levels in homes in Virginia and Connecticut during summer ( 58 homes) and winter (223 homes). For the wintertime measurements, the average indoor $\mathrm{SO}_{2}$ level in kerosene-heater homes $(n=74)$ was $16 \mathrm{ppb}, 20 \times$ higher than the average level of $0.8 \mathrm{ppb}$ inside homes without kerosene heaters $(n=148)$ and $4 \times$ higher than the concurrently measured average outdoor level. The maximum 24-h average indoor level in a kerosene-heater home in that study was $107 \mathrm{ppb}$. Coal used for space heating and cooking can also contribute to elevated indoor $\mathrm{SO}_{2}$ levels. The potential is even greater than with kerosene space heaters because

This article is protected by copyright. All rights reserved 
coal has a higher sulfur content than kerosene. Empirical data are not abundant; however, Seow et al. reported a median $24-h$ average indoor $\mathrm{SO}_{2}$ concentration of $907 \mu \mathrm{g} / \mathrm{m}^{3}$ (350 ppb) for 42 households that used "smokeless" (anthracite) coal as a residential fuel in Yunnan Province, China. ${ }^{168}$

Sulfur dioxide interacts with indoor surfaces. In the absence of indoor sources, the associated net loss to surfaces causes concentrations indoors to be lower than corresponding outdoor levels. Indoor surface reactions would also diminish the contributions of indoor emission sources to indoor concentrations. Although not the subject of many systematic recent investigations, studies of $\mathrm{SO}_{2}$ interactions with indoor surface materials were widely undertaken in the 1960s and 1970s. ${ }^{169-178}$ One exception to the historical pattern is the more recent work by Grøntoft and Raychaudhuri, ${ }^{179}$ who assessed the humidity dependence of $\mathrm{SO}_{2}$ uptake on a variety of indoor surface materials.

It is common to model the irreversible loss of a reactive gas on indoor surfaces through the use of a deposition velocity, $v_{\mathrm{d}}$. In the absence of indoor emission sources, and assuming (a) that penetration from outdoors with ventilation occurs without loss, and (b) that the primary removal processes from indoors are by means of ventilation and irreversible surface uptake, then the average indoor/outdoor concentration ratio, $f$, is reasonably well-modeled by equation (20):

$$
f=\frac{a V}{a V+v_{d} S}
$$

where $a$ is the air-exchange rate, $V$ is the interior volume of the building, and $S$ is the area of surfaces on which irreversible uptake occurs. Singer et al. ${ }^{24}$ reported measured overall surface-to-volume ratios for residential rooms to be in the range 2.9 to $4.6 \mathrm{~m}^{2} / \mathrm{m}^{3}$ with a median of $4.1 \mathrm{~m}^{2} / \mathrm{m}^{3}$. (See also §4.2.) Using that median value along with the mean I/O ratio reported by Spengler et al. ${ }^{166}$ of $f=$ 0.41 and a central-tendency residential air-exchange rate of $0.5 \mathrm{~h}^{-1}$, the inferred effective indoor $\mathrm{SO}_{2}$ deposition velocity is estimated to be $v_{d}=0.18 \mathrm{~m} / \mathrm{h}$ or $0.0049 \mathrm{~cm} / \mathrm{s}$. This deposition velocity is

This article is protected by copyright. All rights reserved 
somewhat smaller than what might be inferred from values reported by Grøntoft and Raychaudhuri. ${ }^{179}$ Wilson ${ }^{169}$ found that coating the interior surfaces of a room with an aqueous solution of the basic compound $\mathrm{Na}_{2} \mathrm{CO}_{3}$ decreased the effective half-life of $\mathrm{SO}_{2}$ from $40-60$ minutes to 7 minutes, corresponding to an increase in the effective deposition velocity of a factor in the range 6-9. The half-life of 7 minutes conforms with expectations for mass-transport-limited uptake.

Studies of $\mathrm{SO}_{2}$ interactions with indoor surfaces, while insufficient to support complete understanding, provide important clues about influencing factors and underlying processes. Cox and Penkett ${ }^{176}$ reported that $\mathrm{SO}_{2}$ uptake on gloss paint increased strongly with humidity, with deposition velocity rising from $0.0012 \mathrm{~cm} / \mathrm{s}(0.042 \mathrm{~m} / \mathrm{h})$ at $30 \% \mathrm{RH}$ to a near mass-transport limited value of $0.039 \mathrm{~cm} / \mathrm{s}(1.4 \mathrm{~m} / \mathrm{h})$ at $86 \%$. Likewise, Grøntoft and Raychaudhuri ${ }^{179}$ report increases in the $\mathrm{SO}_{2}$ uptake rate by factors of 6.5 and 2.2, respectively, comparing $30 \% \mathrm{RH}$ to $90 \% \mathrm{RH}$ conditions for "surface treated wood work and wall boards" $(0.012$ versus $0.078 \mathrm{~cm} / \mathrm{s})$ and "wool carpet" $(0.043$ versus $0.094 \mathrm{~cm} / \mathrm{s}$ ). On the other hand, Edwards et al. ${ }^{170}$ found that $\mathrm{SO}_{2}$ uptake by paper did not vary with humidity. As Wilson ${ }^{169}$ demonstrated through applying a basic coating to walls, Walsh et al. ${ }^{178}$ also found that surface $\mathrm{pH}$ properties could affect $\mathrm{SO}_{2}$ uptake rates, reporting that "deposition velocities ... were lower for carpets with an acid $\mathrm{pH} . "$

The empirical evidence from field studies such as Spengler et al. ${ }^{166}$ indicates that at least a component of the $\mathrm{SO}_{2}$ surface uptake is irreversible. Pure partitioning into condensed water on indoor surfaces combined with acid-base shifts would not be expected to produce sustained irreversible uptake. It seems likely that the irreversible component of uptake reflects either oxidation from $S(I V)$ to $S(V I)$, or the chemical binding of S(IV) to molecules in the surface materials. Supporting the importance of the oxidation pathway are these quotes: "Sulfur dioxide is sorbed by paper and slowly converted to sulphuric acid." 170 "The sorbed $\mathrm{SO}_{2}$ is undoubtedly converted to a large extent to sulphite and thence oxidised to sulphate." 173 "The sorbed sulphur dioxide is oxidised to sulphur trioxide which reacts with water in the leather to produce sulphuric acid."174 "The conversion of $\mathrm{S}(\mathrm{IV}) \rightarrow \mathrm{S}(\mathrm{VI})$ on both iron and zinc was found to have a half-life of approx 24 h."177

This article is protected by copyright. All rights reserved 
In assessing surface uptake of $\mathrm{SO}_{2}$, it is common to treat the process as first-order, meaning that the uptake rate is proportional to the gas-phase $\mathrm{SO}_{2}$ concentration. Evidence in some empirical studies supports that assumption explicitly. ${ }^{169}$ On the other hand, Edwards et al. ${ }^{170}$ reported that the rate was "proportional to the square root of the gas phase sulphur dioxide concentration." A square-root dependence might be expected if the rate-limiting step was governed by the abundance of $\mathrm{HSO}_{3}{ }^{-}$in an aqueous surface film. The aqueous concentration of bisulfite in a solution whose $\mathrm{pH}$ is governed by dissolution of gaseous $\mathrm{SO}_{2}$ increases in proportion to the square root of the gas-phase $\mathrm{SO}_{2}$ concentration.

The capacity of surface materials to react with $\mathrm{SO}_{2}$ appears not to be a limiting factor influencing the fate of indoor $\mathrm{SO}_{2}$. For example, Judeikis and Stewart ${ }^{180}$ studied $\mathrm{SO}_{2}$ uptake capacity for exterior construction materials such as cement and stucco and concluded that "overall capacities were ... 0.4$2.8 \mathrm{~g} \mathrm{SO}_{2} \mathrm{~m}^{-2}$ of solid in moist systems." At a deposition velocity of $0.2 \mathrm{~m} / \mathrm{h}(0.0056 \mathrm{~cm} / \mathrm{s})$ and a gas phase concentration of $10 \mu \mathrm{g} / \mathrm{m}^{3}$, it would take a half century for $1 \mathrm{~g} \mathrm{SO}_{2}$ per $\mathrm{m}^{2}$ to accumulate on an interior surface. Walsh et al. ${ }^{178}$ reported that "pre-exposing carpets to stable $\mathrm{SO}_{2}$ equivalent to $27 \mathrm{yr}$ at $30 \mu \mathrm{g} / \mathrm{m}^{3}$... reduced the amount ... taken up [subsequently] by a factor 3."

The acidic properties of sulfur dioxide parallel those of carbon dioxide. Sulfur dioxide is moderately soluble (Henry's law constant, $K_{\mathrm{H}}=1.3 \mathrm{M} / \mathrm{atm}$ ); ${ }^{142}$ aqueous $\mathrm{SO}_{2}$ forms diprotic sulfurous acid $\left(\mathrm{H}_{2} \mathrm{SO}_{3}\right)$ upon combining with a water molecule. Dissociation liberates the $\mathrm{H}^{+}$ion and forms bisulfite $\left(\mathrm{HSO}_{3}{ }^{-}\right)$ from a first dissociation reaction, and then sulfite $\left(\mathrm{SO}_{3}{ }^{\circ}\right)$ from a second. The respective acid dissociation constants are $\mathrm{pK}_{\mathrm{a}}=1.86$ for $\mathrm{H}_{2} \mathrm{SO}_{3}$ and 7.17 for $\mathrm{HSO}_{3}{ }^{-}$. Compared with carbon dioxide, $\mathrm{SO}_{2}$ has a larger Henry's law constant; and sulfurous acid is much stronger than carbonic acid. The net consequences are that $\mathrm{SO}_{2}$ can contribute to more acidification of condensed water than does $\mathrm{CO}_{2}$, even with much smaller gas-phase abundance. This point is illustrated in Figure 6, which shows the equilibrium $\mathrm{pH}$ for water exposed to $\mathrm{SO}_{2}$ with and without the simultaneous presence of $\mathrm{CO}_{2}$. In this situation, for $\mathrm{SO}_{2}$ levels below about $3 \mathrm{ppb}$, the $\mathrm{pH}$ is a function of both the $\mathrm{CO}_{2}$ and the $\mathrm{SO}_{2}$

This article is protected by copyright. All rights reserved 
levels. For indoor $\mathrm{CO}_{2}$ levels in the range $400-1000$ ppm, and with $\mathrm{SO}_{2}$ at or below $5 \mathrm{ppb}$, the pH spans a range 5.0-5.6. For higher $\mathrm{SO}_{2}$ levels, as might occur from unvented indoor combustion of kerosene, the $\mathrm{pH}$ becomes largely independent of the $\mathrm{CO}_{2}$ level and declines to approximately 4.4 at $100 \mathrm{ppb} \mathrm{SO}_{2}$.

An interesting feature regarding the fate of indoor $\mathrm{SO}_{2}$ is suggested from a detail in the empirical study of Spengler et al. ${ }^{166}$ As displayed in Table 8, the indoor/outdoor $\mathrm{SO}_{2}$ ratio in Kingston, $\mathrm{TN}(f=$ 0.11 ), was markedly lower than in any of the other five cities studied $(f=0.31-0.68)$. The authors noted that all the homes in Kingston were air conditioned. Keeping windows closed (for air conditioning) rather than open (for cooling by natural ventilation) would have the tendency to decrease I/O ratios simply by reducing the air-exchange rate, $a$, as is evident from equation (20). However, it is also plausible that condensing water on air-conditioner coils could constitute an additional sink for $\mathrm{SO}_{2}$. For example, water in equilibrium with $1 \mathrm{ppb}$ of $\mathrm{SO}_{2}$ and $800 \mathrm{ppm} \mathrm{CO}_{2}$ would, at a pH of 5.26, contain $3.3 \mu \mathrm{M}$ of bisulfite. If the air conditioner were to condense and drain $1 \mathrm{~L}$ per hour of liquid water equilibrated with $1 \mathrm{ppb}$ of $\mathrm{SO}_{2}$ at $\mathrm{pH} 5.26$, that would correspond to a removal rate of $210 \mu \mathrm{g} / \mathrm{h}$ of $\mathrm{SO}_{2}$. That amount is equivalent to the removal of $\mathrm{SO}_{2}$ by means of $80 \mathrm{~m}^{3}$ $\mathrm{h}^{-1}$ of ventilation, a ventilation rate that could occur in a closed home with air conditioner use. Consequently, aqueous removal of S(IV) could constitute a meaningful loss mechanism associated with air conditioning in humid climates. As yet, there are no experimental data with which to directly test this inference.

\subsubsection{Sulfate}

In the atmosphere, over a time scale of hours to days, the sulfur in $\mathrm{SO}_{2}$ is oxidized from $\mathrm{S}(\mathrm{IV})$ to $\mathrm{S}(\mathrm{VI})$, as in sulfate. The oxidation process can occur in the gas phase, initiated by the hydroxyl radical, or in the aqueous phase, e.g. in cloud droplets. Atmospheric sulfate is an important contributor to urban and regional air pollution, prominently featured in issues as seemingly disparate as acid deposition, visibility impairment, and cardiovascular health risk. A major attribute of inorganic $\mathrm{S}(\mathrm{VI})$ is that it is essentially nonvolatile. It is found in the atmosphere concentrated in condensed-phase

This article is protected by copyright. All rights reserved 
components, e.g., in cloud water, rain drops, and particulate matter. When aerosol sulfate is formed from gaseous $\mathrm{SO}_{2}$, most of the sulfur mass is concentrated in particles with diameters in the range $0.1-1 \mu \mathrm{m} .{ }^{181}$ Because particles in this size range penetrate and persist well indoors, ${ }^{182}$ and because indoor sources of sulfate are uncommon (albeit not rare), fine-mode aerosol sulfate has been used as an indicator of outdoor air's influence on indoor fine-particle concentrations ${ }^{183}$ and on personal exposures to fine particle mass. ${ }^{184}$

Oxidation of sulfur from S(IV) to S(VI) strongly influences acidification. Whereas $\mathrm{SO}_{2}$ is moderately soluble and so is substantially gaseous, to a good approximation all of the highly soluble sulfuric acid formed in the atmosphere will be transferred to the condensed phase. In addition, sulfurous acid and bisulfite are considerably weaker acids than their respective counterparts, sulfuric acid and bisulfate $\left(\mathrm{HSO}_{4}^{-}\right)$. In the presence of liquid water, each molecule of $\mathrm{SO}_{2}$ that is converted to sulfuric acid can liberate up to two aqueous $\mathrm{H}^{+}$ions along with the sulfate ion $\left(\mathrm{SO}_{4}{ }^{=}\right)$. When considered per atom of sulfur, the net effect of the oxidation reaction occurring in the presence of liquid water is to change the most preferred state from gaseous $\left(\mathrm{as} \mathrm{SO}_{2}\right)$ to aqueous (as $\left.\mathrm{SO}_{4}{ }^{=}\right)$, with the associated liberation of $\mathrm{H}^{+}$ions. Guo et al. ${ }^{185}$ studied the $\mathrm{pH}$ of fine-mode particulate matter in the southeastern United States. They found mean $\mathrm{pH}$ at four study sites to be in the range 1.1-1.3 in summer and at two study sites to be 1.8 and 2.2 in winter. The authors noted that "in the southeastern USA, inorganic ions [in fine-mode aerosol] are currently dominated by sulfate and ammonium."

Figure 7 illustrates the influence that the oxidation of $\mathrm{S}(\mathrm{IV})$ to $\mathrm{S}(\mathrm{VI})$ could have on $\mathrm{pH}$ of condensedphase water indoors. For example, with $1 \mathrm{ppb}$ of $\mathrm{SO}_{2}$ in an indoor environment (and neglecting other gaseous acids and bases), water would have an equilibrium $\mathrm{pH}$ of 5.37. Given an assumed liquid water content of $1 \mathrm{~L}$ per $400 \mathrm{~m}^{3}$ of interior volume $\left(L^{*}=0.0025 \mathrm{~L} / \mathrm{m}^{3}\right)$, converting half of that $\mathrm{SO}_{2}$ to sulfuric acid that is fully transferred to the water would lower the $\mathrm{pH}$ to 4.77 . Complete oxidation would further reduce the $\mathrm{pH}$ to 4.49. Previous discussion has summarized some of the evidence indicating that sulfur oxidation reactions may occur on certain indoor surfaces. Conversely, 
there is not strong evidence to suggest that significant gas-phase oxidation of $\mathrm{S}(\mathrm{IV})$ to $\mathrm{S}(\mathrm{VI})$ occurs indoors.

In indoor air, whereas $\mathrm{SO}_{2}$ would primarily exist as a gas, indoor sulfate is predominantly in airborne particles. Like $\mathrm{SO}_{2}$, evidence supports a view that, in most circumstances, the principal source of indoor sulfate is supply from outdoor air via ventilation. Table 9 provides a summary of measurement results from one major field campaign investigating indoor and outdoor sulfate levels in residences. In that study, the use of unvented kerosene space heaters (average reported use duration $=6.9$ hours per day) was associated with an indoor sulfate concentration several times higher $\left(7.9 \mathrm{\mu g} / \mathrm{m}^{3}\right.$ versus $\left.2.1 \mu \mathrm{g} / \mathrm{m}^{3}\right)$ than in homes without unvented kerosene heaters. ${ }^{132}$ In a source-apportionment study for fine particles and associated elements in residences in New York state, Koutrakis et al. ${ }^{186}$ reported that, "for homes with kerosene heaters, approximately $40-50 \%$ of the sulfur was found to be contributed by kerosene burning." Ruiz et al. ${ }^{187}$ also reported substantially elevated indoor concentrations of fine-particle sulfate and $\mathrm{SO}_{2}$ in homes in Santiago, Chile that had kerosene heaters. In another study, "increased indoor concentrations of sulfates were found to be associated with smoking and also with gas stoves." 188 The associated sulfate increase was $0.046 \mu \mathrm{g} / \mathrm{m}^{3}$ per cigarette for smoking in a fully air-conditioned house and $1.1 \mu \mathrm{g} / \mathrm{m}^{3}$ from use of a gas stove. In the case of smoking, the surprising origin of sulfur was inferred to be the matches used to light cigarettes, rather than the cigarettes themselves. For gas cooking, a likely source is sulfur-containing odorants, such as methyl mercaptan $\left(\mathrm{CH}_{4} \mathrm{~S}\right.$, also known as methanethiol), added to the fuel for safety.

Suh et al. ${ }^{130}$ measured indoor and outdoor levels of fine-particle sulfate in the homes of 24 children in Uniontown, PA. The reported geometric mean outdoor sulfate concentration $(n=46)$ was 125 $\mathrm{nmol} / \mathrm{m}^{3}\left(12.0 \mu \mathrm{g} / \mathrm{m}^{3}\right)$ and the corresponding geometric mean indoor concentration $(n=91)$ was 88 $\mathrm{nmol} / \mathrm{m}^{3}\left(8.4 \mu \mathrm{g} / \mathrm{m}^{3}\right)$. The indoor/outdoor ratio of geometric means was $70 \%$. The authors reported that "indoor $\mathrm{SO}_{4}{ }^{2-}$ levels generally were lower in air-conditioned homes (GM $78 \mathrm{nmol} / \mathrm{m}^{3} \mathrm{GSD}=2.24$ ) as compared to non-air-conditioned homes (GM $\left.=133 \mathrm{nmol} / \mathrm{m}^{3}, \mathrm{GSD}=1.85\right)$."

This article is protected by copyright. All rights reserved 
Spengler et al. ${ }^{189}$ reported on indoor and outdoor sulfate measurements from the large Six-Cities study. Their data were collected from 55 homes, with multiple 24-h measurements made at each site during each season for a year. Altogether, the researchers collected more than 1700 indoor samples and more than 1900 outdoor samples. Table 10 presents a summary of the indoor and outdoor mean values measured in each city in that study. The per-city ratio of mean indoor to mean outdoor levels ranges from 55\% (Steubenville) to 95\% (Watertown), with a central tendency of 70$80 \%$, depending on how the results are aggregated. Among these six cities, there was less variability in the sulfate $\mathrm{I} / \mathrm{O}$ ratios than in the $\mathrm{SO}_{2} \mathrm{l} / \mathrm{O}$ ratios (Table 8).

Wallace and Williams ${ }^{184}$ reported measurements of fine-particle sulfur (presumably corresponding to sulfate) for 36 households in Research Triangle Park, NC. They monitored each home for seven consecutive days in each of four seasons, relying on 24-h average sample results. They concluded that "sulfur has few indoor sources" in the houses they studied. The average indoor to outdoor fineparticle sulfate ratios per household varied across the range 0.26 to 0.87 (median $=0.55$ ). With summer AC use, mean I/O ratio was 0.50 as compared with $0.62-0.63$ for the other three seasons. Based on the reported means for 36 houses (as detailed in Table 2 of the reference), the mean (median) fine-particle sulfate levels were 3.4 (3.2) $\mathrm{\mu g} / \mathrm{m}^{3}$ indoors and 6.2 (5.9) $\mu \mathrm{g} / \mathrm{m}^{3}$ outdoors, with a corresponding average $\mathrm{I} / \mathrm{O}$ ratio of $0.56 .^{184}$

Besides ventilation, the major removal process for $\mathrm{SO}_{2}$ from indoor air is deposition onto interior surfaces, as parameterized using the deposition velocity and with its influence quantified by equation (20). The possibility that $\mathrm{SO}_{2}$ is also removed incidentally by aqueous scrubbing when air conditioning causes water condensation was discussed. For fine-particle sulfate, in addition to ventilation, there would generally be two important mechanisms to consider for removal from indoor air. These are deposition to indoor surfaces and active removal by particle filtration in the mechanical ventilation or central air handling system. Less common, but worth noting, would be removal by means of a portable recirculating air filter.

This article is protected by copyright. All rights reserved 
The deposition of fine-particle sulfate to indoor surfaces has two important distinctions from the case of gaseous $\mathrm{SO}_{2}$. First, fine-mode particles can be assumed to adhere without limit to indoor surfaces that they contact. As a result, the rate of uptake of sulfate particles is purely masstransport limited, whereas for $\mathrm{SO}_{2}$, both mass transport and surface chemistry could influence the overall rate. Second, fine mode particles are transported by diffusive processes much more slowly than are gas molecules. Consequently, the mass-transport limited deposition velocity of $\mathrm{SO}_{2}$ to indoor surfaces would be much larger than the deposition velocity of fine-mode particle sulfate. Overall empirical evidence suggests a somewhat larger deposition velocity for $\mathrm{SO}_{2}$ compared to fine particle sulfate, with the former increasing with increasing $\mathrm{RH}$. Sinclair et al. ${ }^{135-137}$ reported on studies of the concentrations and fates of ionic substances in telephone switching offices in Wichita, KS; Lubbock, TX; Newark, NJ; and Neenah, WI. The fine-mode sulfate deposition velocities at these four sites were in the range $0.004-0.005 \mathrm{~cm} / \mathrm{s}^{137}$

Riley et al. ${ }^{182}$ modeled the indoor/outdoor relationship for fine particle sulfate for different prototypical building types. For two residential scenarios, the predicted I/O values were 0.44 for a continuously operating central air system and 0.95 with high levels of natural ventilation. For offices, with mechanical ventilation, the predicted ratios were 0.18 with a high efficiency particle filter (85\% ASHRAE dust spot average efficiency) and 0.72 when particle filtration efficiency was of a lower grade (40\% ASHRAE dust spot average efficiency).

All of the experimental evidence from field monitoring studies described thus far is based on timeintegrated methods, with sampling typically conducted for a 24-h period followed by chemical analysis in the laboratory. The lack of finer-scale time resolution limits the ability to infer potentially important dynamic processes from the experimental evidence. During the past few years, aerosol mass spectrometry has begun to be utilized in studies of indoor environments. ${ }^{14,80,139}$ In a mixed-use university laboratory space in Philadelphia, PA, the median indoor (outdoor) sulfate mass in submicron particles was measured to be $0.92(1.50) \mu \mathrm{g} / \mathrm{m}^{3}$, with a corresponding $\mathrm{l} / \mathrm{O}$ ratio of $61 \% .{ }^{139}$ 
In a classroom in the same university, the I/O ratio based on mean concentrations was measured to be $31 \%$ for summer and $33 \%$ for winter, with corresponding indoor mean concentrations of 0.43 $\mu \mathrm{g} / \mathrm{m}^{3}$ and $0.28 \mu \mathrm{g} / \mathrm{m}^{3}$, respectively. ${ }^{80}$ In these studies, the researchers treat fine particle sulfate as a nonvolatile marker of the influence of outdoor particles on indoor concentrations. They compare the I/O ratio for other chemical components, including ammonium, nitrate, and organic molecules, to that of sulfur to make novel inferences about dynamic processes affecting indoor aerosol composition and concentrations.

\subsection{Nitric and nitrous acid}

This section focuses on nitric acid $\left(\mathrm{HNO}_{3}\right)$ and nitrous acid ( $\mathrm{HONO}$ ). We also address other important oxides of nitrogen: nitric oxide, nitrogen dioxide, dinitrogen pentoxide and the nitrate radical. Altogether, these six species are closely linked through their chemistry, with nitric oxide being readily oxidized to nitrogen dioxide, and nitrogen dioxide reacting in water and on surfaces to yield nitrous acid and nitric acid. We also briefly address a newly identified indoor pollutant, isocyanic acid (HNCO) (see §3.4.9).

\subsubsection{Units}

Airborne nitric oxide (NO), nitrous acid ( $\mathrm{HONO})$, nitrogen dioxide $\left(\mathrm{NO}_{2}\right)$ and nitric acid $\left(\mathrm{HNO}_{3}\right)$ concentrations are commonly reported either in mass concentration units $\left(\mu \mathrm{g} / \mathrm{m}^{3}\right)$ or in mole fraction or mixing ratio units (ppb). At an air pressure of $1 \mathrm{~atm}$ and a temperature of $25^{\circ} \mathrm{C}$, the conversion factors are as follows: for $\mathrm{NO}, 1 \mathrm{ppb}=1.23 \mu \mathrm{g} / \mathrm{m}^{3}$; for $\mathrm{HONO}, 1 \mathrm{ppb}=1.92 \mu \mathrm{g} / \mathrm{m}^{3}$; for $\mathrm{NO}_{2}, 1 \mathrm{ppb}=1.88 \mu \mathrm{g} / \mathrm{m}^{3}$; and for $\mathrm{HNO}_{3}, 1 \mathrm{ppb}=2.58 \mu \mathrm{g} / \mathrm{m}^{3}$. Given its low concentrations in both outdoor and indoor air, nitrate radical concentrations are typically reported in mixing ratios (ppt) or in molecules/volume of air (molecules $/ \mathrm{cm}^{3}$ ); at $25^{\circ} \mathrm{C}$ and $1 \mathrm{~atm}$ total pressure, $1 \mathrm{ppt}=2.46 \times 10^{7}$ molecules $/ \mathrm{cm}^{3}$. Aerosol nitrate $\left(\mathrm{NO}_{3}{ }^{-}\right)$concentrations tend to be reported in units of $\mathrm{ng} / \mathrm{m}^{3}$ or $\mathrm{nmol} / \mathrm{m}^{3}$. Since the molecular mass of $\mathrm{NO}_{3}{ }^{-}$is $62 \mathrm{~g} / \mathrm{mol}, 1 \mathrm{nmol} / \mathrm{m}^{3}$ of $\mathrm{NO}_{3}{ }^{-}$is equivalent to 62 $\mathrm{ng} / \mathrm{m}^{3}$.

This article is protected by copyright. All rights reserved 


\subsubsection{Sources of nitrogen oxides}

The term "NO" typically refers to the mix of nitric oxide (NO) and nitrogen dioxide $\left(\mathrm{NO}_{2}\right)$. In $\mathrm{NO}$, the nitrogen atom is in the $+\mathrm{Il}$ oxidation state, while in $\mathrm{NO}_{2}$ it is in the +IV oxidation state. Other important inorganic nitrogen containing species are the relatively inert nitrous oxide $\left(\mathrm{N}_{2} \mathrm{O}\right)$, in which nitrogen is in the + l oxidation state; nitrous acid ( $\mathrm{HONO})$ and nitrite ions $\left(\mathrm{NO}_{2}{ }^{-}\right)$, in which nitrogen is in the +III oxidation state; nitric acid $\left(\mathrm{HNO}_{3}\right)$, nitrate ions $\left(\mathrm{NO}_{3}{ }^{-}\right)$and dinitrogen pentoxide $\left(\mathrm{N}_{2} \mathrm{O}_{5}\right)$, in which nitrogen is in the $+\mathrm{V}$ oxidation state; and the nitrate radical $\left(\mathrm{NO}_{3}\right)$, in which nitrogen is in the $+\mathrm{VI}$ oxidation state.

Nitrogen oxides are emitted to the atmosphere most prominently via high temperature combustion processes. A major source is motor vehicle exhaust. In both North America and Europe, nitrogen oxide concentrations have decreased over the last fifty years. In the US, a major factor initially influencing this change was the enactment of the Clean Air Act Amendments of 1970. Catalysts have been added to motor vehicle exhaust systems, and there have been co-occurring reductions in industrial emissions.

In indoor air, major sources of nitrogen oxides include outdoor-to-indoor transport and unvented indoor combustion (e.g., gas-range and gas-oven cooking, kerosene space heaters, smoking). Figure 8 illustrates the chemical processes that impact the concentrations of the dominant inorganic nitrogen species found in indoor air. Certain less consequential reactions, such as the oxidation of NO by the hydroxyl radical to generate HONO, have been omitted from this figure.

Outdoors, during daylight hours, the following three reactions constitute what is known as the primary photolytic cycle.

$$
\begin{aligned}
& \mathrm{NO}_{2}+\mathrm{hv} \rightarrow \mathrm{NO}+\mathrm{O} \\
& \mathrm{O}+\mathrm{O}_{2} \rightarrow \mathrm{O}_{3} \\
& \mathrm{O}_{3}+\mathrm{NO} \rightarrow \mathrm{NO}_{2}+\mathrm{O}_{2}
\end{aligned}
$$

This article is protected by copyright. All rights reserved 
Taken together, these three reactions have no net effect other than to maintain a pseudo-steady balance among $\mathrm{NO}, \mathrm{NO}_{2}$, and $\mathrm{O}_{3} \cdot{ }^{150}$ In the typical diurnal pattern for polluted urban air, the outdoor ozone level rises to peak level in mid-afternoon, influenced by separate net conversion of NO to $\mathrm{NO}_{2}$, a process that is dominated outdoors by peroxy radical oxidation. Indoors, photon fluxes are lower, photochemistry is muted, and, in particular, reactions (21) and (22) are effectively terminated. However, reaction (23) proceeds at a rapid rate provided that both reactants are present at significant levels. (The second-order rate constant for reaction (23) is $1.6 \mathrm{ppb}^{-1} \mathrm{~h}^{-1}$ at 25 ${ }^{\circ} \mathrm{C} .{ }^{190}$ ) Because reaction (23) is fast, it is uncommon to have $\mathrm{NO}$ and $\mathrm{O}_{3}$ simultaneously present indoors at elevated levels (> $5 \mathrm{ppb}$ ).

Ozone can react with $\mathrm{NO}_{2}$ to generate the nitrate radical:

$$
\mathrm{O}_{3}+\mathrm{NO}_{2} \rightarrow \mathrm{NO}_{3}+\mathrm{O}_{2}
$$

Compared to the $\mathrm{O}_{3}+\mathrm{NO}$ reaction, the $\mathrm{O}_{3}+\mathrm{NO}_{2}$ reaction is much slower. (The second-order rate constant $=0.0028 \mathrm{ppb}^{-1} \mathrm{~h}^{-1}$ at $25^{\circ} \mathrm{C}^{190}$ ) Consequently, reaction (24) only contributes meaningfully to indoor chemistry when indoor levels of $\mathrm{NO}$ are low (e.g., after $\mathrm{O}_{3}$ has titrated most $\mathrm{NO}$ ) and airexchange rates are not too high. Given the slow rate of reaction (24), it is not expected to greatly influence the indoor concentrations of either $\mathrm{NO}_{2}$ or $\mathrm{O}_{3}$. However, it can be an important means of generating nitrate radical indoors. The nitrate radical is maintained in equilibrium with dinitrogen pentoxide:

$$
\mathrm{NO}_{3}+\mathrm{NO}_{2}+\mathrm{M} \leftrightarrow \mathrm{N}_{2} \mathrm{O}_{5}+\mathrm{M}
$$

where $\mathrm{M}$, typically $\mathrm{N}_{2}$ or $\mathrm{O}_{2}$ (the predominant components of air), is a third body that stabilizes the forward reaction. The equilibrium constant for reaction (25) is $K_{\text {eq }}=2.9 \times 10^{-11} \mathrm{~cm}^{3}$ molecule $^{-1}(0.71$ $\mathrm{ppb}^{-1}$ ) at $25^{\circ} \mathrm{C} .{ }^{191}$ Dinitrogen pentoxide is less reactive than the nitrate radical and can be viewed as 
a storage molecule for the latter. However, any process that removes $\mathrm{N}_{2} \mathrm{O}_{5}$ also removes nitrate radical because of the rapid equilibration between these species. Nitrate radicals react rapidly with organic compounds that have unsaturated carbon bonds, generating short-lived alkylperoxy radicals $\left(\mathrm{RO}_{2} \cdot\right)$ and more stable organic nitrates, aldehydes, ketones and organic acids. ${ }^{192}$ Nitrate radicals react more slowly with saturated organic compounds, abstracting a hydrogen to form nitric acid and an alkyl radical $(\mathrm{R} \cdot)$. Dinitrogen pentoxide can also form nitric acid via its reaction with water, ${ }^{193}$ especially on indoor surfaces:

$$
\begin{aligned}
& \mathrm{NO}_{3}+\text { unsaturated organic } \rightarrow \text { organonitrate }+ \text { oxidized VOC } \\
& \mathrm{NO}_{3}+\text { saturated organic } \rightarrow \mathrm{HNO}_{3}+\mathrm{R} \cdot \\
& \mathrm{N}_{2} \mathrm{O}_{5}+\mathrm{H}_{2} \mathrm{O} \rightarrow 2 \mathrm{HNO}_{3}
\end{aligned}
$$

Nitrogen dioxide has a relatively low water solubility $\left(K_{H}=0.010 \mathrm{M} / \mathrm{atm}\right) .{ }^{142}$ It undergoes a disproportionation reaction in water, including in aqueous surface films, to yield nitrous acid and nitric acid:194,195

$$
\begin{aligned}
& 2 \mathrm{NO}_{2}+\mathrm{H}_{2} \mathrm{O} \text { (surface) } \rightarrow \mathrm{HONO}(\mathrm{aq})+\mathrm{H}^{+}+\mathrm{NO}_{3}^{-} \\
& \mathrm{HONO}(\mathrm{aq}) \leftrightarrow \mathrm{NO}_{2}^{-}+\mathrm{H}^{+} \\
& \mathrm{HONO}(\mathrm{aq}) \leftrightarrow \mathrm{HONO}(\mathrm{g})
\end{aligned}
$$

At sub-ppm concentrations, nitrogen dioxide has been shown to react with unsaturated fatty acids via abstraction of an allylic hydrogen. This reaction produces nitrous acid and an allylic radical. ${ }^{196}$ The allylic radical can subsequently react with $\mathrm{O}_{2}$ to yield an allylic hydroperoxide and autoxidation products. Pryor and Lightsey speculated that HONO resulting from this process might then react with amines producing nitrosamines. ${ }^{196}$ As is discussed in $\S 3.10$, nitrous acid has been shown to react with nicotine on indoor surfaces to generate nitrosamines. ${ }^{197}$ Although it seems possible that $\mathrm{NO}_{2}$ may react with unsaturated fatty acids in skin surface lipids and in surface films indoors, we know of no studies that have investigated this possibility.

This article is protected by copyright. All rights reserved 
Nitric acid is a very strong acid $\left(\mathrm{p} K_{\mathrm{a}}=-1.4\right)$ and highly soluble in water $\left(K_{\mathrm{H}}=8.9 \times 10^{4} \mathrm{M} / \mathrm{atm}\right) .{ }^{142}$ Nitrous acid is a weaker acid $\left(\mathrm{p} K_{\mathrm{a}}=3.16\right)^{198}$ and much less water soluble $\left(K_{\mathrm{H}}=49 \mathrm{M} / \mathrm{atm}\right),{ }^{142}$ than nitric acid, but more soluble than sulfur dioxide and almost as soluble as ammonia. In aqueous solution, $\mathrm{HONO}(\mathrm{aq})$ rapidly equilibrates with nitrite and $\mathrm{H}^{+}$ions (reaction 30 ). The concentration of $\mathrm{HONO}(\mathrm{aq})$ will also change in a direction to maintain equilibrium with gas-phase nitrous acid (HONO(g)) (reaction 31); however, rates of other source and sink processes affecting gaseous nitrous acid may be sufficiently fast to prevent aqueous and gaseous HONO equilibrating indoors.

Figure 9 shows calculated molecular abundance ratios of gaseous HONO to nitrous acid in an equilibrated aqueous solution ( $\mathrm{HONO}(\mathrm{aq})+\mathrm{NO}_{2}^{-}$) as a function of $\mathrm{pH}$. For $\mathrm{pH}$ values above 3 , acidity of HONO strongly influences this partitioning. The upper line in the figure is for water abundance equivalent to a 10-nm thick aqueous film covering all indoor surfaces in a space whose nominal surface/volume ratio is $3 \mathrm{~m}^{2}$ per $\mathrm{m}^{3}$; the lower line assumes ten times as much equilibrated water. More generally, the fraction in the gas phase scales inversely with the quantity of liquid water available for partitioning. At pH 7, the gas-phase abundance is 4 times as large as the amount dissolved and dissociated in a 10-nm surface film.

\subsubsection{Indoor $\mathrm{NO}$ and $\mathrm{NO}_{2}$ concentrations}

Based on experiments conducted in an unoccupied single-family home, Spicer et al. ${ }^{199}$ determined that the lifetimes of the gas-phase nitrogen oxides varied according to this order: NO HONO > $\mathrm{NO}_{2}>\mathrm{HNO}_{3}$. The surface removal rate for $\mathrm{NO}_{2}$ is larger than that for $\mathrm{NO}^{199,200}$ and smaller than that for $\mathrm{O}_{3} ; 201$ the surface removal of $\mathrm{HNO}_{3}$ is faster than that for $\mathrm{O}_{3}$. Surface uptake of $\mathrm{NO}_{2}$ involves reaction with water and the deposition velocity of $\mathrm{NO}_{2}$ to different surfaces is observed to increase with relative humidity. ${ }^{179,202,203}$ In the absence of indoor sources, indoor/outdoor (I/O) ratios for NO concentrations tend to be close to unity, ${ }^{203,204}$ while those for $\mathrm{NO}_{2}$ tend to be in the range of 0.7 to 0.9 depending on the air-exchange rate and relative humidity. ${ }^{201,203,205}$

This article is protected by copyright. All rights reserved 
Concentrations of nitrogen oxides and inorganic nitrogen acids have been measured inside homes, schools and offices in many studies. Zhou et al. ${ }^{206}$ recently summarized indoor concentrations of NO, $\mathrm{NO}_{2}$, and HONO measured in North American residences; Salonen et al. ${ }^{205}$ have summarized indoor concentrations of $\mathrm{NO}_{2}$, as well as indoor/outdoor $\mathrm{NO}_{2}$ ratios, measured in schools and offices.

Salonen et al. ${ }^{205}$ reported median indoor $\mathrm{NO}_{2}$ concentrations of $21 \mu \mathrm{g} / \mathrm{m}^{3}$ (11 ppb) in schools and 23 $\mu \mathrm{g} / \mathrm{m}^{3}$ (12 ppb) in offices. To a large extent, the values in schools and offices reflect indoor $\mathrm{NO}_{2}$ concentrations in the absence of indoor sources; most of the $\mathrm{NO}_{2}$ in these schools and offices originated outdoors. Tables 11 and 12, respectively, provide a representative, but not exhaustive, summary of indoor and outdoor $\mathrm{NO}_{2}$ and $\mathrm{HNO}_{3}$ concentrations reported in selected studies. Note that many of the measurements of $\mathrm{NO}_{2}$ concentrations using passive samplers, ozone-based chemiluminescence, and electrochemical monitors were likely measuring the sum of $\mathrm{NO}_{2}+\mathrm{HONO}$, rather than $\mathrm{NO}_{2}$ alone. ${ }^{199,206-208}$

Surveys made in southern California in the late 1980 s and early 1990 s are a reminder that nitrogen oxide concentrations were substantially higher in US urban air during those years than they are today. In autumn 1984, Nazaroff and Cass ${ }^{200}$ made time-resolved measurements of nitrogen oxides outside and inside a museum (the Virginia Steele Scott Gallery) in the Los Angeles air basin. For a two-day period, they reported average indoor values of $32 \mathrm{ppb}$ for $\mathrm{NO}$ and $52 \mathrm{ppb}$ for $\mathrm{NO}_{2}$; average outdoor values were $32 \mathrm{ppb}$ and $60 \mathrm{ppb}$, respectively. For both species, indoor values tracked outdoor values. Contemporaneously, Hisham and Grosjean ${ }^{213}$ measured the concentrations of $\mathrm{NO}_{2}$, $\mathrm{HNO}_{3}$, and peroxyacetyl nitrate (PAN), among other species, inside nine southern California museums. The maximum values for $\mathrm{NO}_{2}, \mathrm{HNO}_{3}$, and PAN were $120 \mathrm{ppb}, 10 \mathrm{ppb}$, and $14 \mathrm{ppb}$, respectively. At eight of these museums, indoor concentrations of $\mathrm{NO}_{2}, \mathrm{HNO}_{3}$, and PAN were similar to outdoor levels. Only one, equipped with particulate and activated charcoal filtration, had concentrations that were substantially lower indoors than outdoors. During 1992-1993, Weschler et al. ${ }^{203}$ continuously measured time-resolved outdoor and indoor concentrations of $\mathrm{NO}, \mathrm{NO}_{2}$ and $\mathrm{O}_{3}$ over 14 months at a sparsely occupied telecommunications office in Burbank, CA. They also measured indoor HONO on several occasions. This office had no combustion appliances and smoking

This article is protected by copyright. All rights reserved 
was not permitted. Based on reported monthly medians, the overall levels of $\mathrm{NO}$ and $\mathrm{NO}_{2}$ were comparable between indoors and outdoors. Specifically, the mean value of monthly medians indoors and outdoors were $37.0 \mathrm{ppb}$ and $38.9 \mathrm{ppb}$, respectively, for $\mathrm{NO}_{2}$; for $\mathrm{NO}$, corresponding values were $20.3 \mathrm{ppb}$ indoors and $20.5 \mathrm{ppb}$ outdoors. The indoor level of NO was anticorrelated with the indoor level of $\mathrm{O}_{3}$; the compounds only co-existed at elevated levels (> $5 \mathrm{ppb}$ ) when the concentration of one was increasing and the other was decreasing (so-called "crossover points"). Indoor reactions between $\mathrm{NO}$ and $\mathrm{O}_{3}$ increased the indoor $\mathrm{NO}_{2}$ levels above those that would be anticipated based solely on outdoor-to-indoor transport combined with expected surface loss of indoor $\mathrm{NO}_{2}$.

Combustion, including smoking ${ }^{215}$ and unvented combustion-based space heaters, ${ }^{216}$ generates NO, $\mathrm{HONO}, \mathrm{NO}_{2}$, and $\mathrm{HNO}_{3}$. Starting in the mid-1970s, many studies reported that when combustion appliances were present and operating, the indoor levels of $\mathrm{NO}$ and $\mathrm{NO}_{2}$ were elevated and tended to be much larger than co-occurring outdoor levels. (See the first 21 references in Wainman et al. ${ }^{217}$ ) Using passive samplers in 526 Albuquerque homes with gas ranges, Spengler et al. ${ }^{133}$ measured three-month average indoor $\mathrm{NO}_{2}$ concentrations to be $20 \mathrm{ppb}$ (standard deviation = $16 \mathrm{ppb}$ ); homes in the upper $10^{\text {th }}$ percentile had 3-month average $\mathrm{NO}_{2}$ levels exceeding $36 \mathrm{ppb}$. During years 20112013, Mullen et al. ${ }^{211}$ conducted survey sampling in 352 California homes of which about $90 \%$ had gas appliances. Arithmetic mean indoor $\mathrm{NO}_{2}$ Levels were $23 \mathrm{ppb}$ in kitchens and $18 \mathrm{ppb}$ in bedrooms. The authors also found that homes with pilot lights had higher $\mathrm{NO}_{\mathrm{x}}$ and $\mathrm{NO}_{2}$ levels in kitchens and bedrooms than those without pilot lights.

In the kitchen of a single-family home in Toronto, Collins et al., ${ }^{218}$ making time-resolved measurements, reported short-term peaks for $\mathrm{NO}$ concentrations of $120-150 \mathrm{ppb}$ and for $\mathrm{NO}_{2}$ concentrations in the range 40-60 ppb. In the kitchen of a single-family home in Oakland CA, Arata et al. ${ }^{219}$ measured real-time concentrations as high as $100 \mathrm{ppb}$ for $\mathrm{NO}$ and $170 \mathrm{ppb}$ for $\mathrm{NO}_{2}$ during experiments using a portable butane stove and deliberately injected ozone. In an occupied singlefamily home in Syracuse, NY, Zhou et al. ${ }^{206}$ measured mean $( \pm 1 \sigma)$ 5-min peak concentrations of 113 
$\pm 73 \mathrm{ppb}$ for $\mathrm{NO}$ and $17 \pm 13 \mathrm{ppb}$ for $\mathrm{NO}_{2}$ during cooking events. These contrast with measured background concentrations in the Syracuse home of $4.0 \pm 2.5 \mathrm{ppb}$ for $\mathrm{NO}$ and $2.0 \pm 0.7$ for $\mathrm{NO}_{2}$.

Zhao et al. ${ }^{220}$ recently investigated the building envelope penetration factors for ambient nitrogen oxides in an apartment in Chicago, IL. They found the penetration factor to be unity for NO and 0.72 \pm 0.06 for $\mathrm{NO}_{2}$.

\subsubsection{Indoor nitric acid concentrations}

As is apparent from Table 12, indoor air nitric acid concentrations tend to be very low $1<0.5$ $\mathrm{ppb})^{6,128-130,212,214} \mathrm{and}$, depending on the measurement method, are often indistinguishable from zero. Salmon et al. ${ }^{214}$ measured $\mathrm{HNO}_{3}$ concentrations at five museums in the Los Angeles area during summer and winter months. Mean seasonal concentrations ranged from $<0.04$ to $0.6 \mathrm{ppb}<<0.1$ to $\left.1.5 \mu \mathrm{g} / \mathrm{m}^{3}\right)$. The mean nitric acid concentration measured in two University of Essex buildings was $0.94 \mu \mathrm{g} / \mathrm{m}^{3}$ (0.36 ppb); the corresponding outdoor level was $4.6 \mu \mathrm{g} / \mathrm{m}^{3}(1.8 \mathrm{ppb}) .{ }^{119} \mathrm{In}$ six Boston homes, the mean summer level was $0.84 \mathrm{ppb}$ contrasted with $0.03 \mathrm{ppb}$ for five homes in winter. ${ }^{128}$ In a New Jersey daycare facility, nursing home, and home for the elderly, mean $\mathrm{HNO}_{3}$ concentrations were in the range of 0.2 to 0.4 ppb. ${ }^{129}$ For 229 12-h samples collected In 47 homes in State College $\mathrm{PA}$, the geometric mean (GSD) indoor $\mathrm{HNO}_{3}$ concentration was $0.2 \mathrm{ppb}$ (3.1). ${ }^{131}$ Fischer et al. ${ }^{127}$ made outdoor and indoor measurements of nitric acid, with 30-minute temporal resolution, at an unoccupied home in Clovis, CA. Although the outdoor levels were as high as 3 ppb, and indoor $\mathrm{NH}_{4} \mathrm{NO}_{3}$ dissociation was an additional $\mathrm{HNO}_{3}$ source, the indoor $\mathrm{HNO}_{3}$ levels were normally lower than the uncertainty in the instrument offset $(0.2 \mathrm{ppb})$.

Although concentrations of nitric acid tend to be low indoors, its influence on $\mathrm{pH}$ could still be substantial. For example, the equilibrium pH of water exposed to $800 \mathrm{ppm}$ of $\mathrm{CO}_{2}$ is 5.46 . Water

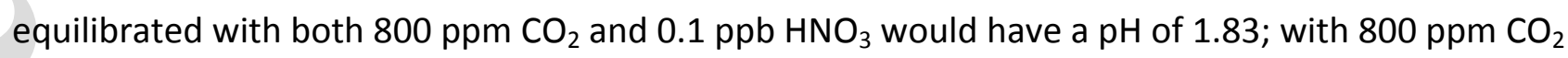
and $0.5 \mathrm{ppb} \mathrm{HNO}_{3}$, equilibrated water would have a pH of 1.48. Ammonia often co-occurs with $\mathrm{CO}_{2}$ indoors. The equilibrium pH of water exposed to $800 \mathrm{ppm}$ of $\mathrm{CO}_{2}$ and $20 \mathrm{ppb}$ of $\mathrm{NH}_{3}$ is 7.12.

This article is protected by copyright. All rights reserved 
Maintaining an abundance of $0.1 \mathrm{ppb}$ of gaseous $\mathrm{HNO}_{3}$ added to this mix would decrease the equilibrium $\mathrm{pH}$ to 3.48 , while sustained exposure to $0.5 \mathrm{ppb}$ of $\mathrm{HNO}_{3}$ would decrease the equilibrium $\mathrm{pH}$ to 3.13. The large impact of low $\mathrm{HNO}_{3}$ concentrations reflects its strong acidity coupled with its very high water-solubility. However, these properties also mean that the time required for nitric acid to equilibrate with bulk water becomes unrealistically large as the equivalent thickness of surface water increases. Consequently, equilibrium calculations involving gaseous nitric acid indoors should be regarded as suggestive rather than as quantitatively accurate.

\subsubsection{Nitrite and nitrate in indoor airborne particles}

Gaseous nitric acid can react with gaseous ammonia, contributing ammonium nitrate to airborne particles. To a lesser extent, nitrous acid can be a precursor for nitrite salts in airborne particles. Table 13 summarizes results from selected studies that have measured indoor and outdoor concentrations of nitrate ions in airborne particles. Only one study has reported measurements of nitrite levels in indoor airborne particles. ${ }^{128}$ In that work, average indoor winter concentrations of nitrite were roughly four times larger than summer concentrations $\left(22 \mathrm{nmol} / \mathrm{m}^{3} \mathrm{vs} .5 .4 \mathrm{nmol} / \mathrm{m}^{3}\right)$. Interestingly, in both winter and summer, the I/O ratios were substantially larger than unity (geometric mean I/O values were 2.2 for summer and 7.3 for winter), indicating an indoor source for particulate nitrite in these homes.

Several studies that have measured outdoor and indoor $\mathrm{NO}_{2}$ or $\mathrm{HNO}_{3}$ have simultaneously measured the levels of nitrate in outdoor and indoor particles. ${ }^{119,128-131}$ Indoor levels of particle-associated nitrate are typically in the range of $1-10 \mathrm{nmol} / \mathrm{m}^{3}$ (Table 13). The presence of unvented gas combustion appliances appears to have little influence on the indoor concentration of particulate nitrate. ${ }^{132}$ In a daycare facility and a nursing home, indoor particulate nitrate concentrations were higher than co-occurring outdoor levels, but in a home for the elderly, indoor levels were lower than outdoor levels. ${ }^{122}$ In their study of 47 homes in State College PA, Suh et al. ${ }^{131}$ measured indoor levels of particulate nitrate that were typically higher than co-occurring outdoor levels. They speculated that the reason for the higher levels of nitrate indoors was the $\mathrm{HNO}_{3}-\mathrm{NH}_{3}$ reaction. Conversely,

This article is protected by copyright. All rights reserved 
dissociation of ammonium nitrate as particles are transported from outdoors to indoors is a recognized occurrence. ${ }^{153}$ (See §3.2.7.)

Sinclair et al. ${ }^{137}$ found that there was a nitrate artifact with Teflon membrane filters used to sample fine and coarse mode airborne particles and, consequently, they did not report nitrate levels in their studies. This outcome occurred despite washing the filters prior to use. In hindsight, the phenomenon might have been caused by $\mathrm{NH}_{3} / \mathrm{HNO}_{3} / \mathrm{NH}_{4} \mathrm{NO}_{3}$ partitioning between air and filter surfaces.

\subsubsection{Indoor nitrous acid concentrations}

In the 1980s, Pitts et al., ${ }^{221}$ using differential optical absorption spectroscopy (DOAS), identified and measured ppb levels of HONO in a mobile laboratory after injecting $\mathrm{NO}_{2}$ sufficient to establish low ppm levels. In a subsequent study, HONO levels were measured to be as high as $\sim 50 \mathrm{ppb}$ in a mobile home during periods when a gas-fired kitchen stove and kerosene- or propane-fueled space heaters were operated. ${ }^{222}$ In the early 1990s, Febo and Perrino measured elevated HONO concentrations in a residence in the suburbs of Rome ${ }^{223}$ and in automobile cabins. ${ }^{224}$ Since then, indoor concentrations of HONO have been measured in numerous studies, although not as many as for $\mathrm{NO}$ and $\mathrm{NO}_{2}$. This body of research has been summarized by Gligorovski ${ }^{225}$ and by Collins et al. ${ }^{218}$ Of note are studies in multiple homes that have been made using integrated measurements, sometimes with passive diffusion samplers for intervals as long as two weeks. For example, in ten Albuquerque, NM homes with gas cooking, Spengler et al. measured average HONO concentrations of $4.7 \pm 2.3$ ppb. ${ }^{133}$ They found a correlation between indoor concentrations of $\mathrm{HONO}$ and $\mathrm{NO}_{2}$, with the indoor HONO level between $5 \%$ and $15 \%$ of indoor $\mathrm{NO}_{2}$. During summer months in homes in Connecticut and Virginia, Leaderer et al. ${ }^{132}$ measured average HONO concentrations of $1.6 \pm 2.1 \mathrm{ppb}$ in air-conditioned (AC) homes $(n=49)$ and $3.5 \pm 2.6 \mathrm{ppb}$ in non-air-conditioned homes $(n=9)$. The lower average values for HONO in AC homes may partially reflect HONO loss to the air conditioner condensate. Dividing these same 58 homes between those with gas stoves and those without, average HONO concentrations were $0.8 \pm 0.8 \mathrm{ppb}$ in non-gas-stove homes $(n=39)$ and $4.0 \pm 2.8 \mathrm{ppb}$ in gas-stove homes $(n=19)$.

This article is protected by copyright. All rights reserved 
During winter months, Leaderer et al. measured average HONO concentrations to be $6.8 \pm 6.1 \mathrm{ppb}$ in kerosene-heater homes $(n=74)$ and $3.5 \pm 3.6 \mathrm{ppb}$ in non-kerosene heater homes $(n=148) .{ }^{132}$ For the homes without kerosene heaters, average wintertime HONO concentrations were $2.4 \pm 3.1 \mathrm{ppb}$ in non-gas-stove homes $(n=96)$ and $5.5 \pm 3.8 \mathrm{ppb}$ in gas-stove homes $(n=52)$. All of this evidence points to unvented combustion as contributing to measurable increases in indoor HONO levels.

In 99 homes in Upland, CA, and San Bernardino County, Lee et al. ${ }^{226}$ measured average HONO concentrations of $4.6 \pm 4.3 \mathrm{ppb}$, considerably higher than the outdoor levels of $0.9 \pm 2.3 \mathrm{ppb}$. Homes with gas ranges had higher indoor $\mathrm{NO}_{2}$ and $\mathrm{HONO}$ concentrations than those without. Indoor concentrations of $\mathrm{HONO}$ were positively correlated with $\mathrm{NO}_{2}$, with $\mathrm{HONO}$ levels occurring at approximately $17 \%$ of the $\mathrm{NO}_{2}$ levels. $\mathrm{HONO}$ concentrations were inversely correlated with $\mathrm{O}_{3}$ concentrations. A similar inverse correlation between $\mathrm{HONO}$ and $\mathrm{O}_{3}$ was reported by Weschler et al. ${ }^{203}$ based on spot measurements made in a Burbank telecommunications office. In both studies, the authors suggest that this observation may be a result of ozone-initiated oxidation of nitrite ions in aqueous surface films; the concentration of nitrite ions in indoor aqueous solutions is linked to gas-phase HONO concentrations (Figure 8).

Semi-continuous measurements of HONO concentrations were made in an unoccupied school classroom in France, ${ }^{227}$ using wet chemical sampling and subsequent quantification with high performance liquid chromatography. Five experiments were conducted with controlled injections of $\mathrm{NO}_{2}$ under different lighting and relative humidity conditions. With average indoor $\mathrm{NO}_{2}$ levels in the range 28-46 ppb and indoor $\mathrm{RH}$ levels in the range 30-60\%, average indoor HONO levels were 5.1-6.2 ppb. ${ }^{228}$ Mendez et al. ${ }^{228}$ developed a description for HONO formation that assumes $\mathrm{NO}_{2}(\mathrm{~g})$ is first sorbed to surface sites, which are limited in number, and that $\mathrm{NO}_{2}$ (sorbed) then reacts with water to produce $\mathrm{HONO}$ and $\mathrm{HNO}_{3}$. Key parameters were fitted based on measurements in one experiment, and, with these fitted parameters, the model reasonably predicted the measured HONO concentrations in the other four experiments.

This article is protected by copyright. All rights reserved 
As part of a study in a Syracuse home, Zhou et al. ${ }^{206}$ made time-resolved measurements of HONO concentrations during baseline conditions and cooking events. Mean \pm standard deviation HONO concentrations were $4.3 \pm 2.2 \mathrm{ppb}$ during baseline conditions, rising to $19.5 \pm 10.5 \mathrm{ppb}$ during cooking (5-min peak concentrations). A short-term peak concentration of $50 \mathrm{ppb}$ was measured. To our knowledge, this is the first study to report indoor baseline HONO concentrations larger than indoor baseline $\mathrm{NO}_{2}$ concentrations $(2.0 \pm 0.7 \mathrm{ppb})$.

Collins et al. ${ }^{218}$ measured time-resolved HONO levels inside and outside a Toronto home in November using a high-resolution time-of-flight chemical ionization mass spectrometer with acetate as the reagent ion. They found that, while indoor $\mathrm{NO}_{2}$ levels varied over a large range depending on outdoor levels, indoor HONO concentrations varied over a relatively narrow range and did not correlate with $\mathrm{NO}_{2}$ concentrations. Perturbation experiments were conducted in the kitchen using a burner on a gas stove and opening/closing windows and a door. During these perturbations, $\mathrm{NO}_{2}$ emitted by the gas burner only weakly affected HONO levels. Flushing the kitchen via open windows and a door reduced HONO levels during the high ventilation period, but when windows and door were closed, HONO returned to a gas-phase concentration close to its pre-airing value. The temporal responses of HONO were similar to those of small carboxylic acids (e.g., formic and acetic) in these airing experiments. The authors concluded that gas-phase HONO was in equilibrium with, and strongly controlled by, surface sources. This inference was further supported by nitrite levels measured on various impermeable vertical surfaces in the kitchen and the upstairs of the home. Nitrite levels averaged approximately $10^{12}$ molecules $\mathrm{cm}^{-2}$; the authors cautioned that this value should be considered a lower limit.

HONO measurements that were made during venting experiments as part of the HOMEChem campaign in Austin TX ${ }^{158}$ substantiate the Toronto home findings by Collins et al. ${ }^{218}$ When the Austin test house was vented, gas-phase HONO concentrations decreased from $\sim 4 \mathrm{ppb}$ to about $1 \mathrm{ppb}$. When windows were then closed, the HONO concentration returned to a level close to that measured before venting. See $§ 4.6$ for further discussion.

This article is protected by copyright. All rights reserved 
It is interesting to compare the influence of $\mathrm{HONO}$ to that of $\mathrm{HNO}_{3}$ on the $\mathrm{pH}$ of aqueous surface films or bulk water. To begin, consider that the equilibrium pH of water exposed to $800 \mathrm{ppm}$ of $\mathrm{CO}_{2}$ and $20 \mathrm{ppb}$ of $\mathrm{NH}_{3}$ is 7.12. Adding $5 \mathrm{ppb}$ of gaseous HONO to this mix would decrease the equilibrium $\mathrm{pH}$ to 6.53 , whereas adding $0.1 \mathrm{ppb}$ of $\mathrm{HNO}_{3}$ would decrease the equilibrium $\mathrm{pH}$ to 3.48 . So, although measured indoor concentrations of HONO tend to be $10-100 \times$ larger than those of $\mathrm{HNO}_{3}$, the expected influence of $\mathrm{HONO}$ on $\mathrm{pH}$ is considerably weaker, based on analyses for equilibrium conditions.

Taken together, these studies illustrate a strong direct contribution from indoor combustion to indoor $\mathrm{HONO}$ concentrations, a contribution from the partial transformation of $\mathrm{NO}_{2}$ to $\mathrm{HONO}$ on indoor surfaces, the potential for ozone to decrease indoor HONO levels via oxidation of nitrite ions in aqueous solution, and the ability of indoor basic surfaces (see Figure 9) to serve as large reservoirs for nitrous acid. More measurements of nitrite ions on indoor surfaces, as well as of the timedependent $\mathrm{pH}$ of aqueous films on different indoor surfaces, would improve our understanding of the reported and inferred dynamics of this inorganic acid.

\subsubsection{Removal of HONO by occupants}

During a study conducted in a $79-\mathrm{m}^{3}$ stainless steel climate chamber, Brauer et al. ${ }^{229}$ examined the impact of human occupants on indoor HONO concentrations. At a high air-exchange rate $\left(12 \mathrm{~h}^{-1}\right)$, four human occupants had only a small effect on HONO concentrations resulting from the addition of $\mathrm{NO}_{2}$ to the chamber. However, at a much lower air-exchange rate $\left(0.5 \mathrm{~h}^{-1}\right)$, the measured indoor HONO concentration with occupants was reduced to $40 \%$ of its value without humans in the chamber (8 ppb vs. 21 ppb). When the subjects left the chamber, HONO levels returned to levels previously observed for the empty chamber. The concentrations of $\mathrm{NO}_{2}$ and $\mathrm{NO}$ were not affected by humans in the chamber. Direct removal by breathing could not account for the observed HONO removal rate. Reaction of $\mathrm{HONO}$ with $\mathrm{NH}_{3}$ emitted by the occupants (thermodynamically unfavorable) also did not explain the observed reduction of indoor HONO levels.

This article is protected by copyright. All rights reserved 
Brauer et al. speculated that "the effect of increased surface area is a plausible explanation for our observations." 229 One can estimate the potential magnitude of HONO removal by exposed skin, hair and clothing of the four subjects in the chamber. Assume that the deposition velocity (mass transfer coefficient) for HONO to human surfaces is similar to that measured for ozone $(\sim 8 \mathrm{~m} / \mathrm{h})^{230}$ and assume a body surface area of $1.8 \mathrm{~m}^{2}$ for each human in the chamber. Then four humans would remove HONO at a rate equivalent to ventilating with clean air at $58 \mathrm{~m}^{3} / \mathrm{h}\left(=8 \mathrm{~m} / \mathrm{h} \times 1.8 \mathrm{~m}^{2} \times 4\right)$ or $0.73 \mathrm{~h}^{-1}$ in the $79 \mathrm{~m}^{3}$ chamber. Such a removal by human occupants is predicted to yield a reduction of approximately $60 \%$ in HONO concentration at a chamber air-exchange rate of $0.5 \mathrm{~h}^{-1}$, which is consistent in scale with the reduction shown in Figure 4 of Brauer et al. ${ }^{229}$ Conversely, the effect of removal on human surfaces would only be expected to reduce the indoor concentrations of HONO by about $5 \%$ for the high air-exchange rate condition of $12 \mathrm{~h}^{-1}$.

If HONO loss does occur on the occupant envelope, important questions remain to be answered. Is this phenomenon transient, terminating when equilibrium partitioning is achieved? Or is HONO being irreversibly sorbed by skin and clothing?

\subsubsection{Nitrate radicals and dinitrogen pentoxide indoors}

Based on 48-h measurements of $\mathrm{O}_{3}$ (14 ppb average) and $\mathrm{NO}_{2}$ (52 ppb average) in a Southern California museum gallery, coupled with their model of indoor chemistry, Nazaroff and Cass ${ }^{200}$ predicted that $\mathrm{O}_{3} / \mathrm{NO}_{2}$ chemistry would generate $\mathrm{NO}_{3}$ and $\mathrm{N}_{2} \mathrm{O}_{5}$ at substantial net rates. Weschler et al. ${ }^{231}$ suggested that under certain circumstances, $\mathrm{O}_{3} / \mathrm{NO}_{2}$ chemistry would generate indoor nitrate radical concentrations comparable to outdoor nighttime levels and that subsequent chemistry could be a substantial source of indoor nitric acid. Using a detailed chemical model, Sarwar et al. ${ }^{232}$ estimated an indoor nitrate radical concentration of 0.15 ppt for "base case" indoor conditions. Using a detailed model of gas-phase indoor chemistry, Carslaw ${ }^{192}$ predicted low $\mathrm{NO}_{3}$ concentrations under indoor conditions that included elevated concentrations of terpenes and unsaturated alkenes, which rapidly consume nitrate radicals. Carslaw noted that an anticipated consequence is formation

This article is protected by copyright. All rights reserved 
of $\mathrm{RO}_{2}$. radicals, and subsequent production of organic acids. $\mathrm{N} \varnothing \mathrm{jgaard} \mathrm{d}^{233}$ made the first timeintegrated measurements ( 10-16 h) of the sum ' $\mathrm{NO}_{3}+\mathrm{N}_{2} \mathrm{O}_{5}$ ' based on concentrations of an oxidation product of the $\mathrm{NO}_{3}$ /cyclohexene reaction. Eleven separate measurements were made in an unoccupied $60 \mathrm{~m}^{3}$ conference room in Copenhagen, DK, during August. There were no indoor sources of $\mathrm{O}_{3}$ or $\mathrm{NO}_{2}$; these species originated outdoors. The sum ' $\mathrm{NO}_{3}+\mathrm{N}_{2} \mathrm{O}_{5}$ ' ranged from 1 to 58 ppt, and was influenced by the fraction of time mechanical ventilation occurred, levels of $\mathrm{O}_{3}$ and $\mathrm{NO}_{2}$, lighting and time of day. For the four samples collected during daylight hours, the sum of $\mathrm{NO}_{3}+$ $\mathrm{N}_{2} \mathrm{O}_{5}$ ranged from 3 to 10 ppt or approximately 0.6 to 1.4 ppt of $\mathrm{NO}_{3}$ given the measured cooccurring $\mathrm{NO}_{2}$ concentrations. These measured values are larger than Carslaw's modeled estimates of $\mathrm{NO}_{3}$ levels under typical indoor conditions. Nøjgaard speculated that this discrepancy might be due to actual NO concentrations being lower than those used in the model and concluded by calling for time-resolved measurements of indoor $\mathrm{NO}_{3}$, such as could be achieved using cavity ringdown spectroscopy.

Arata et al. ${ }^{219}$ made the first real-time indoor $\mathrm{NO}_{3}$ measurements in the kitchen of a single-family home during simulated-use conditions. Experiments included cooking with a butane stove in the presence of deliberately released ozone. At an enhanced $\mathrm{O}_{3}$ level of $40 \mathrm{ppb}$, researchers ignited the stove, operated it for about five minutes to boil water, and turned it off. After $\mathrm{O}_{3}$ had titrated the $\mathrm{NO}$ in the kitchen air, the $\mathrm{N}_{2} \mathrm{O}_{5}$ level began to increase, reaching a value of $190 \mathrm{ppt}$, while the $\mathrm{NO}_{3}$ concentrations leveled off at about 3 ppt. Based on simultaneous measurements of $\mathrm{NO}_{2}, \mathrm{O}_{3}$ and $\mathrm{NO}_{3}$, they estimated total nitrate radical reactivity with volatile organic compounds to be $0.8 \mathrm{~s}^{-1}$. Using a box-model they calculated a peak $\mathrm{NO}_{3}$ production rate of $7 \mathrm{ppb} \mathrm{h}^{-1}$. The model's output indicated that reaction of $\mathrm{N}_{2} \mathrm{O}_{5}$ with indoor surfaces, producing nitric acid, accounted for $20 \%$ of $\mathrm{NO}_{3}$ loss during the period of peak $\mathrm{NO}_{3}$ production. More generally, these studies indicate that, under conditions with elevated indoor levels of $\mathrm{O}_{3}$, combustion events can result in meaningful levels of nitric acid, organonitrates and various oxidized $\mathrm{VOC}-$ even when measured residual $\mathrm{NO}_{3}$ concentrations are relatively low.

This article is protected by copyright. All rights reserved 


\subsubsection{Isocyanic acid}

Isocyanic acid $(\mathrm{HNCO})$ is moderately acidic $\left(\mathrm{p} K_{\mathrm{a}}=3.7\right)^{234,235}$ and moderately soluble $\left(K_{\mathrm{H}}=21\right.$ $\mathrm{M} /$ atm). ${ }^{142}$ It has been recognized as a gas-phase acid in the outdoor atmosphere since $2008 .{ }^{236}$ More recently, experiments have demonstrated that gas-phase oxidation of nicotine by hydroxyl radicals generates HNCO. ${ }^{237}$ Measurements using an acetate CIMS in a chamber and in a Toronto home have explored indoor sources of HNCO. ${ }^{238}$ The chamber studies indicated a molar ratio of $\mathrm{HNCO} / \mathrm{CO}$ in sidestream cigarette smoke of $2.7( \pm 1.1) \times 10^{-3}$. In a home, the background HNCO concentration was $0.15 \mathrm{ppb}$, about twice the outdoor level. A single cigarette's sidestream smoke increased the HNCO concentration to about $1.5 \mathrm{ppb}$. In chamber experiments, there was evidence for photochemical production of HNCO from cigarette smoke, doubling the concentration in about 30 minutes at an $\mathrm{OH}$ concentration of $1.1 \times 10^{7}$ molecules $/ \mathrm{cm}^{3}$. However, in the home there was no evidence of photochemistry influencing the HNCO concentration. Simultaneous, time-resolved measurements of HNCO and $\mathrm{CO}$ indicated that partitioning to indoor surfaces was a significant sink for indoor HNCO. Isocycanic acid reacts with ammonia to form urea. ${ }^{236}$

\subsection{Hydrochloric and hypochlorous acid}

\subsubsection{Hydrochloric acid}

Among halogenated acids, chlorine-containing species are the most noteworthy. In the atmosphere, hydrochloric acid $(\mathrm{HCl})$ is a prominent atmospheric inorganic strong acid. Important sources of atmospheric $\mathrm{HCl}$ are the combustion of fuels and wastes that contain chlorine, which include coal, biofuels, and plastics. Hydrochloric acid is also generated from acid-displacement reactions in which other atmospheric strong acids, such as $\mathrm{HNO}_{3}$, react with sea-salt aerosol, with the net effect represented by $\mathrm{HNO}_{3}(\mathrm{~g})+\mathrm{NaCl}(\mathrm{s}) \rightarrow \mathrm{HCl}(\mathrm{g})+\mathrm{NaNO}_{3}(\mathrm{~s})$. In a global emission inventory of $\mathrm{HCl}$,

combustion and sea-salt dechlorination were the largest sources. ${ }^{239} \mathrm{~A}$ more recent study suggested that garbage burning "is the main global source of $\mathrm{HCl} . " 240$ Garbage often contains polyvinyl chloride, which emits $\mathrm{HCl}$ when burned.

This article is protected by copyright. All rights reserved 
The presence of $\mathrm{HCl}$ in outdoor air means that ventilation contributes $\mathrm{HCl}$ to indoor environments. Indoor $\mathrm{HCl}$ also can be generated, in principle, by unvented indoor combustion processes. For example, there is some evidence, detailed below, that cigarettes can be a meaningful indoor emission source where smoking occurs.

Hydrochloric acid is both highly water soluble and a very strong acid. The relevant thermodynamic parameters are a Henry's law constant of $K_{\mathrm{H}}=1500 \mathrm{M} / \mathrm{atm}^{142}$ and an acid-dissociation constant recently reported as $\mathrm{p} K_{\mathrm{a}}=-5.9 .{ }^{241} \mathrm{Hydrochloric}$ acid is so strong, one can safely assume that $\mathrm{HCl}$ will be fully dissociated in water, regardless of the $\mathrm{pH}$ of the solution. This combination of thermodynamic parameters, along with the reasonable expectation of a negligible vapor pressure of the $\mathrm{Cl}^{-}$ion, suggests that there should be no gaseous $\mathrm{HCl}$ in the presence of an aqueous phase, at least under equilibrium conditions. It also suggests that one could look for elemental $\mathrm{Cl}$ in fine particulate matter as an indicator of the influence of $\mathrm{HCl}$ on the composition of air. Specifically, if there is an aqueous phase associated with particulate matter, then $\mathrm{HCl}$ will dissolve into that water and dissociate to form $\mathrm{H}^{+}$and $\mathrm{Cl}^{-}$. Gaseous $\mathrm{HCl}$ might also react with ammonia to form the ammonium chloride salt, $\mathrm{NH}_{4} \mathrm{Cl}$, which would tend to condense onto preexisting particles. In either case, condensation onto fine-mode particles would be favored because of mass transport considerations. In brief, and to simplify a more complex story, the condensation onto fine mode particles (mainly in the diameter range 0.1-1 $\mu \mathrm{m}$ ) would be favored because the majority of particleassociated surface area is on particles in this size range. By contrast, coarse-mode aerosol chlorine would probably be dominated by primary production, e.g. by sea spray processes associated with breaking waves.

Only a few studies have reported measured indoor air concentrations of $\mathrm{HCl}$ and/or fine-particle chloride. The concentrations tend to be low, typically less than about $1 \mu \mathrm{g} / \mathrm{m}^{3}$. Li and Harrison ${ }^{119}$ measured indoor and outdoor concentrations of $\mathrm{HCl}$ and total aerosol $\mathrm{Cl}^{-}$during repeated 24-h sampling events at the University of Essex, UK. They reported average indoor (outdoor) levels of $0.44(0.95) \mu \mathrm{g} / \mathrm{m}^{3}$ for $\mathrm{HCl}$ and $0.74(1.63) \mu \mathrm{g} / \mathrm{m}^{3}$ for total aerosol $\mathrm{Cl}^{-}$. Allen and Miguel ${ }^{242}$ measured 
indoor and outdoor levels of $\mathrm{HCl}$ and fine-particle chloride at six sites in southeastern Brazil. These sites were characterized as hotel/restaurant $(n=1)$, restaurant $(n=2)$, and office $(n=3)$. Each site was sampled once during normal occupancy over periods ranging from two to six hours. The reported mean $\mathrm{HCl}$ level was $0.28 \mu \mathrm{g} / \mathrm{m}^{3}$ indoors versus $0.52 \mu \mathrm{g} / \mathrm{m}^{3}$ outdoors. Interestingly, the average fine particle chloride levels were substantially higher indoors $\left(0.34 \mu \mathrm{g} / \mathrm{m}^{3}\right)$ than outside $\left(0.04 \mathrm{\mu g} / \mathrm{m}^{3}\right)$. In combination, these results suggest the possibility of an indoor source of $\mathrm{HCl}$ with reactions indoors that convert gaseous $\mathrm{HCl}$ to aerosol $\mathrm{Cl}^{-}$. In the United States, the PTEAM study conducted personal sampling of respirable particles $\left(\mathrm{PM}_{10}\right)$ along with simultaneous residential indoor and outdoor measurements of respirable and fine particles $\left(\mathrm{PM}_{10}\right.$ and $\left.\mathrm{PM}_{2.5}\right)$ for 178 subjects selected to be statistically representative of the population of nonsmoking residents of Riverside, California. ${ }^{243}$ Chemical elements were measured using x-ray fluorescence. As reported by Wallace, ${ }^{244}$ chlorine was predominantly attributable to indoor emission sources in both the fine and inhalable size ranges. The two noted indoor chlorine sources were cigarette smoking and cooking. Estimated mean emission factors for fine-particle $\mathrm{Cl}^{-}$were $103 \mu \mathrm{g} / \mathrm{cig}$ from smoking and $5.9 \mu \mathrm{g} / \mathrm{min}$ from cooking. ${ }^{243}$ In an earlier source apportionment study based on week-long samples in 394 homes in New York state, a fine-particle $\mathrm{Cl}^{-}$emission factor for smoking was determined to be 69 $\mu \mathrm{g} /$ cig. ${ }^{186}$

As previously noted, Sinclair et al. ${ }^{137}$ reported measurements of the ionic composition of airborne fine particles and surface accumulations in telephone switching offices in four US cities. Average indoor concentrations of $\mathrm{Cl}^{-}$were in the range $2-11 \mathrm{ng} / \mathrm{m}^{3}$, lower than the corresponding outdoor range of $11-121 \mathrm{ng} / \mathrm{m}^{3}$. In an earlier report of data from two of the study sites, Sinclair et al. ${ }^{135}$ indicated that the indoor/outdoor ratios of fine particle $\mathrm{Cl}^{-}$ions were elevated compared with other ions; they suggested that cigarette smoking might have been a contributing source. By comparing surface accumulations of soluble $\mathrm{Cl}^{-}$ions on aluminum and zinc surfaces, Sinclair et al. ${ }^{245}$ indicate a role for the deposition of $\mathrm{Cl}$-containing gases (possibly $\mathrm{HCl}$ ): "chloride accumulation on aluminum surfaces was shown to occur almost entirely by particle deposition (>90\%), while chloride

This article is protected by copyright. All rights reserved 
accumulation on zinc surfaces occurred by both particle deposition and reaction with chlorinecontaining gases."

The emergence of advanced instrumentation for atmospheric science studies has permitted realtime measurements of chlorine associated with submicron particles and gaseous $\mathrm{HCl}$. Johnson et al. ${ }^{139}$ reported the first application of aerosol mass spectrometry to "analyze real-time indoor aerosol composition and outdoor-to-indoor transformation." They found, though, that "chloride was rarely above detection [limit]." Dawe et al. ${ }^{246}$ reported the first time-resolved measurements of $\mathrm{HCl}$ indoors using cavity ring-down spectroscopy. Their study entailed residential measurements during three common types of household activities. They found that "surface application of bleach resulted in a reproducible increase of 0.1 ppbv"; "emissions of $\mathrm{HCl}$ from automated dishwashers were observed only when chlorinated detergents were used"; and that indoor $\mathrm{HCl}$ levels increased "during meal preparation on an electric element stovetop."

\subsubsection{Hypochlorous acid}

Arguably, the most important chlorinated acid for indoor environmental quality is hypochlorous $(\mathrm{HOCl})$. This chemical and its conjugate base, the hypochlorite ion $\left(\mathrm{OCl}^{-}\right)$, are associated with the widespread application of chlorine for treating municipal drinking water, for maintaining the hygiene of swimming pools and spas, and as an active ingredient in bleach and other cleaning products used indoors. The impact of $\mathrm{HOCl}$ and $\mathrm{OCl}^{-}$on indoor environmental quality emerges largely indirectly, only partly in relation to their acid-base properties. A key fundamental factor is the oxidative potential of the chlorine atom: in hypochlorite, $\mathrm{Cl}$ is in oxidation state $+\mathrm{l}$, whereas in the chloride ion and in many common chemically combined forms, $\mathrm{Cl}$ is in oxidation state -I.

Hypochlorous acid is weak $\left(\mathrm{p} K_{\mathrm{a}}=7.53\right)$ with moderately high water solubility $\left(K_{\mathrm{H}}=660 \mathrm{M} / \mathrm{atm}\right) .{ }^{142}$ Commercial chlorine bleach for household use commonly is an aqueous solution of $3-6 \% \mathrm{NaOCl}$ $(74.4 \mathrm{~g} / \mathrm{mol})$ along with a strong base, such as $\mathrm{NaOH}$, to establish a basic $\mathrm{pH}$ of approximately 12 . The corresponding molarity of hypochlorite, representing the sum of $[\mathrm{HOCl}]$ and $\left[\mathrm{OCl}^{-}\right]$, would be in 
the range $0.4-0.8 \mathrm{M}$. At $\mathrm{pH} 12$, about 4.5 units above the $\mathrm{p} K_{\mathrm{a}}$ value, the ratio of $\left[\mathrm{OCl}^{-}\right]$to $[\mathrm{HOCl}]$ in solution would be about $10^{4.5}$ or $32,000: 1$. The expected aqueous concentration of [HOCl] would be 13-26 $\mu \mathrm{M}$ and the corresponding equilibrium mole fraction of gaseous $\mathrm{HOCl}$ in the headspace of a bleach bottle would be 19-39 ppb. Decreasing the $\mathrm{pH}$ by 1 unit would increase the equilibrium abundance of gaseous $\mathrm{HOCl}$ in the headspace by $10 \times$.

In common cleaning applications, household bleach is diluted by factors in the approximate range 10-100, which correspondingly reduces the equilibrium partial pressure. However, in application, the $\mathrm{pH}$ of the cleaning solution may shift, and any shift in the direction of lower $\mathrm{pH}$ would tend to increase the relative abundance of $\mathrm{HOCl}$ as a fraction of the total hypochlorite. In turn, this shift would tend to promote increased vapor pressure and enhancements of the gas-phase abundance of $\mathrm{HOCl}$. This point is illustrated in Figure 10, which presents the equilibrium gas-phase concentration of $\mathrm{HOCl}$ versus solution $\mathrm{pH}$ for different fixed levels of the total concentration of hypochlorite in the aqueous solution, $\mathrm{Ct}=[\mathrm{HOCl}]+\left[\mathrm{OCl}^{-}\right]$. The upper three traces in the figure correspond to undiluted consumer bleach (at $4.5 \% \mathrm{NaOCl}$ ), and dilution of this product into water at respective ratios of 1:10 and 1:100.

Hypochlorous acid is a key chemical ingredient when chlorination is used for drinking water disinfection. Chlorine is also commonly used to maintain microbial hygiene in swimming pools. In US municipal drinking water applications, a typical target level of residual free chlorine (a measure of the sum of $\mathrm{HOCl}_{\text {and }} \mathrm{OCl}^{-}$in the water distribution system) is $0.2 \mathrm{ppm}$, which corresponds to $\mathrm{Ct}=2.8$ $\mu \mathrm{M}$. In swimming pool applications, the common target level of free chlorine would be 1-3 ppm, corresponding to $\mathrm{Ct}=14-42 \mu \mathrm{M}$. A common $\mathrm{pH}$ in these treated waters is 7.5. The lower three traces of Figure 10 show that for $\mathrm{Ct}$ values in the range $1-100 \mu \mathrm{M}$ at $\mathrm{pH}=7.5$, the equilibrium gasphase concentration of $\mathrm{HOCl}$ would be in the range $0.8-80 \mathrm{ppb}$.

There are few published measurements of airborne $\mathrm{HOCl}$. Lawler et al. ${ }^{247}$ reported "the first measurements of tropospheric $\mathrm{HOCl}$ " based on a June 2009 atmospheric sampling campaign 
conducted in the eastern tropical Atlantic. They found that "in air with trajectories originating over Europe ... HOCl maxima [exceeded] 100 ppt [0.1 ppb] each day." Wong et al. ${ }^{248}$ reported indoor air concentrations of $\mathrm{HOCl}$ and related compounds in response to applying a bleach solution to the floor of a well-ventilated room (air change rate of $12.7 \mathrm{~h}^{-1}$ ). They utilized online chemical ionization mass spectrometry along with aerosol mass spectrometry and reported peak $\mathrm{HOCl}$ levels of 100s of ppb. They also reported measuring gaseous chlorine $\left(\mathrm{Cl}_{2}\right)$, nitryl chloride $\left(\mathrm{CINO}_{2}\right)$, dichlorine monoxide $\left(\mathrm{Cl}_{2} \mathrm{O}\right)$, and chloramines $\left(\mathrm{NHCl}_{2}\right.$ and $\left.\mathrm{NCl}_{3}\right)$. Peak observed submicron particle $\mathrm{Cl}$ in these experiments was about $0.1 \mu \mathrm{g} / \mathrm{m}^{3}$.

There are several circumstances by which the presence and reactivity of hypochlorous acid in aqueous solutions generates human health risk concerns related to indoor air pollution. The following paragraphs highlight some key points. In these descriptions, we'll use the term "hypochlorous acid" to include both $\mathrm{HOCl}$ and $\mathrm{OCl}^{-}$, recognizing (a) that the aqueous partitioning between these species is controlled by $\mathrm{pH}$ (acidic solutions favoring $\mathrm{HOCl}$ and basic solutions favoring $\mathrm{OCl}^{-}$), and (b) that only $\mathrm{HOCl}$ has a meaningful gas-phase presence. There are three primary species in this system: gaseous $\mathrm{HOCl}$, aqueous $\mathrm{HOCl}$, and aqueous $\mathrm{OCl}^{-}$.

Bleach and certain other consumer cleaning products contain hypochlorous acid. Acute adverse respiratory outcomes have been documented owing to the improper mixing of such products with other chemicals. ${ }^{249}$ For example, combining hypochlorous acid with ammonia-based cleaners can lead to the formation of chloramines, including nitrogen trichloride $\left(\mathrm{NCl}_{3}\right)$, a volatile respiratory irritant. On the other hand, combining bleach with acids that lower the solution $\mathrm{pH}$ increases the release of gaseous $\mathrm{HOCl}$ and can also produce chlorine gas $\left(\mathrm{Cl}_{2}\right)$; both of these species are potentially health harmful if inhaled.

The risks of adverse chemistry initiated by hypochlorous acid is not limited to improper mixing of cleaning products. For example, Odabasi and coworkers ${ }^{250,251}$ have documented that halogenated VOCs including chloroform and carbon tetrachloride can be formed in product bottles that combine 
fragrances or surfactants with hypochlorous acid. Schwartz-Narbonne et al. ${ }^{252}$ studied the reactive chemistry of gaseous $\mathrm{HOCl}$ with surface-bound squalene and oleic acid, compounds prevalent on indoor surfaces. They documented that chlorohydrins are formed in this process at rapid rates, concluding that "chlorination of skin oil, which contains substantial carbon unsaturation, is likely to occur rapidly under common cleaning conditions, potentially leading to the irritation associated with chlorinated bleach."

Epidemiologic studies show an elevated risk of work-related asthma for professional and domestic cleaning. ${ }^{253}$ Specific causes for the elevated risk aren't known, but the use of cleaning products containing hypochlorous acid is considered to be one possible contributor. Interestingly, a study by Nickmilder et al. ${ }^{254}$ found that "children living in a house regularly cleaned with bleach were less likely to have asthma ... eczema ... and of being sensitized to indoor aeroallergens, ... especially house dust mite." The underlying process may be associated with chlorine-based damage of allergenic proteins. On the other hand, there is also evidence of increased risk of respiratory irritation associated with regular use of bleach indoors. ${ }^{249}$

Beyond respiratory irritation, allergenicity, and asthma, the use of hypochlorous acid as a cleaning product ingredient raises other health-risk concerns. Such risks can arise from exposure to disinfection byproducts such as trihalomethanes (THM). The most prominent THM from hypochlorous acid chemistry is chloroform $\left(\mathrm{CHCl}_{3}\right)$, which is among the higher ranking causes of cancer for organic hazardous air pollutants. ${ }^{255}$ The use of hypochlorous acid as a cleaning ingredient has been shown to contribute to indoor emissions of chloroform in the case of residential washing machines ${ }^{256}$ and automatic dishwashers. ${ }^{257}$ In particular, Shepherd et al. ${ }^{256}$ reported that "washing machine environments are very conducive to chloroform formation." They suggested that similar annual emissions of chloroform indoors would occur from bleaching laundry as from showering.

The release of chloroform from indoor use of chlorinated drinking water along with associated exposures has been extensively studied. For example, Weisel et al. ${ }^{258}$ measured chloroform in 
exhaled breath following showering among 49 female subjects throughout New Jersey. They found systematically and substantially higher chloroform exhaled from subjects who had elevated water levels of THMs. Nuckols et al. ${ }^{259}$ noted particularly that "epidemiology studies concerning THMs need to consider hot water use activities as important exposure events." Wallace ${ }^{260}$ provided a thorough review of the state of knowledge regarding human exposure to chloroform in the US, concluding that "the major source of exposure to chloroform is chlorination of water supplies." He also concluded that each of the three main exposure routes - ingestion, inhalation, and dermal absorption - "appear to be potentially substantial contributors to total exposure."

Disinfection byproducts other than THMs can be formed in drinking water treatment. Another category of regulatory concern is the haloacetic acids (HAAs), including chloroacetic acid $\left(\mathrm{CH}_{2} \mathrm{ClCOOH}\right)$, dichloroacetic acid $\left(\mathrm{CHCl}_{2} \mathrm{COOH}\right)$, and trichloroacetic acid $\left(\mathrm{CCl}_{3} \mathrm{COOH}\right)$. These $\mathrm{HAAs}$ have very high Henry's law constants, so any inhalation exposure associated with indoor water use would likely be associated with inhaled particles rather than with gaseous species. Xu and Weisel ${ }^{261}$ conducted experiments to assess the rate of shower-generated particulate HAA and associated exposure. They reported that "the dose from inhalation exposure of disinfection byproducts (DBPs) in the particulate phase [would] represent less than $1 \%$ of the ingestion dose."

There also is a substantial literature on reactive chemistry and associated exposures and health risks from the use of hypochlorous acid for swimming pool disinfection. A highlighted concern in this case is the formation of chloramines, arising from reactions of hypochlorous acid with ammonia and related reduced-nitrogen compounds produced by the swimmers. Among the chloramines, the greatest attention focuses on nitrogen trichloride $\left(\mathrm{NCl}_{3}\right)$, also known as trichloramine, which is considerably more volatile in the presence of water than the other chloramines. (Specifically, the relevant Henry's law constants are $0.10 \mathrm{M}$ /atm for $\mathrm{NCl}_{3}$ as contrasted with $29 \mathrm{M}$ /atm for $\mathrm{NHCl}_{2}$ and $87 \mathrm{M} /$ atm for $\mathrm{NH}_{2} \mathrm{Cl}^{142}$ ) Measured concentrations of gas-phase $\mathrm{NCl}_{3}$ in the air of indoor swimming pool facilities are high, with reported mean values of $\sim 0.5 \mathrm{mg} / \mathrm{m}^{3}$ ( $\left.100 \mathrm{ppb}\right) .{ }^{262-264}$ The chemistry of chloramine formation in swimming pool environments is nicely summarized by Schmalz et al.; ${ }^{265}$ 
more generally, Zwiener et al. ${ }^{266}$ provide a thorough overview of the issues associated with disinfection byproduct formation in chlorinated swimming pools.

Epidemiologically, clear evidence has emerged to document associations between time spent in indoor environments of chlorinated swimming pools and asthma risk. Bernard et al. ${ }^{267}$ stated that "regular attendance at chlorinated pools by young children is associated with an ... increase in the risk of developing asthma." Bernard et al. ${ }^{263}$ later reported that "use of indoor chlorinated pools especially by young children interacts with atopic status to promote the development of childhood asthma." Jacobs et al. ${ }^{264}$ found "an excess risk for respiratory symptoms indicative of asthma ... in swimming pool employees."

\subsection{Carboxylic acids}

Organic acids are a vast class. Even considering only the species that are potentially relevant to indoor environmental concerns leaves a daunting challenge. On the other hand, only a few of the many organic acid species have been extensively studied indoors. The most prominent of these are formic acid and acetic acid, the simplest homologues of $n$-alkanoic carboxylic acids. This section reviews the state of knowledge regarding formic acid and acetic acid, in particular, plus other noteworthy examples from the broader class of carboxylic acids.

Carboxylic acids have the chemical composition $\mathrm{R}-\mathrm{C}(\mathrm{O}) \mathrm{OH}$. The carbon in the functional group is double bonded to an oxygen atom and single bonded to the hydroxy moiety $(-\mathrm{OH})$. For the broadest interpretation of carboxylic acids, $\mathrm{R}$ can represent any organic component. We will restrict our attention here to $n$-alkanoic carboxylic acids, for which $\mathrm{R}$ is a saturated, straight-chain hydrocarbon (or, in the case of formic acid, simply a hydrogen atom).

Table 14 presents information on some of the more prominent of these acids. The compounds with carbon number $\mathrm{C} 1-\mathrm{C} 6$ will be substantially gaseous when airborne. Among these species, there is an overall tendency for the gaseous abundance to decrease with increasing carbon number. The

This article is protected by copyright. All rights reserved 
tendency is not monotonic, however: acetic acid is typically more abundant than formic acid in indoor air. The three highest MW species in Table 14 are likely to be substantially in the particle phase if airborne. (The transition between gas-phase and particle-phase dominance occurs for semivolatile species when the $\log \left(K_{\text {oa }}\right)$ value is about 11 , where $K_{\text {oa }}$ is the octanol-air partition coefficient. See Weschler and Nazaroff, Figure $4 .{ }^{268}$ )

Interest in carboxylic acids indoors arises from several considerations. Acetic and formic acid are among the more abundant organic compounds found indoors, and so, provided there are no analytical barriers in sampling and analysis, broad surveys of indoor volatile organic compounds will include these species. ${ }^{269}$ If present at sufficiently high levels, carboxylic acids can contribute to odor and irritancy. ${ }^{270}$ Formic and acetic acids are among the most prominent and potent corrosive agents in air, so their abundance poses preservation threats for cultural artifacts. ${ }^{271}$ Conservation challenges are amplified because hardwoods, such as oak, which might otherwise be favored for storage cabinets and display cases, can be strong emission sources. ${ }^{272}$ Formic acid is an important oxidation product of atmospheric chemistry; comparing modeled to measured concentrations can help test and refine understanding of oxidative transformation processes. ${ }^{273}$ Particle-phase carboxylic acids are noteworthy tracers for cooking as an air-pollutant emission source. ${ }^{274,275}$

This subsection addresses the following aspects of carboxylic acids indoors: (a) measured airborne concentrations; (b) source characterization; (c) indoor dynamic behavior; and (d) consequences. In the original literature, measured airborne concentrations are commonly reported in either $\mu \mathrm{g} / \mathrm{m}^{3}$ or ppb units. For a temperature of $298 \mathrm{~K}\left(25^{\circ} \mathrm{C}\right)$ and at a pressure of $1 \mathrm{~atm}$, these conversion factors apply: formic acid $1 \mathrm{ppb}=1.88 \mu \mathrm{g} / \mathrm{m}^{3}$; acetic acid $1 \mathrm{ppb}=2.46 \mu \mathrm{g} / \mathrm{m}^{3}$.

The first indoor air measurement of the concentration of a carboxylic acid was reported by Pitts et al. ${ }^{222}$ They studied formic acid in a "mobile office/home" (MOH) using Fourier transform infrared spectroscopy. Over the course of a seven-hour sampling period, they measured concentrations varying across the approximate range 50-140 ppb; higher levels were correlated with higher indoor

This article is protected by copyright. All rights reserved 
temperatures (which varied between 24 and $39^{\circ} \mathrm{C}$ ). The authors inferred that the source of the formic acid was "likely from the structural materials" of the $\mathrm{MOH}$.

During the past three decades, several studies have surveyed the concentrations of formic and acetic acid in ordinarily occupied indoor environments. These studies, summarized in Table 15 , have spanned five continents. The results demonstrate a remarkable degree of coherence in their main features. Average indoor concentrations of formic acid lie within the range 1-30 ppb, and are commonly $2-7 \times$ the corresponding outdoor values. Acetic acid concentrations are somewhat higher than formic acid, with study means spanning an approximate range 4-50 ppb. The indoor acetic acid concentrations also exceed those in outdoor air, commonly by $\sim 10 \times$.

A baseline monitoring survey of formic acid in outdoor air was undertaken in Upland, CA, in the eastern part of the Los Angeles air basin. ${ }^{283}$ The survey, conducted from September 1988 through September 1989 , measured $24-\mathrm{h}$ average concentrations every $6^{\text {th }}$ day (55 samples in all). The average (peak) measured formic acid concentration was $2.8 \mathrm{ppb}(8 \mathrm{ppb})$. A later survey in the Los Angeles area measured the gas plus particle abundance for a homologous series of carboxylic acids (C1-C10). ${ }^{284}$ For the 13 samples collected, the average \pm standard deviation of the summed carboxylic acid species was $2.1 \pm 1.2$ ppb, of which $91 \pm 3 \%$ was formic acid (36 $\pm 5 \%$ ) plus acetic acid $(55 \pm 4 \%)$. An outdoor air survey of formic and acetic acid concentrations was conducted in the northeastern United States during the summer of 1990 (Uniontown, PA, $n=110$ samples) and in the summer of 1991 (Boston, MA, $n=84$ samples). ${ }^{285}$ In Uniontown, the average \pm standard deviation outdoor formic and acetic acid concentrations were $9.3 \pm 8.4 \mathrm{ppb}$ and $3.8 \pm 2.6 \mathrm{ppb}$, respectively. In Boston, corresponding results were $5.4 \pm 3.2 \mathrm{ppb}$ for formic acid and $2.2 \pm 1.1 \mathrm{ppb}$ for acetic acid. ${ }^{285}$

Considering measured indoor concentrations, even at the low ends of the reported ranges, formic and acetic acids could have substantial influence on the $\mathrm{pH}$ of indoor water. For example, the equilibrium pH of water exposed only to 800 ppm of $\mathrm{CO}_{2}$ would be 5.46 . If that level of $\mathrm{CO}_{2}$ were combined with $1 \mathrm{ppb}$ of formic acid and $4 \mathrm{ppb}$ of acetic acid, the equilibrium $\mathrm{pH}$ of exposed water

This article is protected by copyright. All rights reserved 
would decline by more than a full pH unit, to 4.36. Larger, but realistic concentrations of carboxylic acids could cause substantial further $\mathrm{pH}$ decline. Specifically, a combination of $800 \mathrm{ppm} \mathrm{CO}, 30 \mathrm{ppb}$ formic acid, and 70 ppb acetic acid would yield an equilibrium pH for exposed water of 3.64. Starting with $800 \mathrm{ppm}$ of $\mathrm{CO}_{2}$ and $20 \mathrm{ppb}$ of $\mathrm{NH}_{3}$, the equilibrium $\mathrm{pH}$ of exposed water, in the absence of carboxylic acids, would be 7.12. Adding the lower levels of 1 ppb formic acid plus 4 ppb acetic acid to this mix would decrease the equilibrium $\mathrm{pH}$ to 6.02. At the higher carboxylic acid levels of $30 \mathrm{ppb}$ formic acid plus $70 \mathrm{ppb}$ acetic acid, the equilibrium pH would further decline to 5.30. In sum, ordinarily encountered levels of these carboxylic acids in indoor environments have the potential to contribute to notable shifts in the acidity of exposed water.

In several studies, formic and acetic acid have been measured in special types of indoor environments or under special conditions. In museums and archives, these acids pose an unusual concern that arises, in part, because degradation of cellulosic and lignin materials may contribute substantially to indoor emissions, and, in part, because these acids pose corrosive damage risks to certain artifact materials. An extended monitoring campaign was undertaken in the Baroque Library Hall of the National Library, Prague. ${ }^{125}$ Over a nine-month period, the median monthly average indoor concentration of acetic acid was $215 \mu \mathrm{g} / \mathrm{m}^{3}$ (87 ppb). The peak, which occurred during summer, was $417 \mu \mathrm{g} / \mathrm{m}^{3}$ (170 ppb). The corresponding monthly median and monthly peak values for formic acid were $24 \mathrm{\mu g} / \mathrm{m}^{3}$ (13 ppb) and $102 \mu \mathrm{g} / \mathrm{m}^{3}$ (54 ppb). Gibson et al. ${ }^{286}$ reported on the concentrations of acetic acid and formic acid measured by passive sampling over 28-day exposure periods for three locations in each of eight museums and archives in the UK. The average \pm standard deviation results for the 24 reported measurements for each species are $145 \pm 91 \mu \mathrm{g} / \mathrm{m}^{3}(59 \pm 37$ $\mathrm{ppb}$ ) for acetic acid and $63 \pm 61 \mu \mathrm{g} / \mathrm{m}^{3}$ (34 $\pm 33 \mathrm{ppb}$ ) for formic acid.

Hodgson et al. ${ }^{287}$ measured acetic acid concentrations in manufactured houses $(n=4)$ and site-built houses $(n=7)$ in the eastern and southeastern United States. These were sampled shortly after construction under unoccupied and unfurnished conditions. The geometric mean (geometric standard deviation) of the measured concentrations were $117 \mathrm{ppb}(2.0)$ for the manufactured

This article is protected by copyright. All rights reserved 
houses and $54 \mathrm{ppb}(1.4)$ for the site-built homes. Maddalena et al. ${ }^{288}$ sampled acetic acid concentrations in trailers intended to provide emergency shelter in the aftermath of hurricanes in the southern United States. The trailers were sampled for two 1-h periods under unoccupied and closed conditions. The average \pm standard deviation acetic acid concentration for the four trailers was $1090 \pm 340 \mu \mathrm{g} / \mathrm{m}^{3}(440 \pm 140 \mathrm{ppb})$.

Formic and acetic acid have been measured in a simulated aircraft cabin. ${ }^{289}$ Here, in addition to primary emissions from furnishing materials and from the passengers, there is the possibility of secondary production of the acids as byproducts of ozone reaction with skin oils and other unsaturated organic molecules. These experiments utilized a $2 \times 2$ matrix design, with low and high ventilation rates (air-exchange rates of 4.4 and $8.8 \mathrm{~h}^{-1}$, respectively) combined with low and high ozone levels ( $<2$ and 60-80 ppb, respectively). For formic acid, cabin air concentrations ranged from a low of $0.8 \mathrm{ppb}$ for the low ozone - high ventilation condition to $5.3 \mathrm{ppb}$ when the high ozone level was combined with the lower ventilation rate. The analogous results for acetic acid were $3.1 \mathrm{ppb}$ for low ozone - high ventilation and 10.6 ppb for high ozone - low ventilation.

In the past few years, instruments that can measure carboxylic acids (along with many other organic species) with high sensitivity and fast response times have begun to be employed in indoor air studies. The first few of these studies have already revealed important new information about factors influencing the abundance and dynamic behavior of carboxylic acids indoors.

Tang et al. ${ }^{290}$ used proton-transfer-reaction time-of-flight mass spectrometry (PTR-ToF-MS) to make time-resolved measurements of a broad suite of volatile organic compounds in a university classroom during normal use. From the data generated, they apportioned the source of individual VOCs among three major categories: outdoor air, indoor building materials and furnishings, and the occupants. They determined occupant associated emission rates to be $48.5 \mu \mathrm{g} \mathrm{h}^{-1}$ person ${ }^{-1}$ for formic acid and $329 \mathrm{~m} \mathrm{~h}^{-1}$ person ${ }^{-1}$ for acetic acid. On a mass-weighted basis, among the quantified

This article is protected by copyright. All rights reserved 
occupant-associated VOC emissions, acetic acid ranked $3^{\text {rd }}$ and formic acid $10^{\text {th }}$. Both compounds were among those "whose source was 1/3 or more from human occupants."

Liu et al. ${ }^{13}$ also studied the organic gas composition of a university classroom, applying a highresolution time-of-flight chemical ionization mass spectrometer. Carboxylic acids were prominently featured in their study. Overall, the average indoor concentration of total carboxylic gases was 6.8 ppb whereas the average outdoor level was only $1.0 \mathrm{ppb}$. The time-averaged indoor concentrations of $n$-alkanoic carboxylic acids reported in this study were $1.2 \mathrm{ppb}$ for formic acid, 38 ppt for propionic acid, 110 ppt for butyric acid, and 54 ppt for valeric acid. Acetic acid could not be measured with their analytical method.

Duncan et al. ${ }^{32}$ used iodide reagent ion chemistry in high-resolution time-of-flight chemical ionization mass spectrometry to study time-resolved concentrations of water-soluble organic gases, including acetic and formic acid, in a North Carolina residence over several days. Measured concentrations were in the range $30-130 \mu \mathrm{g} / \mathrm{m}^{3}(12-53 \mathrm{ppb})$ for acetic acid and $15-53 \mu \mathrm{g} / \mathrm{m}^{3}(8-28$ $\mathrm{ppb}$ ) for formic acid. A striking feature was the rhythmic and substantial decline of indoor acetic and formic acid concentrations associated with air conditioner $(A C)$ cycling. The authors suggested that "these highly water-soluble compounds ... are taken up by water condensed on the AC surfaces and/or in the AC condensate."

Liu et al. ${ }^{291}$ conducted an extensive monitoring campaign in a single-family house in northern California. They utilized PTR-ToF-MS to analyze indoor air VOC composition with high time resolution over two multiweek sampling campaigns. Among the species quantified were the series of $n$-alkanoic carboxylic acids extending from formic acid through undecanoic acid $\left(\mathrm{CH}_{3}\left(\mathrm{CH}_{2}\right)_{9} \mathrm{COOH}\right)$. Table 16 shows that the time-averaged concentrations tended to decrease with increasing carbon number (with acetic acid, measured at a much higher concentration than formic acid, being an exception). The average indoor air concentrations and the effective emission rates were also consistently higher in the summer than in the winter. Considering the sum of continuously emitted 
compounds (suggestive of a building-related source) that they were able to measure with PTR-ToFMS, the authors reported that "acetic acid alone accounted for half of the summed VOC emission rate." They also observed a systematic temperature dependence of emissions, stating that "comparing $23^{\circ} \mathrm{C}$ to $16^{\circ} \mathrm{C}$, an overall doubling of building-associated VOC emission rate was observed." Another important inference was that "high abundance of acetic acid and furfural in both the attic and in the living zone ... is consistent with the hypothesis of wood decomposition being their major source."

It is worthwhile to highlight a comparison of emissions data from the classroom study of Tang et al. ${ }^{290}$ and the residence study of Liu et al. ${ }^{291}$ In the case of acetic acid, for example, the per-occupant emissions rate in the classroom was about $0.3 \mathrm{mg} / \mathrm{h}$. That value, if applied to the two occupants of the house studied by Liu et al., would account for less than $10 \%$ of the inferred total emissions rate of $12 \mathrm{mg} / \mathrm{h}$ (winter) and $20 \mathrm{mg} / \mathrm{h}$ (summer). Similarly, the per-person emission rate from the classroom study for formic acid, $0.05 \mathrm{mg} / \mathrm{h}$, suggests that occupant-associated emissions are only a small portion of the total indoor generation rates of $2.3 \mathrm{mg} / \mathrm{h}$ (winter) and $4 \mathrm{mg} / \mathrm{h}$ (summer) determined in the study house.

An interesting and important lesson can be extracted from the data in Table 16, when considered in the context of how physiological response varies across compounds in a homologous series. Cometto-Muñiz et al. ${ }^{292}$ measured the odor thresholds for five carboxylic acids. The results spanned 5 orders of magnitude from formic acid ( $1 \mathrm{ppm}$ ) to octanoic acid ( $0.01 \mathrm{ppb}$ ). (Intermediate odor thresholds in the approximate range 1-10 ppb were reported for acetic acid, butyric acid, and hexanoic acid.) The reported average concentrations of formic acid and octanoic acid in Table 16 differ by about two orders of magnitude. Here is a key point: focusing on the most abundant organic compounds, which naturally emerges from chemical analyses, can readily mask the prevalence of compounds that are more important with regard to human physiological response. In this particular instance, the measured average concentration of formic acid is a few orders of

This article is protected by copyright. All rights reserved 
magnitude below its odor threshold. However, the much smaller measured concentration of octanoic acid exceeds its odor threshold by an order of magnitude.

Several studies have assessed carboxylic acid emissions from woods, emphasizing acetic acid as a prominent species. For example, Risholm-Sundman et al. ${ }^{293}$ reported that "some hardwoods give a high emission of acetic acid." The highest reported emissions of acetic acid in their study were from cherry and oak. (They also noted that "the main emission from softwood is terpenes.") Manninen et al. ${ }^{294}$ found that the temperature history of the wood mattered, writing "in the emissions of heattreated wood, the most abundant individual compounds, 2-furancarboxaldehyde, acetic acid and 2propanone, made up about $60 \%$ of the total VOC emission. ... None of these compounds was found in the VOC emission from air-dried wood." Gibson and Watt ${ }^{272}$ stated that, "acetic acid is known to emit from all natural woods with hardwoods, e.g. oak, being thought to emit the highest concentrations of acetic acid ...". They found that emissions were sensitive to temperature, being much higher at $45^{\circ} \mathrm{C}$ than at $20^{\circ} \mathrm{C}$, and also to humidity, with lower emissions for drier conditions.

Carboxylic acids can be generated through the oxidative decomposition of higher molecular weight fatty acids. Linoleic acid is a prominent ingredient of linoleum, a common flooring material. Jensen et al. ${ }^{295}$ modeled the concentrations of propanoic (propionic) acid utilizing emission measurements from a linoleum flooring sample. They predicted an indoor concentration of $56 \mu \mathrm{g} / \mathrm{m}^{3}$ (18 ppb) one month after installation, only $2 \times$ below the odor threshold.

Other processes in atmospheric oxidative chemistry also can generate formic and acetic acids. For example, summed over the global atmosphere, the dominant sources of formic and acetic acids are believed to be "photochemical oxidation of biogenic organic compounds, in particular isoprene."296

Zhang et al. ${ }^{297}$ conducted experiments in a Teflon test chamber designed to explore the production of formic and acetic acid from oxidative chemistry. In that work, ozonation of limonene using indoor-relevant concentrations was found to generate acetic acid. Formic acid was produced in

This article is protected by copyright. All rights reserved 
each of the three systems tested: ozonation of styrene, of limonene, and of 4-vinylcyclohexene, respectively. (That outcome is as expected from ozonation of any organic compound with a terminal double bond.) Destaillats et al. ${ }^{298}$ quantified formic and acetic acid levels in chamber studies of the ozonation of three household consumer products: a pine-oil based cleaner, an orange-oil based degreaser, and a plug-in air freshener. Median reported concentrations in 11 experiments were 14 ppb for formic acid and $22 \mathrm{ppb}$ for acetic acid.

Interior paints can be a source of carboxylic acid emissions. Reiss et al. ${ }^{299}$ studied ozone reactions with latex paints. They did not find formic and acetic acid to be generated by ozone reactions. However, they did report that both compounds off-gassed from the latex paints themselves. They also found that the rates of emissions of these compounds were higher at higher relative humidity. Investigating finishing materials that might be used for preserving cultural artifacts, Schieweck and Bock ${ }^{300}$ reported that "low-VOC" and "zero-VOC" paints "released heightened acetic acid levels and are therefore not favored for the use in sensitive environments."

Incomplete combustion and/or high-temperature volatilization from fuels can be another source of carboxylic acids. For example, Kuo et al. ${ }^{301}$ determined an emissions factor for acetic acid from incense use to be $840 \pm 520 \mu \mathrm{g}$ per g of incense burned, based on experiments with four popular brands. Christian et al. ${ }^{302}$ measured emission factors of formic acid and acetic acid from biomass combustion. Considering open wood cooking fires, they reported $0.25 \pm 0.12 \mathrm{~g}$ of formic acid to be emitted per kg of wood burned. The corresponding emission factor for acetic acid was $1.8 \pm 1.3$ $\mathrm{g} / \mathrm{kg}$.

Let's next consider the phase state of formic and acetic acid. In the presence of condensed water, there are three potentially important states: gaseous, aqueous and undissociated, and aqueous in the form of the conjugate base (i.e., as formate or acetate ions). As we have already described, the partitioning among these three states depends on two key properties of the volatile acid: Henry's law constant $\left(K_{\mathrm{H}}\right)$ and the acid-dissociation constant (represented by $\mathrm{p} K_{\mathrm{a}}$ ). Influential features of the 
indoor environment include the relative abundance of condensed-phase water and the $\mathrm{pH}$ of that water. Factors influencing the $\mathrm{pH}$ of indoor condensed water include the abundances of all of the indoor air acids and bases plus the properties of any material substrate in contact with the water. The presence of any gas-phase carboxylic acid would tend to acidify condensed water. For the present analysis, let's assume that the condensed-water $\mathrm{pH}$ is externally regulated, independent of the influence of carboxylic acids. That could apply, for example, in the limit of a small abundance of the carboxylic acids.

As described in $§ 2.1$, liquid water abundance can be quantified as a volume fraction, with dimensions liters $(\mathrm{L})$ of water per $\mathrm{m}^{3}$ of air. We use the symbol $L^{*}$ to signify an equivalent volume fraction that is chemically equilibrated with indoor air. We restrict analysis here to fixed common indoor conditions of pressure $(P=1 \mathrm{~atm})$ and temperature $(T=298 \mathrm{~K})$. In $\S 3$, we presented equations describing equilibrium quantitative partitioning of a monoprotic acid considering the three phase states. Equation (15) describes the fraction of the total abundance that is in the gas phase.

Figure 11 displays the results for formic acid (upper frame, Figure 11a) and acetic acid (lower frame, Figure $11 \mathrm{~b})$, showing gas fraction $\left(f_{\mathrm{g}}\right)$ in relation to the liquid water volume fraction $\left(L^{*}\right)$ for four different values of $\mathrm{pH}(3,5,7$, and 9). The thermodynamic properties used in these calculations are reported in Table 14. These plots show that the overall behavior of formic and acetic acids is qualitatively similar with regard to phase partitioning between air and water. Even a small amount of condensed water can be a major sink for these carboxylic acids if the water is maintained by external factors to have a high $\mathrm{pH}($ e.g., $\mathrm{pH}=9)$. Conversely, at a low $\mathrm{pH}(\mathrm{pH}=3$ or $\mathrm{pH}=5)$, most of these carboxylic acids will remain gaseous provided that the equilibrated liquid water abundance remains small ( $L^{*}$ values less than approximately $10^{-4}$ to $10^{-3} \mathrm{~L} / \mathrm{m}^{3}$, or about $10-100 \mathrm{~cm}^{3}$ of equilibrated liquid water per $100 \mathrm{~m}^{3}$ of indoor air). In the event that the condensed water is relatively abundant (e.g., for $L^{*}$ in the range $10^{-3}$ to $10^{-2} \mathrm{~L} / \mathrm{m}^{3}$ ), there is the opportunity for substantial partitioning to water, even for acidic $\mathrm{pH}$ conditions.

This article is protected by copyright. All rights reserved 
Because of the material damage risks posed, many studies of carboxylic acids have been conducted in museums and archives. The nature of the specific risks from formic and acetic acid in damaging cultural artifacts is well described by Brimblecombe and Grossi, ${ }^{271}$ including "Byne's disease," which refers to efflorescence of calcareous materials owing to their dissolution upon exposure to organic acids. Prosek et al. ${ }^{303}$ provide a useful introductory overview of corrosion risks associated with volatile carboxylic acids and also describe the development of a direct monitor "to assess small changes in air corrosivity in real time." Graedel ${ }^{304}$ described the corrosive nature of organic acid vapors for lead, indicating that "acetic acid [is] five to ten times as aggressive as formic acid." In an interesting application of corrosion concerns, Niklasson et al. ${ }^{305}$ reported that "high concentrations of acetic and formic acid vapours are present in the wind system of the corroded [church pipe] organs. ... The main source of acetic acid is the wood from which the wind system is built. In contrast, formic acid is generated in the church environment outside the wind system." Reinforcing the idea of wood as an important emission source, Kontozova-Deutsch et al. ${ }^{306}$ measured levels up to $450 \mu \mathrm{g} / \mathrm{m}^{3}$ (235 ppb) of formic acid and up to $1050 \mu \mathrm{g} / \mathrm{m}^{3}$ (420 ppb) of acetic acid in enclosed showcases at the Metropolitan Museum of Art in New York. Much lower levels were found in the galleries.

Concern about material degradation risks posed by organic acids has spurred efforts in the development of novel control technologies. For example, Dedecker et al. ${ }^{307}$ have developed a metal-organic framework (MOF) for removing "low concentrations of acetic acid from indoor air at museums." Among the challenges in sorbent performance that MOF technology has the potential to overcome is poor selectivity for polar compounds compared to the much more abundant water vapor.

Formic and acetic acid have arisen as concerns in relation to other aspects of indoor air quality control. Hodgson et al. ${ }^{269}$ assessed the performance of an air cleaner utilizing ultraviolet photochemical oxidation (often referred to as PCO technology). They reported a strong caution: 
"formaldehyde, acetaldehyde, acetone, formic acid and acetic acid were produced ... due to incomplete mineralization of common VOCs." Truffier-Boutry et al. ${ }^{308}$ assessed photocatalytic paints and found "that the degradation of the organic matrix [of the paint itself] leads to the release of organic compounds (formaldehyde, methanol, acetaldehyde and formic acid) into the air...." This evidence supports a finding that partial oxidation of organic molecules can generate formic acid and acetic acid at levels of potential concern for indoor environmental quality.

In contrast to formic and acetic acid, which have been extensively studied indoors, there is little published work reporting on the higher molecular weight carboxylic acids in indoor environments. However, absence of evidence isn't the same as evidence of absence. The limited available information does point toward the potential for these compounds to be of interest indoors, as highlighted by the following observations.

Liu et al. ${ }^{69}$ characterized the organic matter found in films extracted from interior surfaces of the windows of various building types, including a residence, a restaurant, and an office. They found that monocarboxylic acids dominated among polar compounds, with C11-C31 monoacid densities in the range $6.5-100 \mu \mathrm{g} \mathrm{m}^{-2}$. Fang et al. ${ }^{309}$ reported on chemical characterization of dust extracts collected from homes, a gymnastics studio, and office environments. In the portion of dust extracts most associated with agonism of human peroxisome proliferator-activated nuclear receptor gamma, "fatty acids ... including oleic acid, stearic acid, palmitic acid and myristic acid, were the primary chemicals identified."

Higher molecular weight $n$-alkanoic carboxylic acids, especially palmitic and stearic acids, have been identified as important markers of the impact of cooking emissions on urban air quality. ${ }^{310}$ For example, in an atmospheric monitoring study in the Los Angeles area, carboxylic acids were quantifiable contributors to fine particulate matter. ${ }^{311}$ In that study, monthly average values of palmitic acid in atmospheric fine PM were in the range $0.10-0.25 \mu \mathrm{g} / \mathrm{m}^{3}$. In a study of atmospheric fine particulate matter in Beijing, averaged airborne concentrations were reported for lauric (1.7 
$\left.\mathrm{ng} / \mathrm{m}^{3}\right)$, myristic $\left(6.5 \mathrm{ng} / \mathrm{m}^{3}\right)$, palmitic $\left(21 \mathrm{ng} / \mathrm{m}^{3}\right)$, and stearic acid $\left(20 \mathrm{ng} / \mathrm{m}^{3}\right) .{ }^{312}$ Several studies have reported quantitative emission factors for particle-phase carboxylic acids from commercial or institutional-scale cooking activities, including western-style meat cooking, ${ }^{274,313}$ stir-frying and deep-frying vegetables with seed oils, ${ }^{275}$ and various Chinese styles of cooking. ${ }^{314,315}$ Palmitic and stearic acids are prominently featured among the emitted chemicals in all of these studies.

Candle burning has also been characterized as a source of particle-phase carboxylic acid emissions. ${ }^{316}$ Emissions from paraffin candle wax were predominantly palmitic and stearic acid, as a "result of unburned wax volatilization." 316 For beeswax candles, the most prominent emissions of particle phase $n$-alkanoic carboxylic acids were palmitic and lignoceric (tetracosanoic) acid $\left(\mathrm{C}_{24} \mathrm{H}_{48} \mathrm{O}_{2}\right)$.

A few studies have reported on the indoor carboxylic acid abundance in "quasi-ultrafine" (quasi-UF PM, smaller than $0.25 \mu \mathrm{m}$ diameter) and fine particulate matter. Arhami et al. ${ }^{317}$ studied the abundance and sources of organic compounds in quasi-UF PM in four retirement homes in the Los Angeles basin. They found that the " $n$-alkanoic acids were likely to be influenced by indoor sources." They also reported that, for outdoor air, "hexadecanoic, octadecanoic, and phthalic acids were the most dominant measured acids in quasi-UF PM." Mean outdoor values for palmitic (hexadecanoic) and stearic (octadecanoic) acids were each in the approximate range $40-80 \mathrm{ng} / \mathrm{m}^{3}$. The mean I/O ratio for palmitic acid was 2.1 during cooler weather and 5.8 for warmer periods. The mean I/O ratio for stearic acid was 1.8 during cooler weather and 24 for warmer periods. Hasheminassab et al. ${ }^{318}$ subsequently reported on fine $\mathrm{PM}\left(\mathrm{PM}_{2.5}\right)$ organic chemical composition for three of these study sites. They determined that "organic acids inside the retirement communities were dominated by indoor sources (e.g. food cooking and consumer products)." Total fine particle organic acid concentrations were in the approximate range $0.2-1.7 \mu \mathrm{g} / \mathrm{m}^{3}$. Speciated concentrations were not reported.

This article is protected by copyright. All rights reserved 
Human skin lipids contain a noteworthy abundance of $n$-alkanoic carboxylic acids, spanning a broad range of carbon numbers. Nicolaides ${ }^{319}$ reported that fatty acids comprise about $25 \%$ of skin surface lipids. Among the most prominent of these compounds are palmitic acid ( $25 \%$ of the fatty acid total), myristic acid (7\%) and stearic acid (3\%). Weitkamp et al. ${ }^{320}$ analyzed the fatty acids extracted from the hair of barber shop sweepings and detected the presence of $n$-alkanoic carboxylic acids with carbon numbers ranging from 7 to 22 (excluding 19 and 21); palmitic and stearic acids were especially abundant. Through the routine shedding of particles from the human envelope, ${ }^{321}$ one can anticipate that occupants are primary sources of these carboxylic acids in occupied spaces. The presence in indoor dust of squalene, a major skin lipid, reinforces the idea that occupants constitute emission sources of skin lipids to indoor environments. ${ }^{322}$

Daher et al. ${ }^{323}$ reported on the chemical characterization of both fine and coarse particles "inside the refectory of Santa Maria Delle Grazie Church, home of Leonardo Da Vinci's 'Last Supper.'” This highly controlled environment was well protected from the influence of outdoor air pollution. The investigators found, however, that "fatty acids ... had high indoor-to-outdoor concentration ratios ... showing a good correlation with indoor [fine-particle organic carbon mass concentrations], implying a common indoor source." In their supporting information, the authors report monthly concentrations of indoor $n$-alkanoic carboxylic acids from C14 through C29. Averaged across all months, the three most abundant species were myristic (tetradecanoic), palmitic (hexadecanoic) and stearic (octadecanoic) acids, with respective mean concentrations of $31,27,9.6 \mathrm{ng} / \mathrm{m}^{3}$, which sum to $80 \%$ of the total for all $n$-alkanoic acids $\left(85 \mathrm{ng} / \mathrm{m}^{3}\right)$. Daher et al. ${ }^{323}$ noted that "potential indoor sources include skin emissions from visitors...."

Kristensen et al. ${ }^{15}$ reported on time resolved (1-h to 4-h resolution) measurements of gaseous and submicron particle-phase semivolatile organic compounds (SVOCs) from a weeks-long sampling campaign in a normally occupied single-family home in northern California. That study identified cooking as an important source of indoor SVOCs, especially in the particle phase. The authors

This article is protected by copyright. All rights reserved 
reported that, "the most abundant compounds related to cooking events include straight-chained saturated and unsaturated fatty acids (palmitic, oleic and stearic acids)."

\subsection{Other organic acids}

In §3.6, we summarized the state of knowledge regarding $n$-alkanoic monocarboxylic acids in indoor environments. In this section, we present information about other organic acids. In brief, the number of such species is extraordinarily large; however, the available evidence regarding their occurrence, abundance, behavior, fate, and significance in indoor environments is sparse. Given these circumstances, we report on a selection of species that have been measured in indoor air or whose presence indoors can be inferred from studies of outdoor air composition and/or primary and secondary emissions.

\subsubsection{Lactic acid}

Lactic acid is of interest indoors because of the prominence of human occupants as emission sources. The chemical structure of lactic acid ( $\mathrm{LAC}, \mathrm{C}_{3} \mathrm{H}_{6} \mathrm{O}_{3}, \mathrm{MW}=90.1 \mathrm{~g} / \mathrm{mol}$ ) is displayed in Figure 12. It is classified as an $\alpha$-hydroxy acid owing to the presence of the nonacidic $\mathrm{OH}$-group adjacent to the terminal acid moiety. With $\mathrm{p} K_{\mathrm{a}}=3.86$, it is about an order of magnitude more acidic than acetic acid, reflecting hydrogen bonding between the $\alpha$-hydroxy and the carboxylate group. The first reported indoor air measurements of lactic acid were by Liu et al., ${ }^{13}$ who used chemical ionization mass spectrometry (CIMS) to make time-resolved measurements of a suite of carboxylic acids in a university classroom, including during periods of normal use. The average indoor concentration of LAc measured in their campaign was $4.7 \mathrm{ppb}$, about an order of magnitude higher than the simultaneously determined outdoor air concentration. Lactic acid was easily the most abundant of the indoor carboxylic acids measured in that study. (It is important to emphasize that acetic acid was not measured.) The authors concluded that "human perspiration was likely the major contributor to the elevated indoor concentration of lactic acid."13

This article is protected by copyright. All rights reserved 
Duncan et al. ${ }^{32}$ also utilized CIMS to measure indoor LAc concentrations, in an air-conditioned, single-family home in North Carolina. As in the case of the recent classroom study, ${ }^{13}$ Duncan et al. present evidence that human occupants are an important source of LAc emissions. They reported that the LAc concentration was "highly sensitive to the proximity, number, and activity level of occupants." They also reported that cooking was the most prominent emission source, with indoor concentrations rising "from about $5 \mu \mathrm{g} \mathrm{m}^{-3}$ to 170,360 , and $320 \mu \mathrm{g} \mathrm{m}^{-3}$ during the three episodes in

which bacon and onions were fried." At $P=1 \mathrm{~atm}$ and $T=298 \mathrm{~K}, 1 \mathrm{ppb}$ of LAc corresponds to $3.7 \mu \mathrm{g}$ $\mathrm{m}^{-3}$, so the cooking-related peak mass concentrations correspond to 46,98 , and $87 \mathrm{ppb}$, respectively. Note that the peak concentrations during cooking were about an order of magnitude higher than the time-averaged value reported in the classroom study. ${ }^{13,32}$

Pagonis et al. ${ }^{324}$ reported on a detailed air quality study of 6-weeks duration in a university art museum. They observed a peak LAc concentration of about 7 ppb during a museum exhibit opening event, when occupancy was at its highest.

\subsubsection{Dicarboxylic acids}

Dicarboxylic acids are characterized by having two functional groups of the form - $\mathrm{C}(\mathrm{O}) \mathrm{OH}$. Figure 13 displays the three simplest examples of the aliphatic dicarboxylic acids, and Table 17 presents general information for these and other species encountered in air quality studies.

A striking feature of dicarboxylic acids is the very high value of their Henry's law constants $\left(K_{\mathrm{H}}\right)$. With such high propensity to be dissolved in water, condensed phases of dicarboxylic acids would be highly favored at equilibrium as compared to the gas phase. That outcome is true even without considering the role of the conjugate bases adding second and third condensed-phase compartments. To illustrate, consider the example of adipic acid, for which the Henry's law constant is $2.1 \times 10^{8} \mathrm{M} /$ atm, the lowest value among the species in Table 17. Even with an equilibrated liquid water content of room air at the small value of $L^{*}=10^{-6} \mathrm{~L} / \mathrm{m}^{3}, 84 \%$ of undissociated adipic acid would be in the aqueous phase at equilibrium rather than in the gas phase. With liquid water

This article is protected by copyright. All rights reserved 
content of $L^{*}=10^{-5} \mathrm{~L} / \mathrm{m}^{3}$, the ratio of aqueous to total undissociated adipic acid would rise to $98 \%$. For context, a monolayer of water on the superficial surface area of a room would correspond to a liquid water content of $L^{*} \sim 10^{-6} \mathrm{~L} / \mathrm{m}^{3}$ (see Table 1 ).

Given this perspective, it should not be surprising that Liu et al. ${ }^{69}$ found dicarboxylic acids to be prominent organic components accumulated in indoor window films. Specifically, dicarboxylic acids with carbon numbers in the range 6 to 14 were the second or third most abundant class for most samples, behind monocarboxylic acids (with carbon numbers 11-31) and comparable to $n$-alkanes (with carbon numbers 10-36). Among the dicarboxylic acids, azelaic acid, a product of ozone reacting with oleic acid, was generally the most abundant. Surface densities were highly variable across samples, with the highest reported value for azelaic acid being $7.3 \mu \mathrm{g} \mathrm{m}^{-2}$ on the indoor surface of an urban laboratory site in Toronto. Liu et al. inferred from their data that, "the greater accumulation of dicarboxylic acids in indoor rather than outdoor window films suggests indoor sources such as cooking."

With the high propensity to be in the condensed phase, it is worthwhile to consider whether dicarboxylic acids could materially influence the $\mathrm{pH}$ of indoor aqueous surface films. Consider the example of a surface film density of azelaic acid being $7.3 \mu \mathrm{g} \mathrm{m}^{-2}$. Assume that this abundance represents the sum of undissociated azelaic acid plus the two conjugate bases. Consider the influence on $\mathrm{pH}$ of surface water of this abundance of azelaic acid in isolation. (That is, for this calculation, we neglect the effect of $\mathrm{CO}_{2}, \mathrm{NH}_{3}$, and other acidic and basic gases that are also expected to be present indoors.) We do not have data on the abundance of water in the surface films studied by Liu et al. ${ }^{69}$ For exploration, consider three possibilities, corresponding to surface water thicknesses of $1 \mathrm{~nm}, 3 \mathrm{~nm}$, and $10 \mathrm{~nm}$. Also, assume that the surface water behaves thermodynamically like bulk water. Finally, neglect any substrate effects on aqueous film chemistry. This set of assumptions along with the reported $\mathrm{p} K_{\mathrm{a}}$ values in Table 17 allow for calculation of the equilibrium $\mathrm{pH}$ in the surface water. The results, in relation to the water film thickness, are $\mathrm{pH}=3.0$ for $1 \mathrm{~nm}, \mathrm{pH}=3.2$ for $3 \mathrm{~nm}$, and $\mathrm{pH}=3.5$ for $10 \mathrm{~nm}$. Evidently, with such a highly favored aqueous 
phase, even the relatively weak azelaic acid can be sufficiently abundant to strongly acidify thin water films on indoor surfaces.

\subsubsection{Organic acid concentrations measured in indoor and outdoor air}

Allen and Miguel $^{242}$ were the first to report gas-phase indoor air concentrations of oxalic acid. They also reported concentrations of pyruvic acid, the simplest of the alpha keto acids, whose chemical structure is displayed in Figure 14. Across six sampling sites, which included offices, restaurants, and a hotel, the indoor air concentrations of oxalic acid averaged $0.24 \pm 0.11 \mu \mathrm{g} / \mathrm{m}^{3}$ (66 $\pm 29 \mathrm{ppt}$ ), similar to the levels outdoors. The reported average \pm standard deviation indoor concentrations of pyruvic acid were similar: $0.17 \pm 0.25 \mu \mathrm{g} / \mathrm{m}^{3}$ (48 $\pm 69 \mathrm{ppt}$ ). Allen and Miguel also sampled fine particles. For this phase, the average indoor concentration of oxalate was about $0.16 \pm 0.10 \mu \mathrm{g} / \mathrm{m}^{3}$, similar to the gas-phase concentration of oxalic acid. Pyruvate, by contrast, was present at lower levels, averaging $\sim 0.02 \mu \mathrm{g} / \mathrm{m}^{3}$.

In their classroom monitoring study, Liu et al. ${ }^{13}$ reported measurement results for 14

"diacid/hydroxycarbonyl acid (saturated)" compounds in the gas phase. Oxalic and malonic acid were reported as nondetectable indoors, even though there were substantial concentrations in outdoor air (8.4 and 1.7 ppt, respectively). The three most abundant diacids in indoor air reported in this study (average indoor concentrations, I/O ratio based on average) were succinic acid (butanedioic acid, 13 ppt, 11), glutaric acid (pentanedioic acid, 9.5 ppt, 80), and adipic acid (hexanedioic acid, $0.7 \mathrm{ppt}, 2$ ).

The study by Liu et al. ${ }^{13}$ represents the most extensive and detailed set of gas-phase indoor organic acid data reported to date. Their supplemental information reports time-average indoor and/or outdoor concentrations for 155 species. Table 18 reproduces the indoor and outdoor concentrations for the 18 species for which the time-averaged indoor concentration exceeded 10 ppt. Half of these species were reported as "not detected" (ND) in outdoor air. Among the remaining nine, the ratio of average indoor to average outdoor concentrations $(\mathrm{I} / \mathrm{O})$ ranged from 4 
(for oxobutanoic acid) to 25 (for oxopentanoic acid), with a median ratio of 8 . The consistently high 1/O ratios reflects the importance of indoor emission sources for this group of abundant species. Wisthaler and Weschler ${ }^{326}$ have shown that these oxoacids are major secondary products of ozone/squalene chemistry, noting that squalene is a primary component of human skin lipids.

In an extensive monitoring campaign undertaken in an ordinarily occupied single-family residence, Liu et al. ${ }^{291}$ reported on the gas-phase concentrations of a few other organic acids in addition to several $n$-alkanoic carboxylic acids. With tentative species identification, they reported that the time-average indoor concentration of acrylic acid (see structure depicted in Figure 15) was 375 ppt during summer monitoring and 312 ppt during winter. Analogously, glycolic acid was reported at 32 ppt for summer and $36 \mathrm{ppt}$ for winter. Methanesulfonic acid $\left(\mathrm{CH}_{3} \mathrm{SO}_{3} \mathrm{H}\right)$ was found to be present at an average abundance of $35 \mathrm{ppt}$ in the summer and $115 \mathrm{ppt}$ in the winter. In each case, the I/O ratio was well above 1.0, implicating indoor sources as important contributors to indoor concentrations. That study also reported an observation regarding a dicarboxylic acid: "Spikes of $\mathrm{C}_{2} \mathrm{H}_{3} \mathrm{O}_{4}{ }^{+}($likely attributable to oxalic acid) were observed during some occasions of sautéing in the summer."291 The estimated average oxalic acid concentration in the summer season in the single-family residence was $16 \mathrm{ppt}$; in the winter, the average level was not stated, indicating that it was below the $10 \mathrm{ppt}$ reporting threshold.

In Portugal, Pegas et al. ${ }^{327}$ measured particle-phase organic acids in $\mathrm{PM}_{10}$ samples collected from two schools, one located in urban Aveiro and the other in the nearby suburbs. Sampling was conducted during normal school hours between April and June 2010, with separate weekday and weekend measurements. Table 19 recounts average concentrations of the four specific acids as reported by Pegas et al. Striking features include relatively high concentrations, both indoors and outdoors, of palmitoleic acid (an unsaturated fatty acid), benzoic acid, and pinic acid (a terpenoid). The diterpenoid dehydroabietic acid $\left(\mathrm{C}_{20} \mathrm{H}_{28} \mathrm{O}_{2}\right)$ was found at particularly elevated levels in the suburban classroom.

This article is protected by copyright. All rights reserved 
In a follow-up investigation in Portugal, Alves et al. ${ }^{328}$ sampled $\mathrm{PM}_{10}$ inside and outside of a primary school classroom in the Aveiro city center during the winter and spring of 2011 . They conducted detailed chemical analyses of composited samples, including measurements of diacids, ketoacids and aromatic acids. Table 20 records the reported indoor and outdoor concentrations for eight acidic species whose individual concentrations exceeded $10 \mathrm{ng} / \mathrm{m}^{3}$. A striking feature is the extraordinarily high indoor concentration of malic acid. Alves et al. remarked that, "the fact that this acid is found in many sour or tart-tasting foods can eventually justify its detection at such high levels in indoor particles. The most common use of malic acid is in candy and potato chips."328

Dehydroabietic acid and abietic acid are also known as "resin acids," as they occur in tree resins. Resin acids occur in certain soaps. ${ }^{329}$ They are prominently emitted organic compounds from biomass burning. ${ }^{330}$ Noonan and coworkers ${ }^{331,332}$ have reported on indoor concentrations of abietic acid and dehydroabietic acid in $\mathrm{PM}_{2.5}$ samples collected in homes that used woodstoves for heat. The studies were conducted in association with a remediation program to improve the impact of woodstove use on ambient $\mathrm{PM}_{2.5}$ levels. Sampling in 16 homes, Ward and Noonan ${ }^{331}$ reported average \pm standard deviation indoor concentrations before (and after) the remediation to be $80 \pm 61$ $(187 \pm 128) \mathrm{ng} / \mathrm{m}^{3}$ for dehydroabietic acid and $3.7 \pm 5.7(15 \pm 23) \mathrm{ng} / \mathrm{m}^{3}$ for abietic acid.

Corresponding results for 21 homes as reported by Noonan et al. ${ }^{332}$ were $102 \pm 73(185 \pm 119) \mathrm{ng} / \mathrm{m}^{3}$ for dehydroabietic acid and $8.8 \pm 20(28 \pm 23) \mathrm{ng} / \mathrm{m}^{3}$ for abietic acid. The higher concentrations after remediation were attributed by the study authors to the more effective heating of fuel prior to its combustion in the higher efficiency stoves, leading to enhanced release into indoor air of these semivolatile wood constituents.

Many studies have reported outdoor concentrations in the gas and/or particle phase for dicarboxylic and other organic acids reflecting urban and regional air quality concerns. In summarizing selected results here, we focus on sampling conducted in urban and suburban environments, rather than in the more remote portions of the atmosphere, because of the implicit connection of urban studies to

This article is protected by copyright. All rights reserved 
larger numbers of indoor environments and therefore greater relative significance for indoor air quality concerns, including human exposure.

An early report by Kawamura and Kaplan ${ }^{333}$ characterized outdoor dicarboxylic acids in gas plus particle phases in the Los Angeles area from sampling during summer and autumn of 1984. They concluded that "oxalic acid is the dominant species." Considering the sum of C2-C6 plus C9 (i.e., all species listed in Table 17), the total average concentration \pm standard deviation for 12 atmospheric samples was $8.3 \pm 4.5 \mathrm{nmol} / \mathrm{m}^{3}$. The three most prominent species (average \% contribution) were oxalic acid (62\%), succinic acid (16\%) and adipic acid (9\%). An early study in Tokyo sampled at intervals between late spring and autumn 1989. 334 In that study, dicarboxylic and ketocarboxylic acids were assessed for the particle-phase only, with no particle size cutoff. The total average mass concentration of $n$-alkanoic dicarboxylic acids spanning C2 (oxalic acid) to C10 (sebacic acid) was 440 $\mathrm{ng} / \mathrm{m}^{3}$ with the three most prominent species being oxalic acid (58\%), malonic acid (13\%) and succinic acid (13\%). ${ }^{334}$ Among the total of 24 reported acids, only two other species had reported average concentrations above $30 \mathrm{ng} / \mathrm{m}^{3}$ : pyruvic acid $\left(41 \mathrm{ng} / \mathrm{m}^{3}\right)$ and glyoxylic acid $\left(36 \mathrm{ng} / \mathrm{m}^{3}\right)$. Altogether, diacid concentrations averaged $540 \mathrm{ng} / \mathrm{m}^{3}$ and ketoacids $98 \mathrm{ng} / \mathrm{m}^{3}$.

Rogge et al. ${ }^{311}$ conducted detailed organic chemical composition analysis for fine particles collected outdoors at uniform intervals for year 1982 at four sites in the Los Angeles area. The average concentration of total aliphatic dicarboxylic acids was $239 \mathrm{ng} / \mathrm{m}^{3}$. The four most abundant species (and their respective average concentrations) were succinic acid $\left(64 \mathrm{ng} / \mathrm{m}^{3}\right)$, malonic acid (39 $\left.\mathrm{ng} / \mathrm{m}^{3}\right)$, azelaic acid $\left(33 \mathrm{ng} / \mathrm{m}^{3}\right)$, and glutaric acid $\left(32 \mathrm{ng} / \mathrm{m}^{3}\right)$. These four species contributed $70 \%$ of the total mass concentration reported for aliphatic dicarboxylic acids. Oxalic acid was not reported.

Khwaja ${ }^{335}$ collected and analyzed seven atmospheric samples collected over two days during October 1991 in a semiurban area of New York state. They reported concentrations of oxocarboxylic, ketocarboxylic, and dicarboxylic acids in the particle phase. Average \pm standard deviation levels were $231 \pm 118 \mathrm{ng} / \mathrm{m}^{3}$ (for 6 of 7 samples above the detection limit) for oxalic acid,

This article is protected by copyright. All rights reserved 
$119 \pm 44 \mathrm{ng} / \mathrm{m}^{3}$ (for 6 of 7 samples above the detection limit) for succinic acid, $84 \pm 20 \mathrm{ng} / \mathrm{m}^{3}$ for malonic acid, $59 \pm 21 \mathrm{ng} / \mathrm{m}^{3}$ for pyruvic acid, and $44 \pm 16 \mathrm{ng} / \mathrm{m}^{3}$ for glyoxalic acid.

Several recent studies have reported particle-associated organic acids sampled from outdoor air in and near Beijing, China. ${ }^{336-339}$ Results from one illustrative study are highlighted in Table 21, which reports a subset of species for which the annual average ambient concentration of the analyte in $\mathrm{PM}_{2.5}$ was above $10 \mathrm{ng} / \mathrm{m}^{3}$. Several dicarboxylic acids are featured, with oxalic acid being the most abundant. Seasonally, the average \pm standard deviation for total dicarboxylic acid concentrations varied from a low of $366 \pm 261 \mathrm{ng} / \mathrm{m}^{3}$ in autumn to a high of $763 \pm 701 \mathrm{ng} / \mathrm{m}^{3}$ in winter. Among the other prominent organic acids quantified in $\mathrm{PM}_{2.5}$ in Beijing are phthalic acid and terephthalic acid, whose structures and thermodynamic properties are illustrated in Figure 16 and its caption.

\subsubsection{Organic acid sources: Cooking}

Cooking is a major air pollutant emission source. Even though most cooking occurs indoors, because of the much greater overall research emphasis on outdoor air pollution, most studies on emissions of organic acids from cooking activities have focused on larger-scale cooking operations, e.g. as practiced in restaurants or in the food-preparation industry, rather than from residential cooking. Abdullahi et al. ${ }^{340}$ have reviewed emissions from cooking of particulate matter and associated chemical components. Prominently featured constituents are the unsaturated fatty acids (mainly $n$ alkenoic acids) and dicarboxylic acids.

We've already summarized the few instances in which organic acids have been directly measured indoors in relation to cooking as an emission source. Here, we highlight some studies that have assessed emission factors of organic acids associated with cooking. Because the cooking activities were at restaurant or industrial scale, these results should be considered as indicative rather than quantitatively accurate with regard to emission factors expected from residential cooking.

This article is protected by copyright. All rights reserved 
The first major study to quantify emission factors of particle-associated organic acids from cooking focused on hamburger meat. ${ }^{313}$ The study contrasted griddle frying with charbroiling, and considered the effect of fat content of the meat. Prominent among the emitted compounds were two unsaturated fatty acids: palmitoleic (cis-9-hexadecenoic) and especially oleic (cis-9octadecenoic) acid. Emission factors were about an order of magnitude higher for oleic acid than for palmitoleic acid across fat content and cooking style. The highest reported emission factor was for charbroiling "regular" beef ( $21 \% \mathrm{fat}$ ) over a natural-gas flame: $570 \mathrm{mg}$ of oleic acid emitted per kg of meat cooked. With "extralean" beef (10\% fat), the oleic acid emission factor declined to $82 \mathrm{mg} / \mathrm{kg}$ when charbroiled. A 50:50 mixture of regular and extralean beef, when fried, emitted $11 \mathrm{mg} / \mathrm{kg}$ of oleic acid. Emission factors were also reported for three dicarboxylic acids: succinic, glutaric, and adipic. Summed across the three species, the emission factors were $40 \mathrm{mg} / \mathrm{kg}$ for charbroiling regular beef, $22 \mathrm{mg} / \mathrm{kg}$ for charbroiling extralean beef, and $5 \mathrm{mg} / \mathrm{kg}$ for frying beef with intermediate fat content.

Schauer et al. ${ }^{274}$ reported more detailed chemical characterization from industrial-scale hamburger charbroiling, using beef with $20 \%$ fat. Prominent among the organic species quantified in fine particle emissions was oleic acid, with an average emission factor of $214 \mathrm{mg}$ emitted per $\mathrm{kg}$ of meat cooked. Other emission factors reported for unsaturated organic acids were $18 \mathrm{mg} / \mathrm{kg}$ for palmitoleic acid and $32 \mathrm{mg} / \mathrm{kg}$ for linoleic acid. Among dicarboxylic acids, emission factors were reported for adipic acid at $2 \mathrm{mg} / \mathrm{kg}$ and suberic acid at $4 \mathrm{mg} / \mathrm{kg}$.

A subsequent investigation by Schauer et al. ${ }^{275}$ assessed organic emissions of industrial-scale cooking with seed oils. Specific cooking processes were "vegetables stir-fried in soybean oil, vegetables stirfried in canola oil, and potatoes deep fried in hydrogenated soybean oil." The authors found that "carbonyls and fatty acids ( $n$-alkanoic and $n$-alkenoic acids) make up a significant portion of the organic compounds emitted from all three seed oil cooking procedures." 275 Reported emission factors (normalized by the mass of food cooked) for the three most prominent $n$-alkenoic acids

This article is protected by copyright. All rights reserved 
across the three types of procedures were in the respective ranges $1.9-6.3 \mathrm{mg} / \mathrm{kg}$ for oleic acid, 1.8 $4.2 \mathrm{mg} / \mathrm{kg}$ for linoleic acid, and 0.08-0.31 mg/kg for linolenic acid.

He et al. ${ }^{314}$ assessed organic composition of fine particles emitted from Chinese commercial restaurants that respectively used "Hunan" and "Cantonese" styles of cooking. They reported emission factors normalized as mass of analyte per mass of particles collected (rather than per mass of food cooked). Across the two cooking styles, for $n$-alkenoic acids, the summed emission factors were in the range $11-12 \%$ (111-123 mg/g) and the most abundant compounds were 9,12octadecadienoic (linoleic) acid and 9-octadecenoic (oleic) acid. Total contributions of dicarboxylic acids to fine PM mass were in the range $0.62-0.85 \%(6.2-8.5 \mathrm{mg} / \mathrm{g})$. The most abundant species was azelaic acid followed by suberic acid.

Zhao et al. ${ }^{315}$ assessed the organic composition of fine particles emitted from restaurants with four different styles of Chinese cooking: Cantonese, Sichuan, Dongbei, and Hunan. They reported emission factors as mass of analyte per mass of particulate organic matter. Among the unsaturated fatty acids, oleic acid was the most abundant species, with average emission factors in the range 14 $\mathrm{mg} / \mathrm{g}$ (Cantonese style) to $29 \mathrm{mg} / \mathrm{g}$ (Sichuan style). Linoleic acid emissions were in the range $3 \mathrm{mg} / \mathrm{g}$ (Dongbei style) to $14 \mathrm{mg} / \mathrm{g}$ (Sichuan). Emission factors also were reported for eight dicarboxylic acids. The totals range from $1.1 \mathrm{mg} / \mathrm{g}$ (Cantonese) to $3.2 \mathrm{mg} / \mathrm{g}$ (Sichuan). Among the dicarboxylic acids, the most abundant species was azelaic acid, accounting for roughly half of the total. Zhao et al. ${ }^{341}$ contrasted these emissions from Chinese restaurants with "Western style fast-food cooking" as practiced in China. The reported emission factors were much higher for the Western style of cooking. For example, oleic acid emissions were $76 \mathrm{mg} / \mathrm{g}$ for Western-style fast food cooking compared with an average of $20 \mathrm{mg} / \mathrm{g}$ for the Chinese styles. For quantified dicarboxylic acids, the Western-style cooking emission factor was $58 \mathrm{mg} / \mathrm{g}$ compared to an average of $2 \mathrm{mg} / \mathrm{g}$ for the Chinese styles.

This article is protected by copyright. All rights reserved 
Another important feature of cooking that might be associated with indoor organic acids is the potential for elevated health risks from exposure to cooking oil fumes. In particular, epidemiological research has revealed an excess incidence of lung cancer among never smoking Chinese women that is associated with high-temperature cooking. ${ }^{342,343}$ Qu et al. have found that the "condensates of volatile emissions from rapeseed and soybean cooking oils [are] genotoxic in short-term tests." 344 Shields et al. studied the mutagenicity of substances emitted from "a variety of cooking oils heated to the temperatures typically used in wok cooking." 345 They reported that "the mutagenicity of individual volatile emission condensates was correlated with linolenic acid content." They also determined that "condensates from heated linolenic acid, but not linoleic or eruric acid, were highly mutagenic." 345 Other emitted organic compounds of interest in this study included 1,3-butadiene, benzene, and acrolein.

\subsubsection{Organic acid sources: Incense and tobacco}

In general, the incomplete combustion of carbonaceous materials will generate organic acids among many other partially oxidized compounds. We have already discussed some evidence regarding organic acid emissions associated with heating (by means of wood stoves) and cooking. Other indoor combustion activities that could emit organic acids are considered here, in brief because the empirical evidence regarding emissions remains limited.

Kuo et al. ${ }^{301}$ measured emission factors associated with incense burning. They measured carboxylates in $\mathrm{PM}_{2.5}$. They tested four samples of incense and evaluated the emission factors in units of $\mu \mathrm{g}$ of analyte per $\mathrm{g}$ of incense. The most prominent analytes detected were the $n$-alkanoic ions acetate (average emission factor $442 \mu \mathrm{g} / \mathrm{g}$ ) and formate $(27 \mu \mathrm{g} / \mathrm{g})$. The sum of the remaining quantified carboxylates was $37 \mu \mathrm{g} / \mathrm{g}$, of which the four most prominent were oxalate $(8 \mu \mathrm{g} / \mathrm{g})$, maleate $(6 \mu \mathrm{g} / \mathrm{g})$, phthalate $(6 \mu \mathrm{g} / \mathrm{g})$ and succinate $(4 \mu \mathrm{g} / \mathrm{g})$. The gaseous acetic acid emissions exceeded the $\mathrm{PM}_{2.5}$ acetate emission rate.

This article is protected by copyright. All rights reserved 
The combustion and heating of tobacco remains a major indoor emission source of organic contaminants. In recent studies, emission rates were measured for a suite of organic acids for different types of tobacco products including conventional cigarettes and e-cigarettes ${ }^{346}$ and heatnot-burn tobacco cigarettes. ${ }^{347}$ The emission rates were assessed in units of mass emitted per time. In all, results were reported for 18-19 organic acids. Summed over all reported species, organic acid emission factors ranged from $24 \mu \mathrm{g} / \mathrm{h}$ for heat-not-burn cigarettes without menthol to $323 \mu \mathrm{g} / \mathrm{h}$ for conventional cigarettes. The most prominent species (above $10 \mu \mathrm{g} / \mathrm{h}$ each) from conventional cigarettes were palmitic acid $(129 \mu \mathrm{g} / \mathrm{h})$, linoleic acid $(65 \mu \mathrm{g} / \mathrm{h})$, myristic acid $(16 \mu \mathrm{g} / \mathrm{h})$, eicosanoic (arachidic) acid (14 $\mu \mathrm{g} / \mathrm{h})$, docosanoic (behenic) acid (13 $\mathrm{gg} / \mathrm{h})$, dodecanoic (lauric) acid (12 $\mu \mathrm{g} / \mathrm{h}$ ), and tetracosanoic (lignoceric) acid $(10 \mu \mathrm{g} / \mathrm{h}) .{ }^{346}$ These seven species comprised $80 \%$ of the emissions of organic acids for conventional cigarettes. Although the apportionment varies, these are also the more prominent of the species emitted from the other tobacco products, summing to proportions in the range of $79-84 \%$ of the respective totals.

\subsubsection{Organic acid sources: Bacteria}

Fox et al. ${ }^{348}$ have suggested that particle-associated organic acids may be suitable markers of airborne bacteria in occupied spaces. They note that "muramic acid ... is found in almost all bacteria whereas 3-hydroxy fatty acids ... are found only in Gram-negative bacteria." They demonstrated that the abundance of these compounds in elementary school classrooms was elevated to levels well above those in outdoor air when the classrooms were occupied, yet were lower than outdoor levels when the classrooms were unoccupied. Abundances were small, with average indoor concentrations during occupancy of 0.9-3.5 picomoles/ $\mathrm{m}^{3}$ for $\mathrm{C} 10, \mathrm{C} 12, \mathrm{C} 14$, andC16 fatty acids, and 7 picomoles $/ \mathrm{m}^{3}$ for muramic acid. With a molecular weight of $251 \mathrm{~g} / \mathrm{mol}$, the corresponding average mass concentration of muramic acid would be $1.8 \mathrm{ng} / \mathrm{m}^{3}$.

\subsubsection{Organic acid sources: Ozonolysis of terpenes}

Terpenes and related compounds are commonly found at elevated levels indoors. Among the common indoor sources are cleaning products and air fresheners. ${ }^{145}$ Indoor reactions between 
ozone and terpenes have been demonstrated to produce secondary particulate matter indoors. ${ }^{349}$ Glasius et al. ${ }^{350}$ have shown that reactive chemistry between ozone and terpenes produces dicarboxylic, oxocarboxylic, and hydroxyketocarboxylic acids that contribute to secondary organic aerosol (SOA). Fick et al. ${ }^{351}$ demonstrated that the ozonation of $\alpha$-pinene in a model ventilation system generated norpinic acid, pinic acid, norpinonic acid, and pinonic acid. Larsen et al. ${ }^{352}$ studied the chemical products resulting from ozonation of $\beta$-pinene under "conditions relevant for indoor environments." They quantified "thirteen reaction products ... in SOA, most of which being multifunctional carboxylic acids and carbonyls. Cis-pinic acid was the most abundant compound ...."

\subsubsection{Ozonolysis of fatty acids, squalene, and skin oil}

Ozone-initiated reactions with unsaturated organic compounds can transform already existing organic acids and also create new organic acids indoors. Among the unsaturated organic compounds that are commonly present in occupied indoor spaces are squalene and fatty acids found in skin lipids. ${ }^{11,319,326}$ Also prominent are fatty acids that originate from cooking ${ }^{340}$ and from materials used in manufacturing and maintenance of indoor furnishings, such as linseed and tung oil. 353

Thornberry and $\mathrm{Abbatt}^{354}$ studied the product yields and kinetics for ozonation of surface-bound unsaturated fatty acids: oleic, linoleic, and linolenic acid. Volatile products generated included the aldehydes hexanal, nonanal, and nonenal. Wisthaler and Weschler ${ }^{326}$ investigated the reactions of ozone with skin oils, focusing on the loss of ozone and the production of volatile products. They concluded that "reactions between ozone and human skin lipids reduce the mixing ratio of ozone in indoor air, but concomitantly increase the mixing ratios of volatile products and, presumably, skin surface concentrations of less volatile products." Zhou et al. investigated the condensed-phase end products resulting from the ozonation of surface-bound squalene ${ }^{355}$ and skin oils. ${ }^{356}$ In the investigation of skin oil, the researchers reported that "upon oxidation with 50 ppb ozone for 90 $\mathrm{min}$, there is a rapid loss of alkene, fatty acid, and triglyceride signals resulting from efficient multiphase ozonolysis. Oxygenated products [were identified], including a variety of carboxylic 
acids." 356 In the investigation of squalene, they found that, under dry conditions, "major condensedphase end products were levulinic acid (LLA) and succinic acid (SCA). Under humid conditions (50\% $\mathrm{RH})$, the major end products were 4-oxopentanal, 4-oxobutanoic acid, and LLA." 355 Note that levulinic acid is also known as 4-oxopentanoic acid. Liu et al., ${ }^{13}$ in their classroom study, identified oxopentanoic acid, along with oxobutanoic acid and succinic acid as abundant indoor acids (> 10 ppt) with high I/O ratios (see Table 18).

These studies illuminate an important point, that the acids (and potentially bases) in indoor air not only exert their influence on indoor air composition through altering the $\mathrm{pH}$ of condensed-phase water, some also are active participants in oxidative chemistry.

\subsection{Aerosol strong acidity}

\subsubsection{Introduction}

Airborne particles may contain condensed water. The $\mathrm{pH}$ of this water is influenced by the presence of acidic and basic gases. Soluble minerals can also affect the $\mathrm{pH}$ of the aqueous phase in airborne particles, especially in the coarse size mode (i.e., for particles with diameters larger than approximately $2 \mu \mathrm{m})$. In turn, the $\mathrm{pH}$ of aerosol water can influence important aspects of atmospheric chemistry, such as the phase partitioning and fate of acidic and basic gases, the dissolution of metals, and the rates of acid-catalyzed chemical reactions. Also, visibility impairment and acid deposition processes are affected by particle-phase acidity.

Health concerns are associated with inhalation exposure to particle-phase strong acids. Considering airborne particulate matter overall, current scientific and public policy efforts focus on fine particle mass concentration, as measured through $\mathrm{PM}_{2.5}$ (i.e., the mass concentration of airborne particles whose aerodynamic diameter is smaller than $2.5 \mu \mathrm{m}$ ). Notwithstanding the current emphasis, there is a substantial history of research that aims to understand whether certain components of the particle phase might be specific causal agents of adverse health effects. Some of this work has focused on aerosol strong acids.

This article is protected by copyright. All rights reserved 
A phase shift of acidic species from gas to particle would change the deposition pattern upon inhalation. Gaseous acids tend to be removed by dissolution in the upper airways whereas acids associated with fine particles can penetrate and deposit deeply in the lung. In an epidemiologic study that utilized data from 24 communities in the US and Canada, Dockery et al. wrote that, "Children living in the community with the highest levels of particle strong acidity were significantly more likely ... to report at least one episode of bronchitis in the past year compared to children living in the least-polluted community." 357 However, they also went on to state that, "neither asthma, wheeze, cough, nor phlegm, were associated with levels of particle strong acidity for these children living in a nonurban environment." A decade earlier, Lippmann provided this strong caution about the state of knowledge, writing that "we cannot adequately describe the nature and extent of the effects of the inhalation of acidic pollutants on human health at this time. We just don't know enough about either population exposures or exposure-response relationships to make a satisfactory risk assessment." 358 Scientific knowledge about this subject improved considerably during 1985-1995 and has continued to advance (albeit more slowly) during the past few decades. We can now outline major features of the system, such as what are the causes, nature, and levels of atmospheric aerosol strong acidity; and what are the relationships among indoor concentrations, outdoor concentrations, and personal exposures. But measurements remain challenging, even for stationary sites sampling outdoor air. Empirical data on indoor concentrations of and personal exposure to aerosol strong acidity are sparse. And so Lippman's caution retains much of its validity today, more than three decades later.

In this subsection, we review aerosol strong acidity (also referred to as particle strong acidity) with the primary goal of illuminating what is known about its role as a component of indoor acids and bases. We rely heavily (although not exclusively) on studies of aerosol strong acidity in the outdoor atmosphere because they dominate the existing literature. For additional background information, see Tanner, ${ }^{359}$ who provides an effective tutorial overview. More recently, the importance of and challenges associated with measuring aerosol pH are effectively summarized by Freedman et al. ${ }^{360}$ 
A key parameter of interest is the $\mathrm{pH}$ of condensed water associated with airborne particles. That parameter cannot, as yet, be measured directly. Among the challenges: $\mathrm{pH}$ is influenced by the abundance of particle-phase water, which itself is highly variable and also difficult to measure directly. To circumvent the problems of unknown abundance of particle-phase water, aerosol strong acidity is often reported in terms of the airborne concentration of particle-phase $\mathrm{H}^{+}$ion, most often in units of nanomoles of $\mathrm{H}^{+}$per cubic meter of air $\left(\mathrm{nmol} / \mathrm{m}^{3}\right)$. (In some references, the particlephase $\mathrm{H}^{+}$ion concentration is reported in nanoequivalents (neq) per $\mathrm{m}^{3}$; since $\mathrm{H}^{+}$is singly charged, 1 neq corresponds to $1 \mathrm{nmol}$. Alternatively, some sources report the particle-phase $\mathrm{H}^{+}$concentration in sulfuric acid equivalent mass units. Since $\mathrm{H}_{2} \mathrm{SO}_{4}$ is a diprotic acid with a molecular mass of 98 $\mathrm{g} / \mathrm{mol}, 2 \mathrm{nmol}$ of $\mathrm{H}^{+}$is equivalent to $98 \mathrm{ng}$ of $\mathrm{H}_{2} \mathrm{SO}_{4}$, and so an airborne concentration of $1 \mu \mathrm{g} / \mathrm{m}^{3}(=$ $\left.1000 \mathrm{ng} / \mathrm{m}^{3}\right)$ of $\mathrm{H}_{2} \mathrm{SO}_{4}$ corresponds to a particle-phase $\mathrm{H}^{+}$concentration of $(2 / 98) \times 1000=20$ $\mathrm{nmol} / \mathrm{m}^{3}$.) Particle-phase water can have unusually high ionic strength, leading to a need for activity corrections in accurate evaluations of the relationship between $\mathrm{H}^{+}$concentration and $\mathrm{pH}$. Neglecting that complexity, the following simple expression relates the approximate $\mathrm{pH}$ of particle-phase water (aerosol $\mathrm{pH}$ ) to the aerosol water content (AWC, in $\mu \mathrm{g}$ of particle-associated condensed water per $\mathrm{m}^{3}$ of air) and the particle strong acidity (PSA, in units of nmol of strong-acid $\mathrm{H}^{+}$per $\mathrm{m}^{3}$ of air):

$$
\text { Aerosol } \mathrm{pH}=\log _{10}(\mathrm{AWC})-\log _{10}(\mathrm{PSA})
$$

So, for example, with a PSA of $3 \mathrm{nmol} / \mathrm{m}^{3}$ and an aerosol water content of $10 \mu \mathrm{g} / \mathrm{m}^{3}$, the estimated aerosol $\mathrm{pH}$ would be $1.0-0.5=0.5$. This low $\mathrm{pH}$ value may startle; however, it is not uncommon For example, considering conditions for fine-particle water in the atmosphere of the southeastern US, Guo et al. reported that " $\mathrm{pH}$ normally varied from 0.5 to 2 in the summer and 1 to 3 in the winter, indicating that the aerosol was highly acidic throughout the year."185

Substantial sources of particle strong acidity are generally absent from indoor environments. Instead, supply from outdoor air via all modes of ventilation is the primary source process. Buildings 
provide partial protection from outdoor particle strong acidity. To some degree, that protection reflects loss of outdoor-sourced particles by means of deposition to indoor surfaces and by air filtration. Also contributing to lower indoor particle acidity is neutralization with ammonia emitted from indoor sources. The degree of protection afforded by being indoors can vary among buildings and with conditions in any given building.

In the atmosphere, the main species that influence aerosol strong acidity are sulfuric acid and ammonia, with sulfuric acid, the most prominent acid, partially neutralized by ammonia, the most prominent base. Nitric acid and organic acids also contribute to aerosol strong acidity, but to lesser extents than sulfuric acid. In the US, Canada, and Europe, fine particle $\mathrm{pH}$ values are commonly in the range 0-3. Rural areas tend to exhibit higher degrees of aerosol acidity (corresponding to lower $\mathrm{pH}$ values) than urban environments; the higher density of ammonia emissions in urban areas is the likely cause. In China, in the vicinity of Beijing, prevailing $\mathrm{pH}$ values are higher, commonly in the range $4-5.361,362$

Aerosol pH varies with particle size, with submicron particles being strongly acidic and coarse particles more nearly neutral. Atmospheric sulfuric acid is concentrated in submicron particles. Coarse particles contain soluble minerals, such as carbonates, that can shift the $\mathrm{pH}$ upward.

\subsubsection{Particle strong acidity and aerosol $\mathrm{pH}$ : Key findings from outdoor air studies}

The largest data set regarding particle strong acidity was acquired as part of a respiratory health study conducted at 24 outdoor sites in the United States and Canada. ${ }^{95}$ Samples were collected over 24-h periods every second day for one year. Measured parameters included "ozone, particle strong acidity, sulfate, and mass $\left(\mathrm{PM}_{10}\right.$ and $\left.\mathrm{PM}_{2.1}\right) \ldots$ In 20 of the communities, sulfur dioxide, ammonia, nitric acid, nitrous acid, and particulate nitrate were measured." 95

Table 22 reproduces the annual and summertime mean concentrations of particle strong acidity. The grand average across all 24 sampling sites was $28 \mathrm{nmol} / \mathrm{m}^{3}$ for the annual period and 44 
$\mathrm{nmol} / \mathrm{m}^{3}$ for the summer. The studied sites were more highly concentrated in areas expected to have elevated acidity. The different averages among the geographic clusters illustrate large-scale spatial variability, with annual averages (in $\mathrm{nmol} / \mathrm{m}^{3}$ ) of 41 for the "sulfate belt," 25 in the "transport region," 13 for the "West coast" sites, and 6 for the "background" sites.

The data reported in Table 22 were acquired using a sampling system developed by Koutrakis et al. ${ }^{363}$ For determining particle strong acidity, particles larger than $2.1 \mu \mathrm{m}$ in diameter are excluded by means of an inlet impactor. The sampled air then passes through two denuders in series to remove acidic gases $\left(\mathrm{SO}_{2}, \mathrm{HNO}_{2}\right.$, and $\left.\mathrm{HNO}_{3}\right)$ and ammonia. Fine particles, collected on a Teflon filter downstream of the denuders, are extracted after sampling and analyzed for strong-acid pH. ${ }^{364}$ From the $\mathrm{pH}$ measurement result and the sampling conditions, particle strong acidity is determined, in units of $n m o l$ of $\mathrm{H}^{+}$per $\mathrm{m}^{3}$ of air sampled.

Two essential features of the measurement method should be highlighted. First, removing coarse particles from the sampling stream allows the acidity of fine particles to be isolated from the potential neutralizing contributions of basic minerals associated with coarse airborne particles. Lipfert et al. cautioned that, "an aerosol sampling device that combines small acidic particles with larger basic particles ... may yield misleading information with respect to biological responses." ${ }^{365}$ Second, the use of denuders avoids artifact generation that would result from acidic and basic gases interacting with previously collected particles or with the filter material itself.

That particle $\mathrm{pH}$ varies with size and that small particles tend to be more acidic has been demonstrated in several studies. For example, using a cascade impactor, Ludwig and Klemm ${ }^{366}$ determined the size-dependent acidity of aerosol particles at three locations in Bavaria, Germany. They reported that, "the in situ pH's were calculated as $\mathrm{pH} 1$... 2 for these [fine] particles at all sampling sites. Coarse particles were only slightly acidic, with a mean in situ pH 5.5 ... 6.5." Fang et al. assessed the $\mathrm{pH}$ of size-segregated aerosol particles sampled from roadside and urban sites in Atlanta, GA. ${ }^{367}$ Their assessment used a thermodynamic model applied to measured ionic species. 
Quoting a key result, "sulfate was spatially uniform and found mainly in the fine mode, whereas toxic metals and mineral dust cations were highest at the road-side site and in the coarse mode, resulting in fine mode $\mathrm{pH}<2$ and near neutral coarse mode." 367

The large-scale pattern of aerosol strong acidity is mainly controlled by the respective spatial distribution of the key precursors. On a regional scale, atmospheric sulfate concentrations are relatively uniform owing to the combined effects of numerous emission sources of $\mathrm{SO}_{2}$ (most importantly electricity generation by coal combustion), atmospheric mixing prior to secondary atmospheric production of sulfate from the oxidation of $\mathrm{SO}_{2}$, and relatively slow removal of sulfate from the atmosphere. Being a primary pollutant, ammonia exhibits a spatial pattern more closely associated with the pattern of source emissions, which tend to be more concentrated in urban areas and in rural areas with intensive agricultural activity as contrasted with more remote rural environments. Brook et al. ${ }^{368}$ describe the "Canadian Acid Aerosol Measurement Program," with sampling conducted over three years (1992-94) at 10 sites. They reported that "acidities were lower in areas where the fine particle acidity experienced greater neutralization from reaction with ammonia. This included the major urban centres (i.e., Toronto and Montréal) and areas with greater amounts of agricultural activity, as in rural southern Ontario." 368 Suh et al. studied the spatial variability of aerosol strong acidity in and around Philadelphia. ${ }^{369}$ They reported that, "outdoor sulfate $\left(\mathrm{SO}_{4}{ }^{2-}\right)$ concentrations were uniform within metropolitan Philadelphia; however, aerosol strong acidity $\left(\mathrm{H}^{+}\right)$concentrations varied spatially. This variation ... was related to local factors, such as the $\mathrm{NH}_{3}$ concentration." ${ }^{369}$ Interpreting results from a measurement campaign conducted in three sites in Pennsylvania during the summer of 1990, Liu et al. reported that "aerosol acidity was found to be lower in the urban area (Pittsburgh) than the semi-rural areas. Ammonia levels were higher at the urban site than in the semi-rural environments, probably due to the higher population density at the urban site." 370

The respective balances between atmospheric sulfate and ammonia levels is believed to be responsible for the observation that fine particles in the air in and around Beijing, China, are much

This article is protected by copyright. All rights reserved 
less acidic than in North America and Europe. Liu et al. ${ }^{362}$ studied the $\mathrm{pH}$ of fine particles in Beijing during selected haze episodes occurring during late 2015 and 2016. Using a thermodynamic model to interpret measurements of particle-phase ions and precursor gases, they reported that, "Fine particles were moderately acidic, with a pH range of 3.0-4.9 and an average of 4.2 ... Excess $\mathrm{NH}_{3}$ and high aerosol water content are responsible for the relatively lower aerosol acidity." They reported remarkably high levels of aerosol water content during the haze episodes, up to several hundred $\mu \mathrm{g}$ $\mathrm{m}^{-3}$. Ding et al. ${ }^{361}$ describe a more extensive investigation of the $\mathrm{pH}$ associated with $\mathrm{PM}_{2.5}$ particles in Beijing. They reported that, "In 2016-2017, the mean $\mathrm{PM}_{2.5} \mathrm{pH}$... over four seasons was $4.5 \pm 0.7$ (winter) > $4.4 \pm 1.2$ (spring) > $4.3 \pm 0.8$ (autumn) > $3.8 \pm 1.2$ (summer), showing moderate acidity."

In North America, aerosol acidity has been much more extensively studied in the summer than in other seasons. Among the features that would support such an emphasis would be the lower aerosol water content levels during cold weather. A year-long study in Detroit, MI, using a sampler with an open-faced filter, showed seasonal variation in aerosol strong acidity with highest values during the summer: $39 \mathrm{nmol} / \mathrm{m}^{3}$ (summer), $15 \mathrm{nmol} / \mathrm{m}^{3}$ (fall), $13 \mathrm{nmol} / \mathrm{m}^{3}$ (winter), and $3 \mathrm{nmol} / \mathrm{m}^{3}$ (spring). ${ }^{371}$ An intensive study of aerosol strong acidity during summer months (July and August, 1986-1988) in Toronto separately assessed concentrations during daytime (0900-1700) and overnight (1700-0900). ${ }^{372}$ Averaging first across the monitoring sites and then across the three years, the levels were somewhat higher during daytime hours $\left(34 \mathrm{nmol} / \mathrm{m}^{3}\right)$ than overnight $\left(26 \mathrm{nmol} / \mathrm{m}^{3}\right)$.

With regional variation, the overall global trend has been a decrease in anthropogenic $\mathrm{SO}_{2}$ emissions over the period $1990-2015 .{ }^{373}$ As a result, one might expect substantial shifts in aerosol strong acidity. However, while there is agreement that $\mathrm{SO}_{2}$ emissions and atmospheric sulfate levels are decreasing, there isn't a consensus about the consequences for acidity. Using a modeling approach, Murphy et al. report that, "steep increases in $\mathrm{pH}$ and the gas fraction of $\mathrm{NH}_{\mathrm{x}}$ are found as $\mathrm{NH}_{\mathrm{x}}: \mathrm{SO}_{4}$ varies from below 1 to above $2 . " 374$ They state that, "regions of the world where the ratio of $\mathrm{NH}_{3}: \mathrm{SO}_{2}$ emissions is beginning to exceed 2 on a molar basis may be experiencing rapid increases in aerosol pH of 1-3 pH units." On the other hand, focusing on a rural area in the southeastern US, and

This article is protected by copyright. All rights reserved 
combining experimental observations with modeling interpretation, Weber et al. conclude that, "the reductions in aerosol acidity widely anticipated from sulfur reductions, and expected acidity-related health and climate benefits, are unlikely to occur until atmospheric sulfate concentrations reach near pre-anthropogenic levels." 375

\subsubsection{Indoor and personal exposure studies}

During the period of most intensive study of aerosol strong acidity, which centered on the decade 1985-1995, several investigations reported indoor conditions and/or personal exposures. Key findings are presented here, in approximate chronological order.

Spengler et al. ${ }^{5}$ provided one of the earliest reports substantially concerned with acidic aerosols indoors and associated exposures. They stated that "acidic aerosols occurring indoors are assumed to originate from outdoors." They also reported that, "indoor gaseous ammonia $\left(\mathrm{NH}_{3}\right)$ concentration is expected to be higher compared to outdoors since it is produced by people, pets, and household products." In considering exposures, they stressed the importance of microenvironmental conditions and time-activity patterns, highlighting, for example, that "children are more likely to be outdoors during the day, particularly in the summer." They combined microenvironmental measured and modeled concentrations with time-activity patterns to estimate means and percentiles of the distribution of exposures to aerosol strong acidity for children. For Portage, Wisconsin, the annual average exposure concentration (i.e., the fraction of time outdoors $\times$ average outdoor concentration + fraction of time indoors $\times$ average indoor concentration) for aerosol $\mathrm{H}^{+}$so determined was $7.6 \mathrm{nmol} / \mathrm{m}^{3}$, with variation among averages between $1.2 \mathrm{nmol} / \mathrm{m}^{3}$ for winter and $18 \mathrm{nmol} / \mathrm{m}^{3}$ for summer daytime conditions. Corresponding results for Steubenville, Ohio, were $24 \mathrm{nmol} / \mathrm{m}^{3}$ for the annual average, $5.1 \mathrm{nmol} / \mathrm{m}^{3}$ for winter average, and $55 \mathrm{nmol} / \mathrm{m}^{3}$ for summer daytime average. This report highlighted the finding that atmospheric acidic aerosols could be elevated episodically: "measurements made in Kingston, TN, and Steubenville, $\mathrm{OH}$, resulted in 24$\mathrm{h} \mathrm{H}^{+}$ion concentrations exceeding $100 \mathrm{nmol} / \mathrm{m}^{3}$ more than 10 times during summer months." ${ }^{5} \mathrm{An}$

This article is protected by copyright. All rights reserved 
important conclusion from their investigation is that, "children engaged in summertime outdoor activities can experience $\mathrm{H}^{+}$doses comparable to effects levels reported in human clinical studies."

Brauer et al. ${ }^{6}$ undertook the first direct experimental study of personal exposure to particle strong acids. Sampling was carried out in the Boston metropolitan area for 24 days during the summer of 1988. Two volunteers were each outfitted with two personal sampling systems similar to that described in Koutrakis et al. ${ }^{363}$ In each case, one sampler was operated continuously to collect a 24-h total exposure. For one subject, the second sampler was turned on only when outdoors; for the other subject, the second sampler was turned on only when indoors. Separate stationary samplers were used to measure aerosol strong acidity at a central monitoring site outdoors and overnight in three residences. The authors reported that "personal exposures to aerosol strong $\mathrm{H}^{+}$were slightly lower than concentrations measured at the stationary site due to the neutralization of acidic particles and their incomplete penetration into indoor environments." ${ }^{6}$

Using the same type of sampling system, indoor and outdoor concentrations of aerosol strong acidity were sampled in 11 homes in the Boston area during late winter $(n=5)$ and summer $(n=$ 6). ${ }^{128}$ In this study, the indoor/outdoor ratio of fine-particle strong acidity had geometric mean (geometric standard deviation) values of $0.48(2.03)$ in the summer and $0.36(2.59)$ in the winter. The mean \pm standard deviation indoor $\mathrm{H}^{+}$concentration was $2.4 \pm 1.8 \mathrm{nmol} / \mathrm{m}^{3}$ in the winter and 8.8 $\pm 4.8 \mathrm{nmol} / \mathrm{m}^{3}$ in the summer. The authors reported that, "Indoors, we found a large available excess of $\mathrm{NH}_{3}$, which apparently coexisted at times with particle acidity." 128

Liang and Waldman ${ }^{129}$ measured indoor aerosol strong acidity at three institutional sites in New Jersey: a child care facility, a nursing home, and a home for the elderly. Simultaneously, outdoor sampling was conducted at a nearby central station and at the home for the elderly. Sampling was conducted during a six-week period, June-July 1989. The sampling train included a particle impactor that excluded particles larger than $2.5 \mu \mathrm{m}$ and a denuder to remove gaseous ammonia. Sampling was conducted for 12-h daytime periods at all three indoor and both outdoor sites. Nighttime

This article is protected by copyright. All rights reserved 
samples (12 h) were also collected indoors at the elderly home and at both outdoor sites. The number of samples collected varied between 28 and 41 for each combination of conditions. Table 23 reproduces the mean and $90^{\text {th }}$ percentile values of $\mathrm{H}^{+}$concentrations reported by Liang and Waldman. The authors concluded that, "75\% of the daily dose of aerosol acidity for the elderly was due to indoor exposures" and that "these data suggest that indoor settings are protective, but children may still be at risk from summertime acidic aerosol exposure, depending on their activities outdoors." 129

Suh et al. studied indoor, outdoor, and personal exposure to aerosol strong acidity in Uniontown, PA $^{130}$ and in State College, PA. ${ }^{376}$ The Uniontown study focused on 24 children with monitoring conducted during summer 1990. Measurements were made over a two-day period at each home, "during which four 12-h indoor, two 24-h outdoor, and two 12-h personal samples were collected" using the system described in Koutrakis et al. ${ }^{363,364}$ Geometric mean (geometric standard deviation) for fine-particle strong acidity $\left(\mathrm{H}^{+}\right.$concentrations, in $\left.\mathrm{nmol} / \mathrm{m}^{3}\right)$ were as follows: outdoors $=77(2.7)$, personal $=43(2.2)$, and indoor $=14$ (2.5). The authors reported that, " $\mathrm{H}^{+}$was neutralized by $\mathrm{NH}_{3}$ present inside homes." 130 They specifically found that levels were lower in air-conditioned homes than non-air-conditioned homes and that $\mathrm{NH}_{3}$ levels in the air-conditioned homes were "significantly higher than in non-air-conditioned homes." Importantly, the authors also found that "both outdoor and indoor $\mathrm{H}^{+}$concentrations were poor estimators of personal exposure." ${ }^{130}$ Sampling in State College was undertaken in the summer of $1991 .{ }^{376}$ Measurements during 12-h daytime periods (0800-2000) were acquired for 47 children living in nonsmoking households, about half with airconditioning. For each child and home, indoor samples were collected during five daytime periods. Corresponding outdoor measurements were made at a single site. Geometric mean (geometric standard deviation) for fine-particle strong acidity $\left(\mathrm{H}^{+}\right.$concentrations in $\left.\mathrm{nmol} / \mathrm{m}^{3}\right)$ were as follows: outdoors $=72(2.9)$, personal $=18(3.0)$, indoor $=9(3.5)$. The authors used the data to validate a model for estimating personal exposure that was developed from the Uniontown data, concluding that "predicted personal exposures for ... $\mathrm{H}^{+}$were in excellent agreement with measured personal exposures." 376

This article is protected by copyright. All rights reserved 
Data from the State College study were used again in Suh et al. ${ }^{131}$ Whereas the first paper ${ }^{376}$ in this pair focused on developing and validating an exposure model, the second paper ${ }^{131}$ was more concerned with factors influencing indoor concentrations. In the second paper, the reported geometric mean (geometric standard deviation) of indoor $\mathrm{H}^{+}$concentrations for daytime samples was $9.7 \mathrm{nmol} / \mathrm{m}^{3}$ (3.6). The small discrepancy from reporting in the earlier paper may be related to the number of samples included in the analysis: 229 in 1994 versus 168 in 1993. In exploring influencing factors, the authors found that, "the accumulation of $\mathrm{NH}_{3}$ indoors was ... the primary determinant of indoor $\mathrm{H}^{+}$... levels." 131

We identified only one study that reports measurements of indoor aerosol strong acidity outside the United States. Chan et al. ${ }^{377}$ used the same sampling system described by Koutrakis et al. ${ }^{363,364}$ to measure indoor and outdoor levels of aerosol strong acidity (among other species) during winter of 1993 in Taipei. The report indicates, albeit with ambiguity, that indoor monitoring was conducted in children's homes: "We monitored 2 days a week in four outdoor sites near the residence of 18 asthmatic children." ${ }^{377}$ Across 101 total indoor samples, the mean \pm standard deviation $\mathrm{H}^{+}$ concentration was $6.0 \pm 13.1 \mathrm{nmol} / \mathrm{m}^{3}$, as compared to $4.6 \pm 11.6 \mathrm{nmol} / \mathrm{m}^{3}$ for the 39 outdoor samples. The indoor/outdoor ratio is summarized to have a geometric mean (geometric standard deviation) of 1.24 (4.17).

Waldman et al. provided a review of the state of knowledge about "human exposures to particle strong acidity" (PSA). ${ }^{378}$ Their assessment found that, "where appreciable PSA exists, virtually all exposures occur in the warmer months, and the highest PSA levels are specifically associated with summertime, regional stagnation periods." They went on to state that, "A number of new studies have shown that the effect of the indoors on human exposures to PSA is entirely protective. That is, there are rarely important sources indoors, and most factors affecting the indoor air quality lead to attenuation of PSA levels." 378 Although reasonable, we would judge that these and other conclusions

This article is protected by copyright. All rights reserved 
in the review by Waldman et al. are stated with too much certainty, given the limited empirical foundation on which they are based.

In the past quarter century, there has only been one further study ${ }^{132}$ to have reported broadly on indoor aerosol strong acidity. Measurements were made of fine-particle strong acidity, again using the sampling system described by Koutrakis et al. ${ }^{363,364}$ The study included 281 homes, with 58 sampled during summer and 223 in winter, in each case for a single 24-h period. All homes were nonsmoking. The summary results for fine-particle associated $\mathrm{H}^{+}$concentrations are reported in Table 24. Comparing the wintertime means, kerosene heater use is seen as a possible contributor to indoor $\mathrm{H}^{+}$concentrations, although not strongly so. Summertime indoor levels are higher than wintertime indoor levels, probably because of the much higher outdoor concentrations during the summer months. The air-conditioned homes exhibit moderately lower indoor $\mathrm{H}^{+}$concentrations than non-air-conditioned homes, a finding consistent with prior studies and with the lower airexchange rates and higher $\mathrm{NH}_{3}$ levels in the air-conditioned homes in this study. The authors expressed an important caution about the data for homes with kerosene heat: "The present study did not measure the elevated residential $\mathrm{H}^{+}$concentrations associated with kerosene heater use that were predicted by the chamber studies. A comparison of indoor winter samples using acid-doped Teflon filters and nondoped Teflon filters in kerosene-heater and nonkerosene-heater homes suggested that substantial amounts of collected strong acidity in homes with kerosene heater use may be neutralized on the Teflon filter in the denuder system used to collect particle acid. The mechanism for this possible neutralization is suspected to be denuder breakthrough of ammonia." 132 They went on to state that "Occupants in homes using kerosene heaters are likely to experience peak exposures (several hours at a time) to $\mathrm{PM}_{2.5}$ and $\mathrm{SO}_{4}{ }^{2-}$ and possibly $\mathrm{H}^{+}$in excess of levels typically experienced outdoors during the summer months."

\subsubsection{Investigations assessing aerosol strong acidity influence on health outcomes}

We identified six major papers that have used epidemiological approaches to assess the relationship between particle strong acidity and adverse health effects. Here, we quote key findings from these

This article is protected by copyright. All rights reserved 
studies. Worth noting is that only one $\mathrm{e}^{379}$ includes any explicit consideration of indoor environmental conditions as an exposure modifying factor. In all other cases, the exposure indicators are based directly on outdoor monitoring results.

Ostro et al. ${ }^{379}$ examined potential associations between acidic aerosols and respiratory symptoms among asthmatics in Denver, Colorado. They reported that, "airborne $\mathrm{H}^{+}$was found to be significantly associated with several indicators of asthma status, including moderate or severe cough and shortness of breath." As a caution, though, they report several shortcomings associated with their efforts to measure $\mathrm{H}^{+}$and so relied upon a combination of measured and imputed values.

Dockery et al. ${ }^{380}$ investigated the relationships among total daily mortality and a suite of air pollution indicators for St. Louis and counties in eastern Tennessee near Kingston and Harriman. They found that total mortality was most strongly associated with the $\mathrm{PM}_{10}$ mass concentrations and concluded that, "these data suggest that the acidity of particles is not as important in associations with daily mortality as the mass concentrations of particles."

Thurston et al. ${ }^{381}$ investigated associations between air pollution indicators and daily hospital admissions for respiratory causes for Toronto, Ontario, and Buffalo, NY. The monitoring period focused on summertime months of July and August. Regarding respiratory admissions on the most polluted days, they concluded that "the relative risk estimated from the highest $\mathrm{H}^{+}$day ... was $1.50 \pm$ 0.25 in Toronto and $1.47 \pm 0.16$ in Buffalo."

Dockery et al. ${ }^{357}$ utilized data from the large monitoring effort summarized in Table 22 to investigate air pollution factors that are associated with respiratory symptoms in children across North America. As noted in the introductory section, they found that "Children living in the community with the highest levels of particle strong acidity were significantly more likely ... to report at least one episode of bronchitis in the past year compared to children living in the least-polluted community." The only other association of note was between fine-particle sulfate and bronchitis.

This article is protected by copyright. All rights reserved 
Raizenne et al. ${ }^{382}$ utilized the same pollutant measurement data to explore the relationship between pulmonary function in children and air pollution. They reported that "a $52 \mathrm{nmol} / \mathrm{m}^{3}$ in annual mean particle strong acidity was associated with a 3.5\% ... decrement in adjusted FVC [forced vital capacity] and a $3.1 \%$... decrement in adjusted $\mathrm{FEV}_{1.0}$ [forced expiratory volume in $1 \mathrm{~s}$ ]." They concluded that the data "suggest that long-term exposure to ambient particle strong acidity may have a deleterious effect on lung growth, development, and function."

Gwynn et al. ${ }^{383}$ used a 2.5-y record (May 1988 - October 1990) of daily measurements of fineparticle $\mathrm{H}^{+}$and sulfate sampled outdoors in Buffalo, NY, to explore associations with "respiratory, circulatory, and total daily mortality and hospital admissions." The overall mean $\mathrm{H}^{+}$concentration in this dataset was $36 \mathrm{nmol} / \mathrm{m}^{3}$, with an interquartile range of $15-42 \mathrm{nmol} / \mathrm{m}^{3}$. The authors reported that ${ }^{\prime} \mathrm{H}^{+}$and $\mathrm{SO}_{4}{ }^{2-}$ demonstrated the most coherent associations with both respiratory hospital admissions ... and respiratory mortality." They concluded that "the associations demonstrated in this study support the need for further investigations into the potential health effects of acidic aerosols."

\subsection{Amines and amino acids}

\subsubsection{Terminology}

Amines can be viewed as ammonia molecules where one or more of the hydrogen atoms have been replaced by an organic group. Here are some examples: monomethyl amine, $\mathrm{NH}_{2}\left(\mathrm{CH}_{3}\right)$; dimethyl amine, $\mathrm{NH}\left(\mathrm{CH}_{3}\right)_{2}$; and trimethyl amine, $\mathrm{N}\left(\mathrm{CH}_{3}\right)_{3}$. Amines can also be formed when a hydrogen on ammonia is replaced by an inorganic group. In this category, as discussed in $\S 3.5 .2$, are the chloroamines: monochloramine $\left(\mathrm{NH}_{2} \mathrm{Cl}\right)$; dichloamine $\left(\mathrm{NHCl}_{2}\right)$; and trichloramine $\left(\mathrm{NCl}_{3}\right)$.

Amino acids are a subgroup of organic amines in which one of the hydrogens has been replaced by an organic substituent that contains a carboxyl functional group (-COOH). Amino acids are numerous. Among the species anticipated to be present indoors are those emitted by humans, 
especially in their sweat. There are 22 "human" amino acids, and these have the general formula $\mathrm{H}_{2} \mathrm{NCHRCOOH}$ (see Figure 17), where the $\mathrm{C}$ attached to the $\mathrm{N}$-atom is referred to as the primary carbon, and the R-group is referred to as the "side chain." The side chain influences the pH and water solubility of an amino acid, ${ }^{384}$ making it a weak acid, a weak base, a hydrophile (in the case of the side chain being polar), or a hydrophobe (nonpolar side chain).

\subsubsection{Amines and amino acids in outdoor air}

3.9.2.1. Amines. Amines are common constituents of outdoor air in both gas and particle phases. The occurrence, chemistry, thermodynamic properties, and toxicity of amines in outdoor air have been reviewed in three articles by Wexler and colleagues. ${ }^{385-387}$ The first of these focuses on sources, fluxes and dynamics. ${ }^{385}$ That review includes a table summarizing sources for more than 150 amines identified in the atmosphere and another table that lists concentrations of amines measured in outdoor air at different sampling sites. Yao et al. ${ }^{388}$ used a high-resolution time-of-flight chemical ionization mass spectrometer to make continuous measurements of C1-C6 amines in Shanghai during the summer of 2015 . The average concentrations ( \pm standard deviation) for the C1-C6 amines were $16 \pm 6,40 \pm 14,1.1 \pm 0.6,15 \pm 8,3.3 \pm 3.7$, and 3.5 \pm 2.2 ppt, respectively. The C1-, C2-, and C4-amines were the most abundant, with concentrations of C2-amines as high as $130 \mathrm{ppt}$. These measurements seem to be representative of outdoor aliphatic amines in the continental troposphere: reported concentrations are typically in the range of single digits to tens of ppt. ${ }^{385,388-390}$ Concentrations of outdoor aliphatic amines tend to be roughly three orders of magnitude smaller than that of outdoor ammonia. Concentration of aromatic amines are more variable and tend to be elevated near industrial sites. ${ }^{385,391}$

Amines are being considered as active reagents with large-scale use in potential carbon capture applications for power plants. Such utilization could result in significant local discharges of amines to the atmosphere. Nielsen et al. ${ }^{392,393}$ have examined the atmospheric chemistry and environmental impact of ethylamine, diethylamine and triethylamine emitted from such carbon capture and storage operations.

This article is protected by copyright. All rights reserved 
Amines are found in airborne particles. ${ }^{385,386,389,394,395}$ Although the lower molecular weight amines are highly volatile, their large water solubility means that they often are present in the liquid water associated with particles. For example, measurements in Ontario, Canada found that dimethylamine and the sum of trimethylamine and diethylamine were present in airborne particles at 0.5-4 $\mathrm{ng} \mathrm{m}^{-3}$, while these same amines were present in the gas-phase at levels of 1-10 ppt. ${ }^{389}$ Higher molecular weight amines have low vapor pressures, large octanol-air partition coefficients and strongly partition to airborne particles. ${ }^{386}$

3.9.2. Amino acids. Amino acids have low vapor pressures ${ }^{396}$ and are anticipated to be found primarily in the condensed phase. These compounds have been identified in atmospheric particles, precipitation, and fog water collected over land and marine surfaces. ${ }^{397-403} \mathrm{Ge}$ et al. ${ }^{385}$ tabulated 32 amino acids that have been identified in 12 different studies of atmospheric particles, rain water and fog water. Arginine, glutamic acid, glycine, serine and valine were identified in all of the studies; alanine was identified in 11 of the 12 studies. In some cases, the identified species included those present in proteins and peptides, as well as "free" amino acids.

\subsubsection{Indoor sources of amines}

Given the presence of amines in outdoor air that ventilates buildings, amines are also common constituents of indoor air, including airborne particles, and in indoor surface films. Indoor sources of amines, in addition to outdoor-to-indoor transport, include smoking; ${ }^{404-408}$ cooking; $274,313,409,410$ anticorrosive agents used in humidification or HVAC units; ${ }^{411-413}$ textiles and textile carpet tiles; 414,415 and the decomposition of casein-containing building materials. ${ }^{416}$ Amines, amino acids, and urea are also known constituents of human skin. ${ }^{417-422}$ These compounds are used as active agents in personal care products, including skin moisturizers. ${ }^{423}$

3.9.3.1. Smoking. Schmeltz and Hoffmann reviewed amines and amino acids identified in tobacco smoke. ${ }^{404}$ Their tabulations included 36 aliphatic amines with one to eight carbons, 40 aromatic

This article is protected by copyright. All rights reserved 
amines including many aniline related species, and 16 amino acids. The 16 amino acids are noteworthy, given their relatively low volatility. $\alpha$-Alanine is the most abundant amino acid. Grimmer et al. measured aromatic amines in mainstream and sidestream cigarette smoke. ${ }^{405}$ The identified amines included 2-aminobiphenyl, 1-aminonaphthalene, 2-aminonaphthalene, 4aminobiphenyl, 2-aminofluorene, 1-aminoanthracene, 9-aminophenanthrene, 2-aminoanthracene, 3-aminofluoranthene, 1-aminopyrene. Per cigarette, sidestream smoke contained about ten times the summed mass of amines as in mainstream smoke. Dolara and co-workers, ${ }^{406}$ using a sensitive mass spectrometry method, also measured amines from mainstream and sidestream cigarette smoke. The summed mass of aniline, 2-toluidine, 3-toluidine, 4-toluidine, 2-ethylaniline, 3ethylaniline, 4-ethylaniline, 2,3-dimethylaniline, 2,4-dimethylaniline, 2,5-dimethylaniline, 2,6dimethylaniline, 1-naphthylamine, 2-naphthylamine, 2-methyl-1-naphthylamine, 2-aminobiphenyl,3aminobiphenyl and 4-aminobiphenyl in mainstream smoke was 0.2-1.3 $\mu \mathrm{g} /$ cigarette, while in sidestream smoke the summed mass was $20-30 \mu \mathrm{g} /$ cigarette. They also measured these and other aromatic amines in homes with and without smoking (see §3.9.4). 407

3.9.3.2. Cooking. Amines are anticipated to be emitted during the cooking of proteinaceous foods, especially meat. However, neither Rogge et al. ${ }^{313}$ nor Schauer et al. ${ }^{274}$ mention simple amines in their detailed studies of organic emissions from meat cooking. Certain heterocyclic aromatic amines are known carcinogens, and, consequently, several studies address their occurrence in cooked food products, especially meat, fish, and poultry. ${ }^{340,409,424}$ However, we have found no studies that have examined the emission of heterocyclic aromatic amines into air during cooking. Chiang et al. targeted aromatic (not heterocyclic) amines in cooking oil fumes. ${ }^{410}$ They found that fumes from heated sunflower oil, vegetable oil and refined lard contained 2-naphthylamine and 4aminobiphenyl.

3.9.3.3. Humidifiers. Amines are used as corrosion inhibitors in systems designed to humidify indoor air. Given their volatility, they can be present in the air of rooms that are humidified by such systems. They can also partition to indoor surfaces in the humidified rooms. Early indoor

This article is protected by copyright. All rights reserved 
measurements were made by NIOSH investigators responding to employee complaints at a Cornell University museum in Ithaca, NY. ${ }^{411,425}$ At this site, diethylaminoethanol (DEAE), also known as diethylethanolamine, was used as a corrosion inhibitor at the time of the investigation. Among 14 samples collected by Fannick et al., DEAE was detected in two, at concentrations of 40 and 50 $\mu \mathrm{g} / \mathrm{m}^{3} .{ }^{411}$ The investigators proposed that some of the complaints resulted from contact with surfaces onto which DEAE had sorbed. Volent and Baer review the Cornell museum case and other cases in which DEAE has been identified in the air of museums with humidification systems. ${ }^{412}$ They state that DEAE can react with acidic pollutants in museum environments to form hygroscopic salts that can accelerate metal corrosion. Edgerton et al. used a trace atmospheric gas analyzer to make continuous measurements of DEAE and cyclohexylamine in a typical steam-humidified room at the Battelle facility in Columbus, $\mathrm{OH} .{ }^{413} \mathrm{At} 42 \% \mathrm{RH}$, the concentration of DEAE and cyclohexylamine were $0.6 \mathrm{ppb}\left(2.9 \mu \mathrm{g} / \mathrm{m}^{3}\right)$ and $0.7 \mathrm{ppb}\left(2.8 \mu \mathrm{g} / \mathrm{m}^{3}\right)$, respectively. At $61 \% \mathrm{RH}$, the concentrations were $2.4 \mathrm{ppb}\left(11 \mu \mathrm{g} / \mathrm{m}^{3}\right)$ for DEAE and $0.8 \mathrm{ppb}\left(3.2 \mu \mathrm{g} / \mathrm{m}^{3}\right)$ for cyclohexylamine. During humidification, sorption to room surfaces was found to be a major sink for these amines, with reported rates of transfer to surfaces as follows: at $42 \% \mathrm{RH}, 12 \mu \mathrm{g} / \mathrm{s}$ for DEAE and $8 \mu \mathrm{g} / \mathrm{s}$ for cyclohexylamine; at $61 \%$ $\mathrm{RH}, 14 \mu \mathrm{g} / \mathrm{s}$ for DEAE and $11 \mu \mathrm{g} / \mathrm{s}$ for cyclohexylamine. Given the volume of the room $\left(218 \mathrm{~m}^{3}\right)$ and an estimated surface area $\left(650 \mathrm{~m}^{2}\right.$, assuming a surface-to-volume ratio of $\left.3 \mathrm{~m}^{2} / \mathrm{m}^{3}\right)$, the corresponding average deposition velocity for these amines to room surfaces would be $\sim 16 \mathrm{~m} / \mathrm{h}, \mathrm{a}$ value that exceeds the likely mass-transport limit. When the humidification system was off, the amines decayed more slowly than would be the case for removal by air exchange, indicating that the amines were desorbing from room surfaces.

3.9.3.4. Textiles and textile carpets. Aniline based dyes are commonly used in textiles. ${ }^{415}$ The extent to which such dyes migrate from clothing to indoor environments is not known. Sollinger et al. ${ }^{414}$ identified almost one hundred organic compounds emitted by ten different textile floor coverings that they evaluated in their climate chamber. Amines included aniline, diethylamine, diphenylamine, dimethylquinoline, and 1,2-dihydro-2,2,4-trimethylquinoline.

This article is protected by copyright. All rights reserved 
3.9.3.5. Casein degradation. Karlsson et al. ${ }^{416}$ investigated indoor levels of amines resulting from the decomposition of casein used in certain building materials such as self-leveling floor-topping putty. The decomposition process can be promoted by the growth of Clostridia under moist, high pH conditions. The amines detected in indoor air samples included triethylamine, pyrrolidine, di-isobutylamine, 2-ethylhexylamine and $n$-octylamine. Concentrations were at ppb scale.

\subsubsection{Indoor amine concentrations}

Although numerous studies have examined the emission of amines from indoor sources, only a few have measured amines in indoor air. $391,406,407,426,427$

The Dolara group measured aromatic amines in outdoor and indoor air at offices and residences in the greater Florence region of Italy. ${ }^{406}$ Aniline and 2-toluidine were above the detection limit in all samples. Aniline ranged from $15 \mathrm{ng} / \mathrm{m}^{3}$ in outdoor air to $190 \mathrm{ng} / \mathrm{m}^{3}$ in a hairdresser's shop with smokers, while 2-toluidine ranged from $2.5 \mathrm{ng} / \mathrm{m}^{3}$ in outdoor air to $17 \mathrm{ng} / \mathrm{m}^{3}$ in a recreation room with smokers. The concentrations of these species were elevated in the office of a nonsmoker adjacent to offices with smokers (aniline, $38 \mathrm{ng} / \mathrm{m}^{3}$; 2-toluidine, $6 \mathrm{ng} / \mathrm{m}^{3}$ ). Other amines whose average concentrations exceeded $2 \mathrm{ng} / \mathrm{m}^{3}$ in smoking environments included 3- and 4-toluidine and 2,3-2,4- and 2,5-dimethylaniline.

The Dolara group made more extensive measurements of aromatic amine concentrations in indoor and outdoor air in nine homes and 22 non-domestic buildings in Florence, Italy. ${ }^{407}$ Five of the homes were occupied by nonsmokers and four by smokers; the non-domestic sampling included both smoking and nonsmoking environments. Researchers focused on ten aromatic amines that they had measured in their earlier study: aniline, the three toluidine isomers (o-, m-, and p-), four dimethylaniline isomers (2,3-; 2,4-; 2,5-; and 2,6-), 2-naphtylamine and 4-aminobiphenyl. Excluding aniline, the summed indoor concentrations of nine of these amines were $5-11 \mathrm{ng} / \mathrm{m}^{3}$ in homes with nonsmokers and $15-34 \mathrm{ng} / \mathrm{m}^{3}$ in homes with smokers. In the non-domestic buildings, summed indoor concentrations of these nine amines were $<20 \mathrm{ng} / \mathrm{m}^{3}$ in environments without smokers and 
tended to be higher with smoking. Aniline concentrations were commonly larger than the sum of the other nine amines and did not correlate with the concentrations of these other amines. Several of the non-domestic settings had aniline levels $>400 \mathrm{ng} / \mathrm{m}^{3}$, including a hospital ward and a hospital waiting room. It was apparent that there were indoor aniline sources other than tobacco smoke.

Zhu and Aikawa ${ }^{426}$ targeted nicotine and seven monoaromatic amines, including aniline, in measurements made in 69 residences in two regions of Canada. Smoking occurred in seven of these homes. Of the targeted compounds, only nicotine and aniline were routinely measured at levels above their detection limits. N-Methylaniline was detected in one home at $23 \mathrm{ng} / \mathrm{m}^{3}$ and was otherwise below its detection limit of $6 \mathrm{ng} / \mathrm{m}^{3}$. N,N-Dimethylaniline, 2-ethylaniline, and 2chloroaniline had detection limits of $9-10 \mathrm{ng} / \mathrm{m}^{3}$, while 4-ethylaniline and 2,4-dichloroaniline had detection limits of $20 \mathrm{ng} / \mathrm{m}^{3}$. None of these amines were detected in any of the homes. Aniline was detected in 26 of the 69 homes, including five of the seven homes with smoking, at concentrations above the detection limit of $7 \mathrm{ng} / \mathrm{m}^{3}$. The highest aniline concentration in a home without smoking was $35 \mathrm{ng} / \mathrm{m}^{3}$, while the highest level in a home with smoking was $58 \mathrm{ng} / \mathrm{m}^{3}$. Among the homes in which aniline was successfully measured, without smoking, the mean concentrations in outdoor and indoor air were equal at $11 \mathrm{ng} / \mathrm{m}^{3}$. The mean aniline concentration was higher in homes with smoking, $34 \mathrm{ng} / \mathrm{m}^{3}$. In one of the homes, shoe polishing was demonstrated to contribute to indoor aniline concentrations.

Akyüz developed an analytical method for measuring amines in air samples and demonstrated the method's applicability for indoor and outdoor sampling during summer and winter months at six locations in Turkey. ${ }^{391}$ The indoor sites included both smoking and nonsmoking areas. In smoking environments, piperazine was measured at mean concentrations of $8 \mathrm{ng} / \mathrm{m}^{3}$ in summer and 22 $\mathrm{ng} / \mathrm{m}^{3}$ in winter. In nonsmoking settings, average concentrations were $5 \mathrm{ng} / \mathrm{m}^{3}$ in summer and 10 $\mathrm{ng} / \mathrm{m}^{3}$ in winter. Corresponding averages for aniline were $6 \mathrm{ng} / \mathrm{m}^{3}$ (summer) and $21 \mathrm{ng} / \mathrm{m}^{3}$ (winter) in smoking environments versus $1 \mathrm{ng} / \mathrm{m}^{3}$ (summer) and $4 \mathrm{ng} / \mathrm{m}^{3}$ (winter) in nonsmoking environments. Summed across 33 reported species (and treating non-detects as zero for this 
exercise), the mean concentrations for summer sampling were $42 \mathrm{ng} / \mathrm{m}^{3}$ in smoking environments, $20 \mathrm{ng} / \mathrm{m}^{3}$ in nonsmoking environments, and $13 \mathrm{ng} / \mathrm{m}^{3}$ outdoors. For winter sampling, analogous results were $117 \mathrm{ng} / \mathrm{m}^{3}$ for smoking environments, $47 \mathrm{ng} / \mathrm{m}^{3}$ for nonsmoking environments, and 35 $\mathrm{ng} / \mathrm{m}^{3}$ outdoors.

Based on this small set of studies, we conclude that amines are commonly much more abundant in smoking than nonsmoking locations. In smoking environments, aniline, methylaniline (also known as toluidine) isomers, butylamine, and piperazine dominate, while in the nonsmoking environments, aniline and the alkylamines dominate. Aniline is typically the most abundant amine indoors. The other amines are substantially less abundant. Amines and amino acids that have been measured or are anticipated to occur indoors are listed with some of their key properties in Tables 25 and 26, respectively.

\subsubsection{Indoor amino acids}

Given the reported presence of amino acids in outdoor airborne particles collected at both marine and land-based locations, ${ }^{385}$ coupled with outdoor-to-indoor transport of such particles, one can anticipate that amino acids are present in particles indoors. Amino acids are present in sweat; $^{421,428,429}$ in corneocytes; ${ }^{422}$ in skin surface films; ${ }^{418}$ and in natural moisturizing factor (NMF), ${ }^{430}$ which plays an important role keeping the stratum corneum hydrated. Hence, we expect these amino acids to be transferred to surfaces that humans contact, and to surfaces soiled with their squames (skin flakes). However, we found no peer-reviewed publications that report measurements of amino acids in either indoor airborne particles or indoor surface films.

Dunstan et al. ${ }^{421}$ have reported amino acid levels in sweat collected from male athletes exercising at $32-34{ }^{\circ} \mathrm{C}$. When the subjects began sweating, the net concentration of amino acids in their sweat was almost $10 \mathrm{mM}$. After 35-40 minutes of exercise, the net concentration in sweat had declined to match the net concentration of amino acids in plasma ( $3 \mathrm{mM})$. That is, the sweat was no longer leaching amino acids from the stratum corneum. This abundance is presumably the lower bound for 
net amino acid concentration in sweat (see Figure 2 of Dunstan et al.). In post-exercise sweat, the most abundant amino acids were histidine $(1.4 \mathrm{mM})$, serine $(1.2 \mathrm{mM})$, ornithine $(1.0 \mathrm{mM})$, glycine $(0.9 \mathrm{mM})$, and alanine $(0.6 \mathrm{mM})$; total amino acid abundance was $8 \mathrm{mM}$. How significant are amino acids in sweat for potential accumulation on indoor surfaces? If an occupant transfers $10 \mathrm{ml}$ of sweat to indoor surfaces (e.g., during or immediately after moderate to vigorous activity), then (0.31) $\times 10^{-4}$ moles of total amino acids would also be transferred. If the average molecular weight of the transferred amino acids is $100 \mathrm{~g} / \mathrm{mol}$, this equates to 3-10 $\mathrm{mg}$ of amino acids being transferred to indoor surfaces - equivalent to the whole-body emissions of ammonia over a period of 1-2 $\mathrm{h}$ approximately 5-10 $\mathrm{h}$. The mass of amino acids transferred to clothing is expected to be substantially larger.

\subsubsection{Acid-base chemistry of amines and amino acids}

Amines are the most abundant organic bases in outdoor air. Through acid-base reactions with sulfuric acid, they play key roles in atmospheric nucleation and particle formation. ${ }^{431-433}$ More generally, they can neutralize strong acids in outdoor air. For example, Shen et al. ${ }^{434}$ found that amines, emitted during the burning of coal in the Yangtze River Delta region of China, react with nitric and sulfuric acid to form aminium salts (the salt that results from an amine reacting with a strong acid). Aminium nitrates were more abundant than aminium sulfates, with average concentrations of methylaminium, dimethylaminium and ethylaminium salts in aerosol particles of $6 \pm 3 \mathrm{ng} \mathrm{m}^{-3}, 8 \pm 5 \mathrm{ng} \mathrm{m}^{-3}$, and $20 \pm 17 \mathrm{ng} \mathrm{m}^{-3}$, respectively. However, ammonium nitrate and ammonium sulfate tended to be 1000 to 10,000 times more abundant than these aminium salts, indicating the much more important role of ammonia as an atmospheric base.

Reviews from the Wexler group discuss amine acid-base chemistry, and much of their discussion is applicable to indoor environments. ${ }^{385,386} \mathrm{Ge}$ et al. ${ }^{386}$ specifically addresses chemical properties of amines, including Henry's law constants, acid dissociation constants, vapor pressures, activity coefficients, solubilities, and solid/gas dissociation constants of their aminium salts. Amines contribute to new particle formation, including sulfuric acid nucleation. ${ }^{385,386,431}$ Reactions with 
strong acids such as $\mathrm{HNO}_{3}, \mathrm{HCl}$ and $\mathrm{H}_{2} \mathrm{SO}_{4}$ form aminium salts. ${ }^{386,435}$ Reactions with ozone or hydroxyl radicals form secondary organic aerosols. ${ }^{385,386,390,435,436}$ Reactions with dicarboxylic acids form amides. ${ }^{385,437}$ Amines can also partition from the gas-phase to airborne particles. ${ }^{438}$

To have an impact on particle formation in outdoor or indoor environments, an amine must compete with ammonia for strong acids. Typically, outdoor ammonia concentrations are three orders of magnitude larger than outdoor amine concentrations, and indoor ammonia concentrations are even larger than those outdoors. This feature likely reduces the influence of amine chemistry indoors. For example, trimethylamine, methylamine, triethylamine, diethylamine, ethylamine, and ethanolamine each react with nitric acid to form aminium nitrate particles, ${ }^{435}$ and the dissociation constants of diethyl- and triethylammonium nitrate were found to be similar to that of ammonium nitrate. Since the indoor concentration of $\mathrm{NH}_{3}$ tends to be about four orders of magnitude larger than that of these amines, reactions between nitric acid and either diethyl- or triethylamine are of negligible importance indoors. Similarly, although Murphy et al. ${ }^{435}$ found that $100 \mathrm{ppb}$ of methylamine displaced $\mathrm{NH}_{3}$ from ammonium sulfate in a low humidity chamber, such displacement is anticipated to be of negligible significance indoors where methylamine is present at ppt levels. Ge et al. ${ }^{386}$ have estimated solid/gas equilibrium dissociation constants for aminium chlorides (see Table 4 of cited reference) and aminium nitrates (Table 5 of cited reference) at various temperatures. Of the various amines in these tables, only ethanol amine, diethanolamine and triethanolamine have dissociation constants small enough - five to six orders of magnitude smaller than those for ammonium chloride or ammonium nitrate - to suggest that they can compete with ammonia for either $\mathrm{HCl}$ or $\mathrm{HNO}_{3}$ in typical indoor environments.

In the few surveys of amines in indoor environments, the dominant compound is aniline. This finding is consistent with the known indoor sources of amines, most of which have higher emission rates of aniline compared to other amines. Aniline's concentration in occupied environments is typically three orders of magnitude smaller than ammonia's, and aniline $\left(\mathrm{p} K_{\mathrm{b}}=9.1\right)$ is much less basic than ammonia $\left(\mathrm{p} K_{\mathrm{b}}=4.8\right)$. Aniline has a larger Henry's law constant, $K_{\mathrm{H}}=530 \mathrm{M} / \mathrm{atm}$, than ammonia, $K_{\mathrm{H}}=$ 
$59 \mathrm{M} / \mathrm{atm} .{ }^{142}$ However, the difference is not large enough to compensate for the differences in basicity and gas-phase concentration. Hence, aniline is likely to have much less of an impact on indoor acid-base chemistry than ammonia.

Given the basicity of amines, their presence in indoor aerosols or aqueous surface films will be influenced by acidic or other basic species in these aerosols or films. Ge et al. ${ }^{386}$ examined partitioning of amines into aqueous aerosols. The extent of this process depends on the $\mathrm{pH}$ of the liquid water present in the aerosol. Partitioning increases as the aerosol acidity increases. They conclude that "For several common amines the tendency to partition to the particle phase is similar to or greater than that of ammonia." ${ }^{386}$ Conversely, increasing basicity decreases partitioning of amines into aerosols or films or onto indoor surfaces. Ongwandee et al. ${ }^{155}$ varied the concentration of $\mathrm{NH}_{3}$ as they measured trimethylamine (TMA) on the surface of zirconium silicate beads. At $20 \%$ $\mathrm{RH}, 10 \mathrm{ppm}$ of $\mathrm{NH}_{3}$ decreased the TMA partition coefficient by $10 \%$ compared to its value in the absence of $\mathrm{NH}_{3}$. At $50 \% \mathrm{RH}, \mathrm{NH}_{3}$ decreased the partition coefficient by about $50 \%$. In a subsequent study, Ongwandee and Morrison found that $\mathrm{NH}_{3}$ at 4 and $40 \mathrm{ppm}$ decreased the capacity of carpet and the painted gypsum board for TMA. ${ }^{156}$ Given that $\mathrm{NH}_{3}$ levels indoors are typically two to three orders of magnitude smaller than the levels employed in these experiments, one anticipates a relatively small impact of $\mathrm{NH}_{3}$ on TMA sorption to materials in ordinary indoor environments.

Destaillats et al. ${ }^{439}$ used attenuated total reflection-FTIR spectroscopy to investigate the rate at which pyridine desorbed from cellulose and gypsum surfaces. Their results indicated that there were at least two sorptive states for pyridine - a chemisorbed state and a physisorbed state - and that there was spectroscopic evidence for acid-base interactions between pyridine and these surrogates for common indoor surfaces.

Amino acids possess both a basic $\mathrm{N}$-atom and an acidic $\mathrm{O}$-atom. In the $\mathrm{pH}$ range between approximately 2 and 9 , the $\mathrm{N}$-atom in a "human" amino acid is protonated with the $\mathrm{H}$-atom from its carboxyl group; the $\mathrm{N}$-atom bears a positive charge while the $\mathrm{O}$-atom bears a negative charge, as

This article is protected by copyright. All rights reserved 
illustrated in Figure 18. The resulting entity is called a zwitterion. In the region around $\mathrm{pH} 2$, the zwitterion is in equilibrium with a meaningful fraction of its conjugate acid, which bears a net +1 charge. In this region the amino acid functions as an acidic buffer. In the region around $\mathrm{pH} 9$, the zwitterion is in equilibrium with a meaningful fraction of its conjugate base, which bears a net -1 charge. In this region, the amino acid functions as a basic buffer. Hence, human amino acids serve as "backstops" for $\mathrm{pH}$ in aqueous solutions, buffering against $\mathrm{pH}$ changes in the region of roughly $\mathrm{pH} 1$ to $\mathrm{pH} 3$ as well as in the region of roughly $\mathrm{pH} 8$ to $\mathrm{pH} 10$.

Water on indoor surfaces is expected to contain aldehydes in addition to amines and amino acids. When water containing such species evaporates, low volatility imidazoles and other nitrogen containing oligomers may form. ${ }^{12}$

\subsection{Nicotine}

\subsubsection{Introduction}

Nicotine $\left(\mathrm{C}_{10} \mathrm{H}_{14} \mathrm{~N}_{2}, \mathrm{MW}=162 \mathrm{~g} /\right.$ mole $)$ is the chemical that makes tobacco use addictive. At an air pressure of $1 \mathrm{~atm}$ and a temperature of $298 \mathrm{~K}, 1 \mathrm{ppb}$ of nicotine is equal to $6.6 \mathrm{\mu g} / \mathrm{m}^{3}$. The chemical structure of nicotine is displayed in Figure 19. It is basic; each of its two nitrogen atoms can accept a proton. At $25^{\circ} \mathrm{C}$, the basicity constants for nicotine are $\mathrm{p} K_{\mathrm{b} 1}=6.0$ and $\mathrm{p} K_{\mathrm{b} 2}=10.6 . .^{440}$ Non-ionized nicotine (Nic), also referred to as free-base nicotine, is volatile, whereas protonated nicotine is not. This means that free-base nicotine, but not its protonated forms, is available to be transported as a gaseous molecule and in this manner can become redistributed among indoor airborne particles, settled dust, exposed surfaces, and human skin. Nicotine is highly water soluble - comparable to nitric acid. Its calculated Henry's law constant is $K_{\mathrm{H}}=3.3 \times 10^{5} \mathrm{M} / \mathrm{atm} .{ }^{142}$

\subsubsection{Indoor emission sources}

The only meaningful source of indoor nicotine is tobacco. Nicotine levels are highest in environments where smoking or vaping occurs. Nicotine can also be brought into nonsmoking, nonvaping environments sorbed to clothing or other materials. Because nicotine sorbs reversibly to 
surfaces, it is persistent indoors. Nicotine that has sorbed to indoor surfaces during smoking can also be released back to indoor air after smoking is terminated.

The proportion of US adults who smoke decreased from $43 \%$ in 1965 to $21 \%$ in 2005 . Cigarette smoking has continued to decline slowly, with a reported prevalence among adults of $14 \%$ in 2017. ${ }^{441}$ Random samples, taken between 1990 and 2014, of almost 15,000 individuals living in 13 European countries indicated that smoking bans have significantly reduced exposures to tobacco smoke both at work and, to a lesser extent, at home. ${ }^{442}$ Today, smoking is banned in many public spaces, schools and offices. Even among those who smoke, the fraction who smoke indoors has decreased. Hence, tobacco smoking as a source of indoor nicotine has decreased substantially during the past decades in the US, in Europe, and in some other regions. However, this strong decline has not prevailed in the developing world, although restrictions on indoor smoking in public spaces are increasing. Meanwhile, electronic cigarette use is rising. ${ }^{443-446}$ In 2016, the usage rates of e-cigarettes among US residents ranged from $2.4 \%$ in Washington, DC, to $6.7 \%$ in Oklahoma. ${ }^{447}$ Some vaping occurs indoors ${ }^{445,448}$ and could affect the abundance of nicotine in indoor environments.

\subsubsection{Impact of nicotine's basicity on partitioning to surfaces and PM}

Typical indoor nicotine levels in homes with moderate to heavy smoking are in the range 0.05-0.5 ppb. Even with such relatively low concentrations, nicotine could have a large effect on the $\mathrm{pH}$ of aqueous solutions, especially if they are otherwise acidic. For example, comparing water in equilibrium with 800 ppm CO $\mathrm{CO}_{2}$ to water in equilibrium with $800 \mathrm{ppm} \mathrm{CO}_{2}$ and $0.5 \mathrm{ppb}$ nicotine, the $\mathrm{pH}$ would increase from 5.46 to 7.57. If the mixture also contains $20 \mathrm{ppb}$ of $\mathrm{NH}_{3}$, the $\mathrm{pH}$ would be 7.12 without nicotine and 7.60 with nicotine. Quantitatively, 0.045 ppb of nicotine neutralizes the influence of $1000 \mathrm{ppm} \mathrm{CO}$. Molecule for molecule, nicotine is roughly 300 times as effective as $\mathrm{NH}_{3}$ in this regard.

This article is protected by copyright. All rights reserved 
Nicotine's basicity can strongly influence the amount of total nicotine (free-base nicotine and monoprotonated nicotine) in the aqueous phase of airborne particles and in liquid water in a room, including on indoor surfaces. Figure 20 shows the ratio of nicotine in the gas phase, $\mathrm{Nic}_{\mathrm{g}}$, to total sorbed nicotine, $\mathrm{NiC}_{\mathrm{aq}}+\mathrm{NicH}^{+}$aq, as a function of $\mathrm{pH}$ for $\mathrm{L}^{*}=1 \times 10^{-5} \mathrm{~L} / \mathrm{m}^{3}$ and for $\mathrm{L}^{*}=1 \times 10^{-2} \mathrm{~L} / \mathrm{m}^{3}$. The ratio $L^{*}=1 \times 10^{-5} \mathrm{~L} / \mathrm{m}^{3}$ is equivalent to a $3.3 \mathrm{~nm}$ aqueous film covering all indoor surfaces in a space whose nominal surface/volume ratio is $3 \mathrm{~m}^{2} \mathrm{~m}^{-3}$. The value $L^{*}=1 \times 10^{-2} \mathrm{~L} / \mathrm{m}^{3}$ is within the normal range for a residence (see Table 1). Because the $\mathrm{p} K_{\mathrm{a}}$ of monoprotonated nicotine is 8.0, at $\mathrm{pH}$ levels above 9 there is little change in the ratio of gas-phase nicotine to total nicotine in the aqueous film at either value of $L^{*}$. Conversely, below a pH of 7, this ratio decreases in a manner that is linear on the logarithmic scales of the plots. In other words, for each unit decrease in $\mathrm{pH}$, the proportion of nicotine that is gaseous at equilibrium decreases by a factor of 10 . At $\mathrm{pH} 5,1.2 \%$ of nicotine is gaseous at $L^{*}=1 \times 10^{-5} \mathrm{~L} / \mathrm{m}^{3}$ and only $0.0012 \%$ is gaseous at $L^{*}=1 \times 10^{-2} \mathrm{~L} / \mathrm{m}^{3}$ (i.e., as the volume fraction of water increases, the fraction of nicotine in liquid water at a given $\mathrm{pH}$ increases). It is apparent from Figure 20 that when nicotine is equilibrated with even a relatively small volume of water with $\mathrm{pH}<6$, the fraction of nicotine in the gas phase is low. For gas-phase nicotine equilibrated with water at an abundance of $L^{*}=1 \times 10^{-2} \mathrm{~L} / \mathrm{m}^{3}$, even at the unusually high $\mathrm{pH}$ of 12 , the amount of nicotine in liquid water would be $80 \times$ as large as the amount in the gas phase. However, the time required for gas phase nicotine to equilibrate with liquid water increases as water's mass per unit area increases. For thick reservoirs of liquid water indoors, there may not be sufficient time to achieve equilibrium.

The partitioning of nicotine to airborne particles is influenced by the $\mathrm{pH}$ of the particle phase in a fashion similar to that for aqueous surface films; however, there are less likely to be kinetic constraints on achieving equilibrium. Pankow ${ }^{449}$ presented an excellent tutorial on the partitioning

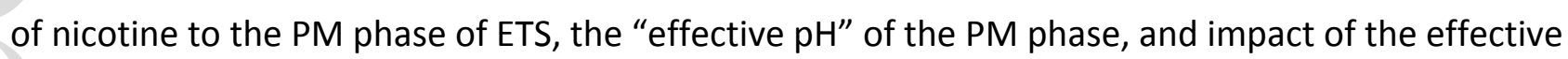

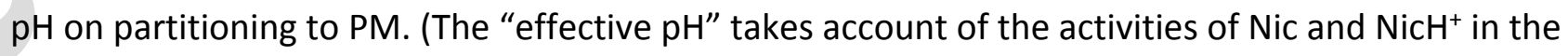
particle phase.) Figure 21 illustrates partitioning of nicotine to the particle phase when the latter is at a lower $\mathrm{pH}$ (Case $\mathrm{A})$ and a higher $\mathrm{pH}$ (Case B). 
It is apparent from Figure 21 that the capacity of indoor PM as a partitioning compartment for total nicotine (free-base plus monoprotonated) increases as the particle $\mathrm{pH}$ decreases. The consequences of such behavior are nicely illustrated in recent papers by DeCarlo et al. ${ }^{14}$ and Collins et al. ${ }^{450}$ DeCarlo et al. describe the use of aerosol mass spectrometry (AMS) to measure constituents of PM in a nonsmoking classroom. The investigators identified a reduced nitrogen compound that constituted almost $30 \%$ of the PM mass at certain times of the year. Although smoking is forbidden in the classroom, the investigators surmise that nicotine enters the room on clothing and from adjacent spaces, partitions to room surfaces, and later partitions from surfaces through the gas phase to fine particles that originated outdoors. The fine particulate matter is strongly acidic ( $\mathrm{pH}$ estimated to range from 0 to 2 ) and this acidity greatly increases its capacity for nicotine. This process requires that an aqueous phase be present in the airborne PM. The phenomenon was observed in the summer when absolute humidity in outdoor air is high, but not in the winter, when absolute humidity in ambient air is low. Controlled laboratory experiments reproduced the process transferring nicotine from ETS to glass walls of a vessel and then to PM of outdoor origin when the relative humidity was high enough for water to constitute a meaningful mass fraction of the PM. In complementary experiments, Collins et al. ${ }^{450}$ measured uptake of constituents in third-hand smoke, previously sorbed to walls of an experimental chamber, to particles consisting of either ammonium sulfate, ammonium bisulfate, sodium sulfate, squalene, or sucrose. Changes in the composition of the aerosol particles were monitored using an AMS. Signals characteristic of nicotine and other reduced nitrogen compounds are clearly apparent in the AMS spectra of the aged aqueous ammonium sulfate and ammonium bisulfate particles, but less so for the other particles. Furthermore, third-hand smoke constituents partitioned to aqueous ammonium sulfate much faster than they partitioned to solid ammonium sulfate. Three hours after the initial "seed" PM was injected, reduced nitrogen compounds accounted for $\sim 30 \%$ of the total organic matter accumulated by aqueous ammonium sulfate and ammonium bisulfate particles, but less than $10 \%$ of the organic mass accumulated by aqueous sodium sulfate or solid ammonium sulfate particles. Quoting the authors: "Temporal trend analysis along with the more general comparison with neutral pH seed 
aerosol (i.e., sodium sulfate) suggest that the uptake of $\mathrm{C}_{x} \mathrm{H}_{y} \mathrm{~N}_{z}$ compounds responded dynamically to aerosol pH." 450

This discussion has focused on the partitioning of nicotine to surface water and bulk water, including the aqueous phase of aerosol particles. However, non-ionized nicotine can also partition to organic matter in airborne particles or settled dust and to organic films on indoor surfaces. A question for future exploration is how partitioning to aqueous surface films and condensed water compares to partitioning to indoor organic films. ${ }^{158}$

\subsubsection{Gas-phase nicotine concentrations indoors}

Leaderer and Hammond ${ }^{451}$ made one-week measurements of vapor-phase nicotine and airborne particle mass in 96 homes in New York state. For all homes, nicotine concentrations were in the range $0-10 \mu \mathrm{g} / \mathrm{m}^{3}(0-1.5 \mathrm{ppb})$, with an average gas-phase concentration of $1.1 \mu \mathrm{g} / \mathrm{m}^{3}(0.17 \mathrm{ppb})$. For homes with nicotine levels above the detection limit $(n=47)$, the average gas-phase concentration was $2.2 \mu \mathrm{g} / \mathrm{m}^{3}$ (0.33 ppb). Similar ranges of gas-phase concentrations were reported by Coultas et al., ${ }^{452}$ with average indoor nicotine concentrations spanning 0.6 to $6.9 \mu \mathrm{g} / \mathrm{m}^{3}$ (0.1-1.0 ppb) in ten smokers' homes. From a study conducted in Munich, Scherer et al. ${ }^{453}$ reported mean concentrations of nicotine in the living room at about $4 \mu \mathrm{g} / \mathrm{m}^{3}(0.6 \mathrm{ppb})$ in 20 smokers' homes, about $200 \times$ as large as the mean for ten nonsmoking homes.

Matt et al. ${ }^{454}$ used passive samplers to measure gas-phase nicotine concentrations in San Diego County homes with infants of mothers who did or didn't smoke. The study sites included three groups: "no exposure" ( $n=17$ households) with non-smoking mothers and no indoor smoking; "indirect exposure" ( $n=13$ ) with maternal smokers but no indoor smoking; and "direct exposure" $(n$ $=15$ ), with maternal smokers and unrestricted indoor smoking. The indoor air nicotine levels varied systematically across the three groups households, with geometric means reported for both living rooms and the infant's bedroom. For the no exposure group, levels were $0.10 \mu \mathrm{g} / \mathrm{m}^{3}(0.015 \mathrm{ppb})$ in the living room and $0.09 \mu \mathrm{g} / \mathrm{m}^{3}(0.014 \mathrm{ppb})$ in the infant's bedroom. For the indirect exposure group, 
geometric mean concentrations were $0.32 \mu \mathrm{g} / \mathrm{m}^{3}(0.048 \mathrm{ppb})$ in the living room and $0.23 \mu \mathrm{g} / \mathrm{m}^{3}$ $(0.035 \mathrm{ppb})$ in the infant's bedroom. The direct exposure group had geometric mean concentrations of $2.6 \mu \mathrm{g} / \mathrm{m}^{3}(0.39 \mathrm{ppb})$ in the living room and $1.5 \mu \mathrm{g} / \mathrm{m}^{3}(0.23 \mathrm{ppb})$ in the infant's bedroom.

Gehring et al. ${ }^{455}$ measured nicotine concentrations in the homes of 347 German and 335 Dutch children using passive samplers. In homes with a light to moderate smoker ( $\leq 5$ cigarettes/day), the median nicotine concentrations were $0.59 \mu \mathrm{g} / \mathrm{m}^{3}$ (0.089 ppb) in Germany and $0.25 \mu \mathrm{g} / \mathrm{m}^{3}(0.038$ $\mathrm{ppb}$ ) in the Netherlands. In homes with a heavier smoker ( $\geq 5$ cigarettes/day) the median nicotine concentrations were $1.4 \mu \mathrm{g} / \mathrm{m}^{3}(0.21 \mathrm{ppb})$ in Germany and $0.65 \mu \mathrm{g} / \mathrm{m}^{3}(0.098 \mathrm{ppb})$ in the Netherlands. A Korean study ${ }^{456}$ reported a median concentration of $3.2 \mu \mathrm{g} / \mathrm{m}^{3}(0.49 \mathrm{ppb})$ in ten homes with smokers consuming $\geq 6$ cigarettes/day. In summary, in homes where no smoking occurs and no smokers live, gas-phase nicotine levels tend to be less than about $0.1 \mu \mathrm{g} / \mathrm{m}^{3}$; in homes with moderate smoking, nicotine levels are commonly between 0.3 and $1 \mu \mathrm{g} / \mathrm{m}^{3}$; and in homes with heavy smoking, levels are between 1 and $5 \mu \mathrm{g} / \mathrm{m}^{3}$.

\subsubsection{Nicotine in indoor settled dust}

At $25^{\circ} \mathrm{C}$, nicotine's vapor pressure is reported to be $0.11 \mathrm{~mm} \mathrm{Hg}(15 \mathrm{~Pa})^{457}$ and 6 Pa. ${ }^{458}$ Its log $\left(K_{\text {oa }}\right)$ value has been calculated to be $8.1 .{ }^{459}$ Nicotine's partitioning to airborne particles and settled dust, if water contents are low, is expected to be dominated by sorption to weakly polar organic matter in the particles or dust, and can be estimated using the octanol-air partition coefficient $\left(K_{\text {oa }}\right)$. When this condition holds, a semivolatile compound's dust/gas partition coefficient $\left(K_{d}\right)$ is expected to be lower than the particle/gas partition coefficient $\left(K_{\mathrm{p}}\right)$, with reported central tendencies of $K_{\mathrm{d}} / K_{\mathrm{p}}$ being 0.12 and $0.25 .{ }^{460,461}$ Based on several studies, in environmental tobacco smoke (ETS), 95\% of indoor airborne nicotine is gaseous (Leaderer and Hammond ${ }^{451}$ and references therein). Typical indoor particle concentrations are lower than particle levels in smoking environments, which would further favor nicotine's presence in the gas phase. However, indoor particles may have a larger water content and lower pH than the particle phase of ETS. Hence, it is difficult to estimate the fraction of airborne nicotine that is gaseous in indoor environments without active smoking.

This article is protected by copyright. All rights reserved 
Regardless, nicotine is often detected in samples of household dust. The total amount of nicotine in dust or particles is expected to be enhanced if the dust is acidic and if there is sufficient associated water for ionization to occur.

Matt et al. ${ }^{454}$ collected vacuumed floor dust samples from the same San Diego homes where they measured gas-phase nicotine with passive samplers. In the 13 homes with indirect exposure, the geometric mean nicotine levels in dust were $1.8 \mu \mathrm{g} / \mathrm{m}^{2}$ in the living room and $0.7 \mu \mathrm{g} / \mathrm{m}^{2}$ in the infant's bedroom. Corresponding results in the 15 homes with direct exposure were $6.9 \mu \mathrm{g} / \mathrm{m}^{2}$ in the living room and $5.4 \mathrm{\mu g} / \mathrm{m}^{2}$ in the infant's bedrooms.

Willers et al. ${ }^{462}$ collected dust samples from the homes of 23 children with asthma using two different methods. Among these households, $n=8$ had no current household ETS exposure, based on self-report, whereas $n=15$ were classified as having current (within last 6 months) ETS exposure. Samples from vacuum cleaner bags had a median nicotine mass fraction of $31 \mu \mathrm{g} / \mathrm{g}$ for the nocurrent-exposure group as compared to $121 \mu \mathrm{g} / \mathrm{g}$ for the exposure group. For dust samples collected from household surfaces, the median nicotine level was $20 \mu \mathrm{g} / \mathrm{g}$ for the unexposed and $212 \mu \mathrm{g} / \mathrm{g}$ for the exposed groups. They found that urinary concentrations of cotinine, a nicotine metabolite, were strongly associated with the mass fraction in dust.

Kim et al. ${ }^{463}$ collected dust samples from 37 Baltimore homes. Among the 7 homes that were selfreported as nonsmoking, the median mass fraction in dust was $12 \mu \mathrm{g} / \mathrm{g}$. Among the 30 homes selfreported as smoking, the median was $43 \mu \mathrm{g} / \mathrm{g}$. They found a significant association between the mass fraction of nicotine in dust and the self-reported number of cigarettes smoked per day per home. In contrast, they did not find such an association for gas-phase nicotine, nor did they find an association between gas-phase nicotine and mass fraction in dust.

Whitehead et al. ${ }^{464}$ measured total nicotine in dust samples collected from 469 homes in Northern California during the period 1999-2007. In homes where no one had smoked in the month prior to 
dust collection $(n=446)$, the median mass fraction of nicotine in dust was $0.26 \mu \mathrm{g} / \mathrm{g}$. In homes where smoking had occurred $(n=21)$, the median mass fraction was $1.26 \mu \mathrm{g} / \mathrm{g}$. Based on concurrently self-reported household cigarette smoking, the authors concluded that the mass fraction of nicotine in indoor dust was a reasonable surrogate for indoor smoking.

In dust samples collected in 2008 from 490 bedrooms of Danish children, the median mass fraction of nicotine was $1.1 \mu \mathrm{g} / \mathrm{g} .{ }^{465} \mathrm{In}$ the homes of smokers ( $\left.n=119\right)$, the median level was $6.6 \mu \mathrm{g} / \mathrm{g}$, while in the home of nonsmokers $(n=371)$ the median level was $0.53 \mu \mathrm{g} / \mathrm{g}$. It is instructive to compare these values to an earlier study of dust samples collected in 72 Danish homes in 1989.466 In that study, the median level in all homes was $50 \mu \mathrm{g} / \mathrm{g}$; it was $242 \mu \mathrm{g} / \mathrm{g}$ in the homes of smokers $(n=34)$ and $18 \mu \mathrm{g} / \mathrm{g}$ in the homes of nonsmokers $(n=38)$. While there are likely multiple factors responsible for the lower levels in 2008 compared to 1989, these results are consistent with a decrease, among smokers with children, of smoking inside their homes. When comparing the homes of nonsmokers, the lower levels in 2008 may partially reflect less nicotine exposure outside the home and subsequently less nicotine brought into the home sorbed to clothing.

\subsubsection{Nicotine on indoor surfaces}

As the abundance of water on or in a surface increases and as a surface becomes more acidic, its capacity for total nicotine (free-base and monoprotonated) increases (Figure 20). Only non-ionized nicotine partitions between a surface and the gas phase.

Several studies have examined the sorption of nicotine to indoor surfaces. Van Loy et al. ${ }^{467}$ reported the sorption of nicotine to the surfaces of a $20-\mathrm{m}^{3}$ stainless-steel chamber with $45.2 \mathrm{~m}^{2}$ of nominal surface area. They found that the amount of nicotine in the gas phase was small compared to that sorbed on chamber walls. For example, at a gas-phase concentration of $33 \mu \mathrm{g} / \mathrm{m}^{3}$, the surface level was $660 \mu \mathrm{g} / \mathrm{m}^{2}$ indicating that $98 \%$ of the nicotine was sorbed to chamber surfaces. In a follow-up study, Van Loy et al. ${ }^{468}$ measured the dynamics of nicotine and phenanthrene sorbing to and desorbing from three different surface materials: stainless steel, a deep pile nylon carpet and 
gypsum wallboard covered on one side with latex paint. The results were reported, in part, in terms of a partitioning coefficient, representing the sorbed surface density (mass sorbed per area of sorbent) normalized by the gas-phase concentration. The partitioning coefficient of stainless steel for sorbed phenanthrene was about 3.6 times as large as for sorbed nicotine. Remarkably, however, for nylon carpet and painted gypsum board, partitioning coefficients for nicotine were 2-3 orders of magnitude greater than for phenanthrene. Van Loy et al. ${ }^{468}$ did not address the underlying reason for these differences. At the relative humidities of these experiments, the amount of water on the stainless-steel surface is anticipated to be small while that on and within the deep pile nylon carpet and gypsum wallboard is likely large, since both of these materials are hygroscopic, and gypsum wallboard is porous; ${ }^{40,469}$ see $§ 2.4$. Hence, the larger capacity of nylon carpet and gypsum board for nicotine compared to phenanthrene may be partially due to the higher water solubility of nicotine. The $\mathrm{pH}$ of sorbed water may also play a role if the $\mathrm{pH}$ of water in the carpet and gypsum board is lower than about 7 (see Figure 20). However, as already noted, if the water content of the carpet or gypsum board is large enough, the fraction of nicotine in the material will be much larger than nicotine's gaseous abundance, independent of $\mathrm{pH}$. It may also be that relatively polar nylon carpet and gypsum board more strongly sorb polar nicotine compared to nonpolar phenanthrene, regardless of the sorbed water content.

In studies conducted in a 50- $\mathrm{m}^{3}$ room that was variably furnished, Singer and colleagues examined the influence on airborne concentrations of sorptive partitioning of nicotine and other gas-phase organics associated with tobacco smoke. ${ }^{470,471}$ Unsurprisingly, they found that for otherwise identical conditions, the sorptive loss of nicotine was largest in a fully furnished room, less in a room with just wallboard and carpet, and even less is in a room with only wallboard. ${ }^{470}$ Most of the nicotine emitted from cigarettes remained sorbed to room surfaces three days after smoking. Singer et al. ${ }^{471}$ introduced the metric exposure relevant emission factor (EREF) that implicitly accounts for sorptive uptake and reemission to give the net mass of individual ETS constituents available for inhalation exposure over a day in which smoking occurs according to a representative indoor pattern. For nicotine, the EREF decreased with decreasing ventilation rate, suggesting continued

This article is protected by copyright. All rights reserved 
sorptive uptake by the indoor surfaces over the duration of the experiments. Sorption reduced nicotine concentration during the smoking period and increased its concentration during nonsmoking periods, "resulting in fractionally higher indirect exposures." 471 When evaluating exposure to gas-phase constituents of ETS, nicotine, as a strongly sorbing constituent, is a poor surrogate for weakly sorbing constituents. Furthermore, given that the sorptive capacity of a surface for nicotine can be influenced by $\mathrm{pH}$, it is a poor surrogate for other gas-phase constituents of ETS that do not ionize and are not affected by $\mathrm{pH}$.

In a related experiment, twenty volatile organics were rapidly vaporized into the fully furnished 50$\mathrm{m}^{3}$ room and their gas-phase concentrations were measured during a sorption period, a flush period, and a desorption period. ${ }^{459}$ Nicotine sorbed quickly, with $99 \%$ sorbed to room surfaces within two hours of initial introduction. During the flush period, nicotine's gas-phase concentration declined, but only a small fraction of nicotine's total mass in the room was removed during flushing. Nicotine returned to a gas-phase concentration that was close to its pre-flush level when the room was resealed.

Matt et al. ${ }^{454}$ measured nicotine levels on surfaces in the San Diego homes where they also measured gas-phase and dust-associated nicotine. For the no-exposure group, nicotine was below the detection limit on all sampled surfaces. For the indirect exposure group, the $40-50 \%$ of samples were quantifiable. Considering only quantifiable samples, geometric means for surface-associated nicotine levels were $10 \mu \mathrm{g} / \mathrm{m}^{2}$ in the living room and $8 \mu \mathrm{g} / \mathrm{m}^{2}$ in the infant's bedroom. In the direct exposure group, $90 \%$ of the samples were quantifiable and the geometric mean nicotine surface levels for those samples were $51 \mu \mathrm{g} / \mathrm{m}^{2}$ in the living room and $42 \mu \mathrm{g} / \mathrm{m}^{2}$ in the infant's bedroom. The paper does not discuss whether these surface levels include the contribution from dust on the sampled surfaces.

In simulating a typical residence, using sorption parameters obtained from previous chamber experiments, Klepeis and Nazaroff estimated that in a room with chronic smoking it would take 
more than five years for surface nicotine levels to plateau. ${ }^{472}$ The extensive sorption of nicotine to typical indoor surfaces indicates that in rooms where smoking regularly occurs, the surfaces remain a strong source of nicotine for extended periods after smoking has ceased. ${ }^{473}$ Given that the capacity of a material for nicotine increases as the $\mathrm{pH}$ of water in the material decreases, acidic sorptive materials are anticipated to require more time to equilibrate with ETS nicotine and to remain strong sources of nicotine for longer periods than sorptive materials that are chemically basic.

Secondhand smoke is a mixture of sidestream smoke from tobacco combustion and mainstream smoke exhaled by a smoker. ${ }^{474}$ Residual constituents of secondhand smoke that sorb to exposed indoor surfaces, including settled dust, are often referred to as thirdhand smoke (THS). ${ }^{14,197,450,474-476}$ As noted, the $\mathrm{pH}$ of sorbing surfaces can influence the capacity for nicotine and other chemically basic reduced-nitrogen constituents of thirdhand smoke (e.g., amines). Spectroscopic measurements indicate that sorbed nicotine and amines are present on surfaces primarily as the monoprotonated species rather than the neutral species, ${ }^{439,477}$ consistent with their basicity. The amount of nicotine on a surface is relevant to health concerns, because, among other reasons, sorbed nicotine can subsequently react with indoor nitrous acid (HONO) to generate carcinogenic nitrosoamines that would otherwise not be present. ${ }^{197}$ It can also react with ozone, with a half-life of $~ 6$ days at $40 \mathrm{ppb}$

$\mathrm{O}_{3}$, to generate various oxidation products including formaldehyde, $\mathrm{N}$-methylformamide, nicotinaldehyde, cotinine, myosmine, and nicotyrine. ${ }^{478,479}$ Given that $\mathrm{pH}$ plays a significant role in nicotine's sorption to surfaces, a related issue for future study is how the reactivity of non-ionized nicotine compares to that of monoprotonated nicotine.

\subsubsection{Nicotine's displacement by ammonia}

As discussed in §3.2.8, ammonia can influence the partitioning of nicotine between the gas phase and indoor surfaces. Introducing ammonia into a room whose surfaces were previously exposed to nicotine can promote the desorption of a fraction of the nicotine from the surfaces. ${ }^{154,157}$ This feature could be consequential for inhalation exposures of people who use ammonia-based cleaners in indoor environments where smoking has occurred.

This article is protected by copyright. All rights reserved 


\section{SURFACES AND SUBSTRATES}

Surfaces and substrates have a much larger impact on chemistry indoors than in outdoor environments. ${ }^{480,481}$ Despite their importance, indoor surfaces and interfaces are poorly defined, especially porous materials such as wood, gypsum board, paint films, vinyl, and carpets. While there is a large body of literature addressing chemistry and catalysis on ideal surfaces, there is a dearth of such information for real-world surfaces. Hence, the information summarized in this section is not as strongly grounded in physical science as that in the previous sections of this review. Despite this limitation, we aim to provide the reader with a clear sense of what is currently known and call out areas that warrant further investigation.

\subsection{Introduction}

Indoor surfaces influence the concentrations, dynamic behaviors, and fates of indoor acids and bases. Gas-phase acids and bases partition to surfaces; acidic and basic constituents of airborne particles deposit on surfaces; acid-base chemistry occurs on surfaces.

When we speak of surfaces, we are referring to the exposed surfaces of building materials, coatings and furnishings, as well as surfaces within these materials that are accessible to indoor air via relatively rapid mass transport. We include the air-surface interface of bulk water and organic films. Indoor surfaces should be understood to have a third dimension, i.e. a thickness that is generally much smaller than the areal dimensions but may be much larger than molecular scale. Scientifically, the extent of surface thicknesses that can interact meaningfully with indoor air composition remains not well resolved. It certainly varies with material properties, such as porosity, permeability, and viscosity. The thickness also varies with the time scales of concern, as the time needed for diffusive transport through a thin layer of a homogeneous substance scales with the inverse square of the layer's thickness. Near one end of the range of possibilities, an organic film on an impermeable indoor surface with a thickness of $\sim 50 \mathrm{~nm}$ would likely be fully accessible to interact with gaseous species without meaningful transport restrictions. A permeable and porous paint layer of 50-100 
$\mu \mathrm{m}$ thickness might also be substantially accessible. ${ }^{482}$ On the other hand, the materials that comprise gypsum wallboard, with typical overall thickness of $13 \mathrm{~mm}$, might not be fully accessible to interact with gaseous species indoors because of lengthy transport times, even though the material is porous and somewhat permeable. For low-porosity and highly impermeable materials, such as tile and glass, the scale of interaction of gaseous species with indoor surfaces may only extend through a few molecules thickness into the surface because of the slow molecular diffusivity into such solids.

In a typical room, indoor surfaces comprise floor, walls, ceiling and furnishings. Through airexchange with hidden spaces, other materials such as wood framing and insulation may also influence indoor air pollutant dynamic behavior. The surface in contact with room air may differ from the underlying material that constitutes the bulk of the floor, walls or ceiling. Wood floors are frequently varnished; concrete floors are often covered by tiles or synthetic flooring (e.g., vinyl, linoleum, laminate), and synthetic floors may be polished, waxed or coated with a polymer. Some floors are partially or completely covered with carpeting. Walls are commonly painted or papered. In China, walls are often "limed," i.e. coated with layers of aqueous $\mathrm{Ca}(\mathrm{OH})_{2}$. External walls have windows, which may have adjustable coverings, such as blinds, shades or drapery. Ceilings may be painted or may be finished with ceiling tiles. Occupants also contribute to indoor surfaces with their clothing, skin, and hair.

\subsection{Surface-to-volume ratios}

An important feature of indoor environments is the high ratio of surface area to volume of air in contact with those surfaces. Surface-to-volume ratios $(S / V)$ are orders of magnitude larger indoors than outdoors. Hence, processes that are impacted by surfaces are of much greater consequence indoors than outdoors. Two moderate-scale studies plus several smaller ones have reported surveyed surface-to-volume ratios. Hodgson et al. ${ }^{23}$ measured $S / V$ in 33 rooms (bathrooms, bedrooms/offices and common rooms such as kitchens or living rooms) in nine residences in San Francisco, CA. All objects with a surface area $>300 \mathrm{~cm}^{2}$ were included in these surveys. Surface areas were based on shape and dimensions, but did not attempt to adjust for fleeciness, roughness or

This article is protected by copyright. All rights reserved 
porosity. The average \pm standard deviation $S / V$ values for all rooms was $3.6 \pm 1.0 \mathrm{~m}^{2} \mathrm{~m}^{-3}$. Bathrooms $(n=7)$ averaged $4.9 \pm 0.3 \mathrm{~m}^{2} \mathrm{~m}^{-3}$; bedrooms/offices $(n=14)$ averaged $3.7 \pm 0.9 \mathrm{~m}^{2} \mathrm{~m}^{-3}$; and common rooms $(n=12)$ averaged $2.8 \pm 0.3 \mathrm{~m}^{2} \mathrm{~m}^{-3}$. More recently, Manuja et al. ${ }^{25}$ measured $S / V$ ratios in ten bedrooms, nine kitchens and three offices in Blacksburg, VA. Including contents, the average \pm standard deviation $S / V$ values for all rooms was $3.2 \pm 1.2 \mathrm{~m}^{2} \mathrm{~m}^{-3}$; offices averaged $3.6 \pm 0.4 \mathrm{~m}^{2} \mathrm{~m}^{-3}$; bedrooms $3.0 \pm 0.4 \mathrm{~m}^{2} \mathrm{~m}^{-3}$; and kitchens $3.2 \pm 1.8 \mathrm{~m}^{2} \mathrm{~m}^{-3}$. These two studies considered only macroscopic surface area. Neither attempted to account for the additional area associated with rough (e.g., carpeted) or porous surfaces (e.g., wood, paint, polymers). Microscopic surface area is anticipated to be much larger than these reported $S / V$ values. As one illustration of the scale of effect that might be expected, Morrison and Nazaroff reported that the microscopic surface area of carpet samples exceeded the floor area covered by factors of 30 and 33 for two commercial loop carpets and by factors of 46 and 66 for two residential, cut-pile carpets. ${ }^{483}$

The surface area of indoor airborne particles contributes negligibly to total indoor surface area. Consider a $30 \mathrm{~m}^{3}$ room with a total superficial surface area of $95 \mathrm{~m}^{2}$. An extensive dataset for outdoor air pollution collected in the Ruhr Valley, Germany, found a median $\mathrm{PM}_{10}$ concentration of $20 \mu \mathrm{g} / \mathrm{m}^{3}$ and a median lung-deposited particle surface area concentration of $36 \mu \mathrm{m}^{2} / \mathrm{cm}^{3}{ }^{484}$ Using this surface area concentration as a magnitude estimate for indoor environments, the corresponding total particle-associated surface area in the $30 \mathrm{~m}^{3}$ room would be $\sim 10^{-3} \mathrm{~m}^{2}$, or about 5 orders of magnitude smaller than the superficial area associated with the fixed interior surfaces.

\subsection{Prevalence of indoor surface materials}

Two surveys of indoor surface materials important for moisture uptake and humidity buffering were mentioned in $\$ 2.4 . .^{33,48}$ In addition to surface-to-volume ratios, Hodgson et al. ${ }^{23}$ and Manuja et al. ${ }^{25}$ catalogued the different materials that constituted the surfaces in their surveyed environments. These material descriptions were used by Hodgson et al.: metal, glass, ceramic/porcelain/tile, finished wood, unfinished wood, painted wood, PVC, other plastic, painted/papered plaster and wallboard, thin fabrics, upholstery/carpet, and paper. Finished/painted surfaces accounted for a

This article is protected by copyright. All rights reserved 
substantial fraction of total surface area in all room types: finished wood with median contributions of $0.54 \mathrm{~m}^{2} \mathrm{~m}^{-3}$ (18\% of the sum of the medians) in common areas, $0.73 \mathrm{~m}^{2} \mathrm{~m}^{-3}(19 \%)$ in bedroom/offices, and $0.26 \mathrm{~m}^{2} \mathrm{~m}^{-3}(5 \%)$ in bathrooms; painted wood with median contributions of $0.38 \mathrm{~m}^{2} \mathrm{~m}^{-3}(13 \%)$ in common areas, $0.34 \mathrm{~m}^{2} \mathrm{~m}^{-3}(9 \%)$ in bedroom/offices, and $0.44 \mathrm{~m}^{2} \mathrm{~m}^{-3}(9 \%)$ in bathrooms; painted/papered plaster and wallboard accounted for a substantial fraction of total surface area in all room types, with median contributions of $1 \mathrm{~m}^{2} \mathrm{~m}^{-3}$ (33\% of the sum of the medians) in common areas, $1.2 \mathrm{~m}^{2} \mathrm{~m}^{-3}(31 \%)$ in bedroom/offices, and $1.6 \mathrm{~m}^{2} \mathrm{~m}^{-3}(31 \%)$ in bathrooms. Impermeable surfaces were extensive in bathrooms, with median $S / V$ for metal, glass, ceramic, porcelain and tile summing to $1.3 \mathrm{~m}^{2} \mathrm{~m}^{-3}$ (27\%). Such impermeable surfaces were less abundant in common areas and bedrooms with median $S / V$ values of $0.16 \mathrm{~m}^{2} \mathrm{~m}^{-3}(5 \%)$. In all room types, vinyl (PVC) and other plastic surfaces had median S/V values of $0.38-0.98 \mathrm{~m}^{2} \mathrm{~m}^{-3}(13-20 \%)$, whereas textiles and fibrous materials (carpets, fabrics, and upholstery) had median $S / V$ values of 0.45-0.55 $\mathrm{m}^{2} \mathrm{~m}^{-3}(9-15 \%)$.

Manuja et al. ${ }^{25}$ used somewhat different material categories: cardboard, concrete, fabric/fiber, glass, metal, paint, paper, plastic, wood (stained), or other. The dominant material was paintcovered surfaces ( $42 \pm 14 \%$ of total surface area), chiefly walls and ceilings, followed by stained wood ( $22 \pm 12 \%$ of total surface area). Fabric/fiber surfaces were abundant in bedrooms; plastic and metal surfaces were abundant in offices and kitchens. Glass surfaces comprised a small proportion of total surface area. Exposed concrete contributed slightly to indoor surfaces in kitchens and was barely present in bedrooms and offices.

It is noteworthy that together painted surfaces and stained/finished-wood surfaces accounted for almost two-thirds of the surfaces in the rooms evaluated in these two studies. The substrates beneath the paint are often gypsum wallboard or pressed wood composites (e.g., plywood, oriented strand board, medium density fiberboard). In these cases, both the paint ${ }^{482}$ and the substrate are somewhat permeable, suggesting that painted surfaces and stained wood could serve as substantial sinks for gas-phase species that interact strongly with their chemical constituents. As summarized in 
$\S 2$, at $50 \% \mathrm{RH}$ the moisture content (mass of water per mass of dry sorbent) of painted gypsum board is $0.5-1.1 \%$, while that of wood is notably higher, at $8-10 \%$. The abundance of such permeable surfaces with significant moisture content may help explain the large indoor reservoirs that are seen for nitrous, formic and acetic acid, as discussed below.

Human occupants can contribute meaningfully to the total surface area of the rooms they occupy, and acid-base chemistry can occur on exposed skin, hair and clothing. A typical adult has a total body surface area (BSA) of approximately $2 \mathrm{~m}^{2} .{ }^{485}$ If two adults occupy a $30-\mathrm{m}^{3}$ room with an $S / \mathrm{V}$ of $3.5 \mathrm{~m}^{2}$ $\mathrm{m}^{-3}$, the human surfaces contribute about $4 \mathrm{~m}^{2}(4 \%)$ to the total surface area. Skin and hair are covered by surface lipids, about $25 \%$ of which are organic acids. ${ }^{319}$ Human skin has a $\mathrm{pH}$ in the range of 4.5 to $6 .{ }^{486,487}$ Bodies are most commonly clothed; certain fabrics in clothing can have substantial moisture content at typical indoor humidity. For example, at $50 \% \mathrm{RH}$, the equilibrium moisture contents of nylon, cotton and wool are approximately $3 \%, 5 \%$, and $10 \%$, respectively (Table 4).

As discussed in $\S 2$, water sorbs to indoor surfaces. When impermeable surfaces have water coverage larger than about five equivalent monolayers, the nature of the surface interacting with room air is closer to that of water than that of the underlying substrate.

Given the importance of surface interactions influencing indoor air constituents, including gaseous acids and bases, the limited available evidence from surveys of indoor surface materials is striking. Surveys similar to those undertaken by Hodgson et al. ${ }^{23}$ and Manuja et al. ${ }^{25}$ are needed in homes, schools and offices in other US cities and in other countries. It would be especially valuable to have results from such surveys conducted in different cultures with large populations and high population densities, such as China and India.

\subsection{Soiling}

All surfaces become soiled. Three processes are primarily responsible for soiling: contact transfer by occupants (including pets), partitioning of semivolatile species from the gas phase, and particle 
deposition. Whereas partitioning and particle deposition impact all exposed surfaces, contact transfer only influences surfaces that are commonly touched by occupants (e.g., portions of floors, furniture, phones, keyboards, touchscreens). As a consequence of contact, chemicals are transferred from a surface to occupants, ${ }^{488,489}$ and also from occupants to surfaces. Fingerprints are a prime example of skin oils left behind on a surface that has been touched. Indeed, Zhou et al. relied on human touch to transfer skin oils to glass capillaries prior to investigating their oxidation by ozone. ${ }^{356}$

Experimental measurements have provided information about film growth and particle deposition on impermeable surfaces. Based on results from such studies, coupled with modeling, we can estimate approximately how long a surface must be exposed to indoor air before soiling has substantially altered the nature of its surface. ${ }^{56}$ Evidence is emerging that soiling imposes a degree of commonality among indoor surfaces that can be quite different from one another when clean. ${ }^{70}$ Absorption of semi-volatile organics to an impermeable surface requires a few layers of organic species on the surface to kick-start the partitioning process. How this might occur has been considered by Eichler et al., ${ }^{71}$ but a full description of the processes that initiate absorptive partitioning on indoor surfaces remains to be elucidated.

To a first approximation, the rate at which soiling occurs via partitioning is independent of surface orientation. Vertical surfaces soil at rates similar to horizontal surfaces. The surface accumulation resulting from partitioning is commonly referred to as a "film." We estimate that a pollutant film of 5 to 10 monolayers is thick enough to alter the interface with which airborne organic compounds interact. For a film composed of primarily indoor SVOCs, this is equivalent to a thickness on the order of $10 \mathrm{~nm}$ or less. ${ }^{56}$ Rates at which films accumulate on initially clean impermeable indoor surfaces have been measured in different indoor environments and are summarized in Table 2 of Weschler and Nazaroff. ${ }^{56}$ Film growth rates in the range $0.1-0.2 \mathrm{~nm} / \mathrm{d}$ have been reported. At such rates, films with thicknesses of 5-10 nm would accumulate on indoor surfaces in 1-3 months. In a composite sample of five homes in urban Toronto, a film thickness of $5 \mathrm{~nm}$ was measured 3-5

This article is protected by copyright. All rights reserved 
months after window cleaning. ${ }^{69}$ Toward the higher end of organic soiling conditions, Wu et al. ${ }^{70}$ exposed aluminum, polished glass and ground glass disks for 2-3 weeks in a kitchen where cooking occurred daily. Prior to exposure, the clean surfaces exhibited significantly different sorptive partitioning of DEHP. The 2-3 weeks of exposure was sufficient for the disks to acquire an organic film that resulted in similar sorptive partitioning of DEHP across diverse substrate materials. Taken together, these measurements suggest that within a period of a few months, impermeable indoor surfaces are covered by a film, acquired via partitioning, that is thick enough to alter the chemical surface that it presents to indoor air.

We note that the deposition velocities for lower molecular weight organic acids are comparable to those for SVOCs. However, the indoor gas-phase concentrations of species such as formic and acetic acid are orders of magnitude larger than those of indoor SVOCs. Hence, the flux of lower molecular weight organic acids to an aqueous surface is potentially orders of magnitude larger than the flux of SVOCs to an incipient surface film.

While the rate at which SVOC partitioning contributes to surface soiling is independent of the surface's orientation, the rate at which particles deposit on a surface varies substantially with orientation. Because particles settle under gravity's influence, upward facing horizontal surfaces soil much faster than vertical or downward-facing surfaces. Based simply on geometry, upward horizontal surfaces account for roughly $20 \%$ of exposed indoor surfaces. Table 3 in Weschler and Nazaroff ${ }^{56}$ presents estimated rates for particle accumulation on vertical and upward-facing horizontal surfaces. The rate at which vertical surfaces (and downward-facing horizontal surfaces) soil via particle deposition is predicted to be much slower than the rate at which they soil via partitioning. Even in the case of upward-facing horizontal surfaces, soiling by fine particle deposition is relatively slow. Since water soluble salts and associated water comprise larger mass fractions of fine particles than of coarse particles, ${ }^{490}$ this is an important consideration.

This article is protected by copyright. All rights reserved 
In summary, on impermeable indoor surfaces, semivolatile organic compounds accumulate much faster than particle-associated water-soluble salts. Only in the instance of an upward-facing horizontal surfaces does particle deposition become important, and, in this case, gravitational settling of coarse particles dominates the deposition process. Upward-facing horizontal surfaces can accumulate particles to a level of $1 \mu \mathrm{g} / \mathrm{cm}^{2}$ on a time scale as short as a few days, whereas surfaces of all orientation can have a $1 \mu \mathrm{g} / \mathrm{cm}^{2}$ accumulation of SVOCs (corresponding to $10 \mathrm{~nm}$ thick film) in a few months. As expected from theoretical considerations, ${ }^{56}$ the specific SVOCs that comprise indoor organic films are similar to those found in indoor airborne particles. In a recent intensive field study conducted in a test house, the HOMEChem project, such similarity was observed experimentally: "the signal intensities of the mass spectra for the indoor aerosol filter and surface extracts have high overlap, with a dot-product of 0.98." 134

While we know something about the formation and composition of films on impermeable indoor surfaces, we have little information about the soiling of semipermeable or porous surfaces such as paint films, vinyl flooring, brick, concrete, carpets and upholstery. Among other factors, morphology, as well as orientation, are expected to influence the soiling of such materials.

\subsubsection{Transformation of surface films}

The chemicals that comprise surface films evolve. They might initially be dominated by SVOCs; however, over time, they acquire particles and the water-soluble salts associated with these particles. The initial SVOCs in the film oxidize, which should tend to increase the oxygen to carbon (O/C) ratio. This process may make the surface film more hygroscopic. ${ }^{491}$ The acquisition of inorganic salts and increases in the $\mathrm{O} / \mathrm{C}$ ratio should lead to increased water content of surface films, especially during periods with higher indoor humidity, ${ }^{492}$ and the viscosity of the film may decrease as a consequence. Such changes could influence heterogeneous acid/base reactions, making them more likely in aged films under high RH conditions. Oxidation of surface films may also lead to phase separations ${ }^{493}$ that might further influence acid/base reactions.

This article is protected by copyright. All rights reserved 


\subsubsection{Separation of aqueous and organic phases on indoor surfaces: Evidence from nicotine}

The $\mathrm{pH}$ of skin's surface typically is in the range $4.5-6 .{ }^{486,487}$ The $\mathrm{p} K_{\mathrm{a}}$ of monoprotonated nicotine is 8.0. 440 Hence, at skin's pH, one would anticipate that most would be ionized (i.e., protonated). Based on measurements from excised pig skin, ionized nicotine passes through skin about fifty times slower than neutral nicotine. ${ }^{494}$ If there is a homogeneous film on the surface of skin that is a mix of water, salt and skin lipids with $\mathrm{pH}$ of $4.5-6$, then the capacity of this film for acquiring a combination of ionized nicotine and neutral nicotine would be very large. Since only the much less abundant neutral fraction is rapidly absorbed by the skin, transport from air through skin to blood should be relatively slow. However, actual measurements of the dermal uptake of nicotine from the gas phase indicate a fast transport rate. ${ }^{495,496} \mathrm{~A}$ possible explanation is that skin surface lipids and aqueous salt solutions coexist on the skin isolated from one another rather than being homogeneously mixed. ${ }^{495}$ As a crude analogy, they may exist more in the fashion of oil and vinegar rather than as mayonnaise. According to this conceptualization, nicotine that partitions from the gas-phase into islands of skin lipids would remain neutral, subsequently passing through the stratum corneum and viable epidermis to the dermal capillaries. Something similar may occur on impervious indoor surfaces; there may exist regions with aqueous surface films isolated from regions with organic-rich films. Within porous surfaces, there may exist pockets of aqueous solutions and pockets of hydrophobic organics. If such is the case, then organic acids and bases could partition to both aqueous and organic substrates, and the relative amounts in each phase could influence the resultant surface chemistry.

\subsection{Chemical nature of indoor surfaces}

Material surfaces have different chemical properties. In terms of indoor acid-base chemistry, three of the more important features of a surface are its acid/base character, its hydrophilic/hydrophobic character, and its polar character.

\subsubsection{Acid/base character}

This article is protected by copyright. All rights reserved 
Different methods have been used to characterize surface acidity. ${ }^{497-501}$ The more common methods have been reviewed by Sun and Berg. ${ }^{501}$ These include colloid titration, indicator dye adsorption, Xray photoelectron spectroscopy, and calorimetry. Most metal surfaces acquire a charge and, consequently, an electrical double layer at an aqueous interface. Protons and hydroxide ions in the aqueous layer influence this surface charge. The isoelectric point is defined as the $\mathrm{pH}$ value at which the potential of the double layer at the interface (i.e., the zeta potential - the potential at the surface of shear) is zero. The isoelectric point (IEP) is frequently used to characterize the acidity of solid surfaces. The IEP is measured by electrokinetic titration, which is a type of colloid titration. Another approach that has been used to evaluate the acidity and basicity of metal oxides is microcalorimetry. Using $\mathrm{NH}_{3}$ and $\mathrm{CO}_{2}$ as probe molecules, Auroux and Gervasini ${ }^{499}$ determined the number and character of basic and acidic sites on twenty metal oxides. Some metal oxides are basic (e.g., sodium and magnesium oxide), some are acidic (e.g., silicon and chromium oxides), and some are amphoteric (iron and rutile), reacting with both acidic and basic gases. ${ }^{499-501}$ Recently, Rindelaub et al. ${ }^{502}$ have made direct measurements of $\mathrm{pH}$ in individual particles using a Raman microspectrometer coupled with a confocal optical microscope. Wei et al. ${ }^{503}$ have applied a related method using 2D and 3D confocal Raman microscopy to determine the $\mathrm{pH}$ of suspended aerosol droplets smaller than $50 \mu \mathrm{m}$ diameter. Such methods might be adapted to probe surface acidity.

The acid-base properties of glass have received considerable attention. ${ }^{500}$ Silicon dioxide, forming the chemical framework of glass, is acidic in a Lewis-acid sense (i.e., it can accept a pair of electrons from an appropriate donor compound). Glass is relatively inert to acids, but is attacked by bases, especially when an aqueous layer in contact with glass has $\mathrm{pH}>9$. The acid-base properties of a polymer can often be described as those of its repeating unit. ${ }^{501}$

A substantial proportion of the SVOCs found in surface films are organic acids. Some of these (e.g., palmitic and myristic acid) can have human origins. ${ }^{319}$ Liu et al. measured the major organic constituents in films on impermeable indoor surfaces from five sites in greater Toronto. ${ }^{69}$ Monocarboxylic acids with $11-31$ carbons accounted for between $76 \%$ and $81 \%$ by mass of the total

This article is protected by copyright. All rights reserved 
organic fraction. Together, monocarboxylic acids, dicarboxylic acids with 6-14 carbon atoms, nine aromatic polycarboxylic acids, and five terpenoid acids accounted for $81-95 \%$ by mass of the total organic fraction, which included $n$-alkanes, PAHs, PCBs, and pesticides. These study results demonstrate an acidic character for organic surface films.

Surfaces that are basic and porous can be large sinks for acidic gases. Concrete, especially if it is improperly cured, and brick are examples of surfaces with basic properties. In China it is common to whitewash (limewash) walls in apartments and other buildings. (Whitewash was also common historically in the US, for both indoor and outdoor surfaces (e.g., the fence in Mark Twain's novel, The Adventures of Tom Sawyer), prior to the introduction of modern paints and sealants. Among some enthusiasts in the US and Europe, whitewashed wood walls, brick walls and furniture are making a comeback (https://www.homedit.com/whitewashed-walls/).) Whitewash is made by mixing hydrated lime with water, producing a white sealant. A whitewashed/limed wall is chemically basic and would have a high capacity for sorptive uptake of gas-phase acids.

To what extent is the $\mathrm{pH}$ of a surface determined by the surface itself versus gases dissolved in water associated with the surface? In the case of a hydrophobic surface, the amount of sorbed water is small and the nature of the surface itself should determine its (Lewis) acidity. In contrast, the acidity of a hydrophilic surface may be largely influenced by gases that have dissolved in the water associated with the material. Such may be the case for cotton fabrics or untreated nylon carpeting.

\subsubsection{Hydrophilic/hydrophobic character}

Some surfaces attract water (i.e., are hydrophilic); others repel water (hydrophobic). Surfaces are somewhat arbitrarily categorized as hydrophilic or hydrophobic based on the contact angle between a water droplet and the surface. If the contact angle is $<90^{\circ}\left(>90^{\circ}\right)$, the surface is considered hydrophilic (hydrophobic). Common hydrophilic surfaces indoors include nylon, glass, stainless steel, gypsum in wallboard, and cotton fabrics. Hydrophobic examples include untarnished silver, chromium, candle wax, and polypropylene. Surfaces that are extremely hydrophobic, such as Teflon 
or those treated with perfluorocarbon stain repellants, repel water and other highly polar compounds.

Ionization of an acidic or basic species is limited on a hydrophobic surface with very little water available, and so, acid-base chemistry would be deterred on such a surface. The degree of hydrophilicity also influences processes such as the disproportionation of $\mathrm{NO}_{2}$ onto indoor surfaces to form $\mathrm{HONO}$ and $\mathrm{HNO}_{3}$. An example of the latter process has been reported for a series of experiments in which $\mathrm{NO}_{2}$ was injected into a $2.5-\mathrm{m}^{3}$ chamber and the airborne concentrations of both $\mathrm{NO}_{2}$ and $\mathrm{HONO}$ monitored. 217 The chamber surfaces were either all Teflon or all vinyl wallpaper (over Teflon); in a subset of experiments, the floor of the Teflon or vinyl chamber was covered with a hydrophilic synthetic carpet. The measured $\mathrm{NO}_{2}$ surface removal rate was more than an order of magnitude larger with carpet on the floor of the chamber (1.1 to $\left.1.3 \mathrm{~h}^{-1}\right)$ than when all the surfaces were Teflon or vinyl (typically $<0.1 \mathrm{~h}^{-1}$ ). Additionally, the peak gas-phase concentration of HONO, generated from the $\mathrm{NO}_{2}$ injection, was larger with carpet in the chamber (12.8 $\left.\pm 2.0 \mathrm{ppb}\right)$ than when all the surfaces were Teflon or vinyl $(7.4 \pm 1.4 \mathrm{ppb})$. These results were likely due to a combination of increased surface area and the larger moisture content of the carpet compared to either Teflon or vinyl. When the chamber surfaces were vinyl wallpaper and the $\mathrm{RH}$ was either $50 \%$ or $70 \% \mathrm{RH}$, HONO decayed significantly more slowly than the air-exchange rate indicating prolonged release of HONO from the surface. However, when the chamber surfaces were Teflon, HONO decayed significantly slower than the air-exchange rate only at $70 \% \mathrm{RH}$; it decayed at a rate similar to the airexchange rate at $50 \% \mathrm{RH}$. The amount of water on a Teflon surface is roughly three times larger at $70 \% \mathrm{RH}$ compared to $50 \% \mathrm{RH},{ }^{504}$ apparently influencing the uptake and subsequent release of HONO from that surface. While exposed Teflon surfaces are rare indoors, carpets and upholstery are commonly treated with perfluorocarbon surfactants. Absent the influences of oxidative aging and/or soiling, such highly hydrophobic surfaces are unlikely to play a role in acid-base chemistry or to serve as reservoirs for gaseous acids or bases.

\subsubsection{Polar/nonpolar character}

This article is protected by copyright. All rights reserved 
Polarizability is the ability of a substance to form a dipole when exposed to an electric field. Won et al. ${ }^{505}$ examined the relationship between the polarizability of eight gas-phase organics and different indoor surfaces, including carpet, gypsum board, upholstery, vinyl flooring, wood flooring, and acoustic tiles. For nonpolar organics, carpet was a strong sorptive sink. For highly polar organics, virgin gypsum board was a substantial sink. Ongwandee et al. ${ }^{506}$ measured the partitioning of five sorbates, including nicotine and phenol, to polypropylene and PVC surfaces. Polypropylene is nonpolar, whereas PVC is polar. They also used previously reported data to examine correlations between hexadecane/air partitioning coefficients and surface polarity. They found that for weak bases, sorption correlated well with a sorbate's hexadecane/air partitioning coefficient regardless of surface polarity. In contrast, for strong bases, surface polarity was important. No correlations were found for sorption to fleecy or plush materials such as carpet.

\subsection{Surfaces as reservoirs}

Elsewhere, we have discussed studies demonstrating that indoor surfaces are large reservoirs for nitrous, formic, acetic, propionic, butyric, and pentanoic acids, ${ }^{218,222}$ for ammonia, ${ }^{97}$ and for nicotine. ${ }^{459}$ Surfaces are also demonstrated to be reservoirs for "total SVOCs," 15 which includes numerous higher molecular weight organics with acid functionality. Theory indicates that the same should be true for other acidic and basic compounds found in indoor air. Species such as nitrous acid, C1-C5 carboxylic acids, and ammonia have a much larger fraction of their mass in indoor surface reservoirs than in the gas-phase. This feature has been clearly illustrated in so-called venting experiments in which the gas-phase concentration of a species quickly returns to a prior steady-state concentration after a short period of enhanced ventilation. ${ }^{15,97,158,218,222,459}$ Surface reservoirs of acidic and basic species are sensitive to temperature; indoor gas-phase concentrations of the acids and bases display fine-scale temperature dependent increases and decreases in concentration corresponding to increases and decreases in temperature.

It should be noted that strong inorganic acids (e.g., $\mathrm{HCl}, \mathrm{HNO}_{3}, \mathrm{H}_{2} \mathrm{SO}_{4}$ ) interact with indoor surfaces chiefly as a consequence of the water associated with these surfaces. The extent to which an indoor 
surface serves as a reservoir for strong inorganic acids depends on the water associated with the surface and its $\mathrm{pH}$, as well as the $\mathrm{p} K_{\mathrm{a}}$ and $K_{\mathrm{H}}$ of the inorganic acid in question. Organic acids and bases, in addition to interacting with water on or in surfaces, also interact with organic surface films and exposed polymeric materials. The extent to which an indoor surface serves as a reservoir for gas-phase organic acids also depends on the abundance of organic sorptive reservoirs in contact with air, as well as with the relevant partition coefficient (often estimated as the octanol-air partition coefficient, or $K_{\text {oa }}$ ) of the organic acid or base. Relatively simple mass-balance models and the selected physical chemical properties of a given organic acid or base $\left(\mathrm{p} K_{\mathrm{a}}, K_{\mathrm{H}}\right.$, and $\left.K_{\mathrm{oa}}\right)$ serve to explain and can be used to predict such behavior. Wang et al. ${ }^{158}$ present phase-partitioning plots that illustrate indoor gas-surface partitioning of various species, including some common organic acids. These plots adapt a scheme first presented to address a three-part phase distribution gaseous, aqueous phase, and condensed organic phase - of chemicals involved in the outdoor formation of secondary aerosols (see Figure 1 in Wania et al. ${ }^{507}$ ).

When considering the role that surfaces play as reservoirs for indoor acids and bases, painted surfaces and stained wood surfaces warrant special comment since such surfaces account for almost two-thirds of the total indoor surface area in the surveys conducted by Hodgson et al. ${ }^{23}$ and Manuja et al. ${ }^{25}$ Paint experimentally applied to tin-plated steel "to obtain a surface similar to a painted wall" yielded thicknesses in the range $25-63 \mu \mathrm{m} .{ }^{44}$ The combination of a layer of primer and two layers of paint applied to drywall has a total thickness of $75-125 \mu \mathrm{m} \cdot{ }^{508,509}$ As the amount of pigment in a paint film increases, its porosity increases. ${ }^{510}$ Above a pigment volume concentration of 40 to $50 \%$, the permeability is fairly large, meaning that most commercial paints are permeable enough for gasphase acids and bases to diffuse through them at meaningful rates. This assumption regarding diffusivity is reinforced by recent measurements (see below). ${ }^{482}$ As noted in Table 2, the equilibrium moisture content of latex paint is $0.35 \%$ at $30 \% \mathrm{RH}$ and $0.86 \%$ at $50 \% \mathrm{RH}$. Hence, at $50 \% \mathrm{RH}$, a 100 $\mu \mathrm{m}$ layer of paint contains moisture equivalent to a water film whose thickness is of order 1 $\mu \mathrm{m}$. Such water might serve as a significant sink for highly water-soluble gas-phase organic acids (e.g., C1-C6 carboxylic acids). Gas-phase organic acids could also partition into the organic polymer 
that constitutes the surface of dry paint. Algrim et al. ${ }^{482}$ have made the first extensive measurements of partitioning between various gas-phase organics, including C3-C7 carboxylic acids, and paint films. For C3-, C5-, C6 and C7-carboxylic acids, the paint film/air partition coefficients were $4.3 \times 10^{5}, 7.5 \times 10^{5}, 16 \times 10^{5}$, and $39 \times 10^{5}$, respectively. These values are relatively close to the corresponding octanol-air partition coefficients ( $K_{\text {oa }}$, see Table 14$)$, suggesting that $K_{\text {oa }}$ can serve as a quantitative indicator for partitioning of carboxylic acids (and possibly other organic acids) to painted surfaces. Algrim et al. ${ }^{482}$ also measured diffusion coefficients in the paint films and the fraction of a given organic that completely penetrated a paint film to reach the underlying wallboard. The diffusion coefficients of C3-C7 carboxylic acids in paint films coated onto glass walls of flow tubes were between $10^{-9}$ and $10^{-10} \mathrm{~cm}^{2} \mathrm{~s}^{-1}$ at $22^{\circ} \mathrm{C}$ and correlated with the vapor pressure of the species. Related experiments indicated that the full volume of the paint film was available for absorption. A large fraction of the carboxylic acids penetrated the paint film after partitioning to it, suggesting the likelihood of further uptake by the underlying substrate.

Clothing may serve as mobile reservoirs for acids and bases. For example, substantial nicotine may sorb to clothing surfaces in one indoor environment and then be transferred to a different indoor environment where the nicotine then redistributes to other indoor compartments. ${ }^{14}$

\subsection{Reactions on surfaces or in surface materials}

One may anticipate that the presence of acidic or basic species influences reactions that occur in or on indoor surface materials. The time constraint that limits gas-phase chemistry to the scale of hours does not apply to reactions on surfaces. Hence, acid- or base-catalyzed hydrolysis is much more important on indoor surfaces than in the gas phase. A well-known example involves PVC flooring plasticized with di(2-ethylhexyl) phthalate (DEHP) atop moist concrete. ${ }^{511-513}$ The alkaline environment promotes the hydrolysis of DEHP to form 2-ethylhexanol and mono(ethylhexyl) phthalate (MEHP). Under similar conditions, the plasticizer di( $n$-butyl) phthalate (DnBP) undergoes hydrolysis to form $n$-butanol and mono(n-butyl) phthalate (MnBP). The hydrolysis of DEHP in dust

This article is protected by copyright. All rights reserved 
has been shown to be larger at elevated relative humidities, ${ }^{514}$ and it is anticipated that the same is true for DEHP in weakly polar organic surface films.

Odaka et al. ${ }^{515}$ have reported that, when soybean oil was added to lime plaster, hexaldehyde was strongly emitted. When linseed oil was added, propionaldehyde was emitted; and when perilla oil was added, acetaldehyde was emitted. One envisions that similar chemistry could occur in a limewalled kitchen when cooking with vegetable oils.

In certain cases, surfaces are intentionally modified to promote reactive chemistry. An example is the use of $\mathrm{TiO}_{2}$ (rutile) as an oxidation catalyst in wall paints. Upon illumination, the $\mathrm{TiO}_{2}$ particles generate hydroxyl radicals. Such paints have been demonstrated to influence indoor concentrations of oxidized organics and nitrogen oxides. ${ }^{516,517}$

We have discussed the manner in which surfaces can serve as reservoirs for gas-phase species and how surfaces can catalyze reactions, either by design or unintentionally. Surfaces also harbor an indoor microbiome. ${ }^{518}$ The bacterial and fungal communities on indoor surfaces have a complex relationship with the surfaces' chemical nature. ${ }^{519}$ The $\mathrm{pH}$ of aqueous surface films influences which bacterial or fungal species thrive, and, in turn, bacterial and fungal species influence surface $\mathrm{pH}$. In the latter instance, bacterial and fungal species can alter the $\mathrm{pH}$ of surface moisture to promote their own growth.

\section{CONCLUSION}

The cumulative body of research reviewed in this article reveals rich complexity that interweaves indoor acids and bases. Among the dozens of species that have been studied for one purpose or another, airborne concentrations can span many orders of magnitude, from tens of ppt for some organic acids and amines to a thousand ppm or more for carbon dioxide. Key physicochemical properties of acidic and basic molecules span even broader ranges: Henry's law constants vary across 12 orders of magnitude between carbon dioxide and malonic acid, acid dissociation constants

This article is protected by copyright. All rights reserved 
span more than 13 orders of magnitude between hydrochloric and hypochlorous acid, and octanolair partition coefficients span 8 orders of magnitude between acetic and stearic acid. Contrasted with these vast ranges, other system features can seem less remarkable, but are also certainly important. Among elements of interest are the order of magnitude or larger scale of concentration differences for a given species among different indoor environments and, for particular species in a given environment, the possibility of order of magnitude temporal variability in response to changing source or removal rates.

Complementing these core features of complexity are several important commonalities. Centrally important is the material-balance concept, which allows for inferences about source and sink processes, e.g., through the measurement of concentrations under experimentally controlled or well-characterized conditions. Core principles from chemical equilibrium apply and can assist in understanding partitioning of indoor acids and bases among gas phase, particle phase, bulk water, surfaces, and other indoor compartments. Chemical kinetic principles and mass-transfer considerations also apply; however, current knowledge regarding rates of key processes is limited and research opportunities in this arena are ample.

This review began with assessing the state of knowledge about water in indoor environments. Although there is often more gas-phase water indoors, the condensed phases are particularly important, in part because of the water solubility of acids and bases and also because bulk water is central in $\mathrm{H}^{+}$exchange reactions. It is noteworthy that, through their influence and dependence on the $\mathrm{pH}$ of water, acidic and basic species have the potential to strongly interact with each other altering their respective airborne concentrations and fates. Based on the evidence summarized throughout this review, it seems likely that equilibrated bulk water on surfaces is on the acidic side of neutral. The dominant indoor acids that influence the $\mathrm{pH}$ of bulk water, are $\mathrm{CO}_{2}, \mathrm{HNO}_{3}$, acetic acid, formic acid, $\mathrm{SO}_{2}$ and possibly $\mathrm{HCl}$ and oxalic acid. While amines are common indoors, with both outdoor and indoor sources, the dominant indoor bases influencing water $\mathrm{pH}$ are ammonia, whose gas-phase concentration is typically three to four orders of magnitude larger than the net gas-phase

This article is protected by copyright. All rights reserved 
concentration of amines, and nicotine, especially in indoor environments where smoking or vaping occurs. The consistently noteworthy role of ammonia as a base, and the more uneven occurrence of indoor nicotine, are likely to be more than compensated by the many and abundant indoor acidic species. In certain aqueous surface films, the possibility exists that the $\mathrm{pH}$ is moderated in the direction of being more basic owing to soluble substrates, such as encountered in limed walls or improperly cured concrete. Overall, there are many ways in which acids and bases interact strongly with indoor surfaces, influencing both surface properties and the chemical composition of indoor air. Water is present within materials as well as on their surfaces. The water content of indoor materials is substantial, especially at elevated relative humidity. However, the roles played by such water in acid-base chemistry are not understood. How mobile is a proton in water that is contained in wood, gypsum board or a paint film? What does $\mathrm{pH}$ even mean in the instance of such water? Important research opportunities exist to better understand the extent to which sorbed and surface-film water participates in acid-base chemistry.

Thorough assessments of indoor air composition must consider sources. Across the spectrum of acids and bases reviewed in this article, a broad suite of particular sources and source categories emerge as important, depending on the species. In an occupied room isolated from outdoors and with no indoor sources, the dominant acid is occupant derived $\mathrm{CO}_{2}$ and the dominant base is occupant derived $\mathrm{NH}_{3}$. The relative rate at which these species are emitted by humans is such that $\mathrm{pH}$ of bulk water equilibrated with this hypothetical room's air would be close to 7 - that is, the ammonia emissions are sufficient to neutralize the carbon dioxide emissions when considering the subsequent impact on the acidity of bulk water. However, such an "ideal" scenario rarely occurs. Rooms exchange air with the outdoors and contain numerous sources of acid and bases in addition to humans. Supply from outdoor air via ventilation is the primary source in most circumstances of sulfur dioxide, sulfate, and the related aerosol strong acidity. Accordingly, sulfate is used as a chemical marker of the penetration and persistence of outdoor fine particulate matter. Indoor environments are partially protective for pollutants of primarily outdoor origin, to extents that vary with factors such as the ventilation rate, surface removal rate, and the effectiveness of air cleaning

This article is protected by copyright. All rights reserved 
technologies (e.g., particle filtration). In many indoor environments, especially those densely occupied, such as classrooms, humans are a principal source for lactic acid and amino acids, in addition to $\mathrm{CO}_{2}$ and $\mathrm{NH}_{3}$. The use of specific products indoors may strongly influence indoor air concentrations of acids and bases. Prominent examples include cleaning products that contain chlorine bleach (hypochlorous acid) or ammonia and the use of tobacco products (including vaping) as a source of nicotine. Nicotine can migrate from one indoor environment to another sorbed on clothing, hair, and other personal items. For some compounds, multiple sources and source categories may make sizable contributions, as is likely the case with formic and acetic acid. Reactive chemistry involving surfaces is an important source of HONO, and reactive chemistry involving HONO can be a source of nitrosamines.

The relative importance of indoor emissions versus ventilation from outdoor air as a source is strongly influential regarding the relationship between indoor and outdoor concentrations, expressed through the I/O ratio. There is clear evidence to support an expectation of $\mathrm{I} / \mathrm{O}<1$ being the norm for $\mathrm{SO}_{2}$, sulfate, nitric acid, and aerosol strong acidity. Conversely, $\mathrm{l} / \mathrm{O}>1$ is most common for $\mathrm{CO}_{2}, \mathrm{NH}_{3}$, hypochlorous acid, carboxylic acids, nicotine, and certain amines. In trying to understand the relationship between air pollution and health effects, it is especially important to recognize that exposures to pollutants with outdoor-source dominance often can be reasonably estimated using urban air monitoring networks. Conversely, we risk a level of epidemiological blindness regarding the air-pollution/health nexus for pollutants of primarily indoor source origin if we rely solely on outdoor-air concentration information as a basis for estimating exposures.

Among ingredients that can catalyze research progress are recognizing the importance of a subject, keenly understanding the existing state of knowledge and its limitations, and possessing technology to enable answering incisively posed questions. Over the arc of research history in a field, topics once deemed important are sometimes neglected for a period. In the domain of indoor acids and bases, we can see both needs and opportunities. New possibilities are emerging from the application of advanced instrumentation that is enabling sensitive, real-time monitoring of airborne

This article is protected by copyright. All rights reserved 
species as a tool for identifying dynamic processes that influence concentrations and fates. Also emerging is awareness of the importance of organic acids and their potentially prominent influence on certain features of indoor air quality. Specific topics that have been dormant merit a fresh look, such as sulfur dioxide and aerosol strong acidity as components of indoor air. Water in its many forms clearly influences the concentrations and fates of indoor acids and bases, and is also important for many other aspects of indoor environmental quality. Similarly, improving understanding of surface-associated processes indoors is a ripe area for near-term research progress, and only partly owing to interests regarding acids and bases. A major motivator for conducting this review has been to strengthen the scientific foundation so that the work already accomplished and the knowledge so gained can be put to effective use in guiding future research and improving indoor environmental quality.

\section{REFERENCES}

1. Salthammer T, Zhang Y, Mo J, Koch HM, Weschler CJ. Assessing human exposure to organic pollutants in the indoor environment. Angewandte Chemie International Edition. 2018;57:1222812263.

2. Nazaroff WW. Max von Pettenkofer award. Indoor Air. 2012;22:443-445.

3. Biersteker K, de Graaf H, Nass CAG. Indoor air pollution in Rotterdam homes. International Journal of Air and Water Pollution. 1965;9:343-350.

4. Andersen I. Relationships between outdoor and indoor air pollution. Atmospheric Environment. $1972 ; 6: 275-278$.

5. Spengler JD, Keeler GJ, Koutrakis P, Ryan PB, Raizenne M, Franklin CA. Exposures to acidic aerosols. Environmental Health Perspectives. 1989;79:43-51.

6. Brauer M, Koutrakis P, Spengler JD. Personal exposures to acidic aerosols and gases. Environmental Science \& Technology. 1989;23:1408-1412.

7. Baer NS, Banks PN. Indoor air pollution: Effects on cultural and historic materials. The International Journal of Museum Management and Curatorship. 1985;4:9-20.

This article is protected by copyright. All rights reserved 
8. Rice DW, Cappell RJ, Kinsolving W, Laskowski JJ. Indoor corrosion of metals. Journal of the Electrochemical Society. 1980;127:891-900.

9. Comizzoli RB, Frankenthal RP, Milner PC, Sinclair JD. Corrosion of electronic materials and devices. Science. 1986;234:340-345.

10. Satish $U$, Mendell MJ, Shekhar K, et al. Is $\mathrm{CO}_{2}$ an indoor pollutant? Direct effects of low-tomoderate $\mathrm{CO}_{2}$ concentrations on human decision-making performance. Environmental Health Perspectives. 2012;120:1671-1677.

11. Weschler CJ. Roles of the human occupant in indoor chemistry. Indoor Air. 2016;26:6-24.

12. Duncan SM, Sexton KG, Turpin BJ. Oxygenated VOCs, aqueous chemistry, and potential impacts on residential indoor air composition. Indoor Air. 2018;28:198-212.

13. Liu S, Thompson SL, Stark H, Ziemann PJ, Jimenez JL. Gas-phase carboxylic acids in a university classroom: Abundance, variability, and sources. Environmental Science \& Technology. 2017;51:5454-5463.

14. DeCarlo PF, Avery AM, Waring MS. Thirdhand smoke uptake to aerosol particles in the indoor environment. Science Advances. 2018;4:eaap8368.

15. Kristensen K, Lunderberg DM, Liu Y, et al. Sources and dynamics of semivolatile organic compounds in a single-family residence in northern California. Indoor Air. 2019;29:645-655.

16. Mendell MJ, Kumagai K. Observation-based metrics for residential dampness and mold with dose-response relationships to health: A review. Indoor Air. 2017;27:506-517.

17. Marr LC, Tang JW, Van Mullekom J, Lakdawala SS. Mechanistic insights into the effect of humidity on airborne influenza virus survival, transmission and incidence. Journal Royal Society Interface. 2019;16:20180298.

18. Wolkoff P. Indoor air humidity, air quality, and health - An overview. International Journal of Hygiene and Environmental Health. 2018;221:376-390.

19. Park JH, Kim HJ, Kwon GY, et al. Humidifier disinfectants are a cause of lung injury among adults in South Korea: A community-based case-control study. PLoS One. 2016;11:e0151849.

20. Sain AE, Zook J, Davy BM, Marr LC, Dietrich AM. Size and mineral composition of airborne particles generated by an ultrasonic humidifier. Indoor Air. 2018;28:80-88.

This article is protected by copyright. All rights reserved 
21. Rim D, Schiavon S, Nazaroff WW. Energy and cost associated with ventilating office buildings in a tropical climate. PLoS One. 2015;10:e0122310.

22. Opitz A, Scherge M, Ahmed SI-U, Schaefer JA. A comparative investigation of thickness measurements of ultra-thin water films by scanning probe techniques. Journal of Applied Physics. 2007;101:064310.

23. Hodgson AT, Ming KY, Singer BC. Quantifying object and material surface areas in residences. Report LBNL-56786. Berkeley, CA: Indoor Environment Department, Lawrence Berkeley National Laboratory. 2004.

24. Singer BC, Hodgson AT, Hotchi T, et al. Sorption of organic gases in residential rooms. Atmospheric Environment. 2007;41:3251-3265.

25. Manuja A, Ritchie J, Buch K, et al. Total surface area in indoor environments. Environmental Science: Processes \& Impacts. 2019;21:1384-1392.

26. Hinds WC. Aerosol Technology: Properties, Behavior, and Measurement of Airborne Particles. $2^{\text {nd }}$ Edition. New York: Wiley. 1999.

27. Nguyen JL, Schwartz J, Dockery DW. The relationship between indoor and outdoor temperature, apparent temperature, relative humidity, and absolute humidity. Indoor Air. 2014;24;103-112.

28. Energy Star. Market \& Industry Scoping Report: Residential Humidifiers. October 2012. At https://www.energystar.gov/products/scoping_reports. Last accessed 2 August 2019.

29. TenWolde A, Walker IS. Interior moisture design loads for residences. In Performance of Exterior Envelopes of Whole Buildings VIII: Integration of Building Envelopes. Atlanta, GA: American Society of Heating, Refrigerating and Air-Conditioning Engineers. 2001.

30. TenWolde A, Pilon CL. The effect of indoor humidity on water vapor release in homes. In 30 Years of Research Proceedings Thermal Performance of Exterior Envelopes of Whole Buildings $X$. US Department of Energy, Oak Ridge National Laboratory Report ORNL 07-Go1409/aas; Atlanta: American Society for Heating, Refrigerating, and Air-Conditioning Engineers, Inc., Buildings $X$ Conference, Clearwater Beach, Florida, 2-7 December 2007.

31. DeOreo WB, Mayer P, Dziegielewski B, Kiefer J. Residential end uses of water, Version 2: Executive report. Denver: Water Research Foundation. 2016. 
32. Duncan SM, Tomaz S, Morrison G, et al. Dynamics of residential water-soluble organic gases: Insights into sources and sinks. Environmental Science \& Technology. 2019;53:1812-1821.

33. Woods J, Winkler J. Effective moisture penetration depth model for residential buildings: Sensitivity analysis and guidance on model inputs. Energy \& Buildings. 2018;165:216-232.

34. Atkinson JK. Environmental conditions for the safeguarding of collections: A background to the current debate on the control of relative humidity and temperature. Studies in Conservation. 2014;59:205-212.

35. Mendell MJ, Macher JM, Kumagai K. Measured moisture in buildings and adverse health effects: A review. Indoor Air. 2018;28:488-499.

36. Janssen H, Roels S. Qualitative and quantitative assessment of interior moisture buffering by enclosures. Energy \& Buildings. 2009;41:382-394.

37. Forest Products Laboratory. Wood Handbook - Wood as an Engineering Material. General Technical Report FPL-GTR-190. Madiscon, WI: US Department of Agriculture, Forest Products Laboratory. 2010.

38. James C, Simonson CJ, Talukdar P, Roels S. Numerical and experimental data set for benchmarking hygroscopic buffering materials. International Journal of Heat and Mass Transfer. 2010;53:3638-3654.

39. Karoglou M, Moropoulou A, Maroulis ZB, Krokida MK. Water sorption isotherms of some building materials. Drying Technology. 2005;23:289-303.

40. Adams RI, Chen W, Kumagai K, Macher JM, Mendell MJ. Relating measured moisture of gypsum board to estimated water activity using moisture meters. Building and Environment. 2019;147:284-298.

41. van der Zanden AJJ, Goossens ELJ. The measurement of the sorption isotherm of water in paint films. Chemical Engineering and Processing. 2004;43:739-743.

42. Hill CAS, Ramsay J, Keating B, et al. The water vapour sorption properties of thermally modified and densified wood. Journal of Material Science. 2012;47:3191-3197.

43. Hill CAS, Norton A, Newman G. The water vapor sorption behavior of natural fibers. Journal of Applied Polymer Science. 2009;112:1524-1537.

This article is protected by copyright. All rights reserved 
44. Clausen PA, Wolkoff P, Host E, Nielsen PA. Long-term emission of volatile organic compounds from waterborne paints - Methods of comparison. Indoor Air. 1991;1:562-576.

45. Engelund ET, Thygesen LG, Svensson S, Hill CAS. A critical discussion of the physics of woodwater interactions. Wood Science and Technology. 2013;47:141-161.

46. Bertram AK, Martin ST, Hanna SJ, et al. Predicting the relative humidities of liquid-liquid phase separation, efflorescence, and deliquescence of mixed particles of ammonium sulfate, organic material, and water using the organic-to-sulfate mass ratio of the particle and the oxygen-tocarbon elemental ratio of the organic component. Atmospheric Chemistry and Physics. 2011;11:10995-11006.

47. Rode C, Peuhkuri RH, Mortensen LH, et al., Moisture buffering of building materials. BYG Report No R-127, Lyngby, DK: Technical University of Denmark. 2005.

48. Svennberg K, Wadsö L. Sorption isotherms for textile fabrics, foams and batting used in the indoor environment. Journal of the Textile Institute. 2008;99:125-132.

49. Feng C, Michielsen S, Attinger D. Impact of carpet construction on fluid penetration: The case of blood. Forensic Science International. 2018;284:184-193.

50. Rowen JW, Blaine RL. Sorption of nitrogen and water vapor on textile fibers. Industrial and Engineering Chemistry. 1947;39:1659-1663.

51. Bhouri N, Bhouri N, Houngan A, Bennasrallah S, Perre P. Comparison between sorption isotherms of non-ironed and steam-ironed plain weave fabrics. Applied Thermal Engineering. 2017;126:429-435.

52. Bull HB. Adsorption of water vapor by proteins. Journal of the American Chemical Society. 1944;66:1499-1507.

53. Cassie ABD. Absorption of water by wool. Transactions of the Faraday Society. 1945;41:458-464.

54. Watt IC, D'Arcy RL. 26-Water-vapour adsorption isotherms of wool. Journal of the Textile Institute. 1979;70:298-307.

55. Whigham LD, Schoeller DA, Johnson LK, Atkinson RL. Effect of clothing weight on body weight. International Journal of Obesity. 2013;37:160-161.

This article is protected by copyright. All rights reserved 
56. Weschler CJ, Nazaroff WW. Growth of organic films on indoor surfaces. Indoor Air. 2017;27:1101-1112.

57. Razouk RI, Salem AS. The adsorption of water vapor on glass surfaces. Journal of Physical Chemistry. 1948;52:1208-1227.

58. McClellan AL, Harnsberger HF. Cross-sectional areas of molecules adsorbed on solid surfaces. Journal of Colloid and Interface Science. 1967;23:577-599.

59. Leygraf C, Wallinder IO, Tidblad J, Graedel T. Atmospheric Corrosion. Second edition. Hoboken, NJ: Wiley. 2016.

60. Ma Q, He H, Liu Y. In situ DRIFTS study of hygroscopic behavior of mineral aerosol. Journal of Environmental Sciences. 2010;22:555-560.

61. Gustafsson RJ, Orlov A, Badger CL, Griffiths PT, Cox RA, Lambert RM. A comprehensive evaluation of water uptake on atmospherically relevant mineral surfaces: DRIFT spectroscopy, thermogravimetric analysis and aerosol growth measurements. Atmospheric Chemistry and Physics. 2005;5:3415-3421.

62. Goss K-U. Effects of temperature and relative humidity on the sorption of organic vapors on clay minerals. Environmental Science \& Technology. 1993;27:2127-2132.

63. Ruiz J, Bilbao R, Murillo MB. Adsorption of different VOC onto soil minerals from gas phase: Influence of mineral, type of VOC, and air humidity. Environmental Science \& Technology. 1998;32:1079-1084.

64. Rubasinghege G, Grassian VH. Role(s) of adsorbed water in the surface chemistry of environmental interfaces. Chemical Communications. 2013;49:3071-3094.

65. Lin T-F, Little JC, Nazaroff WW. Transport and sorption of volatile organic compounds and water vapor within dry soil grains. Environmental Science \& Technology. 1994;28:322-330.

66. Goss K-U. Effects of temperature and relative humidity on the sorption of organic vapors on quartz sand. Environmental Science \& Technology. 1992;26:2287-2294.

67. Schuttlefield J, Al-Hosney H, Zachariah A, Grassian VH. Attenuated total reflection Fourier transform infrared spectroscopy to investigate water uptake and phase transitions in atmospherically relevant particles. Applied Spectroscopy. 2007;61:283-292.

This article is protected by copyright. All rights reserved 
68. Ong SK, Lion LW. Trichloroethylene vapor sorption onto soil minerals. Soil Science Society of America Journal. 1991;55:1559-1568.

69. Liu Q-T, Chen R, McCarry BE, Diamond ML, Bahavar B. Characterization of polar organic compounds in the organic film of indoor and outdoor glass windows. Environmental Science \& Technology. 2003;37:2340-2349.

70. Wu Y, Eichler CMA, Leng W, Cox SS, Marr LC, Little JC. Adsorption of phthalates on impervious indoor surfaces. Environmental Science \& Technology. 2017;51:2907-2913.

71. Eichler CMA, Cao J, Isaacman-VanWertz G, Little JC. Modeling the formation and growth of organic films on indoor surfaces. Indoor Air. 2019;29:17-29.

72. Schwartz-Narbonne H, Donaldson DJ. Water uptake by indoor surface films. Scientific Reports. 2019;9:11089.

73. Fang $\mathrm{Y}$, Tang $\mathrm{M}$, Grassian VH. Competition between displacement and dissociation of a strong acid compared to a weak acid adsorbed on silica particle surfaces: The role of adsorbed water. Journal of Physical Chemistry A. 2016;120:4016-4024.

74. Wellen BA, Lach EA, Allen HC. Surface $p K_{a}$ of octanoic, nonanoic, and decanoic fatty acids at the air-water interface: applications to atmospheric aerosol chemistry. Physical Chemistry Chemical Physics. 2017;19:26551-26558.

75. Parashar S, Lesnicki D, Sulpizi M. Increased acid dissociation at the quartz/water interface. Journal of Physical Chemistry Letters. 2018;9:2186-2189.

76. Nguyen TKV, Zhang Q, Jimenez JL, Pike M, Carlton AG. Liquid water: Ubiquitous contributor to aerosol mass. Environmental Science \& Technology Letters. 2016;3:257-263.

77. Carlton AG, Turpin BJ. Particle partitioning potential of organic compounds is highest in the Eastern US and driven by anthropogenic water. Atmospheric Chemistry and Physics. 2013;13:10203-10214.

78. Meng Z, Seinfeld JH, Saxena P, Kim YP. Contribution of water to particulate mass in the South Coast Air Basin. Aerosol Science and Technology. 1995;22:111-123.

This article is protected by copyright. All rights reserved 
79. Parworth $\mathrm{CL}$, Young DE, Kim H, et al. Wintertime water-soluble aerosol composition and particle water content in Fresno, California. Journal of Geophysical Research: Atmospheres. 2017;122:3155-3170.

80. Avery AM, Waring MS, DeCarlo PF. Seasonal variation in aerosol composition and concentration upon transport from the outdoor to indoor environment. Environmental Science: Processes and Impacts. 2019;21:528-547.

81. Thakkar H, Eastman S, Hajari A, Rownaghi AA, Knox JC, Rezaei F. 3D-printed zeolite monoliths for $\mathrm{CO}_{2}$ removal from enclosed environments. ACS Applied Materials \& Interfaces. 2016;8:2775327761.

82. Persily A, de Jonge L. Carbon dioxide generation rates for building occupants. Indoor Air. 2017;27:868-879.

83. Bekö G, Lund T, Nors F, Toftum J, Clausen G. Ventilation rates in the bedrooms of 500 Danish children. Building and Environment 2010;45:2289-2295.

84. Muscatiello N, McCarthy A, Kielb C, Hsu W-H, Hwang S-A, Lin S. Classroom conditions and $\mathrm{CO}_{2}$ concentrations and teacher health symptom reporting in 10 New York State schools. Indoor Air. 2015;25:157-167.

85. Hudda N, Fruin SA. Carbon dioxide accumulation inside vehicles: The effect of ventilation and driving conditions. Science of the Total Environment. 2018;610-611:1448-1456.

86. Chiu C-F, Chen M-H, Chang F-H. Carbon dioxide concentrations and temperatures within tour buses under real-time traffic conditions. PLoS One. 2015;10:e0125117.

87. Giaconia C, Orioli A, Di Gangi A. Air quality and relative humidity in commercial aircrafts: An experimental investigation on short-haul domestic flights. Building and Environment. 2013;67:69-81.

88. Azuma K, Kagi N, Yanagi U, Osawa H. Effects of low-level inhalation exposure to carbon dioxide in indoor environments: A short review on human health and psychomotor performance. Environment International. 2018;121:51-56.

89. Butler JN. Carbon Dioxide Equilibria and Their Applications. Chelsea, MI: Lewis. 1991.

This article is protected by copyright. All rights reserved 
90. ApSimon HM, Kruse M, Bell JNB. Ammonia emissions and their role in acid deposition. Atmospheric Environment. 1987;21:1939-1946.

91. Cass GR, Gharib S, Peterson M, Tilden JW. The origin of ammonia emissions to the atmosphere in an urban area. Open File Report 82-6. Pasadena: Environmental Quality Laboratory, California Institute of Technology. 1982.

92. Liu T, Wang $\mathrm{X}$, Wang $\mathrm{B}$, et al. Emission factor of ammonia $\left(\mathrm{NH}_{3}\right)$ from on-road vehicles in China: tunnel tests in urban Guangzhou. Environmental Research Letters. 2014;9:064027.

93. National Research Council. Ammonia. A report by the Subcommittee on Ammonia, Committee on Medical and Biologic Effects of Environmental Pollutants. Baltimore, MD: National Research Council, University Park Press. 1977.

94. Schlesinger $\mathrm{WH}$, Hartley AE. A global budget for atmospheric $\mathrm{NH}_{3}$. Biogeochemistry. 1992;15:191-211.

95. Spengler JD, Koutrakis P, Dockery DW, Raizenne M, Speizer FE. Health effects of acid aerosols on North American children: Air pollution exposures. Environmental Health Perspectives. $1996 ; 104: 492-499$.

96. Ito K, Chasteen CC, Chung H-K, Poruthoor SK, Genfa Z, Dasgupta PK. A continuous monitoring system for strong acidity in aerosols. Analytical Chemistry. 1998;70:2839-2847.

97. Ampollini L, Katz EF, Bourne S, et al. Observations and contributions of real-time indoor ammonia concentrations during HOMEChem. Environmental Science \& Technology. 2019;53:8591-8598.

98. Brunnemann KD, Hoffmann D. Chemical studies on tobacco smoke XXXIV. Gas chromatographic determination of ammonia in cigarette and cigar smoke. Journal of Chromatographic Science. 1975;13:159-163.

99. Ingebrethsen BJ, Lyman CS, Risner CH, Martin P, Gordon BM. Particle-gas equilibria of ammonia and nicotine in mainstream cigarette smoke. Aerosol Science and Technology. 2001;35:874-886.

100. Risner $\mathrm{CH}$, Conner JM. Collection of ammonia in indoor air by means of a weak cation exchange cartridge. Environmental Toxicology and Chemistry. 1991;10:1417-1423.

This article is protected by copyright. All rights reserved 
101. Bai Z, Dong Y, Wang Z, Zhu T. Emission of ammonia from indoor concrete wall and assessment of human exposure. Environment International. 2006;32:303-311.

102. Cho A, Jang H-S, Roh YS, et al. Detrimental effects of cement mortar and fly ash mortar on asthma progression. Environmental Toxicology and Pharmacology. 2013;36:1087-1096.

103. Jang $\mathrm{H}$, So $\mathrm{H}$, So $\mathrm{S}$. Emission characteristic of ammonia in cement mortars using different sand from area of production. Environmental Engineering Research. 2016;21:241-246.

104. Vaattovaara PE, Kivimäenpää M, Vaattovaara P, Pasanen P, Heinonen-Tanski H. Airborne enteric micro-organisms and ammonia levels in diaper-changing rooms in kindergartens. Letters in Applied Microbiology. 2012;54:462-467.

105. Lee DS, Longhurst JWS. Estimates of emissions of $\mathrm{SO}_{2}, \mathrm{NO}_{\mathrm{x}}, \mathrm{HCl}$ and $\mathrm{NH}_{3}$ from a densely populated region of the UK. Environmental Pollution. 1993;79:37-44.

106. Healy TV, McKay HAC, Pilbeam A, Scargill D. Ammonia and ammonium sulfate in the troposphere over the United Kingdom. Journal of Geophysical Research. 1970;75:2317-2321.

107. Russell AG, McRae GJ, Cass GR. Mathematical modeling of the formation and transport of ammonium nitrate aerosol. Atmospheric Environment. 1983;17:949-964.

108. Möller D, Schieferdecker H. Ammonia emission and deposition of $\mathrm{NH}_{\mathrm{x}}$ in the G.D.R. Atmospheric Environment. 1989;23:1187-1193.

109. Larson TV, Covert DS, Frank R, Charlson RJ. Ammonia in the human airways: Neutralization of inspired acid sulfate aerosols. Science. 1977;197:161-163.

110. Norwood DM, Wainman T, Lioy PJ, Waldman JM. Breath ammonia depletion and its relevance to acidic aerosol exposure studies. Archives of Environmental Health. 1992;47:309313.

111. Schmidt FM, Vaittinen O, Metsälä M, et al. Ammonia in breath and emitted from skin. Journal of Breath Research. 2013;7:017109.

112. Mochalski P, Unterkofler K, Teschl G, Amann A. Potential of volatile organic compounds as markers of entrapped humans for use in urban search-and-rescue operations. Trends in Analytical Chemistry. 2015;68:88-106.

This article is protected by copyright. All rights reserved 
113. Furukawa S, Sekine Y, Kimura K, Umezawa K, Asai S, Miyachi H. Simultaneous and multi-point measurement of ammonia emanating from human skin surface for the estimation of whole body dermal emission rate. Journal of Chromatography B. 2017;1053:60-64.

114. Li M, Weschler CJ, Bekö G, Wargocki P, Lucic G, Williams J. Human ammonia emissions under various indoor environmental conditions. Environmental Science \& Technology. Submitted.

115. Ng TW, Chan PY, Chan TT, Wu H, Lai KM. Skin squames contribute to ammonia and volatile fatty acid production from bacteria colonizing in air-cooling units with odor complaints. Indoor Air. 2018;28:258-265.

116. Lindgren T. A case of indoor air pollution of ammonia emitted from concrete in a newly built office in Beijing. Building and Environment. 2010;45:596-600.

117. Pankow JF, Mader BT, Isabelle LM, Luo W, Pavlick A, Liang C. Conversion of nicotine in tobacco smoke to its volatile and available free-base form through the action of gaseous ammonia. Environmental Science \& Technology. 1997;31:2428-2433. Corrections: 1999;33:1320.

118. Sisovic A, Sega K, Kalinic N. Indoor/outdoor relationship of ammonia concentrations in selected office buildings. Science of the Total Environment. 1987;61:73-77.

119. Li Y, Harrison RM. Comparison of indoor and outdoor concentrations of acid gases, ammonia and their associated salts. Environmental Technology. 1990;11:315-326.

120. Atkins DHF, Lee DS. Indoor concentrations of ammonia and the potential contribution of humans to atmospheric budgets. Atmospheric Environment 1993;27A:1-7.

121. Tidy G, Cape JN. Ammonia concentrations in houses and public buildings. Atmospheric Environment. 1993;27A:2235-2237.

122. Tuomainen M, Pasanen A-L, Tuomainen A, Liesivuori J, Juvonen P. Usefulness of the Finnish classification of indoor climate, construction and finishing materials: comparison of indoor climate between two new blocks of flats in Finland. Atmospheric Environment. 2001;35:305-313.

123. Järnström H, Saarela K, Kalliokoski P, Pasanen A-L. Reference values for indoor air pollutant concentrations in new, residential buildings in Finland. Atmospheric Environment. 2006;40:71787191.

This article is protected by copyright. All rights reserved 
124. Salonen HJ, Pasanen A-L, Lappalainen SK, et al. Airborne concentrations of volatile organic compounds, formaldehyde and ammonia in Finnish office buildings with suspected indoor air problems. Journal of Occupational and Environmental Hygiene. 2009;6:200-209.

125. López-Aparicio S, Smolík J, Masková L, et al. Relationship of indoor and outdoor air pollutants in a naturally ventilated historical building envelope. Building and Environment. 2011;46:14601468.

126. Ohira S-I, Heima M, Yamasaki T, Tanaka T, Koga T, Toda K. Flow-based ammonia gas analyzer with an open channel scrubber for indoor environments. Talanta. 2013;116:527-534.

127. Fischer ML, Littlejohn D, Lunden MM, Brown NJ. Automated measurements of ammonia and nitric acid in indoor and outdoor air. Environmental Science \& Technology. 2003;37:2114-2119.

128. Brauer M, Koutrakis P, Keeler GJ, Spengler JD. Indoor and outdoor concentrations of inorganic acidic aerosols and gases. Journal of the Air \& Waste Management Association. $1991 ; 41: 171-181$.

129. Liang CSK, Waldman JM. Indoor exposures to acidic aerosols at child and elderly care facilities. Indoor Air. 1992;2:196-207.

130. Suh HH, Spengler JD, Koutrakis P. Personal exposures to acid aerosols and ammonia. Environmental Science \& Technology. 1992;26:2507-2517.

131. Suh $\mathrm{HH}$, Koutrakis $\mathrm{P}$, Spengler JD. The relationship between airborne acidity and ammonia in indoor environments. Journal of Exposure Analysis and Environmental Epidemiology. 1994;4:122.

132. Leaderer BP, Naeher L, Jankun $T$, et al. Indoor, outdoor, and regional summer and winter concentrations of $\mathrm{PM}_{10}, \mathrm{PM}_{2.5}, \mathrm{SO}_{4}{ }^{2-}, \mathrm{H}^{+}, \mathrm{NH}_{4}{ }^{+}, \mathrm{NO}_{3}{ }^{-}, \mathrm{NH}_{3}$, and nitrous acid in homes with and without kerosene space heaters. Environmental Health Perspectives. 1999;107:223-231.

133. Spengler JD, Brauer M, Samet JM, Lambert WE. Nitrous acid in Albuquerque, New Mexico, homes. Environmental Science \& Technology. 1993;27:841-845.

134. Farmer DK, Vance ME, Abbatt JPD, et al. Overview of HOMEChem: House Observations of Microbial and Environmental Chemistry. Environmental Science: Processes and Impacts. 2019;21:1280-1300.

This article is protected by copyright. All rights reserved 
135. Sinclair JD, Psota-Kelty LA, Weschler CJ. Indoor/outdoor concentrations and indoor surface accumulations of ionic substances. Atmospheric Environment. 1985;19:315-323.

136. Sinclair JD, Psota-Kelty LA, Weschler CJ. Indoor/outdoor ratios and indoor surface accumulations of ionic substances at Newark, New Jersey. Atmospheric Environment. 1988;22:461-469.

137. Sinclair JD, Psota-Kelty LA, Weschler CJ, Shields HC. Measurement and modeling of airborne concentrations and indoor surface accumulation rates of ionic substances at Neenah, Wisconsin. Atmospheric Environment. 1990;24A:627-638.

138. Ligocki MP, Salmon LG, Fall T, Jones MC, Nazaroff WW, Cass GR. Characteristics of airborne particles inside southern California museums, Atmospheric Environment. 1993;27A:697-711.

139. Johnson AM, Waring MS, DeCarlo PF. Real-time transformation of outdoor aerosol components upon transport indoors measured with aerosol mass spectrometry. Indoor Air. 2017;27:230-240.

140. Ligocki MP, Liu HIH, Cass GR, John W. Measurements of particle deposition rates inside southern California museums, Aerosol Science and Technology. 1990;13:85-101.

141. Opila RL Jr, Weschler CJ, Schubert R. Acidic vapors above saturated salt solutions commonly used for control of humidity. IEEE Transactions on Components, Hybrids, and Manufacturing Technology. 1989;12;114-120.

142. Sander R. Compilation of Henry's law constants (version 4.0) for water as solvent. Atmospheric Chemistry and Physics. 2015;15:4399-4981.

143. Bates RG, Pinching GD. Acidic dissociation constant of ammonium ion at $0^{\circ}$ to $50^{\circ} \mathrm{C}$, and the base strength of ammonia. Journal of the Research of the National Bureau of Standards. 1949;42:419-430.

144. Sarangapani R, Wexler AS. Growth and neutralization of sulfate aerosols in human airways. Journal of Applied Physiology. 1996;81:480-490.

145. Nazaroff WW, Weschler CJ. Cleaning products and air fresheners: Exposure to primary and secondary air pollutants. Atmospheric Environment. 2004;38:2841-2865.

This article is protected by copyright. All rights reserved 
146. Na K, Song C, Switzer C, Cocker DR III. Effect of ammonia on secondary organic aerosol formation from $\alpha$-pinene ozonolysis in dry and humid conditions. Environmental Science \& Technology. 2007;41:6096-6102.

147. Huang $\mathrm{Y}$, Lee SC, Ho KF, et al. Effect of ammonia on ozone-initiated formation of indoor secondary products with emissions from cleaning products. Atmospheric Environment. 2012;59,224-231.

148. Niu X, Ho SSH, Ho KF, et al. Indoor secondary organic aerosols formation from ozonolysis of monoterpene: An example of D-limonene with ammonia and potential impacts on pulmonary inflammations. Science of the Total Environment. 2017;579:212-220.

149. Chemistry Libre Texts. Amides, making amides from carboxylic acids. https://chem.libretexts.org/Bookshelves/Organic_Chemistry/Supplemental_Modules_Organic_ Chemistry)/Amides/Synthesis_of_Amides/Making_Amides_from_Carboxylic_Acids. Last accessed July 3, 2019.

150. Finlayson-Pitts BJ, Pitts Jr JN. Chemistry of the Upper and Lower Atmosphere: Theory, Experiments, and Applications. San Diego, CA: Academic Press. 2000.

151. Mozurkewich M. The dissociation constant of ammonium nitrate and its dependence on temperature, relative humidity and particle size. Atmospheric Environment. 1993;27A:261-270.

152. Doyle GJ, Tuazon EC, Graham RA, Mischke TM, Winer AM, Pitts JN Jr. Simultaneous concentrations of ammonia and nitric acid in a polluted atmosphere and their equilibrium relationship to particulate ammonium nitrate. Environmental Science \& Technology. 1979;13:1416-1419.

153. Lunden MM, Revzan KL, Fischer ML, et al. The transformation of outdoor ammonium nitrate aerosols in the indoor environment. Atmospheric Environment. 2003;37:5633-5644.

154. Webb AM, Singer BC, Nazaroff WW. Effect of gaseous ammonia on nicotine sorption. In: Levin H, Ed. Indoor Air 2002: Proceedings of the Ninth International Conference on Indoor Air Quality and Climate, Vol. 3, Santa Cruz, CA, pp. 512-517. 2002.

155. Ongwandee M, Bettinger SS, Morrison GC. The influence of ammonia and carbon dioxide on the sorption of a basic organic pollutant to a mineral surface. Indoor Air. 2005;15:408-419.

This article is protected by copyright. All rights reserved 
156. Ongwandee M, Morrison GC. Influence of ammonia and carbon dioxide on the sorption of a basic organic pollutant to carpet and latex-painted gypsum board. Environmental Science \& Technology. 2008;42:5415-5420.

157. Ongwandee M, Sawanyapanich P. Influence of relative humidity and gaseous ammonia on the nicotine sorption to indoor materials. Indoor Air. 2012;22:54-63.

158. Wang C, Collins DB, Arata C, et al., Surface reservoirs dominate dynamic gas-surface partitioning of many indoor air constituents. Science Advances. 2020;6:eaay8973.

159. Updyke KM, Nguyen TB, Nizkorodov SA. Formation of brown carbon via reactions of ammonia with secondary organic aerosols from biogenic and anthropogenic precursors. Atmospheric Environment. 2012;63:22-31.

160. Hand JL, Schichtel BA, Malm WC, Pitchford ML. Particulate sulfate ion concentration and $\mathrm{SO}_{2}$ emission trends in the United States from the early 1990s through 2010. Atmospheric Chemistry and Physics. 2012;12:10353-10365.

161. Denby B, Sundvor I, Cassiani M, de Smet P, de Leeuw F, Horálek J. Spatial mapping of ozone and $\mathrm{SO}_{2}$ trends in Europe. Science of the Total Environment. 2010;408;4795-4806.

162. Lu Z, Zhang Q, Streets DG. Sulfur dioxide and primary carbonaceous aerosol emissions in China and India, 1996-2010. Atmospheric Chemistry and Physics. 2011;11:9839-9864.

163. Wang $\mathrm{T}$, Wang $\mathrm{P}$, Theys $\mathrm{N}$, et al. Spatial and temporal changes in $\mathrm{SO}_{2}$ regimes over China in the recent decade and the driving mechanism. Atmospheric Chemistry and Physics. 2018;18:18063-18078.

164. Khan A, Kim K-H, Szulejko JE, et al. Long-term trends in airborne $\mathrm{SO}_{2}$ in an air quality monitoring station in Seoul, Korea, from 1987 to 2013. Journal of the Air \& Waste Management Association. 2017;67:923-932.

165. Klimont K, Smith SJ, Cofala J. The last decade of global anthropogenic sulfur dioxide: 20002011 emissions. Environmental Research Letters. 2013;8:014003.

166. Spengler JD, Ferris BG Jr, Dockery DW, Speizer FE. Sulfur dioxide and nitrogen dioxide levels inside and outside homes and the implications on health effects research. Environmental Science \& Technology. 1979;13:1276-1280.

This article is protected by copyright. All rights reserved 
167. Lam NL, Smith KR, Gauthier A, Bates MN. Kerosene: A review of household uses and their hazards in low- and middle-income countries. Journal of Toxicology and Environmental Health, Part B Critical Reviews. 2012;15:396-432.

168. Seow WJ, Downward GS, Wei H, et al. Indoor concentrations of nitrogen dioxide and sulfur dioxide from burning solid fuels for cooking and heating in Yunnan Province, China. Indoor Air. 2016;26:776-783.

169. Wilson MJG. Indoor air pollution. Proceedings of the Royal Society A. 1968;300:215-221.

170. Edwards CJ, Hudson FL, Hockey JA. Sorption of sulphur dioxide by paper. Journal of Applied Chemistry. 1968;18:146-148.

171. Spedding DJ. The fate of sulphur-35/sulphur dioxide released in a laboratory. Atmospheric Environment. 1969;3:341-346.

172. Spedding DJ, Rowlands RP. Sorption of sulphur dioxide by indoor surfaces I. Wallpapers. Journal of Applied Chemistry. 1970;20:143-146.

173. Spedding DJ. Sorption of sulphur dioxide by indoor surfaces II. Wood. Journal of Applied Chemistry. 1970;20:226-228.

174. Spedding DJ, Rowlands RP, Taylor JE. Sorption of sulphur dioxide by indoor surfaces III. Leather. Journal of Applied Chemistry and Biotechnology. 1971;21:68-70.

175. Spedding DJ. The sorption of sulphur dioxide by indoor surfaces IV. Flooring materials. Journal of Applied Chemistry and Biotechnology. 1972;22:1-8.

176. Cox RA, Penkett SA. Effect of relative humidity on the disappearance of ozone and sulphur dioxide in contained systems. Atmospheric Environment. 1972;6:365-368.

177. Duncan JR, Spedding DJ. Initial reactions of $\mathrm{SO}_{2}$ after adsorption on to metals. Corrosion Science. 1973;13:881-889.

178. Walsh $\mathrm{M}$, Black $\mathrm{A}$, Morgan $\mathrm{A}, \mathrm{Crawshaw} \mathrm{GH}$. Sorption of $\mathrm{SO}_{2}$ by typical indoor surfaces including wool carpets, wallpaper and paint. Atmospheric Environment. 1977;11:1107-1111.

179. Grøntoft T, Raychaudhuri MR. Compilation of tables of surface deposition velocities for $\mathrm{O}_{3}$, $\mathrm{NO}_{2}$ and $\mathrm{SO}_{2}$ to a range of indoor surfaces. Atmospheric Environment. 2004;38:533-544.

This article is protected by copyright. All rights reserved 
180. Judeikis HS, Stewart TB. Laboratory measurement of $\mathrm{SO}_{2}$ deposition velocities on selected building materials and soils. Atmospheric Environment. 1976;10:769-776.

181. Hering SV, Friedlander SK. Origins of aerosol sulfur size distributions in the Los Angeles basin. Atmospheric Environment. 1982;16:2647-2656.

182. Riley WJ, McKone TE, Lai ACK, Nazaroff WW. Indoor particulate matter of outdoor origin: Importance of size-dependent removal mechanisms. Environmental Science \& Technology. 2002;36:200-207.

183. Sarnat JA, Long CM, Koutrakis P, Coull BA, Schwartz J, Suh HH. Using sulfur as a tracer of outdoor fine particulate matter. Environmental Science \& Technology. 2002;36:5305-5314.

184. Wallace L, Williams R. Use of personal-indoor-outdoor sulfur concentrations to estimate the infiltration factor and outdoor exposure factor for individual homes and persons. Environmental Science \& Technology. 2005;39:1707-1714.

185. Guo H, Xu L, Bougiatioti A, et al. Fine-particle water and $\mathrm{pH}$ in the southeastern United States. Atmospheric Chemistry and Physics. 2015;15:5211-5228.

186. Koutrakis P, Briggs SLK, Leaderer BP. Source apportionment of indoor aerosols in Suffolk and Onondaga Counties, New York. Environmental Science \& Technology. 1992;26:521-527.

187. Ruiz PA, Toro C, Cáceres J, López G, Oyola P, Koutrakis P. Effect of gas and kerosene space heaters on indoor air quality: A study in homes of Santiago, Chile. Journal of the Air \& Waste Management Association. 2010;60:98-108.

188. Dockery DW, Spengler JD. Indoor-outdoor relationships of respirable sulfates and particles. Atmospheric Environment. 1981;15:335-343.

189. Spengler JD, Dockery DW, Turner WA, Wolfson JM, Ferris BG Jr. Long-term measurements of respirable sulfates and particles inside and outside homes. Atmospheric Environment. 1981;15:23-30.

190. Atkinson R, Baulch DL, Cox RA, Hampson RF Jr, Kerr JA, Troe J. Evaluated kinetic and photochemical data for atmospheric chemistry: Supplement IV. IUPAC subcommittee on gas kinetic data evaluation for atmospheric chemistry. Journal of Physical and Chemical Reference Data. 1992;21:1125-1568.

This article is protected by copyright. All rights reserved 
191. DeMore WB, Sander SP, Golden DM, et al. Chemical kinetics and photochemical data for use in stratospheric modeling: Evaluation Number 12. JPL Publication 97-4. Pasadena: Jet Propulsion Laboratory. 1997.

192. Carslaw N. A new detailed chemical model for indoor air pollution. Atmospheric Environment. 2007;41:1164-1179.

193. Sverdrup GM, Spicer CW, Ward GF. Investigation of the gas phase reaction of dinitrogen pentoxide with water vapor. International Journal of Chemical Kinetics. 1987;19:191-205.

194. Cheung JL, Li YQ, Boniface J, et al. Heterogeneous interactions of $\mathrm{NO}_{2}$ with aqueous surfaces. Journal of Physical Chemistry A. 2000;104:2655-2662.

195. Finlayson-Pitts BJ, Wingen LM, Sumner AL, Syomin D, Ramazan KA. The heterogeneous hydrolysis of $\mathrm{NO}_{2}$ in laboratory systems and in outdoor and indoor atmospheres: An integrated mechanism. Physical Chemistry Chemical Physics. 2003;5:223-242.

196. Pryor WA, Lightsey JW. Mechanisms of nitrogen dioxide reactions: Initiation of lipid peroxidation and the production of nitrous acid. Science. 1981;214:435-437.

197. Sleiman M, Gundel LA, Pankow JF, Jacob P III, Singer BC, Destaillats H. Formation of carcinogens indoors by surface-mediated reactions of nicotine with nitrous acid, leading to potential thirdhand smoke hazards. Proceedings of the National Academy of Sciences of the USA. 2010;107:6576-6581.

198. Da Silva G, Kennedy EM, Dlugogorski BZ. Ab Initio procedure for aqueous-phase $p K_{\mathrm{a}}$ calculation: The acidity of nitrous acid. Journal of Physical Chemistry A. 2006;110:11371-11376.

199. Spicer CW, Kenny DV, Ward GF, Billick IH. Transformations, lifetimes, and sources of $\mathrm{NO}_{2}$, $\mathrm{HONO}$, and $\mathrm{HNO}_{3}$ in indoor environments. Journal of the Air \& Waste Management Association. 1993;43:1479-1485.

200. Nazaroff WW, Cass GR. Mathematical modeling of chemically reactive pollutants in indoor air. Environmental Science \& Technology. 1986:20;924-934.

201. Nazaroff WW, Gadgil AJ, Weschler CJ. Critique of the use of deposition velocity in modeling indoor air quality, Modeling of Indoor Air Quality and Exposure. Special Technical Publication 1205. Philadelphia, PA: American Society for Testing and Materials. pp 81-104. 1993.

This article is protected by copyright. All rights reserved 
202. Yamanaka S. Decay rates of nitrogen oxides in a typical Japanese living room. Environmental Science \& Technology. 1984;18:566-570.

203. Weschler $\mathrm{CJ}$, Shields $\mathrm{HC}$, Naik DV. Indoor chemistry involving $\mathrm{O}_{3}, \mathrm{NO}$, and $\mathrm{NO}_{2}$ as evidenced by 14 months of measurements at a site in southern California. Environmental Science \& Technology. 1994;28:2120-2132.

204. Lee SC, Chan LY, Chiu MY. Indoor and outdoor air quality investigation at 14 public places in Hong Kong. Environment International. 1999;25:443-450.

205. Salonen $\mathrm{H}$, Salthammer T, Morawska L. Human exposure to $\mathrm{NO}_{2}$ in school and office indoor environments. Environment International. 2019;130:104887.

206. Zhou S, Young CJ, VandenBoer TC, Kowal SF, Kahan TF. Time-resolved measurements of nitric oxide, nitrogen dioxide, and nitrous acid in an occupied New York home. Environmental Science \& Technology. 2018;52:8355-8364.

207. Spicer CW, Kenny DV, Ward GF, Billick IH, Leslie NP. Evaluation of $\mathrm{NO}_{2}$ measurement methods for indoor air quality applications. Journal of the Air \& Waste Management Association. 1994;44:163-168.

208. Spicer CW, Billick IH, Yanagisawa Y. Nitrous acid interference with passive $\mathrm{NO}_{2}$ measurement methods and the impact on indoor $\mathrm{NO}_{2}$ data. Indoor Air. 2001;11:156-161.

209. Spengler JD, Duffy CP, Letz R, Tibbitts TW, Ferris BG Jr. Nitrogen dioxide inside and outside 137 homes and implications for ambient air quality standards and health effects research. Environmental Science \& Technology. 1983;17:164-168.

210. Gilbert NL, Gauvin D, Guay M, et al. Housing characteristics and indoor concentrations of nitrogen dioxide and formaldehyde in Quebec City, Canada. Environmental Research. 2006;102:1-8.

211. Mullen NA, Li J, Russell ML, Spears M, Less BD, Singer BC. Results of the California Healthy Homes Indoor Air Quality Study of 2011-2013: impact of natural gas appliances on air pollutant concentrations. Indoor Air. 2016;26:231-245.

This article is protected by copyright. All rights reserved 
212. Vichi F, Masková L, Frattoni M, Imperiali A, Smolik J. Simultaneous measurement of nitrous acid, nitric acid, and nitrogen dioxide by means of a novel multipollutant diffusive sampler in libraries and archives. Heritage Science. 2016;4:4.

213. Hisham MWM, Grosjean D. Air-pollution in southern California museums: Indoor and outdoor levels of nitrogen dioxide, peroxyacetyl nitrate, nitric-acid, and chlorinated hydrocarbons. Environmental Science \& Technology. 1991;25:857-862.

214. Salmon LG, Nazaroff WW, Ligocki MP, Jones MC, Cass GR. Nitric acid concentrations in southern California museums. Environmental Science \& Technology. 1990;24:1004-1013.

215. Norman V, Keith CH. Nitrogen oxides in tobacco smoke. Nature. 1965;205:915-916.

216. Leaderer BP. Air pollutant emissions from kerosene space heaters. Science. 1982;218:11131115.

217. Wainman T, Weschler CJ, Lioy PJ, Zhang J. Effects of surface type and relative humidity on the production and concentration of nitrous acid in a model indoor environment. Environmental Science \& Technology. 2001;35:2200-2206.

218. Collins DB, Hems RF, Zhou S, et al. Evidence for gas-surface equilibrium control of indoor nitrous acid. Environmental Science \& Technology. 2018;52:12419-12427.

219. Arata $\mathrm{C}$, Zarzana KJ, Misztal PK, et al. Measurement of $\mathrm{NO}_{3}$ and $\mathrm{N}_{2} \mathrm{O}_{5}$ in a residential kitchen. Environmental Science \& Technology Letters. 2018;5:595-599.

220. Zhao H, Gall ET, Stephens B. Measuring the building envelope penetration factor for ambient nitrogen oxides. Environmental Science \& Technology. 2019;53:9695-9704.

221. Pitts JN Jr, Wallington TJ, Biermann, HW, Winer AM. Identification and measurement of nitrous acid in an indoor environment. Atmospheric Environment. 1985;19:763-767.

222. Pitts JN Jr, Biermann HW, Tuazon EC, Green M, Long WD, Winer AM. Time-resolved identification and measurement of indoor air pollutants by spectroscopic techniques: Gaseous nitrous acid, methanol, formaldehyde and formic acid. JAPCA. 1989;39:1344-1347.

223. Febo A, Perrino C. Prediction and experimental evidence for high air concentration of nitrous acid in indoor environments. Atmospheric Environment. 1991;25A:1055-1061.

This article is protected by copyright. All rights reserved 
224. Febo A, Perrino C. Measurement of high concentration of nitrous acid inside automobiles. Atmospheric Environment. 1995;29:345-351.

225. Gligorovski S. Nitrous acid (HONO): An emerging indoor pollutant. Journal of Photochemistry and Photobiology A: Chemistry. 2016;314:1-5.

226. Lee K, Xue J, Geyh AS, et al. Nitrous acid, nitrogen dioxide, and ozone concentrations in residential environments. Environmental Health Perspectives. 2002;110:145-149.

227. Gómez Alvarez E, Amedro D, Afif C, et al. Unexpectedly high indoor hydroxyl radical concentrations associated with nitrous acid. Proceedings of the National Academy of Sciences of the USA. 2013;110:13294-13299.

228. Mendez M, Blond N, Amedro D, et al. Assessment of indoor HONO formation mechanisms based on in situ measurements and modeling. Indoor Air. 2017;27:443-451.

229. Brauer M, Rasmussen TR, Kjaergaard SK, Spengler JD. Nitrous acid formation in an experimental exposure chamber. Indoor Air. 1993;3:94-105.

230. Tamás G, Weschler CJ, Bakó-Biró Z, Wyon DP, Strøm-Tejsen P. Factors affecting ozone removal rates in a simulated aircraft cabin environment. Atmospheric Environment. 2006;40:6122-6133.

231. Weschler CJ, Brauer M, Koutrakis P. Indoor ozone and nitrogen dioxide: a potential pathway to the generation of nitrate radicals, dinitrogen pentaoxide, and nitric acid indoors. Environmental Science \& Technology. 1992;26:179-184.

232. Sarwar G, Corsi R, Allen D, Weschler C. Production and levels of selected indoor radicals: A modeling assessment. In: Levin H, Ed., Indoor Air 2002: Proceedings of the Ninth International Conference on Indoor Air Quality and Climate, Vol. 5, Santa Cruz, CA, pp. 80-85. 2002.

233. Nøjgaard JK. Indoor measurements of the sum of the nitrate radical, $\mathrm{NO}_{3}$, and nitrogen pentoxide, $\mathrm{N}_{2} \mathrm{O}_{5}$ in Denmark. Chemosphere. 2010;79:898-904.

234. Borduas N, Place B, Wentworth GR, Abbatt JPD, Murphy JG. Solubility and reactivity of HNCO in water: insights into HNCO's fate in the atmosphere. Atmospheric Chemistry and Physics. 2016;16:703-714.

This article is protected by copyright. All rights reserved 
235. Roberts JM, Veres PR, Cochran AK, et al. Isocyanic acid in the atmosphere and its possible link to smoke-related health effects. Proceedings of the National Academy of Sciences of the USA. 2011;108:8966-8971.

236. Leslie MD, Ridoli M, Murphy JG, Borduas-Dedekind N. Isocyanic acid (HNCO) and its fate in the atmosphere: a review. Environmental Science: Processes \& Impacts. 2019;21:793-808.

237. Borduas N, Murphy JG, Wang C, da Silva G, Abbatt JPD. Gas phase oxidation of nicotine by $\mathrm{OH}$ radicals: Kinetics, mechanisms, and formation of HNCO. Environmental Science \& Technology Letters. 2016;3:327-331.

238. Hems RF, Wang C, Collins DB, et al. Sources of isocyanic acid (HNCO) indoors: a focus on cigarette smoke. Environmental Science: Processes \& Impacts. 2019;21:1334-1341.

239. Keene WC, Khalil MAK, Erickson DJ III, et al. Composite global emissions of reactive chlorine from anthropogenic and natural sources: Reactive chlorine emissions inventory. Journal of Geophysical Research. 1999;104:8429-8440.

240. Akagi SK, Yokelson RJ, Wiedinmyer C, et al. Emission factors for open and domestic biomass burning for use in atmospheric models. Atmospheric Chemistry and Physics. 2011;11:4039-4072.

241. Trummal A, Lipping L, Kaljurand I, Koppel IA, Leito I. Acidity of strong acids in water and dimethyl sulfoxide. Journal of Physical Chemistry A. 2016;120:3663-3669.

242. Allen AG, Miguel AH. Indoor organic and inorganic pollutants: in-situ formation and dry deposition in southeastern Brazil. Atmospheric Environment. 1995;29:3519-3526.

243. Özkaynak H, Xue J, Spengler J, Wallace L, Pellizzari E, Jenkins P. Personal exposure to airborne particles and metals: Results from the Particle TEAM study in Riverside, California. Journal of Exposure Analysis and Environmental Epidemiology. 1996;6:57-78.

244. Wallace L. Indoor particles: A review. Journal of the Air and Waste Management Association. 1996;46:98-126.

245. Sinclair JD, Psota-Kelty LA, Weschler CJ, Shields HC. Deposition of airborne sulfate, nitrate, and chloride salts as it relates to corrosion of electronics. Journal of the Electrochemical Society. 1990;137:1200-1206.

This article is protected by copyright. All rights reserved 
246. Dawe KER, Furlani TC, Kowal SF, Kahan TF, VandenBoer TC, Young CJ. Formation and emission of hydrogen chloride in indoor air. Indoor Air. 2019;29:70-78.

247. Lawler $\mathrm{MJ}$, Sander $\mathrm{R}$, Carpenter $\amalg$, et al. $\mathrm{HOCl}$ and $\mathrm{Cl}_{2}$ observations in marine air. Atmospheric Chemistry and Physics. 2011;11:7617-7628.

248. Wong JPS, Carslaw N, Zhao R, Zhou S, Abbatt JPD. Observations and impacts of bleach washing on indoor chlorine chemistry. Indoor Air. 2017;27:1082-1090.

249. Zock J-P, Plana E, Antó JM, et al. Domestic use of hypochlorite bleach, atopic sensitization, and respiratory symptoms in adults. Journal of Allergy and Clinical Immunology. 2009;124:731738.

250. Odabasi M. Halogenated volatile organic compounds from the use of chlorine-bleachcontaining household products. Environmental Science \& Technology. 2008;42:1445-1451.

251. Odabasi M, Elbir T, Dumanoglu Y, Sofuoglu SC. Halogenated volatile organic compounds in chlorine-bleach-containing household products and implications for their use. Atmospheric Environment. 2014;92:376-383.

252. Schwartz-Narbonne H, Wang C, Zhou S, Abbatt JPD, Faust J. Heterogeneous chlorination of squalene and oleic acid. Environmental Science \& Technology. 2019;53,1217-1224.

253. Siracusa A, De Blay F, Folletti I, et al. Asthma and exposure to cleaning products - a European Academy of Allergy and Clinical Immunology task force consensus statement. Allergy. 2013;68:1532-1545

254. Nickmilder M, Carbonnelle S, Bernard A. House cleaning with chlorine bleach and the risks of allergic and respiratory diseases in children. Pediatric Allergy and Immunology. 2007;18:27-35.

255. Loh MM, Levy JI, Spengler JD, Houseman EA, Bennett DH. Ranking cancer risks of organic hazardous air pollutants in the United States. Environmental Health Perspectives. 2007;115:1160-1168.

256. Shepherd JL, Corsi RL, Kemp J. Chloroform in indoor air and wastewater: The role of residential washing machines. Journal of the Air and Waste Management Association. $1996 ; 46: 631-642$.

This article is protected by copyright. All rights reserved 
257. Olson DA, Corsi RL. In-home formation and emissions of trihalomethanes: The role of residential dishwashers. Journal of Exposure Analysis and Environmental Epidemiology. 2004;14:109-119.

258. Weisel CP, Kim H, Haltmeier P, Klotz JB. Exposure estimates to disinfection by-products of chlorinated drinking water. Environmental Health Perspectives. 1999;107:103-110.

259. Nuckols JR, Ashley DL, Lyu C, Gordon SM, Hinckley AF, Singer P. Influence of tap water quality and household water use activities on indoor air and internal dose levels of trihalomethanes. Environmental Health Perspectives. 2005;113:863-870.

260. Wallace LA. Human exposure and body burden for chloroform and other trihalomethanes. Critical Reviews in Environmental Science \& Technology. 1997;27:113-194.

261. Xu X, Weisel CP. Inhalation exposure to haloacetic acids and haloketones during showering. Environmental Science \& Technology. 2003;37:569-576.

262. Thickett KM, McCoach JS, Gerber JM, Sadhra S, Burge PS. Occupational asthma caused by chloramines in indoor swimming-pool air. European Respiratory Journal. 2002;19:827-832.

263. Bernard A, Carbonnelle S, de Burbure C, Michel O, Nickmilder M. Chlorinated pool attendance, atopy, and the risk of asthma during childhood. Environmental Health Perspectives 2006;114:1567-1573.

264. Jacobs JH, Spaan S, van Rooy GBGJ, et al. Exposure to trichloramine and respiratory symptoms in indoor swimming pool workers. European Respiratory Journal. 2007;29:690-698.

265. Schmalz C, Frimmel FH, Zwiener C. Trichloramine in swimming pools - Formation and mass transfer. Water Research. 2011;45:2681-2690.

266. Zwiener C, Richardson SD, De Marini DM, Grummt T, Glauner T, Frimmel FH. Drowning in disinfection byproducts? Assessing swimming pool water. Environmental Science \& Technology. 2007;41:363-372.

267. Bernard A, Carbonnelle S, Michel O, et al. Lung hyperpermeability and asthma prevalence in schoolchildren: Unexpected associations with the attendance at indoor chlorinated swimming pools. Occupational and Environmental Medicine. 2003;60:385-394.

This article is protected by copyright. All rights reserved 
268. Weschler CJ, Nazaroff WW. Semivolatile organic compounds in indoor environments. Atmospheric Environment. 2008;42:9018-9040.

269. Hodgson AT, Destaillats H, Sullivan DP, Fisk WJ. Performance of ultraviolet photocatalytic oxidation for indoor air cleaning applications. Indoor Air. 2007:17;305-316.

270. Nielsen GD, Hansen LF, Nexø BA, Poulsen OM. Indoor air guideline levels for formic, acetic, propionic and butyric acid. Indoor Air. 1998;Suppl. 5:8-24.

271. Brimblecombe P, Grossi CM. Carbonyl compounds indoors in a changing climate. Chemistry Central Journal 2012;6:21.

272. Gibson LT, Watt CM. Acetic and formic acids emitted from wood samples and their effect on selected materials in museum environments. Corrosion Science. 2010;52:172-178.

273. Yuan B, Veres PR, Warneke C, et al. Investigation of secondary formation of formic acid: urban environment vs. oil and gas producing region. Atmospheric Chemistry and Physics. 2015;15:1975-1993.

274. Schauer JJ, Kleeman MJ, Cass GR, Simoneit BRT. Measurement of emissions from air pollution sources. 1. $\mathrm{C}_{1}$ through $\mathrm{C}_{29}$ organic compounds from meat charbroiling. Environmental Science \& Technology. 1999;33:1566-1577.

275. Schauer JJ, Kleeman MJ, Cass GR, Simoneit BRT. Measurement of emissions from air pollution sources. 4. $\mathrm{C}_{1}-\mathrm{C}_{27}$ organic compounds from cooking with seed oils. Environmental Science \& Technology. 2002;36:567-575.

276. Zhang J, Wilson WE, Lioy PJ. Sources of organic-acids in indoor air: A field-study. Journal of Exposure Analysis and Environmental Epidemiology. 1994;4:25-47.

277. Reiss R, Ryan PB, Tibbetts SJ, Koutrakis P. Measurement of organic acids, aldehydes, and ketones in residential environments and their relation to ozone. Journal of the Air \& Waste Management Association. 1995;45:811-822.

278. Duncan SM, Sexton K, Collins L, Turpin BJ. Residential water-soluble organic gases: Chemical characterization of a substantial contributor to indoor exposures. Environmental Science: Processes \& Impacts. 2019;21:1364-1373.

This article is protected by copyright. All rights reserved 
279. Uchiyama S, Tomizawa T, Tokoro A, et al. Gaseous chemical compounds in indoor and outdoor air of 602 houses throughout Japan in winter and summer. Environmental Research. 2015;137:364-372.

280. Cheng M, Galbally IE, Molloy SB, et al. Factors controlling volatile organic compounds in dwellings in Melbourne, Australia. Indoor Air. 2016;26:219-230.

281. Godoi RHM, Godoi AFL, Gonçalves SJ Jr, et al. Healthy environment — indoor air quality of Brazilian elementary schools nearby petrochemical industry. Science of the Total Environment. 2013;463-464:639-646.

282. Stranger M, Potgieter-Vermaak S, Sacco P, et al. Analysis of indoor gaseous formic and acetic acid, using radial diffusive samplers. Environmental Monitoring and Assessment. 2009;149:411417.

283. Grosjean D. Ambient levels of formaldehyde, acetaldehyde, and formic acid in southern California: Results of a one-year base-line study. Environmental Science \& Technology. 1991;25:710-715.

284. Kawamura K, Steinberg S, Kaplan IR. Homologous series of $\mathrm{C}_{1}-\mathrm{C}_{10}$ monocarboxylic acids and $\mathrm{C}_{1}-\mathrm{C}_{6}$ carbonyls in Los Angeles air and motor vehicle exhausts. Atmospheric Environment. 2000;34:4175-4191.

285. Lawrence JE, Koutrakis P. Measurement of atmospheric formic and acetic acids: Methods evaluation and results from field studies. Environmental Science \& Technology. 1994;28:957-964.

286. Gibson LT, Ewlad-Ahmed A, Knight B, Horie V, Mitchell G, Robertson CJ. Measurement of volatile organic compounds emitted in libraries and archives: an inferential indicator of paper decay? Chemistry Central Journal. 2012;6:42.

287. Hodgson AT, Rudd AF, Beal D, Chandra S. Volatile organic compound concentrations and emission rates in new manufactured and site-built houses. Indoor Air. 2000;10:178-192.

288. Maddalena R, Russell M, Sullivan DP, Apte MG. Formaldehyde and other volatile organic chemical emissions in four FEMA temporary housing units. Environmental Science \& Technology. 2009;43:5626-5632.

This article is protected by copyright. All rights reserved 
289. Weschler CJ, Wisthaler A, Cowlin S, et al. Ozone-initiated chemistry in an occupied simulated aircraft cabin. Environmental Science \& Technology. 2007;41:6177-6184.

290. Tang X, Misztal PK, Nazaroff WW, Goldstein AH. Volatile organic compound emissions from humans indoors. Environmental Science \& Technology. 2016;50:12686-12694.

291. Liu Y, Misztal PK, Xiong J, et al. Characterizing sources and emissions of volatile organic compounds in a northern California residence using space- and time-resolved measurements. Indoor Air. 2019;29:630-644.

292. Cometto-Muñiz JE, Cain WS, Abraham MH. Nasal pungency and odor of homologous aldehydes and carboxylic acids. Experimental Brain Research. 1998;118:180-188.

293. Risholm-Sundman M, Lundgren M, Vestin E, Herder P. Emissions of acetic acid and other volatile organic compounds from different species of solid wood. Holz als Roh- und Werkstoff. 1998;56:125-129.

294. Manninen A-M, Pasanen P, Holopainen JK. Comparing the VOC emissions between air-dried and heat-treated Scots pine wood. Atmospheric Environment. 2002;36:1763-1768.

295. Jensen B, Wolkoff P, Wilkins CK, Clausen PA. Characterization of linoleum. Part 1: Measurement of volatile organic compounds by use of the Field and Laboratory Emission Cell, "FLEC." Indoor Air. 1995;5:38-43.

296. Paulot F, Wunch D, Crounse JD, et al. Importance of secondary sources in the atmospheric budgets of formic and acetic acids. Atmospheric Chemistry and Physics. 2011;11:1989-2013.

297. Zhang J, Wilson WE, Lioy PJ. Indoor air chemistry: Formation of organic acids and aldehydes. Environmental Science \& Technology. 1994;28:1975-1982.

298. Destaillats H, Lunden MM, Singer BC, et al. Indoor secondary pollutants from household product emissions in the presence of ozone: A bench-scale chamber study. Environmental Science \& Technology. 2006;40:4421-4428.

299. Reiss R, Ryan PB, Koutrakis P, Tibbetts SJ. Ozone reactive chemistry on interior latex paint. Environmental Science \& Technology. 1995;29:1906-1912.

This article is protected by copyright. All rights reserved 
300. Schieweck A, Bock M-C. Emissions from low-VOC and zero-VOC paints - Valuable alternatives to conventional formulations also for use in sensitive environments? Building and Environment. $2015 ; 85: 243-252$.

301. Kuo S-C, Tsai YI, Sopajaree K. Emission characteristics of carboxylates in $\mathrm{PM}_{2.5}$ from incense burning with the effect of light on acetate. Atmospheric Environment. 2016;138:125-134.

302. Christian TJ, Yokelson RJ, Cárdenas B, Molina LT, Engling G, Hsu S-C. Trace gas and particle emissions from domestic and industrial biofuel use and garbage burning in central Mexico. Atmospheric Chemistry and Physics. 2010;10:565-584.

303. Prosek T, Taube M, Dubois F, Thierry D. Application of automated electrical resistance sensors for measurement of corrosion rate of copper, bronze and iron in model indoor atmospheres containing short-chain volatile carboxylic acids. Corrosion Science. 2014;87:376382.

304. Graedel TE. Chemical mechanisms for the atmospheric corrosion of lead. Journal of the Electrochemical Society. 1994;141:922-927.

305. Niklasson A, Langer S, Arrhenius K, et al. Air pollutant concentrations and atmospheric corrosion of organ pipes in European church environments. Studies in Conservation. 2008;53:2440.

306. Kontozova-Deutsch V, Deutsch F, Bencs L, Krata A, Van Grieken R, De Wael K. Optimization of the ion chromatographic quantification of airborne fluoride, acetate and formate in the Metropolitan Museum of Art, New York. Talanta. 2011;86:372-376.

307. Dedecker K, Pilla RS, Nouar F, et al. Metal-organic frameworks for cultural heritage preservation: The case of acetic acid removal. ACS Applied Materials \& Interfaces. 2018;10:13886-13894.

308. Truffier-Boutry D, Fiorentino B, Bartolomei V, et al. Characterization of photocatalytic paints: A relationship between the photocatalytic properties - release of nanoparticles and volatile organic compounds. Environmental Science: Nano. 2017;4:1998-2009.

This article is protected by copyright. All rights reserved 
309. Fang M, Webster TF, Stapleton HM. Effect-directed analysis of human peroxisome proliferator-activated nuclear receptors (PPAR $\gamma 1$ ) ligands in indoor dust. Environmental Science \& Technology. 2015;49:10065-10073.

310. Robinson AL, Subramanian R, Donahue NM, Bernardo-Bricker A, Rogge WF. Source apportionment of molecular markers and organic aerosol. 3. Food cooking emissions. Environmental Science \& Technology. 2006;40:7820-7827.

311. Rogge WF, Mazurek MA, Hildemann LM, Cass GR, Simoneit BRT. Quantification of urban organic aerosols at a molecular level: Identification, abundance and seasonal variation. Atmospheric Environment. 1993;27A:1309-1330.

312. Hou X, Zhuang G, Lin Y, Li J, Jiang Y, Fu JS. Emission of fine organic aerosol from traditional charcoal broiling in China. Journal of Atmospheric Chemistry. 2008;61:119-131.

313. Rogge WF, Hildemann LM, Mazurek MA, Cass GR, Simoneit BRT. Sources of fine organic aerosol. 1. Charbroilers and meat cooking operations. Environmental Science \& Technology. 1991;25: 1112-1125.

314. He L-Y, Hu M, Huang X-F, Yu B-D, Zhang Y-H, Liu D-Q. Measurement of emissions of fine particulate organic matter from Chinese cooking. Atmospheric Environment. 2004;38:6557-6564.

315. Zhao Y, Hu M, Slanina S, Zhang Y. Chemical compositions of fine particulate organic matter emitted from Chinese cooking. Environmental Science \& Technology. 2007;41:99-105.

316. Fine PM, Cass GR, Simoneit BRT. Characterization of fine particle emissions from burning church candles. Environmental Science \& Technology. 1999;33:2352-2362.

317. Arhami M, Minguillón MC, Polidori A, Schauer JJ, Delfino RJ, Sioutas C. Organic compound characterization and source apportionment of indoor and outdoor quasi-ultrafine particulate matter in retirement homes of the Los Angeles Basin. Indoor Air. 2010;20:17-30.

318. Hasheminassab S, Daher N, Shafer MM, Schauer JJ, Delfino RJ, Sioutas C. Chemical characterization and source apportionment of indoor and outdoor fine particulate matter $\left(\mathrm{PM}_{2.5}\right)$ in retirement communities of the Los Angeles Basin. Science of the Total Environment. 2014;490:528-537.

319. Nicolaides N. Skin lipids: Their biochemical uniqueness. Science. 1974;186:19-26.

This article is protected by copyright. All rights reserved 
320. Weitkamp AW, Smiljanic AM, Rothman S. The free fatty acids of human hair fat. Journal of the American Chemical Society. 1947;69:1936-1939.

321. Licina D, Tian Y, Nazaroff WW. Emission rates and the personal cloud effect associated with particle release from the perihuman environment. Indoor Air. 2017;27:791-802.

322. Weschler CJ, Langer S, Fischer A, Bekö G, Toftum J, Clausen G. Squalene and cholesterol in dust from Danish homes and daycare centers. Environmental Science \& Technology. 2011;45:3872-3879.

323. Daher N, Ruprecht A, Invernizzi G, et al. Chemical characterization and source apportionment of fine and coarse particulate matter inside the refectory of Santa Maria Delle Grazie Church, home of Leonardo da Vinci's "Last Supper." Environmental Science \& Technology. 2011;45:10344-10353.

324. Pagonis D, Price DJ, Algrim LB, et al. Time-resolved measurements of indoor chemical emissions, deposition, and reactions in a university art museum. Environmental Science \& Technology. 2019;53:4794-4802.

325. Bretti C, Crea F, Foti C, Sammartano S. Solubility and activity coefficients of acidic and basic nonelectrolytes in aqueous salt solutions. 2 . Solubility and activity coefficients of suberic, azelaic, and sebacic acids in $\mathrm{NaCl}(\mathrm{aq}),\left(\mathrm{CH}_{3}\right)_{4} \mathrm{NCl}(\mathrm{aq})$, and $\left(\mathrm{C}_{2} \mathrm{H}_{5}\right)_{4} \mathrm{NI}(\mathrm{aq})$ at different ionic strengths and at $t=25^{\circ} \mathrm{C}$. Journal of Chemical and Engineering Data. 2006;51:1660-1667.

326. Wisthaler A, Weschler CJ. Reactions of ozone with human skin lipids: Sources of carbonyls, dicarbonyls, and hydroxycarbonyls in indoor air. Proceedings of the National Academy of Sciences of the USA. 2010;107:6568-6575.

327. Pegas PN, Nunes T, Alves CA, et al. Indoor and outdoor characterisation of organic and inorganic compounds in city centre and suburban elementary schools of Aveiro, Portugal. Atmospheric Environment. 2012;55:80-89.

328. Alves CA, Urban RC, Pegas PN, Nunes T. Indoor/outdoor relationships between $\mathrm{PM}_{10}$ and associated organic compounds in a primary school. Aerosol and Air Quality Research. 2014;14:86-98.

This article is protected by copyright. All rights reserved 
329. Erhardt D, Bischoff JJ. The roles of various components of resin soaps, bile acid soaps and gels, and their effects on oil paint films. Studies in Conservation. 1994;39:3-27.

330. Zhang Y, Obrist D, Zielinska B, Gertler A. Particulate emissions from different types of biomass burning. Atmospheric Environment. 2013;72:27-35.

331. Ward $\mathrm{T}$, Noonan $\mathrm{C}$. Results of a residential indoor $\mathrm{PM}_{2.5}$ sampling program before and after a woodstove changeout. Indoor Air. 2008;18:408-415.

332. Noonan CW, Navidi W, Sheppard L, et al. Residential indoor $\mathrm{PM}_{2.5}$ in wood stove homes: Follow-up of the Libby changeout program. Indoor Air. 2012;22:492-500.

333. Kawamura K, Kaplan IR. Motor exhaust emissions as a primary source for dicarboxylic acids in Los Angeles ambient air. Environmental Science \& Technology. 1987;21:105-110.

334. Kawamura K, Yasui O. Diurnal changes in the distribution of dicarboxylic acids, ketocarboxylic acids and dicarbonyls in the urban Tokyo atmosphere. Atmospheric Environment. 2005;39:19451960.

335. Khwaja HA. Atmospheric concentrations of carboxylic acids and related compounds at a semiurban site. Atmospheric Environment. 1995;29:127-139.

336. Zhao W, Kawamura K, Yue S, et al. Molecular distribution and compound-specific stable carbon isotopic composition of dicarboxylic acids, oxocarboxylic acids and $\alpha$-dicarbonyls in $\mathrm{PM}_{2.5}$ from Beijing, China. Atmospheric Chemistry and Physics. 2018;18:2749-2767.

337. Ho KF, Lee SC, Ho SSH, et al. Dicarboxylic acids, ketocarboxylic acids, $\alpha$-dicarbonyls, fatty acids, and benzoic acid in urban aerosols collected during the 2006 Campaign of Air Quality Research in Beijing (CAREBeijing-2006). Journal of Geophysical Research. 2010;115:D19312.

338. He N, Kawamura K, Okuzawa K, et al. Diurnal and temporal variations of water-soluble dicarboxylic acids and related compounds in aerosols from the northern vicinity of Beijing: Implications for photochemical aging during atmospheric transport. Science of the Total Environment. 2014;499:154-165.

339. Wang J, Wang G, Gao J, et al. Concentrations and stable carbon isotope compositions of oxalic acid and related SOA in Beijing before, during, and after the 2014 APEC. Atmospheric Chemistry and Physics. 2017;17:981-992.

This article is protected by copyright. All rights reserved 
340. Abdullahi KL, Delgado-Saborit JM, Harrison RM. Emissions and indoor concentrations of particulate matter and its specific chemical components from cooking: A review. Atmospheric Environment. 2013;71:260-294.

341. Zhao Y, Hu M, Slanina S, Zhang Y. The molecular distribution of fine particulate organic matter emitted from Western-style fast food cooking. Atmospheric Environment. 2007;41:81638171.

342. Zhong L, Goldberg MS, Gao Y-T, Jin F. Lung cancer and indoor air pollution arising from Chinese-style cooking among nonsmoking women living in Shanghai, China. Epidemiology. 1999;10:488-494.

343. Ko Y-C, Cheng L S-C, Lee $\mathrm{C}-\mathrm{H}$, et al. Chinese food cooking and lung cancer in women nonsmokers. American Journal of Epidemiology. 2000;151:140-147.

344. Qu YH, Xu GX, Zhou JZ, et al. Genotoxicity of heated cooking oil vapors. Mutation Research. 1992;298:105-111.

345. Shields PG, Xu GX, Blot WJ, et al. Mutagens from heated Chinese and U.S. cooking oils. Journal of the National Cancer Institute. 1995;87:836-841.

346. Saffari A, Daher N, Ruprecht A, et al. Particulate metals and organic compounds from electronic and tobacco-containing cigarettes: Comparison of emission rates and secondhand exposure. Environmental Science: Processes and Impacts. 2014;16:2259-2267.

347. Ruprecht AA, De Marco C, Saffari A, et al. Environmental pollution and emission factors of electronic cigarettes, heat-not-burn tobacco products, and conventional cigarettes Aerosol Science and Technology. 2017;51:674-684.

348. Fox A, Harley W, Feigley C, Salzberg D, Sebastian A, Larsson L. Increased levels of bacterial markers and $\mathrm{CO}_{2}$ in occupied school rooms. Journal of Environmental Monitoring. 2003;5:246252.

349. Weschler CJ, Shields HC. Indoor ozone/terpene reactions as a source of indoor particles. Atmospheric Environment. 1999;33:2301-2312.

This article is protected by copyright. All rights reserved 
350. Glasius M, Lahaniati M, Calogirou A, et al. Carboxylic acids in secondary aerosols from oxidation of cyclic monoterpenes by ozone. Environmental Science \& Technology. 2000;34:10011010.

351. Fick J, Nilsson C, Andersson B. Formation of oxidation products in a ventilation system. Atmospheric Environment. 2004;38:5895-5899.

352. Larsen BR, Breinbjerg B, Duane $M$, et al. Ozonolysis of $\beta$-pinene at conditions relevant for indoor environments: Influence of temperature on the composition of secondary organic aerosol. Fresenius Environmental Bulletin. 2012;21:2795-2804.

353. Morrison GC, Nazaroff WW. Ozone interactions with carpet: Secondary emissions of aldehydes. Environmental Science \& Technology. 2002;36:2185-2192.

354. Thornberry T, Abbatt JPD. Heterogeneous reaction of ozone with liquid unsaturated fatty acids: detailed kinetics and gas-phase product studies. Physical Chemistry Chemical Physics. 2004;6:84-93.

355. Zhou S, Forbes MW, Abbatt JPD. Kinetics and products from heterogeneous oxidation of squalene with ozone. Environmental Science \& Technology. 2016;50:11688-11697.

356. Zhou S, Forbes MW, Katrib Y, Abbatt JPD. Rapid oxidation of skin oil by ozone. Environmental Science \& Technology Letters. 2016;3:170-174.

357. Dockery DW, Cunningham J, Damokosh Al, et al. Health effects of acid aerosols on North American children: Respiratory symptoms. Environmental Health Perspectives. 1996;104:500505.

358. Lippmann M. Airborne acidity: Estimates of exposure and human health effects. Environmental Health Perspectives. 1985;63:63-70.

359. Tanner RL. Measuring the strong acid content of atmospheric aerosol particles. Advances in Chemistry Series. 1993;232:229-241.

360. Freedman MA, Ott EJE, Marak KE. Role of $\mathrm{pH}$ in aerosol processes and measurement challenges. Journal of Physical Chemistry A. 2019;123:1275-1284.

361. Ding J, Zhao P, Su J, Dong Q, Du X, Zhang Y. Aerosol pH and its driving factors in Beijing. Atmospheric Chemistry and Physics. 2019;19:7939-7954.

This article is protected by copyright. All rights reserved 
362. Liu M, Song Y, Zhou T, et al. Fine particle pH during severe haze episodes in northern China. Geophysical Research Letters. 2017;44:5213-5221.

363. Koutrakis P, Wolfson JM, Slater JL, et al. Evaluation of an annular denuder/filter pack system to collect acidic aerosols and gases. Environmental Science \& Technology. 1988;22:1463-1468.

364. Koutrakis P, Wolfson JM, Spengler JD. An improved method for measuring aerosol strong acidity: Results from a nine-month study in St Louis, Missouri and Kingston, Tennessee. Atmospheric Environment. 1988;22:157-162.

365. Lipfert FW, Morris SC, Wyzga RE. Acid aerosols: The next criteria air pollutant? Environmental Science \& Technology. 1989;23:1316-1322.

366. Ludwig J, Klemm O. Acidity of size-fractionated aerosol particles. Water, Air, and Soil Pollution. 1990;49:35-50.

367. Fang T, Guo H, Zeng L, Verma V, Nenes A, Weber RJ. Highly acidic ambient particles, soluble metals, and oxidative potential: A link between sulfate and aerosol toxicity. Environmental Science \& Technology. 2017;51:2611-2620.

368. Brook JR, Wiebe AH, Woodhouse SA, et al. Temporal and spatial relationships in fine particle strong acidity, sulphate, $\mathrm{PM}_{10}$ and $\mathrm{PM}_{2.5}$ across multiple Canadian locations. Atmospheric Environment. 1997;31:4223-4236.

369. Suh HH, Allen GA, Koutrakis P, Burton RM. Spatial variation in acidic sulfate and ammonia concentrations within metropolitan Philadelphia. Journal of the Air \& Waste Management Association. 1995;45:442-452.

370. Liu L-JS, Burton R, Wilson WE, Koutrakis P. Comparison of aerosol acidity in urban and semirural environments. Atmospheric Environment. 1996;30:1237-1245.

371. Cadle SH. Seasonal variations in nitric acid, nitrate, strong aerosol acidity, and ammonia in an urban area. Atmospheric Environment. 1985;19:181-188.

372. Thurston GD, Gorczynski JE Jr, Currie JH, et al. The nature and origin of acid summer haze air pollution in metropolitan Toronto, Ontario. Environmental Research. 1994;65:254-270.

373. Aas W, Mortier A, Bowersox V, et al., Global and regional trends of atmospheric sulfur. Scientific Reports 2019;9:953.

This article is protected by copyright. All rights reserved 
374. Murphy JG, Gregoire PK, Tevlin AG, et al. Observational constraints on particle acidity using measurements and modelling of particles and gases. Faraday Discussions. 2017;200:379-395.

375. Weber RJ, Guo H, Russell AG, Nenes A. High aerosol acidity despite declining atmospheric sulfate concentrations over the past 15 years. Nature Geoscience. 2016;9:282-285.

376. Suh HH, Koutrakis P, Spengler JD. Validation of personal exposure models for sulfate and aerosol strong acidity. Journal of the Air \& Waste Management Association. 1993;43:845-850.

377. Chan C-C, Hung H-F, Fu L-F. The indoor/outdoor relationship of acid aerosols in Taipei. Science of the Total Environment. 1994;153:267-273.

378. Waldman JM, Koutrakis P, Allen GA, Thurston GD, Burton RM, Wilson WE. Human exposures to particle strong acidity. Inhalation Toxicology. 1995;7:657-669.

379. Ostro BD, Lipsett MJ, Wiener MB, Selner JC. Asthmatic responses to airborne acid aerosols. American Journal of Public Health. 1991;81:694-702.

380. Dockery DW, Schwartz J, Spengler JD. Air pollution and daily mortality: Associations with particulates and acid aerosols. Environmental Research. 1992;59:362-373.

381. Thurston GD, Ito K, Hayes CG, Bates DV, Lippmann M. Respiratory hospital admissions and summertime haze air pollution in Toronto, Ontario: Consideration of the role of acid aerosols. Environmental Research. 1994;65:271-290.

382. Raizenne M, Neas LM, Damokosh Al, et al. Health effects of acid aerosols on North American children: Pulmonary function. Environmental Health Perspectives. 1996;104:506-514.

383. Gwynn RC, Burnett RT, Thurston GD. A time-series analysis of acidic particulate matter and daily mortality and morbidity in the Buffalo, New York, region. Environmental Health Perspectives. 2000;108:125-133.

384. Creighton TH. Proteins: Structures and Molecular Properties. Second edition. San Francisco: W. H. Freeman. 1993.

385. Ge X, Wexler AS, Clegg SL. Atmospheric amines - Part I. A review. Atmospheric Environment. 2011;45:524-546.

386. Ge X, Wexler AS, Clegg SL. Atmospheric amines - Part II. Thermodynamic properties and gas/particle partitioning. Atmospheric Environment. 2011;45:561-577.

This article is protected by copyright. All rights reserved 
387. Lee DY, Wexler AS. Atmospheric amines - Part III: Photochemistry and toxicity. Atmospheric Environment. 2013;71:95-103.

388. Yao L, Wang M-Y, Wang X-K, et al. Detection of atmospheric gaseous amines and amides by a high-resolution time-of-flight chemical ionization mass spectrometer with protonated ethanol reagent ions. Atmospheric Chemistry and Physics. 2016;16:14527-14543.

389. VandenBoer TC, Markovic MZ, Petroff A, Czar MF, Borduas N, Murphy JG. Ion chromatographic separation and quantitation of alkyl methylamines and ethylamines in atmospheric gas and particulate matter using preconcentration and suppressed conductivity detection. Journal of Chromatography A. 2012;1252:74-83.

390. You Y, Kanawade VP, de Gouw JA, et al. Atmospheric amines and ammonia measured with a chemical ionization mass spectrometer (CIMS). Atmospheric Chemistry and Physics. 2014;14:12181-12194.

391. Akyüz M. Simultaneous determination of aliphatic and aromatic amines in indoor and outdoor air samples by gas chromatography-mass spectrometry. Talanta. 2007;71:486-492.

392. Nielsen CJ, D’Anna B, Bossi R, et al. Atmospheric Degradation of Amines (ADA): Summary report from atmospheric chemistry studies of amines, nitrosamines, nitramines and amides. CLIMIT project no. 208122. Oslo, Norway, 2012.

393. Nielsen CJ, Herrmann H, Weller C. Atmospheric chemistry and environmental impact of the use of amines in carbon capture and storage (CCS). Chemical Society Reviews. 2012;41:66846704.

394. Akyüz M. Simultaneous determination of aliphatic and aromatic amines in ambient air and airborne particulate matters by gas chromatography-mass spectrometry. Atmospheric Environment. 2008;42:3809-3819.

395. Qiu C, Zhang R. Multiphase chemistry of atmospheric amines. Physical Chemistry Chemical Physics. 2013;15:5738-5752.

396. Svec HJ, Clyde DD. Vapor pressures of some $\alpha$-amino acids. Journal of Chemical \& Engineering Data. 1965;10:151-152.

This article is protected by copyright. All rights reserved 
397. Mopper K, Zika RG. Free amino acids in marine rains: evidence for oxidation and potential role in nitrogen cycling. Nature. 1987;325:246-249.

398. Zhang $Q$, Anastasio C. Free and combined amino compounds in atmospheric fine particles $\left(\mathrm{PM}_{2.5}\right)$ and fog waters from Northern California. Atmospheric Environment. 2003;37;2247-2258.

399. Matsumoto K, Uematsu M. Free amino acids in marine aerosols over the western North Pacific Ocean. Atmospheric Environment. 2005;39:2163-2170.

400. Mandalakis M, Apostolaki M, Tziaras T, Polymenakou P, Stephanou EG. Free and combined amino acids in marine background atmospheric aerosols over the Eastern Mediterranean. Atmospheric Environment. 2011;45:1003-1009.

401. Di Filippo P, Pomata D, Riccardi C, Buiarelli F, Gallo V, Quaranta A. Free and combined amino acids in size-segregated atmospheric aerosol samples. Atmospheric Environment. 2014;98:179189.

402. Ren L, Bai H, Yu X, et al. Molecular composition and seasonal variation of amino acids in urban aerosols from Beijing, China. Atmospheric Research. 2018;203:28-35.

403. Xu Y, Wu D, Xiao H, Zhou J. Dissolved hydrolyzed amino acids in precipitation in suburban Guiyang, southwestern China: Seasonal variations and potential atmospheric processes. Atmospheric Environment. 2019;211:247-255.

404. Schmeltz I, Hoffmann D. Nitrogen-containing compounds in tobacco and tobacco smoke. Chemical Reviews. 1977;77:295-311.

405. Grimmer G, Naujack K-W, Dettbarn G. Gaschromatographic determination of polycyclic aromatic hydrocarbons, aza-arenes, aromatic amines in the particle and vapor phase of mainstream and sidestream smoke of cigarettes. Toxicology Letters. 1987;35:117-124.

406. Luceri F, Pieraccini G, Moneti G, Dolara P. Primary aromatic amines from side-stream cigarette smoke are common contaminants of indoor air. Toxicology and Industrial Health. 1993;9:405-413.

407. Palmiotto G, Pieraccini G, Moneti G, Dolara P. Determination of the levels of aromatic amines in indoor and outdoor air in Italy. Chemosphere. 2001;43:355-361.

This article is protected by copyright. All rights reserved 
408. Deng H, Yang F, Li Z, et al. Rapid determination of 9 aromatic amines in mainstream cigarette smoke by modified dispersive liquid liquid microextraction and ultraperformance convergence chromatography tandem mass spectrometry. Journal of Chromatography A. 2017;1507:37-44.

409. Gross GA, Grüter A. Quantitation of mutagenic/carcinogenic heterocyclic aromatic amines in food products. Journal of Chromatography. 1992;592:271-278.

410. Chiang T-A, Wu P-F, Liao S-Y, Wang L-F, Ko YC. Mutagenicity and aromatic amine content of fumes from heated cooking oils produced in Taiwan. Food and Chemical Toxicology. 1999;37:125-134.

411. Fannick N, Lipscomb J, McManus K. NIOSH, Health hazard evaluation report no. HETA 83-0201351. Cincinnati: US Department of Health and Human Services, Public Health Service, CDC. 1983. https://www.cdc.gov/niosh/nioshtic-2/00135380.html (last accessed 8/17/2019)

412. Volent $P$, Baer NS. Volatile amines used as corrosion inhibitors in museum humidification systems. International Journal of Museum Management and Curatorship. 1985;4:359-364.

413. Edgerton SA, Kenny DV, Joseph DW. Determination of amines in indoor air from steam humidification. Environmental Science \& Technology. 1989;23:484-488.

414. Sollinger S, Levsen K, Wünsch G. Indoor pollution by organic emissions from textile floor coverings: Climate test chamber studies under static conditions. Atmospheric Environment. 1994;28:2369-2378.

415. Licina D, Morrison GC, Bekö G, Weschler CJ, Nazaroff WW. Clothing-mediated exposures to chemicals and particles. Environmental Science \& Technology. 2019;53:5559-5575.

416. Karlsson S, Banhidi ZG, Albertsson A-C. Gas chromatographic detection of volatile amines found in indoor air due to putrefactive degradation of casein-containing building materials. Materials and Structures. 1989;22:163-169.

417. Robinson S, Robinson AH. Chemical composition of sweat. Physiological Reviews. $1954 ; 34: 202-220$.

418. Burke RC, Lee TH, Buettner-Janusch V. Free amino acids and water soluble peptides in stratum corneum and skin surface film in human beings. Yale Journal of Biology and Medicine. 1966;38:355-373.

This article is protected by copyright. All rights reserved 
419. Caspers PJ, Lucassen GW, Carter EA, Bruining HA, Puppels GJ. In vivo confocal Raman microspectroscopy of the skin: Noninvasive determination of molecular concentration profiles. Journal of Investigative Dermatology. 2001;116:434-442.

420. Slominski AT, Zmijewski MA, Skobowiat C, Zbytek B, Slominski RM, Steketee JD. Sensing the environment: Regulation of local and global homeostasis by the skin's neuroendocrine system. Advances in Anatomy, Embryology and Cell Biology. 2012;212.1-115.

421. Dunstan RH, Sparkes DL, Dascombe BJ, et al. Sweat facilitated amino acid losses in male athletes during exercise at 32-34 ${ }^{\circ} \mathrm{C}$. PLoS One. 2016;11:e0167844.

422. Hussain H, Ziegler J, Hause G, Wohlrab J, Neubert RHH. Quantitative analysis of free amino acids and urea derived from isolated corneocytes of healthy young, healthy aged, and diseased skin. Skin Pharmacology and Physiology. 2019;32:94-100.

423. Celleno L. Topical urea in skincare: A review. Dermatologic Therapy. 2018;31:e12690.

424. Keating G, Bogen K. Estimates of heterocyclic amine intake in the US population. Journal of Chromatography B. 2004;802:127-133.

425. McManus KP, Baker DB. NIOSH, Health hazard evaluation report no. HETA 81-247-958. Cincinnati: US Department of Health and Human Services, Public Health Service, CDC. 1981. https://www.cdc.gov/niosh/nioshtic-2/00119085.html. Last accessed 18 August 2019.

426. Zhu J, Aikawa B. Determination of aniline and related mono-aromatic amines in indoor air in selected Canadian residences by a modified thermal desorption GC/MS method. Environment International. 2004;30:135-143.

427. Rampfl M, Mayer F, Breuer K, Neissner R. Derivatization-free analysis of volatile aliphatic and aromatic primary, secondary and tertiary amines in indoor air by HPLC-ESI-MS. In Yang X, Zhao B, Zhao R. Indoor Air 2005: Proceedings of the Tenth International Conference on Indoor Air Quality and Climate, Beijing, China, pp. 2144-2148. 2005.

428. Hier SW, Cornbleet T, Bergeim O. The amino acids of human sweat. Journal of Biological Chemistry. 1946;166:327-333.

429. Coltman CA Jr, Rowe NJ, Atwell RJ. The amino acid content of sweat in normal adults. American Journal of Clinical Nutrition. 1966;18:373-378.

This article is protected by copyright. All rights reserved 
430. Nakagawa N, Sakai S, Matsumoto M, et al. Relationship between NMF (lactate and potassium) content and the physical properties of the stratum corneum in healthy subjects. Journal of Investigative Dermatology. 2004;122:755-763.

431. Kurtén T, Loukonen V, Vehkamäki H, Kulmala M. Amines are likely to enhance neutral and ion-induced sulfuric acid-water nucleation in the atmosphere more effectively than ammonia. Atmospheric Chemistry and Physics. 2008;8:4095-4103.

432. Zhao J, Smith JN, Eisele FL, Chen M, Kuang C, McMurry PH. Observation of neutral sulfuric acid-amine containing clusters in laboratory and ambient measurements. Atmospheric Chemistry and Physics. 2011;11:10823-10836.

433. Kürten A, Jokinen $\mathrm{T}$, Simon $\mathrm{M}$, et al. Neutral molecular cluster formation of sulfuric aciddimethylamine observed in real time under atmospheric conditions. Proceedings of the National Academy of Sciences of the USA. 2014;111:15019-15024.

434. Shen $\mathrm{W}$, Ren $\mathrm{L}$, Zhao $\mathrm{Y}$, et al. C1-C2 alkyl aminiums in urban aerosols: Insights from ambient and fuel combustion emission measurements in the Yangtze River Delta region of China. Environmental Pollution. 2017;230:12-21.

435. Murphy SM, Sorooshian A, Kroll JH, et al. Secondary aerosol formation from atmospheric reactions of aliphatic amines. Atmospheric Chemistry and Physics. 2007;7:2313-2337.

436. Zahardis J, Geddes S, Petrucci GA, The ozonolysis of primary aliphatic amines in fine particles. Atmospheric Chemistry and Physics. 2008;8:1181-1194.

437. Barsanti KC, Pankow JF. Thermodynamics of the formation of atmospheric organic particulate matter by accretion reactions-Part 3: Carboxylic and dicarboxylic acids. Atmospheric Environment. 2006;40:6676-6686.

438. Liu F, Bi X, Zhang G, et al. Gas-to-particle partitioning of atmospheric amines observed at a mountain site in southern China. Atmospheric Environment. 2018;195:1-11.

439. Destaillats H, Singer BC, Gundel LA. Evidence of acid-base interactions between amines and model indoor surfaces by ATR-FTIR spectroscopy. Atmospheric Environment. 2007;41:3177-3181.

440. Fowler RT. A redetermination of the ionization constants of nicotine. Journal of Applied Chemistry. 1954;4:449-452.

This article is protected by copyright. All rights reserved 
441. Wang TW, Asman K, Gentzke AS, et al. Tobacco product use among adults - United States, 2017. Morbidity and Mortality Weekly Report. 2018;67:1225-1232.

442. Olivieri M, Murgia N, Carsin A-E, et al. Effects of smoking bans on passive smoking exposure at work and at home. The European Community respiratory health survey. Indoor Air. 2019;29:670-679.

443. Czogala J, Goniewicz ML, Fidelus B, Zielinska-Danch W, Travers MJ, Sobczak A. Secondhand exposure to vapors from electronic cigarettes. Nicotine \& Tobacco Research. 2014;16:655-662.

444. Grana R, Benowitz N, Glantz SA. E-cigarettes: A scientific review. Circulation. 2014;129:19721986.

445. Schober W, Szendrei K, Matzen W, et al. Use of electronic cigarettes (e-cigarettes) impairs indoor air quality and increases FeNO levels of e-cigarette consumers. International Journal of Hygiene and Environmental Health. 2014;217:628-637.

446. Forrester MB. Pediatric exposures to electronic cigarettes reported to Texas poison centers. The Journal of Emergency Medicine. 2015;49:136-142.

447. Hu SS, Homa DM, Wang T, et al. State-specific patterns of cigarette smoking, smokeless tobacco use, and e-cigarette use among adults - United States, 2016. Preventing Chronic Disease. 2019;16:E17.

448. Schripp T, Markewitz D, Uhde E, Salthammer T. Does e-cigarette consumption cause passive vaping? Indoor Air. 2013;23:25-31.

449. Pankow JF. A consideration of the role of gas/particle partitioning in the deposition of nicotine and other tobacco smoke compounds in the respiratory tract. Chemical Research in Toxicology. 2001;14:1465-1481.

450. Collins DB, Wang C, Abbatt JPD. Selective uptake of third-hand tobacco smoke components to inorganic and organic aerosol particles. Environmental Science \& Technology. 2018;52:1319513201.

451. Leaderer BP, Hammond SK. Evaluation of vapor-phase nicotine and respirable suspended particle mass as markers for environmental tobacco smoke. Environmental Science \& Technology. 1991;25:770-777.

This article is protected by copyright. All rights reserved 
452. Coultas DB, Samet JM, McCarthy JF, Spengler JD. Variability of measures of exposure to environmental tobacco smoke in the home. American Review of Respiratory Disease. 1990;142:602-606.

453. Scherer G, Meger-Kossien I, Riedel K, Renner T, Meger M. Assessment of the exposure of children to environmental tobacco smoke (ETS) by different methods. Human and Experimental Toxicology. 1999;18:297-301.

454. Matt GE, Quintana PJE, Hovell MF, et al. Households contaminated by environmental tobacco smoke: sources of infant exposures. Tobacco Control. 2004;13:29-37.

455. Gehring U, Leaderer BP, Heinrich J, et al. Comparison of parental reports of smoking and residential air nicotine concentrations in children. Occupational and Environmental Medicine. 2006;63:766-772.

456. Kim H, Lim Y, Lee S, et al. 2004. Relationship between environmental tobacco smoke and urinary cotinine levels in passive smokers at their residence. Journal of Exposure Science and Environmental Epidemiology. 2004;14:S65-S70.

457. Young HD, Nelson OA. Vapor pressures of fumigants. IV - Vapor pressure of nicotine. Industrial \& Engineering Chemistry. 1929;21:321-322.

458. Siitsman C, Kamenev I, Oja V. Vapor pressure data of nicotine, anabasine and cotinine using differential scanning calorimetry. Thermochimica Acta. 2014;595:35-42.

459. Singer BC, Revzan KL, Hotchi T, Hodgson AT, Brown NJ. Sorption of organic gases in a furnished room. Atmospheric Environment. 2004;38:2483-2494.

460. Wei W, Mandin C, Blanchard O, et al. Distributions of the particle/gas and dust/gas partition coefficients for seventy-two semi-volatile organic compounds in indoor environment. Chemosphere. 2016;153:212-219.

461. Weschler CJ, Nazaroff WW. SVOC partitioning between the gas phase and settled dust indoors. Atmospheric Environment. 2010;44:3609-3620.

462. Willers S, Hein HO, Jansson L. Assessment of environmental tobacco smoke exposure: urinary cotinine concentrations in children are strongly associated with the house dust concentrations of nicotine at home. Indoor Air. 2004;14:83-86.

This article is protected by copyright. All rights reserved 
463. Kim S, Aung T, Berkeley E, Diette GB, Breysse PN. Measurement of nicotine in household dust. Environmental Research. 2008;108:289-293.

464. Whitehead T, Metayer $\mathrm{C}$, Ward MH, et al. Is house-dust nicotine a good surrogate for household smoking? American Journal of Epidemiology. 2009;169:1113-1123.

465. Weschler CJ, Langer S, Fischer A, Bekö G, Toftum J, Clausen G. Nicotine in dust samples collected from children's bedrooms and daycare centers in Denmark. In: Proceedings of the 12th International Conference on Indoor Air Quality and Climate, 2011.

https://www.isiaq.org/docs/presentations/0326_Weschler.pdf (last accessed Sept 3, 2019).

466. Hein HO, Suadicani P, Skov P, Gyntelberg F. Indoor dust exposure: an unnoticed aspect of involuntary smoking. Archives of Environmental Health. 1991;46:98-101.

467. Van Loy MD, Lee VC, Gundel LA, Daisey JM, Sextro RG, Nazaroff WW. Dynamic behavior of semivolatile organic compounds in indoor air: 1 . Nicotine in a stainless steel chamber. Environmental Science \& Technology. 1997;31:2554-2561.

468. Van Loy MD, Riley WJ, Daisey JM, Nazaroff WW. Dynamic behavior of semivolatile organic compounds in indoor air. 2. Nicotine and phenanthrene with carpet and wallboard. Environmental Science \& Technology. 2001;35:560-567.

469. Dedesko S, Siegel JA. Moisture parameters and fungal communities associated with gypsum drywall in buildings. Microbiome. 2015;3:71.

470. Singer BC, Hodgson AT, Guevarra KS, Hawley EL, Nazaroff WW. Gas-phase organics in environmental tobacco smoke: 1 . Effects of smoking rate, ventilation, and furnishing level on emission factors. Environmental Science \& Technology. 2002;36:846-853.

471. Singer BC, Hodgson AT, Nazaroff WW. Gas-phase organics in environmental tobacco smoke: 2. Exposure-relevant emission factors and indirect exposures from habitual smoking. Atmospheric Environment. 2003;37:5551-5561.

472. Klepeis NE, Nazaroff WW. Modeling residential exposure to secondhand tobacco smoke. Atmospheric Environment. 2006;40:4393-4407. 
473. Van Loy MD, Nazaroff WW, Daisey JM. Nicotine as a marker for environmental tobacco smoke: Implications of sorption on indoor surface materials. Journal of the Air \& Waste Management Association. 1998;48:959-968.

474. Matt GE, Quintana PJE, Destaillats $\mathrm{H}$, et al. Thirdhand tobacco smoke: Emerging evidence and arguments for a multidisciplinary research agenda. Environmental Health Perspectives. 2011;119:1218-1226.

475. Matt GE, Quintana PJE, Fortmann AL, et al. Thirdhand smoke and exposure in California hotels: non-smoking rooms fail to protect non-smoking hotel guests from tobacco smoke exposure. Tobacco Control. 2014;23:264-272.

476. Sleiman M, Logue JM, Luo W, Pankow JF, Gundel LA, Destaillats H. Inhalable constituents of thirdhand tobacco smoke: Chemical characterization and health impact considerations. Environmental Science \& Technology. 2014;48:13093-13101.

477. Ongwandee M, Morrison GC, Guo X, Chusuei CC. Adsorption of trimethylamine on zirconium silicate and polyethylene powder surfaces. Colloids and Surfaces A: Physicochemical and Engineering Aspects. 2007;310:62-67.

478. Destaillats H, Singer BC, Lee SK, Gundel LA. Effect of ozone on nicotine desorption from model surfaces: Evidence for heterogeneous chemistry. Environmental Science \& Technology. 2006;40:1799-1805.

479. Petrick L, Destaillats H, Zouev I, Sabach S, Dubowski Y. Sorption, desorption, and surface oxidative fate of nicotine. Physical Chemistry Chemical Physics. 2010;12:10356-10364.

480. Weschler CJ, Carslaw N. Indoor chemistry. Environmental Science \& Technology. 2018;52:2419-2428.

481. Abbatt JPD, Wang C. The atmospheric chemistry of indoor environments. Environmental Science: Processes and Impacts. 2020;22:25-48.

482. Algrim LB, Pagonis D, de Gouw JA, Jimenez JL, Ziemann PJ. Measurements and modeling of absorptive partitioning of volatile organic compounds to painted surfaces. Indoor Air. In press. doi: 10.1111/ina.12654

This article is protected by copyright. All rights reserved 
483. Morrison GC, Nazaroff WW. The rate of ozone uptake on carpets: Experimental studies. Environmental Science \& Technology. 2000;34:4963-4968.

484. Hennig F, Quass U, Hellack B, et al., Ultrafine and fine particle number and surface area concentrations and daily cause-specific mortality in the Ruhr area, Germany, 2009-2014. Environmental Health Perspectives. 2018;126:027008.

485. Verbraecken J, Van de Heyning P, De Backer W, Van Gaal L. Body surface area in normalweight, overweight, and obese adults. A comparison study. Metabolism Clinical and Experimental. 2006;55:515-524.

486. Fluhr JW, Darlenski R, Lachmann N, et al. Infant epidermal skin physiology: adaptation after birth. British Journal of Dermatology. 2012;166:483-490.

487. Levin J, Maibach H. Human skin buffering capacity: an overview. Skin Research and Technology. 2008;14:121-126.

488. Cohen Hubal EA, Egeghy PP, Leovic KW, Akland GG. Measuring potential dermal transfer of a pesticide to children in a child care center. Environmental Health Perspectives. 2006;114:264269.

489. Cohen Hubal EA, Nishioka MG, Ivancic WA, Morara M, Egeghy PP. Comparing surface residue transfer efficiencies to hands using polar and nonpolar fluorescent tracers. Environmental Science \& Technology. 2008;42:934-939.

490. Butler DA, Madhavan G, Alper J. Health Risks of Indoor Exposure to Particulate Matter: Workshop Summary. Washington, DC: National Academies Press. doi: 10.17226/23531. 2016.

491. Asad A, Mmereki BT, Donaldson DJ. Enhanced uptake of water by oxidatively processed oleic acid. Atmospheric Chemistry and Physics. 2004;4:2083-2089.

492. Zhou S, Shiraiwa M, McWhinney RD, Pöschl U, Abbatt JPD. Kinetic limitations in gas-particle reactions arising from slow diffusion in secondary organic aerosol. Faraday Discussions. 2013;165:391-406.

493. Zhou S, Hwang BCH, Lakey PSJ, Zuend A, Abbatt JPD, Shiraiwa M. Multiphase reactivity of polycyclic aromatic hydrocarbons is driven by phase separation and diffusion limitations. Proceedings of the National Academy of Sciences of the USA. 2019;116: 11658-11663.

This article is protected by copyright. All rights reserved 
494. Nair MK, Chetty DJ, Ho H, Chien YW. Biomembrane permeation of nicotine: Mechanistic studies with porcine mucosae and skin. Journal of Pharmaceutical Sciences. 1997;86:257-262.

495. Bekö G, Morrison G, Weschler CJ, et al. Measurements of dermal uptake of nicotine directly from air and clothing. Indoor Air. 2017;27:427-433.

496. Bekö G, Morrison G, Weschler CJ, et al. Dermal uptake of nicotine from air and clothing: Experimental verification. Indoor Air. 2018;28:247-257.

497. Tanabe K, Yamaguchi T. Basicity and acidity of solid surfaces. Journal of the Research Institute for Catalysis Hokkaido University. 1964;11:179-184.

498. Yamanaka T, Tanabe K. A new determination of acid-base strength distribution of a common scale on solid surfaces. The Journal of Physical Chemistry. 1975;79:2409-2411.

499. Auroux A, Gervasini A. Microcalorimetric study of the acidity and basicity of metal oxide surfaces. Journal of Physical Chemistry. 1990;94:6371-6379.

500. Fowkes FM, Dwight DW, Cole DA, Huang TC. Acid-base properties of glass surfaces. Journal of Non-Crystalline Solids. 1990;120:47-60.

501. Sun C, Berg JC. A review of the different techniques for solid surface acid-base characterization. Advances in Colloid and Interface Science. 2003;105:151-175.

502. Rindelaub JD, Craig RL, Nandy L, et al. Direct measurement of pH in individual particles via Raman microspectroscopy and variation in acidity with relative humidity. The Journal of Physical Chemistry A. 2016;120:911-917.

503. Wei H, Vejerano EP, Leng W, et al. Aerosol microdroplets exhibit a stable pH gradient. Proceedings of the National Academy of Sciences of the USA. 2018;115:7272-7277.

504. Svensson R, Ljungström E, Lindqvist $\mathrm{O}$. Kinetics of the reaction between nitrogen dioxide and water vapour. Atmospheric Environment. 1987;21:1529-1539.

505. Won D, Corsi RL, Rynes M. Sorptive interactions between VOCs and indoor materials. Indoor Air. 2001;11:246-256.

506. Ongwandee M, Chatsuvan T, Suksawas Na Ayudhya W, Morris J. Understanding interactions in the adsorption of gaseous organic compounds to indoor materials. Environmental Science and Pollution Research. 2017;24:5654-5668.

This article is protected by copyright. All rights reserved 
507. Wania F, Lei YD, Wang C, Abbatt JPD, Goss K-U. Using the chemical equilibrium partitioning space to explore factors influencing the phase distribution of compounds involved in secondary organic aerosol formation. Atmospheric Chemistry and Physics. 2015;15:3395-3412.

508. DeFelsko Inspection Instruments. Paint Thickness Measurements - Drywall. https://www.defelsko.com/resources/paint-thickness-measurement-drywall (last accessed Sept 18, 2019).

509. ASTM. Standard Test Method for Nondestructive Measurement of Dry Film Thickness of Applied Organic Coatings Using an Ultrasonic Coating Thickness Gage. ASTM D6132-13. West Conshohocken, PA: ASTM International. 2013.

510. Eckhaus S, Wolock I, Harris BL. Porosity of paint films. Water vapor adsorption and permeability. Industrial \& Engineering Chemistry. 1953;45:426-428.

511. Sjöberg A, Ramnäs O. An experimental parametric study of VOC from flooring systems exposed to alkaline solutions. Indoor Air. 2007;17:450-457.

512. Uhde E, Salthammer T. Impact of reaction products from building materials and furnishings on indoor air quality-A review of recent advances in indoor chemistry. Atmospheric Environment. 2007;41:3111-3128.

513. Chino S, Kato S, Seo J, Ataka Y. Study on emission of decomposed chemicals of esters contained in PVC flooring and adhesive. Building and Environment. 2009;44:1337-1342.

514. Bope A, Haines SR, Hegarty B, Weschler CJ, Peccia J, Dannemiller KC. Degradation of phthalate esters in floor dust at elevated relative humidity. Environmental Science: Processes \& Impacts. 2019;21:1268-1279.

515. Odaka Y, Seto H, Nakaoka H, Hanazato M, Todaka E, Mori C. Aldehyde emissions from lime plaster containing vegetable oil. Indoor and Built Environment. 2016;25:254-261.

516. Salthammer T, Fuhrmann F. Photocatalytic surface reactions on indoor wall paint. Environmental Science \& Technology. 2007;41:6573-6578.

517. Schwartz-Narbonne H, Jones SH, Donaldson DJ. Indoor lighting releases gas phase nitrogen oxides from indoor painted surfaces. Environmental Science \& Technology Letters. 2019;6:92-97.

This article is protected by copyright. All rights reserved 
518. NASEM. National Academies of Sciences, Engineering, and Medicine. Microbiomes of the Built Environment: A Research Agenda for Indoor Microbiology, Human Health, and Buildings. Washington, DC: National Academies Press. doi: 10.17226/23647. 2017.

519. Adams RI, Bhangar S, Dannemiller KC, et al. Ten questions concerning the microbiomes of buildings. Building and Environment. 2016;109:224-234.

This article is protected by copyright. All rights reserved 
Table 1. Values of $L^{*}$ for different indoor circumstances. ${ }^{\text {a }}$

\begin{tabular}{|c|c|}
\hline Scenario & $L^{*}\left(L / m^{3}\right)^{b}$ \\
\hline Monolayer $\left(0.25 \mathrm{~nm}\right.$ thick) on all surfaces in a room with $S / V=3.5 \mathrm{~m}^{2} / \mathrm{m}^{3}$ & $0.9 \times 10^{-6}$ \\
\hline Surface layer (10 $\mathrm{nm}$ thick) on all surfaces in a room with $S / V=3.5 \mathrm{~m}^{2} / \mathrm{m}^{3}$ & $3.5 \times 10^{-5}$ \\
\hline Condensed water $(140 \mathrm{~g})$ on $8.4 \mathrm{~m}^{2}$ of interior windows in $350-\mathrm{m}^{3}$ residence & $4 \times 10^{-4}$ \\
\hline Sorbed water $(19 \mathrm{~g})$ in $2.2 \mathrm{~kg}$ of paint on walls and ceiling of $28-\mathrm{m}^{3}$ bedroom & $7 \times 10^{-4}$ \\
\hline Bulk condensed water $(0.35-35 \mathrm{~L})$ in $350-\mathrm{m}^{3}$ residence & $0.001-0.1$ \\
\hline Sorbed water $(4.5-9 \mathrm{~kg})$ on $150-300 \mathrm{~kg}$ of carpet fibers in a $350-\mathrm{m}^{3}$ residence & $0.013-0.026$ \\
\hline Bulk water $(2 \mathrm{~L})$ in coffee pot, vases and sink in $50-\mathrm{m}^{3}$ kitchen & 0.04 \\
\hline Sorbed water (1.3 kg) on $400 \mathrm{~kg}$ of gypsum board in a $28-\mathrm{m}^{3}$ bedroom & 0.05 \\
\hline Bulk water $(1 \mathrm{~L})$ in toilet bowl of $10 \mathrm{~m}^{3}$ bathroom & 0.1 \\
\hline
\end{tabular}

${ }^{a} L^{*}$ represents an equivalent volume fraction (water volume per air volume) that is chemically equilibrated with indoor air. In these scenarios we assume that all condensed-phase water is chemically equilibrated with indoor air in the same manner as for bulk liquid water. ${ }^{b}$ Dimensions for $L^{*}$ : liters (L) of water per $\mathrm{m}^{3}$ of air, equivalent to $\mathrm{kg}$ of water per $\mathrm{m}^{3}$ of air.

This article is protected by copyright. All rights reserved 
Table 2. Equilibrium moisture content of selected construction materials. ${ }^{\text {a }}$

\begin{tabular}{|c|c|c|c|c|}
\hline \multirow[b]{2}{*}{ Material } & \multicolumn{3}{|c|}{ Moisture content (mass $\mathrm{H}_{2} \mathrm{O} /$ mass material) } & \multirow[b]{2}{*}{ Reference } \\
\hline & $\mathbf{R H}=\mathbf{3 0} \%$ & $\mathbf{R H}=\mathbf{5 0} \%$ & $\mathbf{R H}=\mathbf{7 0} \%$ & \\
\hline Brick (BRI) b & $0.1-0.2 \%$ & $0.2-0.3 \%$ & $0.3-0.5 \%$ & 39 \\
\hline Brick (BRM) ${ }^{b}$ & $0.01-0.03 \%$ & $0.04-0.06 \%$ & $0.08-0.10 \%$ & 39 \\
\hline Drywall & $0.23 \%$ & $0.37 \%$ & $0.5 \%$ & 33 \\
\hline Gypsum board & $0.23 \%$ & $0.33 \%$ & $0.5 \%$ & 38 \\
\hline GB, unpainted ${ }^{b}$ & Unmeasured & $0.5-1.1 \%^{d}$ & $0.7-1.4 \%$ & 40 \\
\hline GB, painted ${ }^{b}$ & Unmeasured & $0.5-1.1 \%{ }^{d}$ & $0.8-1.4 \%$ & 40 \\
\hline GB, resistant $\mathrm{b}, \mathrm{c}$ & Unmeasured & $0.3-0.9 \%{ }^{d}$ & $0.6-1.1 \%$ & 40 \\
\hline Latex paint $\mathrm{e}$ & $0.35 \%$ & $0.86 \%$ & $2.1 \%$ & 41 \\
\hline Plaster (PEM) ${ }^{b}$ & $0.3-0.9 \%$ & $0.5-1.2 \%$ & $0.7-1.6 \%$ & 39 \\
\hline Plaster (PMP) ${ }^{b}$ & $0.2-0.4 \%$ & $0.4-0.5 \%$ & $0.5-0.7 \%$ & 39 \\
\hline Plaster (PRL) b & $0.3-0.7 \%$ & $0.4-1.0 \%$ & $0.6-1.3 \%$ & 39 \\
\hline Plaster (PTI) b & $0.2-0.5 \%$ & $0.3-0.6 \%$ & $0.4-0.7 \%$ & 39 \\
\hline Plaster (PTR) b & $1.0-2.9 \%$ & $1.9-3.4 \%$ & $3.1-4.3 \%$ & 39 \\
\hline Plaster (PTZ) b & $0.1-0.3 \%$ & $0.2-0.5 \%$ & $0.7-0.9 \%$ & 39 \\
\hline Stone (SCY) b & $0.2-1.0 \%$ & $0.2-1.4 \%$ & $0.3-1.8 \%$ & 39 \\
\hline Stone $(\mathrm{SRH})^{\mathrm{b}}$ & $0.07-0.09 \%$ & $0.14-0.18 \%$ & $0.19-0.25 \%$ & 39 \\
\hline Stone (SRW) ${ }^{b}$ & $0.08-0.13 \%$ & $0.18-0.22 \%$ & $0.34-0.42 \%$ & 39 \\
\hline Stone (SRY) b & $0.2-0.3 \%$ & $0.3-0.4 \%$ & $0.5-0.6 \%$ & 39 \\
\hline Scots pine ${ }^{b}$ & $5.3-6.8 \%$ & $8.0-10.2 \%$ & $12.1-14.7 \%$ & 42 \\
\hline Sitka spruce b & $5.5-7.3 \%$ & $8.2-10.7 \%$ & $12.0-14.6 \%$ & 43 \\
\hline Wood & $6.1 \%$ & $9.1 \%$ & $13.0 \%$ & 37 \\
\hline Wood & $5.2 \%$ & $8.6 \%$ & $12.6 \%$ & 33 \\
\hline
\end{tabular}

a Temperature at $25^{\circ} \mathrm{C}$, except where otherwise noted. ${ }^{b}$ Range indicative of hysteresis, with lower end for exposure to increasing humidity (adsorption) and higher end for drying conditions (desorption).

This article is protected by copyright. All rights reserved 


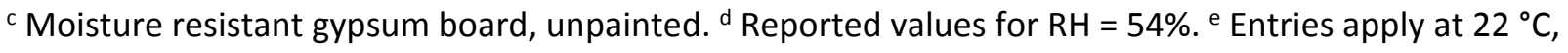
using equation (6) from the cited reference, and assuming paint density $=1 \mathrm{~g} / \mathrm{cm}^{3}$.

Table 3. Moisture buffer values $\left(\mathrm{MBV}_{\text {practical }}\right)$ for several materials. ${ }^{47}$

\begin{tabular}{|l|c|}
\hline Material & $\mathbf{M B V}_{\text {practical }}\left(\mathbf{g ~ m}^{\mathbf{- 2}} \mathbf{\text { per }} \mathbf{\text { RH}} \mathbf{)}\right.$ \\
\hline Spruce boards & 1.17 \\
\hline Cellular concrete & 1.00 \\
\hline Birch panels & 0.76 \\
\hline Lightweight aggregate concrete with stucco & 0.74 \\
\hline Gypsum & 0.62 \\
\hline Laminated wood with varnish & 0.44 \\
\hline Brick & 0.40 \\
\hline Concrete & 0.37 \\
\hline
\end{tabular}

Table 4. Equilibrium moisture content of selected fibrous materials. ${ }^{a}$

\begin{tabular}{|c|c|c|c|c|}
\hline \multirow[b]{2}{*}{ Material } & \multicolumn{3}{|c|}{ Moisture content (mass $\mathrm{H}_{2} \mathrm{O} /$ mass material) } & \multirow[b]{2}{*}{ Reference } \\
\hline & $\mathbf{R H}=\mathbf{3 0} \%$ & $\mathbf{R H}=\mathbf{5 0} \%$ & $\mathbf{R H}=\mathbf{7 0} \%$ & \\
\hline Acetate & $2.7 \%$ & $4.4 \%$ & $7.1 \%$ & 50 \\
\hline Carpet & $0.48 \%$ & $0.85 \%$ & $1.25 \%$ & 33 \\
\hline Coir b & $4.7-6.4 \%$ & $7.6-9.9 \%$ & $11.3-14.3 \%$ & 43 \\
\hline Cotton & $4.0 \%$ & $5.5 \%$ & $7.7 \%$ & 50 \\
\hline Cotton ${ }^{b}$ & $3.5-4.0 \%$ & $5.3-6.1 \%$ & $7.0-8.6 \%$ & 51 \\
\hline Cotton b & $3.0-3.8 \%$ & $4.5-5.9 \%$ & $6.6-8.4 \%$ & 43 \\
\hline Cotton ${ }^{b}$ & $3.2-4.3 \%$ & $4.6-6.2 \%$ & $6.9-8.9 \%$ & 48 \\
\hline Cotton b & $4.0-4.9 \%$ & $5.6-7.1 \%$ & $8.1-9.9 \%$ & 48 \\
\hline
\end{tabular}

This article is protected by copyright. All rights reserved 


\begin{tabular}{|l|l|l|c|c|}
\hline Cotton/flax $^{\mathrm{b}}$ & $3.6-4.3 \%$ & $5.1-6.0 \%$ & $7.6-8.7 \%$ & 48 \\
\hline Cotton/flax $^{\mathrm{b}}$ & $2.1-2.8 \%$ & $3.1-4.0 \%$ & $4.6-5.8 \%$ & 48 \\
\hline Flax $^{\mathrm{b}}$ & $4.2-5.3 \%$ & $6.4-7.6 \%$ & $9.3-10.4 \%$ & 43 \\
\hline Hemp $^{\mathrm{b}}$ & $4.6-5.7 \%$ & $7.0-8.2 \%$ & $10.0-11.6 \%$ & 43 \\
\hline Jute $^{\mathrm{b}}$ & $5.1-6.3 \%$ & $7.8-9.6 \%$ & $11.0-13.6 \%$ & 43 \\
\hline Nylon & $2.0 \%$ & $3.1 \%$ & $4.5 \%$ & 50 \\
\hline Polyamide/wool & $6.0-8.4 \%$ & $8.1-11.3 \%$ & $11.1-14.4 \%$ & 48 \\
\hline Polyester & $0.3 \%$ & $0.4 \%$ & $0.5-0.6 \%$ & 48 \\
\hline Silk & $5.2 \%$ & $7.4 \%$ & $10.2 \%$ & 52 \\
\hline Silk & $4.5 \%$ & $6.8 \%$ & $9.7 \%$ & 50 \\
\hline Viscose & $6.5 \%$ & $9.1 \%$ & $12.9 \%$ & 50 \\
\hline Viscose/Wool ${ }^{\mathrm{b}}$ & $6.9-9.2 \%$ & $9.5-12.5 \%$ & $13.7-17.2 \%$ & 48 \\
\hline Wool & $8.2 \%$ & $11.4 \%$ & $15.6 \%$ & 52 \\
\hline Wool & $8.8 \%$ & $12.7 \%$ & $17.7 \%$ & 53 \\
\hline Wool & $7.6 \%$ & $10.7 \%$ & $14.8 \%$ & 50 \\
\hline Wool c & $8.2 \%$ & $12.0 \%$ & $16.6 \%$ & 54 \\
\hline Wool ${ }^{b}$ & $6.3-9.0 \%$ & $8.5-12.1 \%$ & $12.2-16.2 \%$ & 48 \\
\hline Wool ${ }^{b}$ & $8.8-13.1 \%$ & $12.5-17.1 \%$ & 48 \\
\hline
\end{tabular}

a Temperature at $25^{\circ} \mathrm{C}$, except where otherwise noted. ${ }^{b}$ Range indicative of hysteresis, with lower end for exposure to increasing humidity (adsorption) and higher end for drying conditions (desorption).

c Temperature at $20^{\circ} \mathrm{C}$; data linearly interpolated from Table II.

This article is protected by copyright. All rights reserved 
Table 5. Number of equivalent monolayers of water sorbed on mineral surfaces at relative humidity values of $30 \%, 50 \%$, and $70 \%$. ${ }^{\text {a }}$

\begin{tabular}{|c|c|c|c|c|}
\hline Material & $\mathrm{RH}=30 \%$ & $\mathrm{RH}=\mathbf{5 0} \%$ & $\mathrm{RH}=70 \%$ & Reference \\
\hline$\alpha-\mathrm{Al}_{2} \mathrm{O}_{3}$ & 1.2 & 1.9 & 3.2 & 60 \\
\hline Arizona test dust & 1.9 & 2.3 & 3.1 & 61 \\
\hline $\mathrm{CaCO}_{3}$, calcite & 0.8 & 1.4 & 3.1 & 61 \\
\hline Clay, kaolinite b,d & 1.9 & 3.1 & 4.5 & 62 \\
\hline Clay ${ }^{c, d}$ & 2.5 & 3.8 & 6.6 & 63 \\
\hline $\mathrm{Fe}_{2} \mathrm{O}_{3}$ & 1.0 & 1.7 & 2.9 & 60 \\
\hline$\alpha-\mathrm{Fe}_{2} \mathrm{O}_{3}{ }^{\mathrm{d}, \mathrm{e}}$ & 2.1 & 2.9 & 4.6 & 64 \\
\hline Limestone ${ }^{c, d}$ & 1.5 & 2.2 & 3.8 & 63 \\
\hline $\mathrm{MgO}$ & 1.1 & 1.8 & 2.8 & 60 \\
\hline Sand $b, d$ & 8 & 11 & 14 & 65 \\
\hline Sand ${ }^{c, d}$ & 3.3 & 5.3 & 9.6 & 63 \\
\hline Sand, quartz b,d & 2.5 & 3.2 & 4.9 & 66 \\
\hline $\mathrm{SiO}_{2}$ & 1.6 & 2.1 & 3.4 & 67 \\
\hline $\mathrm{SiO}_{2}$ & 1.0 & 1.4 & 1.8 & 60 \\
\hline Silica b,d & 3.6 & 4.8 & 5.5 & 68 \\
\hline Soil, SSM b,d & 3.4 & 5.0 & 6.5 & 65 \\
\hline $\mathrm{TiO}_{2}$ & 1.4 & 1.9 & 3.0 & 60 \\
\hline
\end{tabular}

${ }^{a}$ Unless otherwise noted, entries are read from figures presented in the cited reference. ${ }^{b}$ Determined from reported isotherm of water on sorbent (mass or volume of $\mathrm{H}_{2} \mathrm{O}$ sorbed per mass of sorbent material) combined with specific surface area $\left(\mathrm{m}^{2} / \mathrm{g}\right)$ based on an $\mathrm{N}_{2}$-BET measurement. ${ }^{c}$ Sorbed quantities of water at $\mathrm{RH}=30 \%, 50 \%, 70 \%$ based on reported BET sorption isotherm parameters in Table 2 of cited reference. ${ }^{d}$ Effective surface area of water molecule taken to be $0.125 \mathrm{~nm}^{2}$ (corresponding to a monolayer thickness of $0.24 \mathrm{~nm}$ ), based on review ${ }^{58}$ by McClellan and Harnsberger. ${ }^{e}$ Sorption isotherm reported as "surface coverage" (water molecules per area of sorbent) versus RH.

This article is protected by copyright. All rights reserved 
Table 6. Indoor and outdoor ammonia concentrations (mean \pm standard deviation) reported in selected studies.

\begin{tabular}{|l|l|c|c|}
\hline Location (no. sites) & Indoor (ppb) & Outdoor (ppb) & Reference \\
\hline Univ. Essex buildings (2); 13 samples & $29 \pm 18$ & $2.8 \pm 0.9$ & 119 \\
\hline Boston homes summer (6); 31 samples & $8.1 \pm 6.5$ & $1.9 \pm 2.1$ & 128 \\
\hline Boston homes winter (5); 18 samples & $19 \pm 6$ & $1.1 \pm 0.9$ & 128 \\
\hline NJ daycare; 24 samples a & $61 \pm 44$ & $3.1 \pm 1.6^{b}$ & 129 \\
\hline NJ nursing home; 37 samples c & $56 \pm 30$ & $3.1 \pm 1.6^{b}$ & 129 \\
\hline NJ elderly home, day; 41 samples d & $31 \pm 38$ & $10 \pm 12$ & 129 \\
\hline NJ elderly home, night; 28 samples d & $29 \pm 26$ & $9 \pm 6$ & 129 \\
\hline CT, VA homes, summer, AC (49) & $32 \pm 19$ & $2.8 \pm 2.5$ & 132 \\
\hline CT, VA homes, summer, no AC (9) & $28 \pm 18$ & $2.8 \pm 2.5$ & 132 \\
\hline CT, VA homes, winter, kerosene-heater (74) & $44 \pm 45$ & $1.6 \pm 4.6$ & 132 \\
\hline CT, VA homes, winter, no kerosene (148) & $38 \pm 36$ & $1.6 \pm 4.6$ & 132 \\
\hline Albuquerque homes (10) & $20 \pm 5$ & & 133 \\
\hline
\end{tabular}

${ }^{a}$ Window air conditioner; no ventilation. ${ }^{b}$ Central monitoring location within $5 \mathrm{~km}$ of indoor locations.

${ }^{c}$ Central air conditioning. ${ }^{d}$ Natural ventilation.

Table 7. Indoor and outdoor aerosol ammonium concentrations (mean \pm standard deviation) reported in selected studies.

\begin{tabular}{|l|c|c|c|}
\hline Location (no. sites) & $\begin{array}{c}\text { Indoor } \\
\left(\mathrm{nmol} / \mathrm{m}^{3}\right)\end{array}$ & $\begin{array}{c}\text { Outdoor } \\
\left(\mathrm{nmol} / \mathrm{m}^{3}\right)\end{array}$ & Reference \\
\hline Univ. Essex bldgs. (2); 14 samples & $136 \pm 112$ & $157 \pm 108$ & 119 \\
\hline Boston homes, summer (6); 31 samples & $298 \pm 291$ & $129 \pm 89$ & 128 \\
\hline Boston homes, winter (5); 18 samples & $66 \pm 35$ & $67 \pm 32$ & 128 \\
\hline NJ daycare; 24 samples ${ }^{a}$ & $92 \pm 93$ & $131 \pm 108^{\mathrm{b}}$ & 129 \\
\hline
\end{tabular}

This article is protected by copyright. All rights reserved 


\begin{tabular}{|l|c|c|c|}
\hline NJ nursing home; 37 samples $^{c}$ & $73 \pm 79$ & $131 \pm 108^{\mathrm{b}}$ & 129 \\
\hline NJ elderly home, day; 41 samples $^{\mathrm{d}}$ & $117 \pm 109$ & $148 \pm 175$ & 129 \\
\hline NJ elderly home, night; 28 samples $^{\mathrm{d}}$ & $108 \pm 101$ & $113 \pm 119$ & 129 \\
\hline CT, VA homes, summer, AC (49) & $78 \pm 77$ & $129 \pm 88$ & 132 \\
\hline CT, VA homes, summer, no AC (9) & $97 \pm 69$ & $129 \pm 88$ & 132 \\
\hline CT, VA homes, winter, kerosene-heater (74) & $126 \pm 155$ & $64 \pm 39$ & 132 \\
\hline CT, VA homes, winter, no kerosene (148) & $9 \pm 22$ & $64 \pm 39$ & 132 \\
\hline
\end{tabular}

${ }^{\mathrm{a}}$ Window air conditioner; no mechanical ventilation. ${ }^{\mathrm{b}}$ Central monitoring location within $5 \mathrm{~km}$ of indoor locations. ${ }^{\mathrm{c}}$ Central air conditioning. ${ }^{\mathrm{d}}$ Natural ventilation.

This article is protected by copyright. All rights reserved 
Table 8. Sulfur dioxide levels measured in residences and corresponding outdoor levels. ${ }^{\text {a }}$

\begin{tabular}{|l|c|c|c|c|}
\hline Community & $\mathbf{N}$ houses & Indoor $\left(\boldsymbol{\mu g} / \mathrm{m}^{\mathbf{3}}\right)$ & Outdoor $\left(\boldsymbol{\mu g} / \mathrm{m}^{\mathbf{3}}\right)$ & I/O ratio \\
\hline Kingston, TN & 11 & 1.4 & 12.9 & 0.11 \\
\hline Portage, WI & 11 & 5.3 & 7.7 & 0.68 \\
\hline St. Louis, MO & 15 & 12.4 & 39.7 & 0.31 \\
\hline Steubenville, OH & 11 & 21.9 & 56.9 & 0.38 \\
\hline Topeka, KS & 14 & 1.2 & 1.9 & 0.64 \\
\hline Watertown, MA & 11 & 8.2 & 24.1 & 0.34 \\
\hline Six-City mean & $\mathbf{7 3}$ & $\mathbf{8 . 3}(\mathbf{3 . 2} \mathbf{~ p p b )}$ & $\mathbf{2 3 . 8 ( 9 . 2 ~ \mathbf { ~ p b } )}$ & $\mathbf{0 . 4 1}$ \\
\hline
\end{tabular}

a Source: Spengler et al. ${ }^{166}$ Indoor and outdoor measurement results reflect annual means for period May 1977 - April 1978, as extracted from Figure 1 of the cited work. The "six-city mean" represents the weighted average of the six study sites, and the reported I/O ratio in this row is the weighted average of the respective $\mathrm{l} / \mathrm{O}$ ratios for the six cities.

Table 9. Average (arithmetic mean \pm standard deviation) fine-particle sulfate levels measured in residences and corresponding indoor/outdoor ratios. ${ }^{a}$

\begin{tabular}{|l|c|c|}
\hline Condition ( $\boldsymbol{n}$ samples) & Indoor $\left(\boldsymbol{\mu g} / \mathrm{m}^{\mathbf{3}}\right)$ & $\mathrm{I} / 0$ ratio \\
\hline Summer, AC homes (47) & $4.6 \pm 3.5$ & 0.57 \\
\hline Summer, nonAC homes (9) & $6.0 \pm 3.6$ & 0.75 \\
\hline Winter, kerosene heating (74) & $7.9 \pm 7.3$ & 2.70 \\
\hline Winter, no kerosene heat (149) & $2.1 \pm 0.3$ & 0.71 \\
\hline
\end{tabular}

${ }^{\text {a }}$ Source: Leaderer et al. ${ }^{132}$ Measurement results reported in units of $\mathrm{nmol} / \mathrm{m}^{3}$, converted to mass concentrations by multiplying by the molecular weight of the sulfate ion, $96 \mathrm{~g} / \mathrm{mol}$. The $1 / 0$ ratios are based on the average measured indoor level divided by the average measured outdoor level. The latter was differentiated only by season, not by home category; it was reported as $84 \mathrm{nmol} / \mathrm{m}^{3}\left(=8.0 \mu \mathrm{g} / \mathrm{m}^{3} ; n=42\right.$ samples) for summer and $31 \mathrm{nmol} / \mathrm{m}^{3}\left(=2.9 \mu \mathrm{g} / \mathrm{m}^{3} ; n=52\right.$ samples) for winter. Homes were located in southwest and central Virginia (261 homes) and in Connecticut (20 homes).

This article is protected by copyright. All rights reserved 
Table 10. Mean indoor and outdoor sulfate levels measured in homes in the Six-Cities study (19771978). ${ }^{\text {a }}$

\begin{tabular}{|l|c|c|l|}
\hline Location (no. homes) & Indoor $\left(\boldsymbol{\mu g} / \mathrm{m}^{\mathbf{3}}\right)$ & Outdoor $\left(\boldsymbol{\mu g} / \mathrm{m}^{\mathbf{3}}\right)$ & $\mathbf{1 / 0}$ \\
\hline Portage, WI (11) & 3.4 & 4.4 & 0.78 \\
\hline Topeka, KS (10) & 3.2 & 3.6 & 0.89 \\
\hline Kingston, TN (8) & 5.7 & 8.5 & 0.67 \\
\hline Watertown, MA (8) & 5.5 & 5.7 & 0.96 \\
\hline St. Louis, MO (10) & 5.7 & 7.5 & 0.76 \\
\hline Steubenville, OH (8) & 7.1 & 12.8 & 0.56 \\
\hline Six-city mean (55) & $\mathbf{5 . 1}$ & $\mathbf{7 . 1}$ & $\mathbf{0 . 7 7}$ \\
\hline
\end{tabular}

a Source: Spengler et al. ${ }^{189}$ Indoor and outdoor mean concentrations for each city extracted from Figure 4 of the referenced article. Indoor/outdoor (I/O) parameter reflects the ratio of the means. The six-city means are the unweighted averages.

Table 11. Indoor and outdoor $\mathrm{NO}_{2}$ concentrations (mean \pm standard deviation) reported in selected studies.

\begin{tabular}{|l|c|c|c|}
\hline Location (no. sites); number of samples & Indoor (ppb) & Outdoor (ppb) & Reference \\
\hline Kitchens, electric stoves, WI (20-23); 174 & $4.5 \pm 2.5$ & $6.8 \pm 3.0$ & 209 \\
\hline Kitchens, gas stoves, WI (28-32); 237 & $35 \pm 16$ & $8.4 \pm 3.4$ & 209 \\
\hline Kitchens, LP gas stoves, WI (65-76); 568 & $35 \pm 20$ & $6.3 \pm 3.0$ & 209 \\
\hline Homes, Quebec City (96) & $5.1 \pm 2.8$ & & 210 \\
\hline Kitchens, California (343) & $23(17 ; 2.3)^{\text {a }}$ & $17(15 ; 1.8)^{\text {a }}$ & 211 \\
\hline Bedrooms, California (343) & $18(13 ; 2.1)^{\text {a }}$ & $17(15 ; 1.8)^{\text {a }}$ & 211 \\
\hline Homes, Boston, summer, (6); 31 & $18 \pm 8$ & $19 \pm 8$ & 128 \\
\hline
\end{tabular}

This article is protected by copyright. All rights reserved 


\begin{tabular}{|l|c|c|c|}
\hline Library, Bern 2 ${ }^{\text {nd }}$ summer (5); 15 & $2.3 \pm 1.5^{\circ}$ & 6.4 & 212 \\
\hline Library, Bern, winter (5); 15 & $0.9 \pm 0.1^{\mathrm{b}}$ & 17 & 212 \\
\hline Library, Geneva, summer (3); 9 & $2.1 \pm 0.4^{\mathrm{c}}$ & 8.6 & 212 \\
\hline Library, Geneva, winter (3); 9 & $4.9 \pm 1.7^{\circ}$ & 21 & 212 \\
\hline
\end{tabular}

${ }^{a}$ Arithmetic mean (geometric mean; geometric standard deviation). ${ }^{b}$ Excluded from analysis are two of five sites reporting "below detection limit." c Excluded from analysis is one of three sites reporting "below detection limit."

This article is protected by copyright. All rights reserved 
Table 12. Indoor and outdoor $\mathrm{HNO}_{3}$ concentrations (mean \pm standard deviation) reported in selected studies.

\begin{tabular}{|c|c|c|c|}
\hline Location (no. sites) & Indoor (ppb) & Outdoor (ppb) & Reference \\
\hline Univ. Essex buildings (2); 13 samples & $0.36 \pm 0.21$ & $1.8 \pm 1.0$ & 119 \\
\hline Boston homes, summer (6); 31 samples & $0.84 \pm 0.58$ & $1.4 \pm 0.8$ & 128 \\
\hline Boston homes, winter (5); 29 samples & $0.029 \pm 0.057$ & $0.59 \pm 0.47$ & 128 \\
\hline NJ daycare; 24 samples a & $0.3 \pm 0.3$ & $2.5 \pm 1.6^{b}$ & 129 \\
\hline NJ nursing home; 37 samples $^{c}$ & $0.3 \pm 0.6$ & $2.5 \pm 1.6^{b}$ & 129 \\
\hline NJ elderly home, day; 41 samples $^{d}$ & $0.4 \pm 0.2$ & $1.4 \pm 1.9$ & 129 \\
\hline NJ elderly home, night; 28 samples $^{d}$ & $0.2 \pm 0.3$ & $0.8 \pm 0.6$ & 129 \\
\hline State College PA, homes (47); 229 samples & $0.2(3.1)^{\mathrm{e}}$ & $1.0(2.1)^{\mathrm{e}}$ & 131 \\
\hline Library, Bern, $2^{\text {nd }}$ summer (5) & $0.08 \pm 0.02$ & 0.81 & 212 \\
\hline Library, Bern, winter (5) & $0.13 \pm 0.02^{f}$ & $\mathrm{BDL}^{\mathrm{f}}$ & 212 \\
\hline Library, Geneva, summer (3) & $0.16 \pm 0.05^{g}$ & 0.27 & 212 \\
\hline Library, Geneva, winter (3) & $0.17 \pm 0.04$ & 0.27 & 212 \\
\hline Sepulveda House (museum), LA, summer ${ }^{h}$ & $0.59 \pm 0.07$ & $1.6 \pm 0.3$ & 214 \\
\hline Sepulveda House (museum), LA, winter ${ }^{h}$ & $0.24 \pm 0.05$ & $0.61 \pm 0.10$ & 214 \\
\hline Southwest Museum, LA, summer ${ }^{i}$ & $0.08 \pm 0.02$ & $2.3 \pm 0.3$ & 214 \\
\hline Southwest Museum, LA, winter ${ }^{i}$ & $0.03 \pm 0.02$ & $0.87 \pm 0.19$ & 214 \\
\hline Norton Simon, Pasadena CA, summer ${ }^{j}$ & $<0.04$ & $3.0 \pm 0.3$ & 214 \\
\hline Norton Simon, Pasadena CA, winter ${ }^{j}$ & $<0.04$ & $0.50 \pm 0.12$ & 214 \\
\hline Scott Gallery, San Marino CA, summer ${ }^{j}$ & $0.08 \pm 0.02$ & $2.8 \pm 0.3$ & 214 \\
\hline Scott Gallery, San Marino CA, winter ${ }^{j}$ & $0.04 \pm 0.02$ & $0.48 \pm 0.10$ & 214 \\
\hline Getty Museum, Los Angeles, summer ${ }^{j}$ & $0.04 \pm 0.02$ & $0.52 \pm 0.10$ & 214 \\
\hline Getty Museum, Los Angeles, winter ${ }^{j}$ & $0.07 \pm 0.02$ & $0.48 \pm 0.09$ & 214 \\
\hline
\end{tabular}

${ }^{\mathrm{a}}$ Window air conditioner; no ventilation. ${ }^{\mathrm{b}}$ Central monitoring location within $5 \mathrm{~km}$ of indoor locations.

${ }^{c}$ Central air conditioning. ${ }^{d}$ Natural ventilation. e Geometric mean (geometric standard deviation).

This article is protected by copyright. All rights reserved 
${ }^{\mathrm{f}} \mathrm{BDL}=$ below detection limit; indoor summary excludes two of five sites reported as BDL. $\mathrm{g}$ Indoor summary excludes one of three sites reported as below detection limit. ${ }^{\mathrm{h}}$ Natural ventilation. ${ }^{\mathrm{i}}$ Partial mechanical ventilation. ${ }^{j}$ Mechanical ventilation/filtration including activated carbon filters.

This article is protected by copyright. All rights reserved 
Table 13. Indoor and outdoor aerosol $\mathrm{NO}_{3}{ }^{-}$concentrations (mean \pm standard deviation) reported in selected studies.

\begin{tabular}{|c|c|c|c|}
\hline Location (no. sites) & $\begin{array}{c}\text { Indoor } \\
\left(\mathrm{nmol} / \mathrm{m}^{3}\right)\end{array}$ & $\begin{array}{l}\text { Outdoor } \\
\left(\mathrm{nmol} / \mathrm{m}^{3}\right)\end{array}$ & Reference \\
\hline University of Essex buildings (2); 12 samples & $40 \pm 29$ & $104 \pm 83$ & 119 \\
\hline Boston homes, summer (6); 31 samples & $5.0 \pm 3.9$ & $6.1 \pm 3.8$ & 128 \\
\hline Boston homes, winter (5); 30 samples & $5.5 \pm 5.6$ & $12 \pm 11$ & 128 \\
\hline NJ daycare; 24 samples ${ }^{a}$ & $12 \pm 10$ & $15 \pm 11^{b}$ & 129 \\
\hline NJ nursing home; 37 samples $^{c}$ & $13 \pm 6$ & $15 \pm 11^{b}$ & 129 \\
\hline NJ elderly home, day; 41 samples $^{d}$ & $0.5 \pm 1.3$ & $13 \pm 19$ & 129 \\
\hline NJ elderly home, night; 28 samples $^{d}$ & $1.6 \pm 3.7$ & $17 \pm 23$ & 129 \\
\hline CT, VA homes, summer air conditioned (49) & $5.5 \pm 8.9$ & $8.0 \pm 5.4$ & 132 \\
\hline CT, VA homes, summer, no AC (9) & $6.8 \pm 4.6$ & $8.0 \pm 5.4$ & 132 \\
\hline CT, VA homes, winter kerosene heater (74) & $6.5 \pm 9.4$ & $21 \pm 22$ & 132 \\
\hline CT, VA homes, winter, no kerosene (148) & $6.3 \pm 9.1$ & $21 \pm 22$ & 132 \\
\hline
\end{tabular}

${ }^{a}$ Window air conditioner; no ventilation. ${ }^{b}$ Central monitoring location within $5 \mathrm{~km}$ of indoor locations.

${ }^{c}$ Central air conditioning. ${ }^{d}$ Natural ventilation.

This article is protected by copyright. All rights reserved 
Table 14. Properties of selected carboxylic acids $(T=298 \mathrm{~K})$. $^{\text {a }}$

\begin{tabular}{|c|c|c|c|c|c|c|}
\hline $\begin{array}{l}\text { Common } \\
\text { forename }\end{array}$ & $\begin{array}{l}\text { IUPAC } \\
\text { forename }\end{array}$ & Formula & $\begin{array}{l}\text { MW } \\
\text { (g/mol) }\end{array}$ & $\mathrm{p} K_{\mathrm{a}}$ & $\begin{array}{l}K_{\mathrm{H}} \\
\text { (M/atm) }\end{array}$ & $\log \left(K_{\text {oa }}\right)$ \\
\hline Formic & Methanoic & $\mathrm{HCOOH}$ & 46.0 & 3.75 & $8.9 \times 10^{3}$ & $4.8^{c}$ \\
\hline Acetic & Ethanoic & $\mathrm{CH}_{3} \mathrm{COOH}$ & 60.1 & 4.76 & $4.1 \times 10^{3}$ & $4.8^{c}$ \\
\hline Propionic & Propanoic & $\mathrm{CH}_{3} \mathrm{CH}_{2} \mathrm{COOH}$ & 74.1 & 4.87 & $1.5 \times 10^{3}$ & $4.9^{c}$ \\
\hline Lactic & $\begin{array}{l}\text { 2-Hydroxy } \\
\text { propanoic acid }\end{array}$ & $\mathrm{CH}_{3} \mathrm{CH}(\mathrm{OH}) \mathrm{COOH}$ & 90.1 & 3.86 & $1.2 \times 10^{4}$ & $4.7^{c}$ \\
\hline Butyric & Butanoic & $\mathrm{CH}_{3}\left(\mathrm{CH}_{2}\right)_{2} \mathrm{COOH}$ & 88.1 & 4.83 & $9.8 \times 10^{2}$ & $5.2^{c}$ \\
\hline Valeric & Pentanoic & $\mathrm{CH}_{3}\left(\mathrm{CH}_{2}\right)_{3} \mathrm{COOH}$ & 102 & 4.83 & $2.3 \times 10^{3}$ & $6.1^{c}$ \\
\hline Caproic & Hexanoic & $\mathrm{CH}_{3}\left(\mathrm{CH}_{2}\right)_{4} \mathrm{COOH}$ & 116 & 4.85 & $1.3 \times 10^{3}$ & $6.4^{c}$ \\
\hline Enanthic & Heptanoic & $\mathrm{CH}_{3}\left(\mathrm{CH}_{2}\right)_{5} \mathrm{COOH}$ & 130 & 4.89 & $9.7 \times 10^{2}$ & $6.8^{c}$ \\
\hline Caprylic & Octanoic & $\mathrm{CH}_{3}\left(\mathrm{CH}_{2}\right)_{6} \mathrm{COOH}$ & 144 & 4.89 & 15 & $5.6^{c}$ \\
\hline Pelargonic & Nonanoic & $\mathrm{CH}_{3}\left(\mathrm{CH}_{2}\right)_{7} \mathrm{COOH}$ & 158 & 4.96 & $3.9 \times 10^{2}$ & $7.4^{c}$ \\
\hline Capric & Decanoic & $\mathrm{CH}_{3}\left(\mathrm{CH}_{2}\right)_{8} \mathrm{COOH}$ & 172 & $4.9^{b}$ & $6.6 \times 10^{2}$ & $8.3^{c}$ \\
\hline Lauric & Dodecanoic & $\mathrm{CH}_{3}\left(\mathrm{CH}_{2}\right)_{10} \mathrm{COOH}$ & 200 & $5.3^{b}$ & $4.6 \times 10^{2}$ & $8.6^{c}$ \\
\hline Myristic & Tetradecanoic & $\mathrm{CH}_{3}\left(\mathrm{CH}_{2}\right)_{12} \mathrm{COOH}$ & 228 & $4.9^{b}$ & $2.2 \times 10^{3 \mathrm{~b}}$ & $10.8^{c}$ \\
\hline Palmitic & Hexadecanoic & $\mathrm{CH}_{3}\left(\mathrm{CH}_{2}\right)_{14} \mathrm{COOH}$ & 256 & $4.85^{b}$ & $3.1 \times 10^{2 d}$ & $11.1^{d}$ \\
\hline Stearic & Octadecanoic & $\mathrm{CH}_{3}\left(\mathrm{CH}_{2}\right)_{16} \mathrm{COOH}$ & 284 & $4.75^{b}$ & $2.2 \times 10^{3 \mathrm{~d}}$ & $13.0^{d}$ \\
\hline
\end{tabular}

${ }^{a}$ Sources, except where otherwise noted: For $\mathrm{p} K_{\mathrm{a}}$ values, "Dissociation Constants of Organic Acids and Bases" from CRC Handbook of Chemistry and Physics, downloaded at https://sites.chem.colostate.edu/diverdi/all_courses/CRC\%20reference\%20data/dissociation\%20constants \%20of\%20organic\%20acids\%20and\%20bases.pdf; for Henry's law constants, Sander. ${ }^{142}$

${ }^{b}$ PubChem (https://pubchem.ncbi.nlm.nih.gov/); for palmitic acid, $\mathrm{p} K_{\mathrm{a}}$ entry is average of two values reported (4.75 and 4.95). Last accessed 5 March 2020. ${ }^{c}$ Derived from $K_{\text {ow }}$ and Henry's law constant as reported in PubChem $\left[\log \left(K_{\text {oa }}\right)=\log \left(K_{\text {ow }}\right)+\log \left(K_{\mathrm{H}} \times R T\right)\right] .{ }^{\text {d }}$ Derived from $K_{\text {ow }}$, water solubility, and vapor pressure as reported in PubChem $\left[K_{\mathrm{H}}=\right.$ saturated water concentration $(\mathrm{M})$ divided by vapor pressure $(\mathrm{atm}) ; \log \left(K_{\mathrm{oa}}\right)$ as in note $c]$

This article is protected by copyright. All rights reserved 
Table 15. Formic and acetic acid concentrations $(\mathrm{ppb})$ surveyed in ordinary occupied environments. ${ }^{a}$

\begin{tabular}{|c|c|c|c|c|c|}
\hline \multirow[b]{2}{*}{ Study site ( $n$ sites) } & \multicolumn{2}{|c|}{ Formic acid } & \multicolumn{2}{|l|}{ Acetic acid } & \multirow[b]{2}{*}{ Reference } \\
\hline & Indoors & Outdoors & Indoors & Outdoors & \\
\hline New Jersey homes (6) ${ }^{b}$ & $8.8 \pm 3.6$ & $1.2 \pm 0.4$ & $24 \pm 11$ & $3.0 \pm 1.9$ & 276 \\
\hline Boston homes, W (4) & $9.8 \pm 2.5$ & $3.1 \pm 1.6$ & $16 \pm 3$ & $1.8 \pm 0.8$ & 277 \\
\hline Boston homes, S (9) & $18 \pm 7$ & $3.9 \pm 1.6$ & $29 \pm 20$ & $2.0 \pm 1.2$ & 277 \\
\hline NJ and NC homes (13) & $21 \pm 7$ & & $48 \pm 14^{c}$ & & 278 \\
\hline Japan homes, W (602) & 29 & 6.9 & 38 & 15 & 279 \\
\hline Japan homes, S (602) & 15 & 8.0 & 53 & 16 & 279 \\
\hline Melbourne homes (40) & & & $4.3 \pm 4.2$ & $0.04 \pm 0.1$ & 280 \\
\hline Curitiba homes (12) d & 1.5 & & 4.3 & & 281 \\
\hline Antwerp schools (10) & $5.3 \pm 3.5$ & $1.2 \pm 1.3$ & $17 \pm 9$ & $0.6 \pm 0.4$ & 282 \\
\hline Curitiba schools (6) d & 2.4 & 1.3 & 8.3 & 1.9 & 281 \\
\hline São Paulo, other (6) e & $6.5 \pm 4.6$ & $3.2 \pm 1.5$ & $17 \pm 16$ & $3.7 \pm 1.5$ & 242 \\
\hline
\end{tabular}

${ }^{a}$ Reported concentrations are averages \pm standard deviations (where available). $W=$ winter sampling; $S=$ summer sampling. ${ }^{b}$ Entries are based on average of six measurements at each home. ${ }^{c}$ Includes undifferentiated contribution from lactic acid. ${ }^{d}$ Weighted average of reported suburban (33\%) and urban (67\%) sampling results. e Building types (n): hotel/restaurant (1), restaurant (2), office (3)

Table 16. Time-averaged indoor concentrations and effective indoor emission rates for gas-phase carboxylic acids measured in a single-family dwelling in northern California. ${ }^{291}$

\begin{tabular}{|l|c|l|c|c|}
\hline & \multicolumn{2}{|l|}{ Avg. concentration (ppb) } & \multicolumn{2}{l|}{ Avg. emission rate (mg/h) } \\
\hline Species & Summer & Winter & Summer & Winter \\
\hline Formic acid & 13.8 & 11.6 & 4.0 & 2.3 \\
\hline Acetic acid & 51.5 & 45.7 & 20 & 12 \\
\hline Propionic acid & 3.1 & 2.7 & 1.4 & 0.86 \\
\hline
\end{tabular}

This article is protected by copyright. All rights reserved 


\begin{tabular}{|l|l|l|l|l|}
\hline Butyric acid & 1.43 & 1.07 & 0.78 & 0.45 \\
\hline Valeric acid & 0.57 & 0.32 & 0.34 & 0.22 \\
\hline Hexanoic acid & 0.59 & 0.38 & 0.48 & 0.23 \\
\hline Heptanoic acid & 0.13 & 0.06 & 0.13 & 0.045 \\
\hline Octanoic acid & 0.26 & 0.14 & 0.30 & 0.11 \\
\hline Nonanoic acid & 0.09 & 0.05 & 0.12 & 0.043 \\
\hline Decanoic acid & 0.032 & 0.015 & 0.046 & 0.014 \\
\hline Undecanoic acid & 0.016 & 0.008 & 0.024 & 0.007 \\
\hline
\end{tabular}

This article is protected by copyright. All rights reserved 
Table 17. Properties of selected dicarboxylic acids $(T=298 \mathrm{~K}){ }^{\text {a }}$

\begin{tabular}{|l|l|l|l|l|c|c|}
\hline $\begin{array}{l}\text { Common } \\
\text { forename }\end{array}$ & $\begin{array}{l}\text { IUPAC } \\
\text { forename }\end{array}$ & Formula & $\begin{array}{l}\mathbf{M W} \\
(\mathrm{g} / \mathrm{mol})\end{array}$ & $\mathbf{p} \boldsymbol{K}_{\mathrm{a}}$ & $\boldsymbol{K}_{\mathrm{H}}(\mathbf{M} / \mathbf{a t m})$ & $\mathbf{L o g}\left(\boldsymbol{K}_{\text {oa }}\right)^{\mathrm{b}}$ \\
\hline Oxalic & Ethanedioic & $\mathrm{C}_{2} \mathrm{H}_{2} \mathrm{O}_{4}$ & 90 & $1.25,3.81$ & $6.2 \times 10^{8}$ & 9.4 \\
\hline Malonic & Propanedioic & $\mathrm{C}_{3} \mathrm{H}_{4} \mathrm{O}_{4}$ & 104 & $2.85,5.70$ & $3.9 \times 10^{10}$ & 11.2 \\
\hline Succinic & Butanedioic & $\mathrm{C}_{4} \mathrm{H}_{6} \mathrm{O}_{4}$ & 118 & $4.21,5.64$ & $2.7 \times 10^{9}$ & 10.2 \\
\hline Glutaric & Pentanedioic & $\mathrm{C}_{5} \mathrm{H}_{8} \mathrm{O}_{4}$ & 132 & $4.32,5.42$ & $1.9 \times 10^{9}$ & 10.4 \\
\hline Adipic & Hexanedioic & $\mathrm{C}_{6} \mathrm{H}_{10} \mathrm{O}_{4}$ & 146 & $4.41,5.41$ & $2.1 \times 10^{8}$ & 9.8 \\
\hline Azelaic & Nonanedioic & $\mathrm{C}_{9} \mathrm{H}_{16} \mathrm{O}_{4}$ & 188 & $4.55,5.50^{c}$ & $9.0 \times 10^{9}$ & 12.9 \\
\hline
\end{tabular}

a Sources, except where otherwise noted: For acidity $\left(\mathrm{p} K_{\mathrm{a}}\right)$ values, "Dissociation Constants of Organic Acids and Bases" from CRC Handbook of Chemistry and Physics, downloaded at https://sites.chem.colostate.edu/diverdi/all_courses/CRC\%20reference\%20data/dissociation\%20constants\%2 Oof\%20organic\%20acids\%20and\%20bases.pdf; for Henry's law constants $\left(K_{\mathrm{H}}\right)$, Sander. ${ }^{142}$ b Derived from $K_{\text {ow }}$ values and Henry's law constants as reported in PubChem $\left[\log \left(K_{\mathrm{oa}}\right)=\log \left(K_{\mathrm{ow}}\right)+\log \left(K_{\mathrm{H}} \times R T\right)\right]$.

c Source: Bretti et al. ${ }^{325}$

Table 18. Time-averaged indoor $\left(C_{\text {in }}\right)$ and outdoor $\left(C_{\text {out }}\right)$ concentrations ${ }^{13}$ of organic acids from a university classroom study. ${ }^{\text {a }}$

\begin{tabular}{|c|c|c|c|}
\hline Formula & Name $^{b}$ & $C_{\text {in }}(\mathrm{ppt})$ & $C_{\text {out }}$ (ppt) \\
\hline $\mathrm{CH}_{2} \mathrm{O}_{2}$ & Formic (methanoic) acid & 1200 & 230 \\
\hline $\mathrm{C}_{3} \mathrm{H}_{6} \mathrm{O}_{2}$ & Propionic (propanoic) acid & 38 & ND \\
\hline $\mathrm{C}_{4} \mathrm{H}_{8} \mathrm{O}_{2}$ & Butyric (butanoic) acid & 110 & ND \\
\hline $\mathrm{C}_{5} \mathrm{H}_{10} \mathrm{O}_{2}$ & Pentanoic (valeric) acid & 54 & ND \\
\hline $\mathrm{C}_{6} \mathrm{H}_{12} \mathrm{O}_{2}$ & Hexanoic (caproic) acid & 58 & ND \\
\hline $\mathrm{C}_{7} \mathrm{H}_{14} \mathrm{O}_{2}$ & Heptanoic (enanthic) acid & 15 & ND \\
\hline $\mathrm{C}_{8} \mathrm{H}_{16} \mathrm{O}_{2}$ & Octanoic (caprylic) acid & 39 & ND \\
\hline
\end{tabular}

This article is protected by copyright. All rights reserved 


\begin{tabular}{|l|l|c|c|}
\hline $\mathrm{C}_{9} \mathrm{H}_{18} \mathrm{O}_{2}$ & Nonanoic (pelargonic) acid & 17 & $\mathrm{ND}$ \\
\hline $\mathrm{C}_{4} \mathrm{H}_{6} \mathrm{O}_{4}$ & Butanedioic (succinic) acid & 13 & 1.2 \\
\hline $\mathrm{C}_{2} \mathrm{H}_{4} \mathrm{O}_{3}$ & Glycolic (hydroacetic) acid & 91 & $\mathrm{ND}$ \\
\hline $\mathrm{C}_{3} \mathrm{H}_{6} \mathrm{O}_{3}$ & Lactic (2-hydroxypropanoic) acid & 4700 & 440 \\
\hline $\mathrm{C}_{3} \mathrm{H}_{6} \mathrm{O}_{4}$ & Glyceric (2,3-dihydroxypropanoic) acid & 36 & 2.9 \\
\hline $\mathrm{C}_{4} \mathrm{H}_{8} \mathrm{O}_{3}$ & Hydroxybutyric (3-hydroxybutanoic) acid & 14 & 3.6 \\
\hline $\mathrm{C}_{3} \mathrm{H}_{4} \mathrm{O}_{3}$ & Pyruvic (2-oxopropanoic) acid & 31 & 7.3 \\
\hline $\mathrm{C}_{4} \mathrm{H}_{6} \mathrm{O}_{3}$ & Oxobutanoic acid & 73 & 19 \\
\hline $\mathrm{C}_{5} \mathrm{H}_{8} \mathrm{O}_{3}$ & Oxopentanoic acid & 190 & 7.7 \\
\hline $\mathrm{C}_{6} \mathrm{H}_{10} \mathrm{O}_{3}$ & Oxohexanoic acid & 37 & 4.6 \\
\hline $\mathrm{C}_{7} \mathrm{H}_{6} \mathrm{O}_{2}$ & Benzoic acid & 15 & ND \\
\hline
\end{tabular}

a Species reported here have average indoor levels above 10 ppt. This study used acetate as a reagent ion and, hence, was unable to measure acetic acid. ${ }^{b}$ Primary naming of species in this table follows reporting by Liu et al. ${ }^{13}$ Where available, in parenthesis is an alternative, either the common name or the preferred IUPAC name.

This article is protected by copyright. All rights reserved 
Table 19. Average concentrations $\left(\mathrm{ng} / \mathrm{m}^{3}\right)$ of $\mathrm{PM}_{10}$-associated organic acids measured inside and outside two elementary school classrooms in Aveiro, Portugal, as sampled on weekdays. ${ }^{327}$

\begin{tabular}{|l|c|c|c|c|}
\hline Species & $\begin{array}{l}\text { Urban } \\
\text { indoor }\end{array}$ & $\begin{array}{l}\text { Urban } \\
\text { outdoor }\end{array}$ & $\begin{array}{l}\text { Suburban } \\
\text { indoor }\end{array}$ & $\begin{array}{l}\text { Suburban } \\
\text { outdoor }\end{array}$ \\
\hline Dehydroabietic acid & 17 & 12 & 399 & 19 \\
\hline Palmitoleic acid & 488 & 506 & 638 & 299 \\
\hline Benzoic acid & 139 & 96 & 222 & 113 \\
\hline Pinic acid & 143 & 203 & 122 & 170 \\
\hline
\end{tabular}

Table 20. Mean concentrations \pm standard deviations $\left(\mathrm{ng} / \mathrm{m}^{3}\right)$ of $\mathrm{PM}_{10}$-associated acids measured indoors and outdoors at a primary school ${ }^{328}$ in Aveiro, Portugal. a

\begin{tabular}{|l|c|c|c|}
\hline Species & \multicolumn{1}{|l|}{ Indoor } & Outdoor & I/O ratio \\
\hline Glycolic acid & $169 \pm 100$ & $59 \pm 23$ & 2.9 \\
\hline Cinnamic acid & $20.9 \pm 5.7$ & $6.0 \pm 2.2$ & 3.5 \\
\hline Levulinic acid & $13.2 \pm 6.7$ & $4.9 \pm 1.9$ & 2.7 \\
\hline Benzoic acid & $11.3 \pm 5.7$ & $3.6 \pm 1.2$ & 3.2 \\
\hline Succinic acid & $13.1 \pm 3.8$ & $5.5 \pm 4.2$ & 2.4 \\
\hline Malic acid & $1920 \pm 730$ & $91 \pm 52$ & 21 \\
\hline Pinic acid & $151 \pm 92$ & $11.7 \pm 4.1$ & 13 \\
\hline Azelaic acid & $20.7 \pm 7.0$ & $7.5 \pm 3.7$ & 2.8 \\
\hline
\end{tabular}

${ }^{\text {a }}$ Concentrations of eighteen species were reported in Table 2 of Alves et al. ${ }^{328}$ The subset reported here are those for which the indoor concentrations exceeded $10 \mathrm{ng} / \mathrm{m}^{3}$.

Table 21. Mean concentrations \pm standard deviations $\left(\mathrm{ng} / \mathrm{m}^{3}\right)$ of $\mathrm{PM}_{2.5}$-associated acids measured outdoors in Beijing ${ }^{336}$ during the period September 2013 - July 2014. ${ }^{a}$

This article is protected by copyright. All rights reserved 


\begin{tabular}{|l|c|c|c|c|}
\hline Species & Autumn $(\boldsymbol{n}=\mathbf{1 6})$ & Winter $(\boldsymbol{n}=\mathbf{1 5})$ & Spring $(\boldsymbol{n}=\mathbf{1 9})$ & Summer $(\boldsymbol{n}=\mathbf{1 5})$ \\
\hline Oxalic acid & $472 \pm 490$ & $149 \pm 123$ & $262 \pm 120$ & $267 \pm 146$ \\
\hline Malonic acid & $44 \pm 36$ & $20 \pm 16$ & $33 \pm 14$ & $31 \pm 13$ \\
\hline Succinic acid & $67 \pm 62$ & $32 \pm 21$ & $38 \pm 17$ & $31 \pm 14$ \\
\hline Glutaric acid & $15 \pm 14$ & $9 \pm 6$ & $10 \pm 4$ & $9 \pm 3$ \\
\hline Adipic acid & $16 \pm 9$ & $9 \pm 5$ & $14 \pm 4$ & $11 \pm 4$ \\
\hline Azelaic acid & $32 \pm 14$ & $27 \pm 15$ & $27 \pm 11$ & $19 \pm 5$ \\
\hline Phthalic acid & $26 \pm 16$ & $38 \pm 27$ & $23 \pm 7$ & $25 \pm 8$ \\
\hline Terephthalic acid & $40 \pm 25$ & $49 \pm 41$ & $20 \pm 9$ & $16 \pm 6$ \\
\hline Pyruvic acid & $16 \pm 15$ & $14 \pm 18$ & $12 \pm 5$ & $11 \pm 6$ \\
\hline Glyoxylic acid & $44 \pm 50$ & $44 \pm 69$ & $25 \pm 15$ & $25 \pm 17$ \\
\hline
\end{tabular}

a Concentrations of 33 species (mostly acids) were reported in Table 1 of Zhao et al. ${ }^{336}$ The subset reported here are those acids for which the average concentrations across the four seasons exceeded $10 \mathrm{ng} / \mathrm{m}^{3}$. The samples were collected using 23-h sampling periods.

This article is protected by copyright. All rights reserved 
Table 22. Particle strong acidity measured in 24 communities in the US and Canada (1988-1991). ${ }^{95}$

\begin{tabular}{|c|c|c|}
\hline City & Annual mean $\left(\mathrm{nmol} / \mathrm{m}^{3}\right)$ & Summer mean $\left(\mathrm{nmol} / \mathrm{m}^{3}\right)$ \\
\hline Henderson, TN & 39 & 64 \\
\hline Oak Ridge, TN & 43 & 67 \\
\hline Morehead, KY & 44 & 77 \\
\hline Blacksburg, VA & 34 & 59 \\
\hline Charlottesville, VA & 37 & 64 \\
\hline Zanesville, $\mathrm{OH}$ & 35 & 65 \\
\hline Athens, $\mathrm{OH}$ & 44 & 77 \\
\hline Parsons, WV & 48 & 82 \\
\hline Uniontown, PA & 52 & 88 \\
\hline Penn Hills, PA & 35 & 69 \\
\hline State College, PA & 41 & 67 \\
\hline Average, Sulfate Belt ${ }^{a}$ & 41 & 71 \\
\hline Leamington, ON & 19 & 30 \\
\hline Newton, CT & 26 & 42 \\
\hline Egbert, ON & 6 & 11 \\
\hline Pembroke, ON & 21 & 29 \\
\hline Dunnville, ON & 29 & 54 \\
\hline South Brunswick, NJ b & 48 & 48 \\
\hline Average, Transport Region ${ }^{a}$ & 25 & 36 \\
\hline Simi Valley, CA & 16 & 19 \\
\hline Livermore, CA & 12 & 11 \\
\hline Monterey, CA & 10 & 9 \\
\hline Average, West Coast ${ }^{a}$ & 13 & 13 \\
\hline Springdale, AR & 13 & 21 \\
\hline Aberdeen, SD & 2 & 4 \\
\hline
\end{tabular}

This article is protected by copyright. All rights reserved 


\begin{tabular}{|l|c|c|}
\hline Yorkton, SK & $0^{c}$ & $0^{c}$ \\
\hline Penticton, BC & 9 & 9 \\
\hline Average, Background Sites ${ }^{a}$ & 6 & 9 \\
\hline Average, All 24 Sites & 28 & 44 \\
\hline
\end{tabular}

a Groupings of "sulfate belt," "transport region," "west coast," and "background" are as reported by Spengler et al. ${ }^{95}$ b South Brunswick, NJ was only sampled during the summer (1988). ${ }^{c}$ Annual mean reported as "below limit of detection; set to zero." 95 Summer mean also reported as zero without qualification.

This article is protected by copyright. All rights reserved 
Table 23. Aerosol strong acidity in fine particles $\left(\mathrm{H}^{+}, \mathrm{nmol} / \mathrm{m}^{3}\right)$ as reported by Liang and Waldman ${ }^{129}$ indoors at three study sites and outdoors in New Jersey.

\begin{tabular}{|l|c|c|c|c|}
\hline & \multicolumn{2}{|c|}{ Daytime (0700-1900) } & \multicolumn{2}{c|}{ Nighttime (1900-0700) } \\
\hline Site & Mean & $9^{\text {th }}$ percentile & Mean & 90 $^{\text {th }}$ percentile \\
\hline Daycare center, indoors ${ }^{\mathrm{a}}$ & 15 & 44 & NA & NA \\
\hline Nursing home, indoors $^{\mathrm{b}}$ & 17 & 42 & NA & NA \\
\hline Home for elderly, indoors $^{c}$ & 21 & 53 & 29 & 66 \\
\hline Home for elderly, outdoors $^{c}$ & 54 & 152 & 39 & 94 \\
\hline Central site, outdoors & 66 & 135 & 31 & 71 \\
\hline
\end{tabular}

${ }^{a}$ Window air conditioner; no mechanical ventilation. ${ }^{b}$ Central air conditioning. ${ }^{c}$ Natural ventilation.

Table 24. Fine-particle strong acidity $\left(\mathrm{H}^{+}\right.$, in $\left.\mathrm{nmol} / \mathrm{m}^{3}\right)$ measured inside and outside of homes in Connecticut $(n=20)$ and Virginia $(n=261) .{ }^{\text {a }}$

\begin{tabular}{|l|c|c|}
\hline Site condition & No. Samples & Mean \pm standard deviation \\
\hline Outside all homes, summer & 45 & $33 \pm 37$ \\
\hline Inside AC homes, summer & 49 & $12 \pm 15$ \\
\hline Inside non-AC homes, summer & 9 & $17 \pm 9$ \\
\hline Outside all homes, winter & 52 & $6.5 \pm 9.8$ \\
\hline Inside kerosene-heater homes, winter & 74 & $5.7 \pm 6.9$ \\
\hline Inside nonkerosene heater homes, winter & 149 & $3.1 \pm 5.0$ \\
\hline
\end{tabular}

a Source: Leaderer et al. ${ }^{132}$

This article is protected by copyright. All rights reserved 
Table 25. Properties of selected amines identified or anticipated to occur indoors $(T=298 \mathrm{~K}) .^{\mathrm{a}}$

\begin{tabular}{|c|c|c|c|c|c|}
\hline $\begin{array}{l}\text { Common name (IUPAC name or } \\
\text { alternate common name) }\end{array}$ & Formula & $\begin{array}{l}\mathrm{MW} \\
(\mathrm{g} / \mathrm{mol})\end{array}$ & $\mathrm{p} K_{\mathrm{b}} \mathrm{b}$ & $\begin{array}{l}K_{\mathrm{H}} \\
\text { (M/atm) }\end{array}$ & $\log \left(K_{\text {oa }}\right)^{c}$ \\
\hline Methylamine (methanamine) & $\mathrm{NH}_{2}\left(\mathrm{CH}_{3}\right)$ & 31.1 & 3.3 & 35 & 2.4 \\
\hline $\begin{array}{l}\text { Dimethylamine }(N- \\
\text { methylmethanamine) }\end{array}$ & $\mathrm{NH}\left(\mathrm{CH}_{3}\right)_{2}$ & 45.1 & 3.3 & 30 & 2.5 \\
\hline Ethylamine (ethanamine) & $\mathrm{NH}_{2}\left(\mathrm{C}_{2} \mathrm{H}_{5}\right)$ & 45.1 & 3.3 & 35 & 2.8 \\
\hline $\begin{array}{l}\text { Trimethylamine }(N, N- \\
\text { dimethylmethanamine) }\end{array}$ & $\mathrm{N}\left(\mathrm{CH}_{3}\right)_{3}$ & 59.1 & 4.2 & 7.7 & 2.4 \\
\hline Diethylamine ( $N$-ethylethanamine) & $\mathrm{NH}\left(\mathrm{C}_{2} \mathrm{H}_{5}\right)_{2}$ & 73.1 & 3.2 & 40 & 3.6 \\
\hline Butylamine (butan-1-amine) & $\mathrm{NH}_{2}\left(\mathrm{C}_{4} \mathrm{H}_{9}\right)$ & 73.1 & 3.4 & $57^{c}$ & 4.1 \\
\hline Triethylamine (N,N-diethylethanamine) & $\mathrm{C}_{6} \mathrm{H}_{15} \mathrm{~N}$ & 101 & 3.2 & 6.7 & 3.7 \\
\hline $\begin{array}{l}\text { Diethylethanolamine } \\
\text { (diethylaminoethanol) }\end{array}$ & $\mathrm{C}_{6} \mathrm{H}_{15} \mathrm{NO}$ & 117 & $4.1^{d}$ & $2.6 \times 10^{7 d}$ & 7.4 \\
\hline Cyclohexylamine (cyclohexamine) & $\mathrm{C}_{6} \mathrm{H}_{13} \mathrm{~N}$ & 99 & 3.4 & 240 & 5.3 \\
\hline Aniline (benzenamine) & $\mathrm{NH}_{2}\left(\mathrm{C}_{6} \mathrm{H}_{5}\right)$ & 93 & 9.1 & 530 & 5.0 \\
\hline 2-Methylaniline (o-toluidine) & $\mathrm{NH}_{2}\left(\mathrm{C}_{7} \mathrm{H}_{7}\right)$ & 107 & 9.5 & 510 & 5.4 \\
\hline 3-Methylaniline (m-toluidine) & $\mathrm{NH}_{2}\left(\mathrm{C}_{7} \mathrm{H}_{7}\right)$ & 107 & 9.3 & 600 & 5.6 \\
\hline 4-Methylaniline ( $p$-toluidine) & $\mathrm{NH}_{2}\left(\mathrm{C}_{7} \mathrm{H}_{7}\right)$ & 107 & 8.9 & 1320 & 5.9 \\
\hline 2,6-Dimethylaniline (2,6-xylidine) & $\mathrm{C}_{8} \mathrm{H}_{11} \mathrm{~N}$ & 121 & 10.1 & $400^{d}$ & 5.8 \\
\hline 2-Chloroaniline (2-chlorobenzenamine) & $\mathrm{C}_{6} \mathrm{H}_{6} \mathrm{CIN}$ & 128 & 11.3 & $190^{d}$ & 5.6 \\
\hline $\begin{array}{l}\text { 2,4-Dichloroaniline (2,4- } \\
\text { dichlorobenzenamine) }\end{array}$ & $\mathrm{C}_{6} \mathrm{H}_{5} \mathrm{Cl}_{2} \mathrm{~N}$ & 162 & 11.9 & 630 & 7.1 \\
\hline 4-Aminophenol (4-hydroxyaniline) & $\mathrm{C}_{6} \mathrm{H}_{7} \mathrm{NO}$ & 109 & $\begin{array}{l}8.5 \\
3.7\end{array}$ & $2.7 \times 10^{6}$ & 7.9 \\
\hline 2-Naphthylamine (naphthalen-2-amine) & $\mathrm{C}_{10} \mathrm{H}_{9} \mathrm{~N}$ & 143 & 9.8 & $1.2 \times 10^{4}$ & 7.8 \\
\hline 4-Aminobiphenyl (4-phenylaniline) & $\mathrm{C}_{12} \mathrm{H}_{11} \mathrm{~N}$ & 169 & 9.6 & 6700 & 8.1 \\
\hline
\end{tabular}

This article is protected by copyright. All rights reserved 


\begin{tabular}{|l|l|l|l|l|l|}
\hline Piperazine (1,4-diazacyclohexane) & $\mathrm{C}_{4} \mathrm{H}_{10} \mathrm{~N}_{2}$ & 86 & 4.3, & $1.0 \times 10^{4}$ & 3.9 \\
& & & 8.7 & & \\
\hline
\end{tabular}

a Sources: Unless otherwise noted, for $\mathrm{p} K_{\mathrm{a}}$ values, "Dissociation Constants of Organic Acids and Bases" from CRC Handbook of Chemistry and Physics, downloaded at https://sites.chem.colostate.edu/diverdi/all_courses/CRC\%20reference\%20data/dissociation\%20constants \%20of\%20organic\%20acids\%20and\%20bases.pdf; for Henry's law constants, Sander. ${ }^{142}$ b Basicity constants determined from reported acidity constants of conjugate acids, as $\mathrm{p} K_{\mathrm{b}}=14.0-\mathrm{p} K_{\mathrm{a}}$. ${ }^{\mathrm{c}}$ Except where noted, derived from $K_{\text {ow }}$ and Henry's law constant as reported in PubChem $\left[\log \left(K_{\text {oa }}\right)=\log \left(K_{\text {ow }}\right)+\log \left(K_{\mathrm{H}} \times R T\right)\right]$. ${ }^{d}$ Source: PubChem.

This article is protected by copyright. All rights reserved 
Table 26. Properties of selected amino acids anticipated to occur indoors $(T=298 \mathrm{~K}) .^{\text {a }}$

\begin{tabular}{|c|c|c|c|c|c|}
\hline $\begin{array}{l}\text { Common name (IUPAC name or } \\
\text { alternate common name) }\end{array}$ & Formula & $\begin{array}{l}\mathrm{MW} \\
\text { (g/mol) }\end{array}$ & $\mathrm{p} K_{\mathrm{a}}$ & $\begin{array}{l}K_{\mathrm{H}} \\
\text { (M/atm) }\end{array}$ & $\log \left(K_{\text {oa }}\right)^{b}$ \\
\hline Histidine (glyoxaline-5-alanine) & $\mathrm{C}_{6} \mathrm{H}_{9} \mathrm{~N}_{3} \mathrm{O}_{2}$ & 155 & $\begin{array}{l}1.80,6.04, \\
9.33\end{array}$ & & \\
\hline $\begin{array}{l}\text { Serine ((S)-2-amino-3- } \\
\text { hydroxypropanoic acid) }\end{array}$ & $\mathrm{C}_{3} \mathrm{H}_{7} \mathrm{NO}_{3}$ & 105 & $2.19,9.21$ & $4.0 \times 10^{12}$ & 10.9 \\
\hline $\begin{array}{l}\text { Ornithine ((S)-2,5- } \\
\text { diaminopentanoic acid) }\end{array}$ & $\mathrm{C}_{5} \mathrm{H}_{12} \mathrm{~N}_{2} \mathrm{O}_{2}$ & 132 & $\begin{array}{l}1.71,8.69, \\
10.8\end{array}$ & & \\
\hline Glycine (2-aminoacetic acid) & $\mathrm{C}_{2} \mathrm{H}_{5} \mathrm{NO}_{2}$ & 75 & $2.35,9.78$ & $1.2 \times 10^{13}$ & 11.3 \\
\hline $\begin{array}{l}\text { Alanine ((S)-2-aminopropanoic } \\
\text { acid) }\end{array}$ & $\mathrm{C}_{3} \mathrm{H}_{7} \mathrm{NO}_{2}$ & 89 & $2.34,9.87$ & $3.5 \times 10^{12}$ & 11.1 \\
\hline $\begin{array}{l}\text { Arginine ((S)-2-amino-5- } \\
\text { guanidinopentanoic acid) }\end{array}$ & $\mathrm{C}_{6} \mathrm{H}_{14} \mathrm{~N}_{4} \mathrm{O}_{2}$ & 174 & $\begin{array}{l}1.82,8.99, \\
12.5\end{array}$ & $1.0 \times 10^{17}$ & 14.2 \\
\hline $\begin{array}{l}\text { Glutamic acid ((S)-2- } \\
\text { aminopentanedioic acid) }\end{array}$ & $\mathrm{C}_{5} \mathrm{H}_{9} \mathrm{NO}_{4}$ & 147 & $\begin{array}{l}2.13,4.31 \\
9.67\end{array}$ & $1.0 \times 10^{13}$ & 10.7 \\
\hline
\end{tabular}

a Sources: For $\mathrm{p} K_{\mathrm{a}}$ values, "Dissociation Constants of Organic Acids and Bases" from CRC Handbook of Chemistry and Physics, downloaded at https://sites.chem.colostate.edu/diverdi/all_courses/CRC\%20reference\%20data/dissociation\%20constants \%20of\%20organic\%20acids\%20and\%20bases.pdf; for Henry's law constants, Sander. ${ }^{142}$ b Derived from $K_{\text {ow }}$ and Henry's law constant as reported in PubChem $\left[\log \left(K_{\text {oa }}\right)=\log \left(K_{\text {ow }}\right)+\log \left(K_{\mathrm{H}} \times R T\right)\right]$. 


\section{Figure Legends}

Figure 1. Sorption isotherms describing the equilibrium moisture content of wood ${ }^{37}$ at $21^{\circ} \mathrm{C}$ and gypsum board ${ }^{38}$ at an unspecified temperature as a function of relative humidity.

Figure 2. Scattergram of the acid dissociation constant $\left(p K_{\mathrm{a}}\right)$ and Henry's law constant $\left(K_{\mathrm{H}}\right)$ for some acids regularly encountered indoors. Note the spans: 12 orders-of-magnitude range in Henry's law constants between carbon dioxide and malonic acid; and more than 13 orders-of-magnitude difference in acid dissociation constants, $K_{\mathrm{a}}$, between hypochlorous and hydrochloric acid.

Figure 3. Increase of indoor carbon dioxide concentration attributable to metabolic emissions in relation to the ventilation rate per person. The different $\mathrm{CO}_{2}$ emission rates correspond to average per-person emission rates for different building types, based on Persily and de Jonge, ${ }^{82}$ as follows: $18 \mathrm{~g} / \mathrm{h}$ for a child's bedroom, $21 \mathrm{~g} / \mathrm{h}$ for a classroom (5 to $8 \mathrm{y}$ ), $25 \mathrm{~g} / \mathrm{h}$ for an adult bedroom, $28 \mathrm{~g} / \mathrm{h}$ for a residence, $34 \mathrm{~g} / \mathrm{h}$ for an office or conference room, and $38 \mathrm{~g} / \mathrm{h}$ for a lobby. The dashed line at a 700-ppm metabolic increment (added to a typical baseline in the vicinity of $400 \mathrm{ppm}$ ) is often used as a guideline or design value to provide sufficient ventilation to avoid conditions that would be deemed unsatisfactory owing to sensory perception of bioeffluents, based on the seminal work of von Pettenkofer. ${ }^{2}$

Figure 4. Equilibrium $\mathrm{pH}$ of liquid water exposed to gaseous carbon dioxide. The water is assumed to be pure apart from the influence of carbonic acid. Conditions are $T=25^{\circ} \mathrm{C}$ and $P=1 \mathrm{~atm}$. The effective Henry's law constant relating aqueous carbonic acid to gaseous $\mathrm{CO}_{2}$ is $0.033 \mathrm{M} /$ atm. The $\mathrm{p} K_{\mathrm{a}}$ values for carbonic acid are 6.35 and $10.3 .{ }^{89}$

Figure 5. Equilibrium pH of otherwise pure water exposed simultaneously to $\mathrm{CO}_{2}$ (none, $400 \mathrm{ppm}$, or $1000 \mathrm{ppm}$ ) and to a specific concentration of gaseous $\mathrm{NH}_{3}$ within the range 1-300 ppb. The following thermodynamic parameters were used in the calculations. Henry's law constants of 59 
$\mathrm{M} /$ atm for ammonia and $0.033 \mathrm{M} /$ atm for $\mathrm{CO}_{2}$; acid dissociation constants $\left(\mathrm{p} K_{\mathrm{a}}\right)$ of 9.24 for $\mathrm{NH}_{4}{ }^{+}$, 6.35 for $\mathrm{H}_{2} \mathrm{CO}_{3}$, and 10.3 for $\mathrm{HCO}_{3}^{-}$.

Figure 6. Equilibrium pH of liquid water exposed simultaneously to gaseous $\mathrm{CO}_{2}$ and $\mathrm{SO}_{2}$.

Figure 7. Equilibrium pH of water exposed to a mixture of $\mathrm{SO}_{2}$ and $\mathrm{H}_{2} \mathrm{SO}_{4}$. The total abundance of sulfur oxides in the system is considered to range from $0.1 \mathrm{ppb}$ (uppermost, red line) to $100 \mathrm{ppb}$ (lowest, black line). That abundance of sulfur oxides is divided into two groups, respectively in oxidation state $\mathrm{S}(\mathrm{IV})$ and $\mathrm{S}(\mathrm{VI})$. In this analysis, the proportion of sulfur that is sulfate $(\mathrm{S}(\mathrm{VI}))$ varies from 0 to $100 \%$ of the total sulfur oxides, as represented by the horizontal axis position. $\mathrm{S}(\mathrm{VI})$ is assumed to be fully taken up in condensed water and fully dissociated from the initial state sulfuric acid $\left(\mathrm{H}_{2} \mathrm{SO}_{4}\right)$ to the final state sulfate $\left(\mathrm{SO}_{4}{ }^{\circ}\right)$. The remaining sulfur oxide species is considered to be initially gaseous $\mathrm{SO}_{2}$, which partitions into water according to Henry's law and undergoes acid-base chemistry establishing a balance among $\mathrm{H}_{2} \mathrm{SO}_{3}, \mathrm{HSO}_{3}{ }^{-}$, and $\mathrm{SO}_{3}{ }^{=}$. The equilibrium pH calculation considers simultaneously the protons liberated from aqueous $\mathrm{S}(\mathrm{IV})$ and $\mathrm{S}(\mathrm{VI})$. The assumed effective liquid water content in the indoor space is $L^{*}=0.0025 \mathrm{~L} \mathrm{~m}^{-3}$, corresponding to $1 \mathrm{~L}$ of liquid water per $400 \mathrm{~m}^{3}$ of interior volume.

Figure 8. Schematic illustrating chemical transformations among indoor inorganic N-species

Figure 9. Ratio of gas-phase nitrous acid $(\mathrm{HONO}(\mathrm{g}))$ to the sum of aqueous nitrous acid plus nitrate, $\left(\mathrm{HONO}(\mathrm{aq})+\mathrm{NO}_{2}{ }^{-}\right)$, as a function of $\mathrm{pH}$, under equilibrium conditions for $L^{*}=3 \times 10^{-5} \mathrm{~L} / \mathrm{m}^{3}$ and $L^{*}=$ $3 \times 10^{-4} \mathrm{~L} / \mathrm{m}^{3}$, where $L^{*}$ indicates the equilibrated volume fraction of water in indoor air.

Figure 10. Equilibrium gas-phase concentration of $\mathrm{HOCl}$ in relation to $\mathrm{pH}$ for an aqueous solution of $\mathrm{NaOCl}$. In the analysis, it is assumed that $\mathrm{NaOCl}$ is fully soluble, that $\mathrm{OCl}^{-}$is nonvolatile, and that the $\mathrm{pH}$ is independently adjusted through the addition of strong base and/or strong acid. Relevant

This article is protected by copyright. All rights reserved 
thermodynamic data for $\mathrm{HOCl}$ are $\mathrm{p} K_{\mathrm{a}}=7.53$ and $K_{\mathrm{H}}=660 \mathrm{M} /$ atm. Total air pressure of 1 atm is assumed.

Figure 11. Relative abundance of (a, upper) formic acid and (b, lower) acetic acid in the gas phase as a fraction of the total in the gas plus condensed phases versus the volume of liquid water in equilibrium per volume of air $\left(L^{*}\right)$. The results are presented for four $\mathrm{pH}$ values, which are assumed to be externally regulated, independent of the carboxylic acid.

Figure 12. The chemical structure of lactic acid $\left(\mathrm{C}_{3} \mathrm{H}_{6} \mathrm{O}_{3}\right)$. The Henry's law constant is $K_{\mathrm{H}}=1.2 \times 10^{4}$ $\mathrm{M} /$ atm. ${ }^{142}$ The acid dissociation constant is $\mathrm{p} K_{\mathrm{a}}=3.86$.

Figure 13. Chemical structures of some dicarboxylic acids.

Figure 14. The structure of pyruvic acid $\left(\mathrm{C}_{3} \mathrm{H}_{4} \mathrm{O}_{3}, \mathrm{MW}=88 \mathrm{~g} / \mathrm{mol}\right)$. The Henry's law constant for pyruvic acid is $3.1 \times 10^{5} \mathrm{M} / \mathrm{atm} .{ }^{142}$ The acid dissociation constant is $\mathrm{p} K_{\mathrm{a}}=2.39$.

Figure 15. The structure of acrylic acid (propenoic acid, $\mathrm{CH}_{2}=\mathrm{CHCOOH}, \mathrm{MW}=72 \mathrm{~g} / \mathrm{mol}$ ). The Henry's law constant is $K_{\mathrm{H}}=3.1 \times 10^{3} \mathrm{M} /$ atm. ${ }^{142}$ The acid dissociation constant is $\mathrm{p} K_{\mathrm{a}}=4.25$.

Figure 16. The respective structures of the diacids, phthalic acid and terephthalic acid $\left(\mathrm{C}_{8} \mathrm{H}_{6} \mathrm{O}_{4}, \mathrm{MW}=\right.$ $166 \mathrm{~g} / \mathrm{mol})$. For phthalic acid, the $\mathrm{p} K_{\mathrm{a}}$ values are 2.94 and 5.43; the corresponding values for terephthalic acid are 3.54 and 4.34. The reported Henry's law constants are $5 \times 10^{7} \mathrm{M} /$ atm for phthalic acid and $2.5 \times 10^{9} \mathrm{M} /$ atm for terephthalic acid. ${ }^{142}$

Figure 17. Generic structure of amino acids that are precursors to human proteins.

Figure 18. (a) "Human" amino acid and (b) its zwitterion.

This article is protected by copyright. All rights reserved 
Figure 19. Chemical structure of nicotine.

Figure 20. Ratio of nicotine in the gas phase, $\mathrm{Nic}_{\mathrm{g}}$, to nicotine equilibrated with liquid water, $\mathrm{Nic}_{\mathrm{aq}}+$ $\mathrm{NicH}^{+}$aq, as a function of $\mathrm{pH}$ for $L^{*}=10^{-5} \mathrm{~L} / \mathrm{m}^{3}$ and $L^{*}=10^{-2} \mathrm{~L} / \mathrm{m}^{3}$, where $L^{*}$ indicates the volume fraction of water equilibrated with indoor air. The $\mathrm{p} K_{\mathrm{a}}$ value for $\mathrm{NicH}^{+}$is 8.0 and the Henry's law constant for nicotine is $3.3 \times 10^{5} \mathrm{M} /$ atm.

Figure 21. Partitioning of free-base nicotine (Nic) between the particle phase and gas-phase for aerosol particles, including ETS. Monoprotonated nicotine $\left(\mathrm{NicH}^{+}\right)$occurs only in the particle phase. In Case $\mathrm{A}$ (upper) the lower $\mathrm{pH}$ of the aqueous phase in the particle leads to substantial protonation of aqueous nicotine and therefore a relatively smaller abundance of the gas-phase Nic. Conversely, in Case B (lower), the higher aerosol pH causes a larger fraction of condensed-phase nicotine to be in the free-base form, which, in turn, permits a greater abundance of gaseous nicotine. Figure based on Pankow. ${ }^{449}$

This article is protected by copyright. All rights reserved 
Figures for

INDOOR ACIDS AND BASES

WW Nazaroff and CJ Weschler

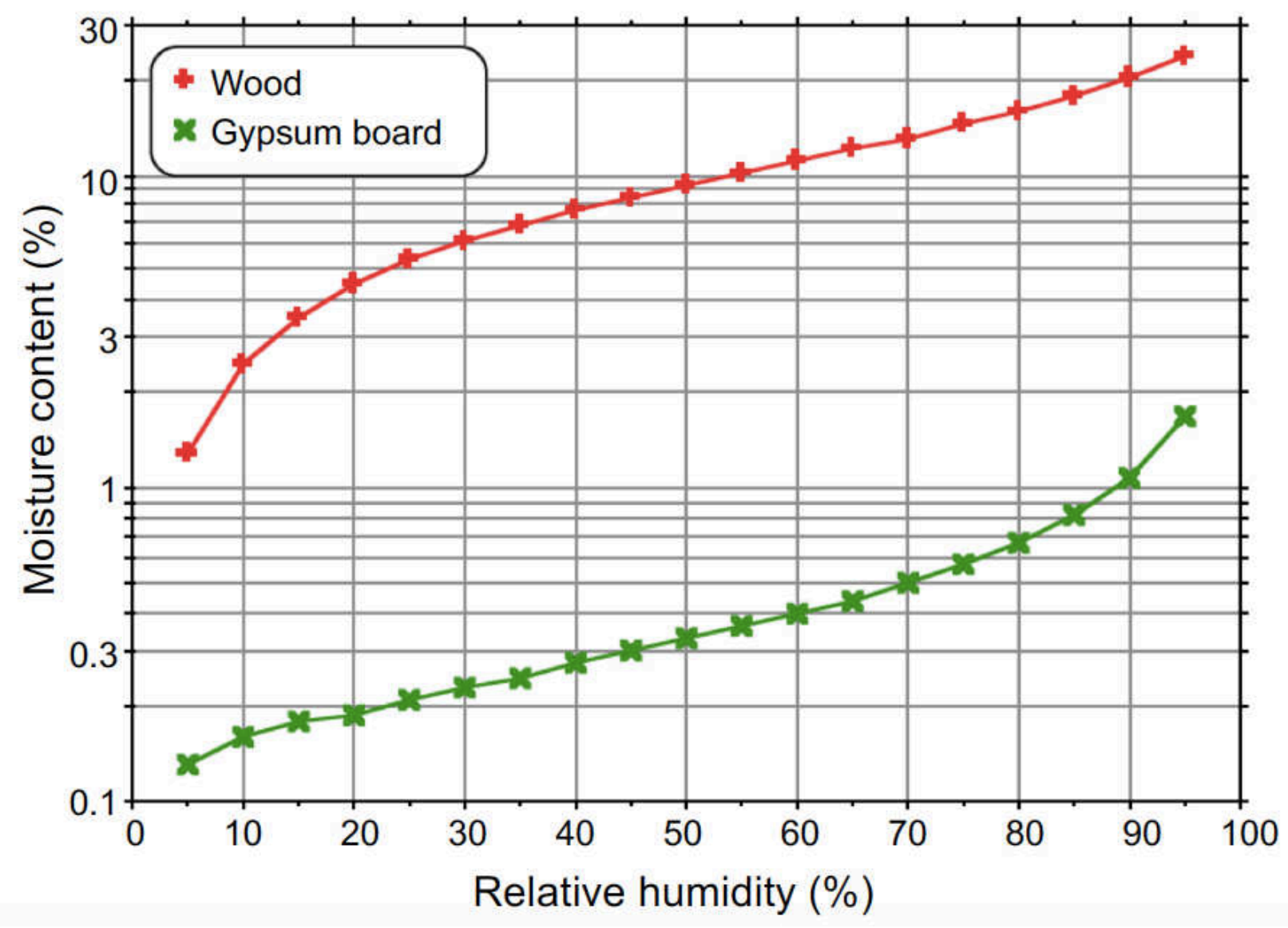

Figure 1. 


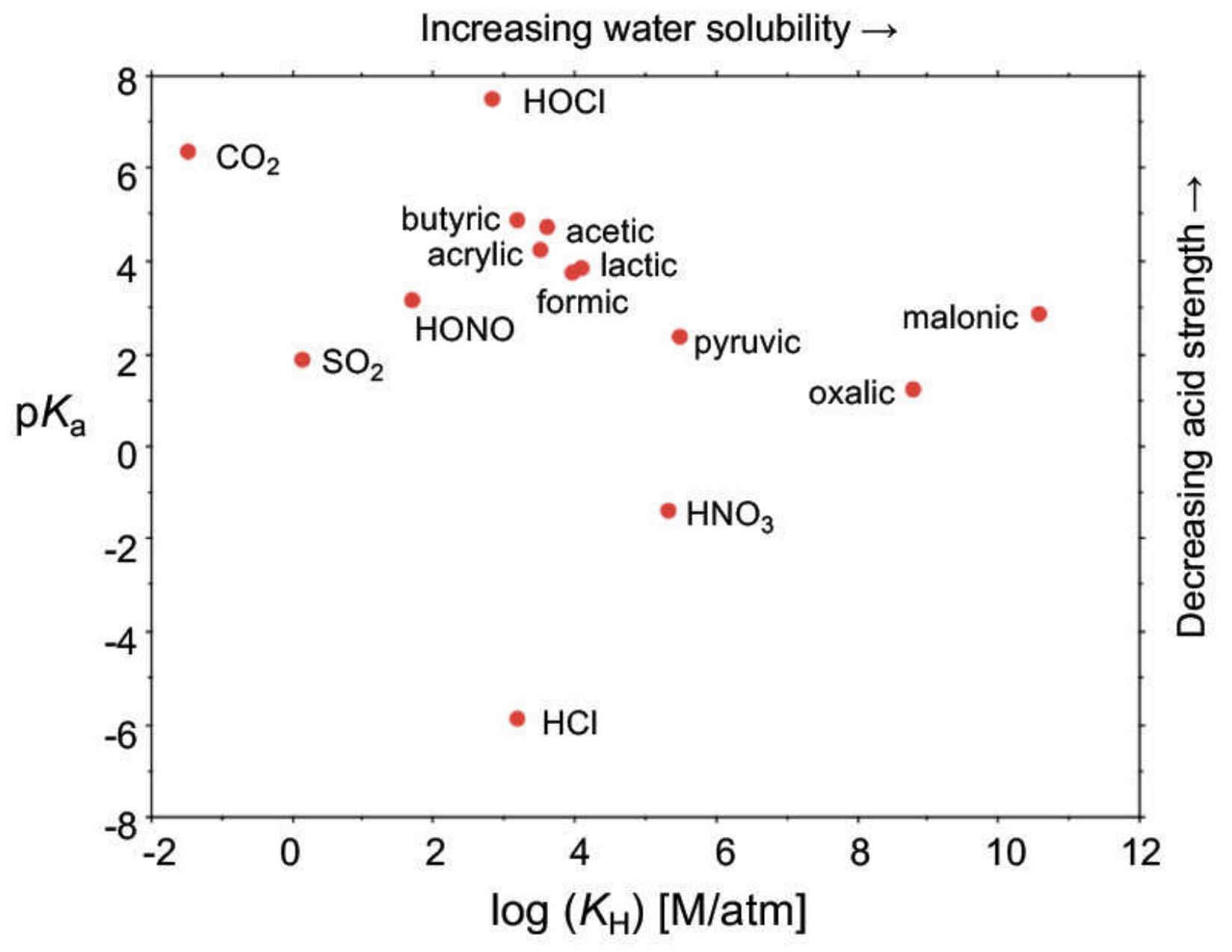

Figure 2. 


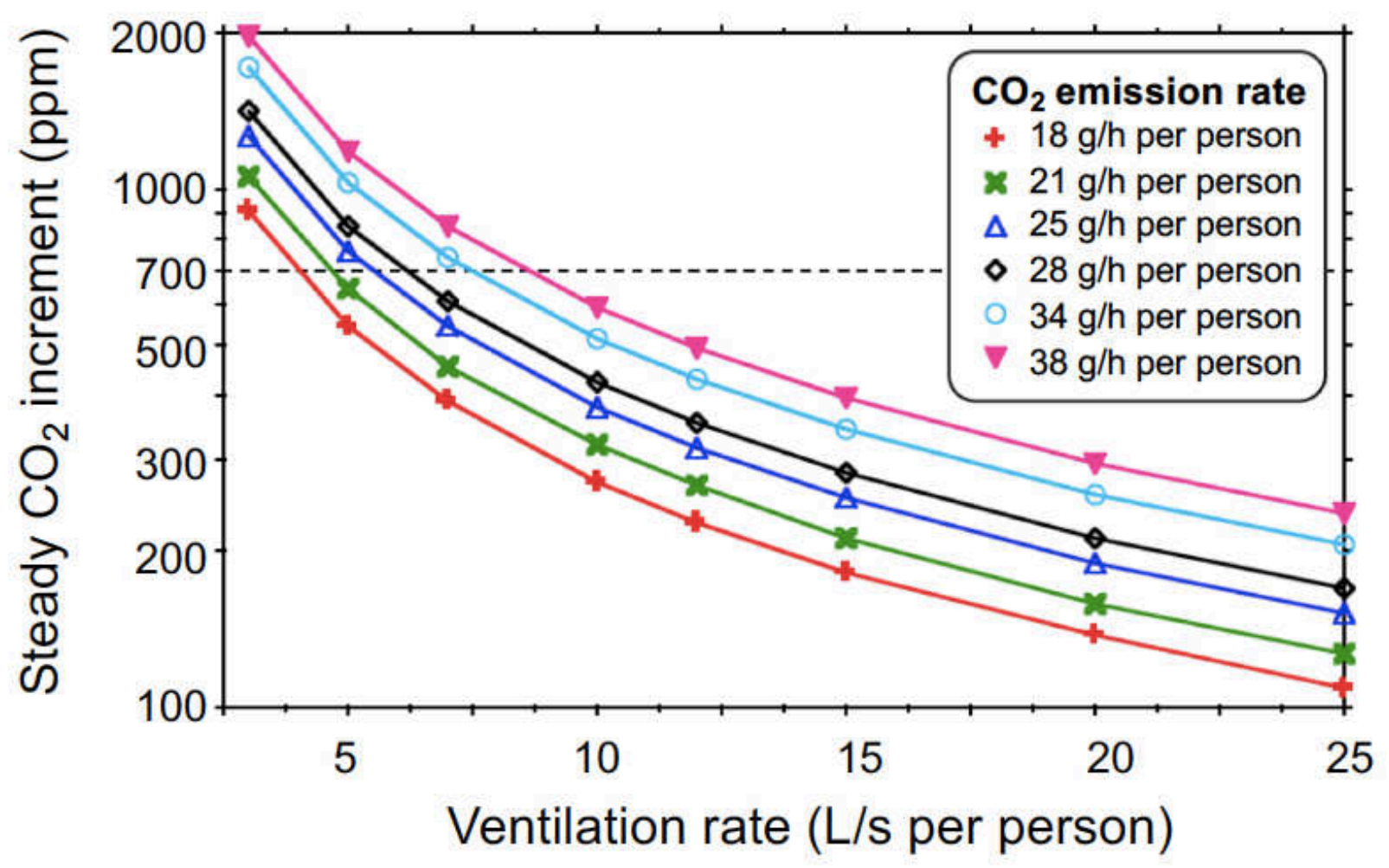

Figure 3.

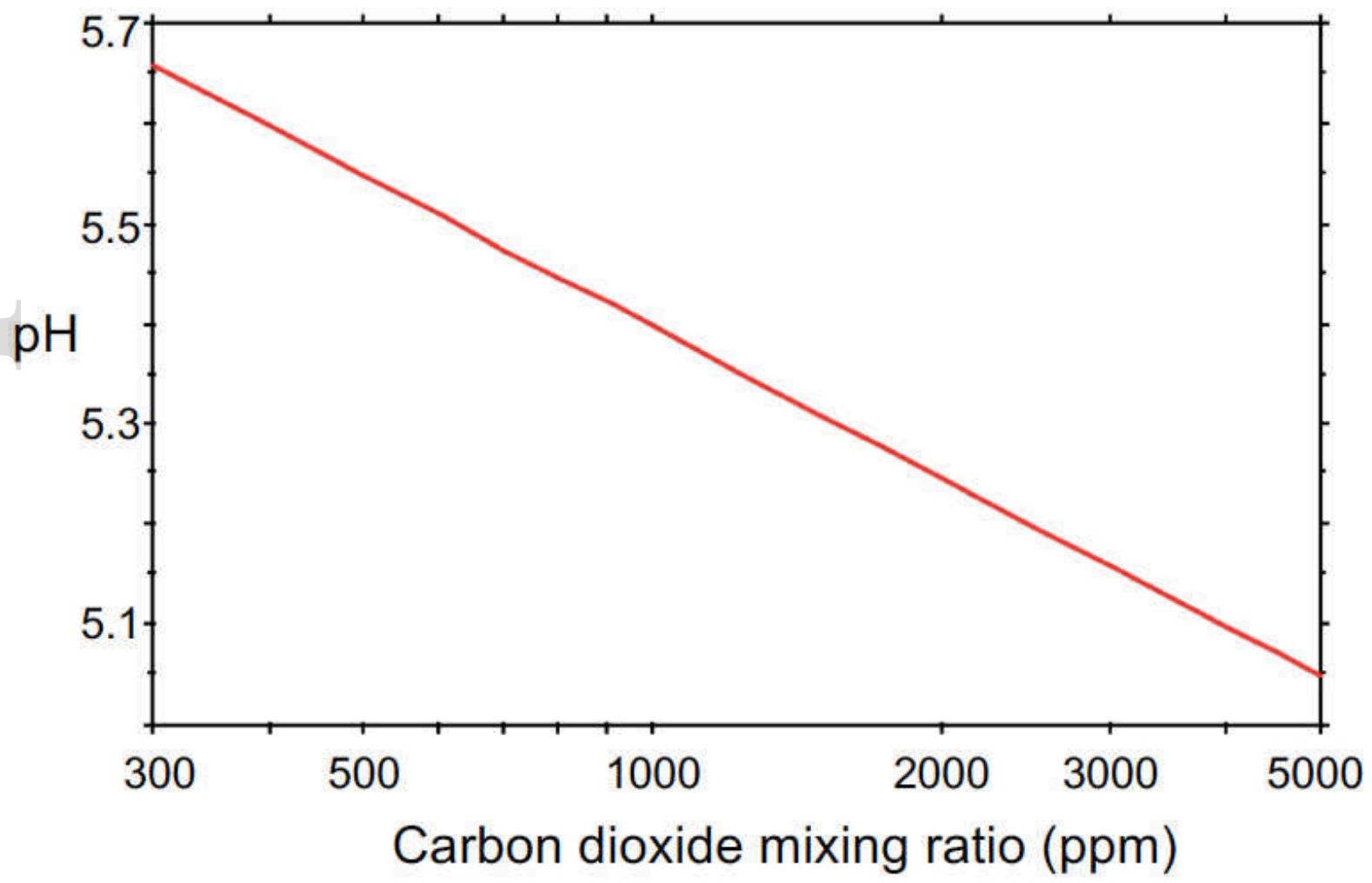

Figure 4.

This article is protected by copyright. All rights reserved 


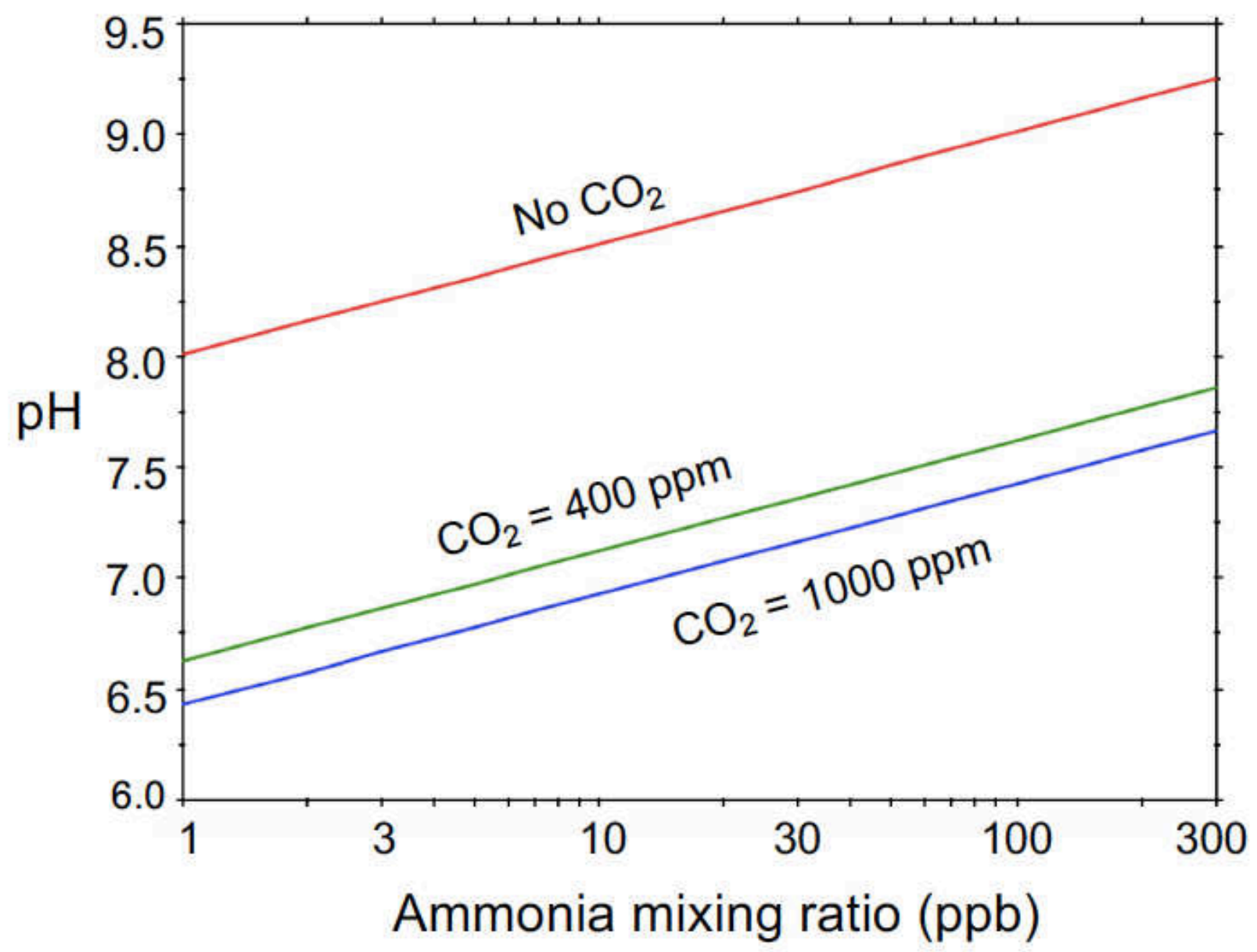

Figure 5. 


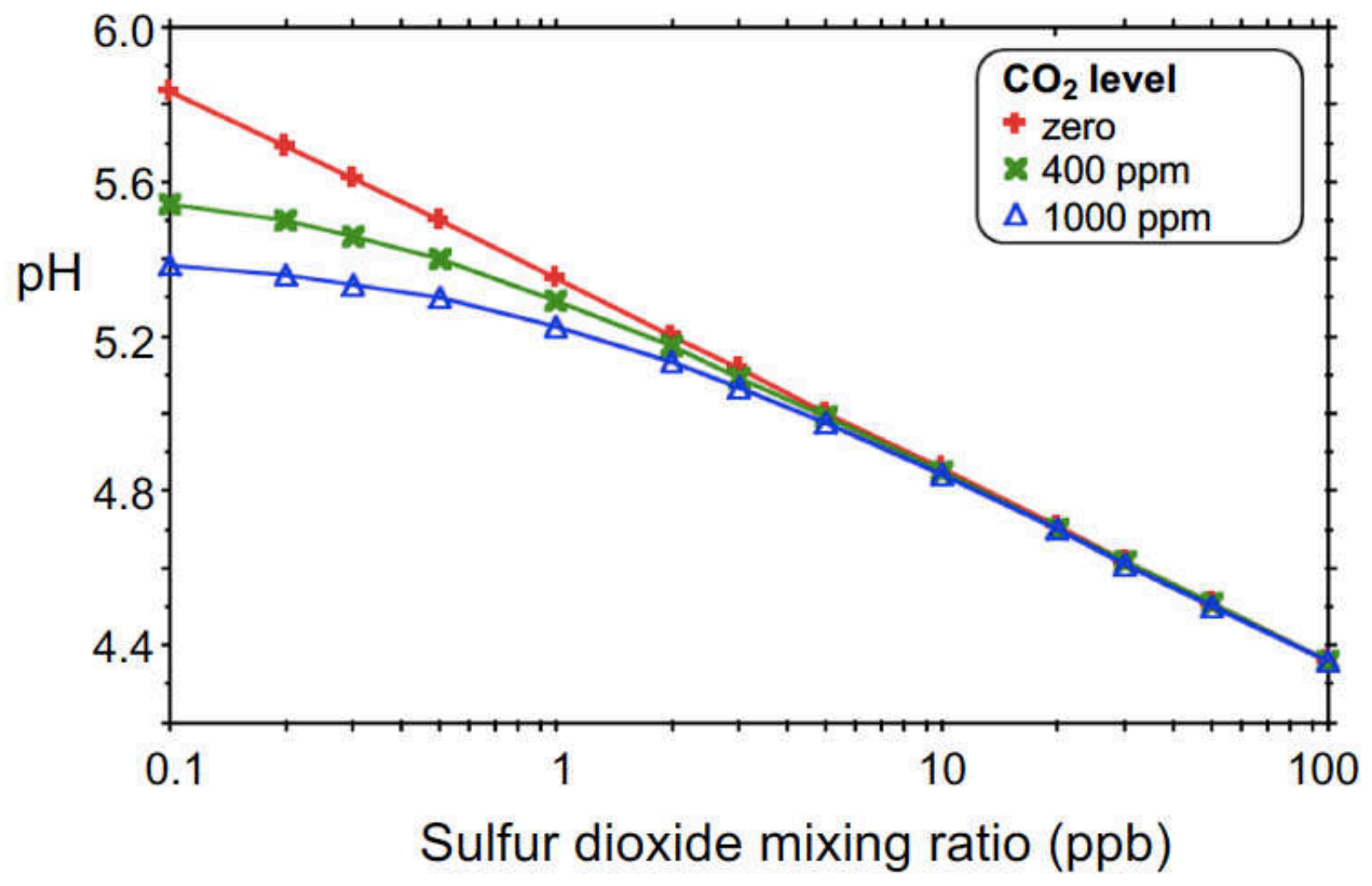

Figure 6. 


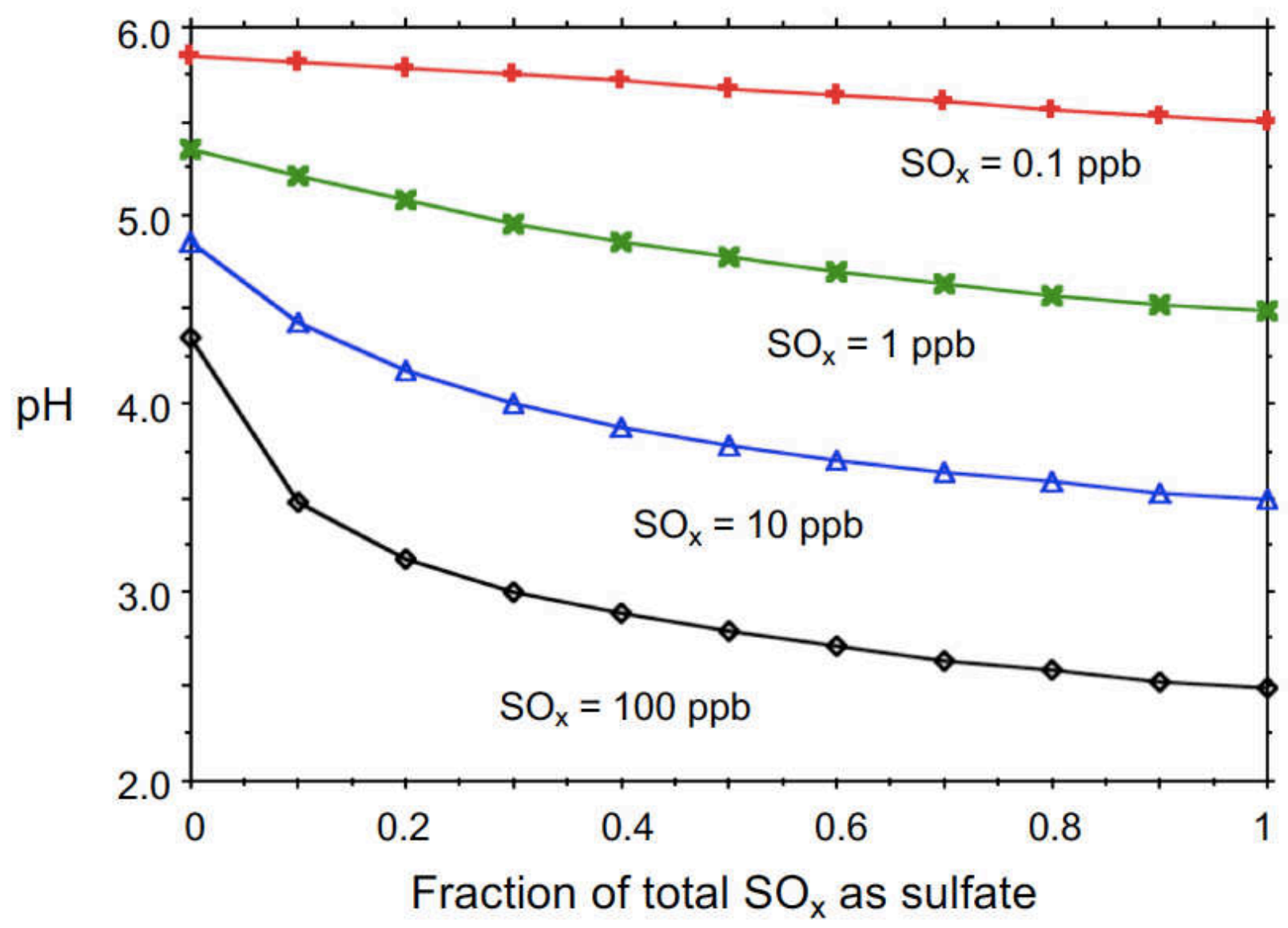

Figure 7. 


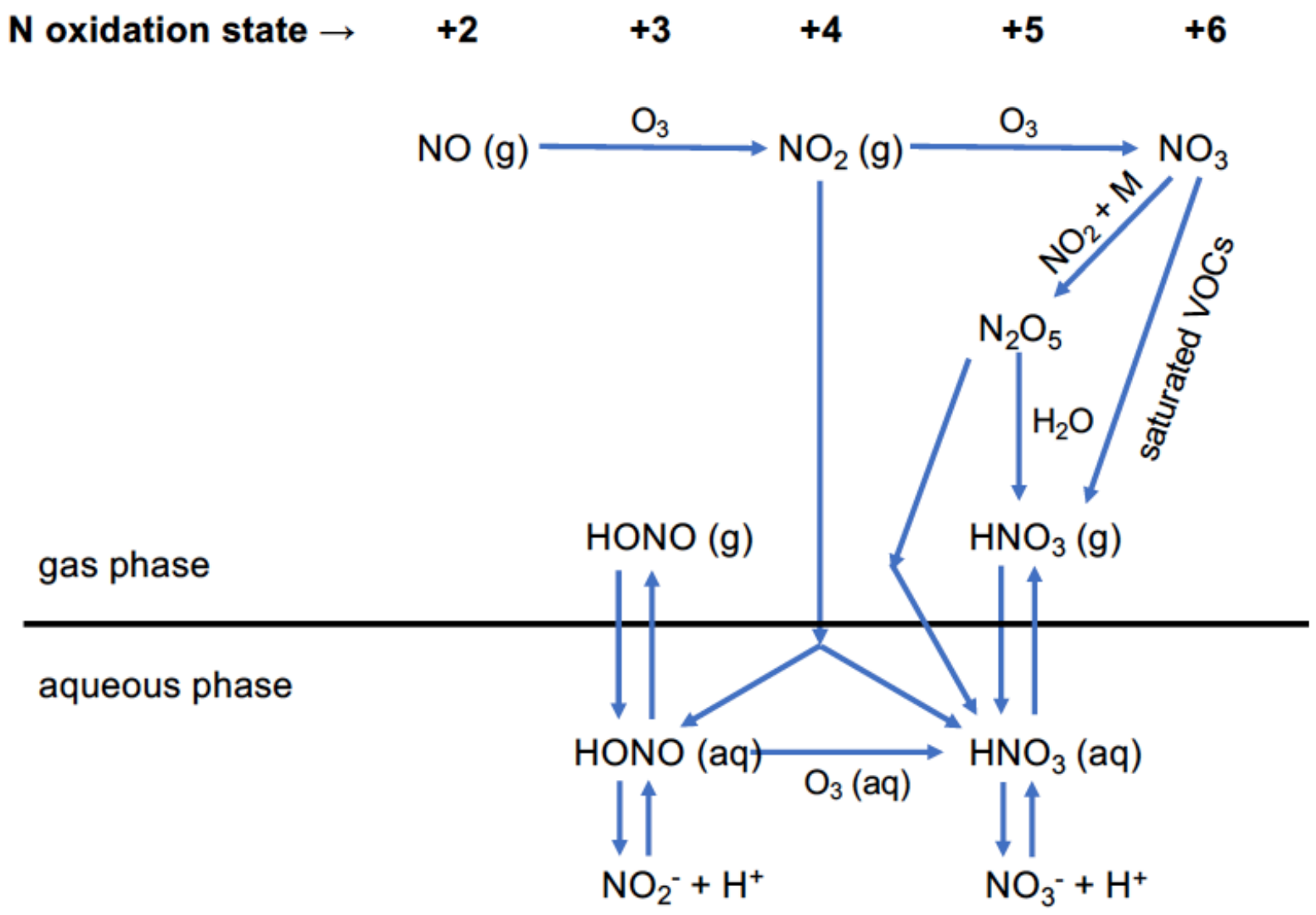

Figure 8. 


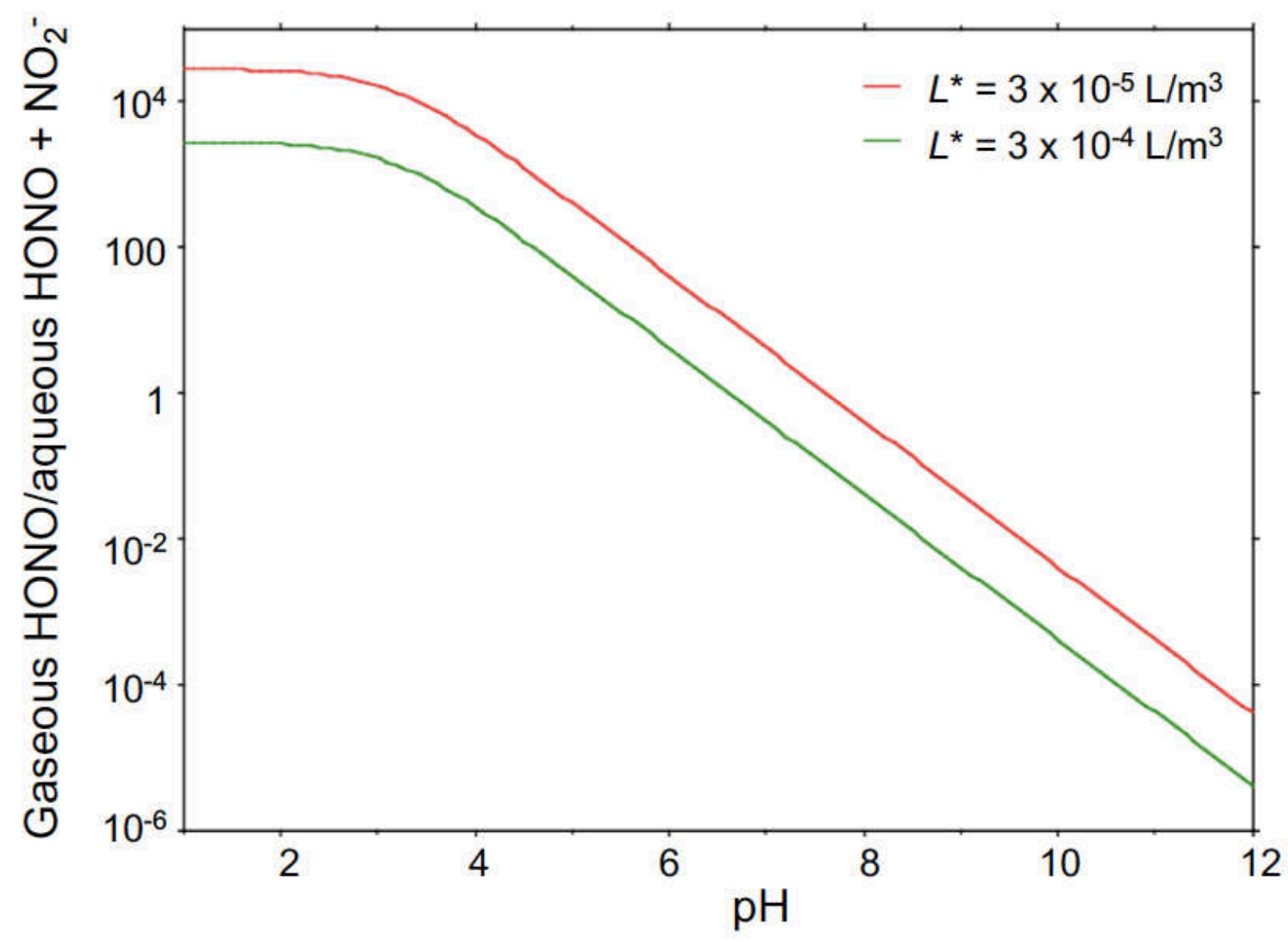

Figure 9. 


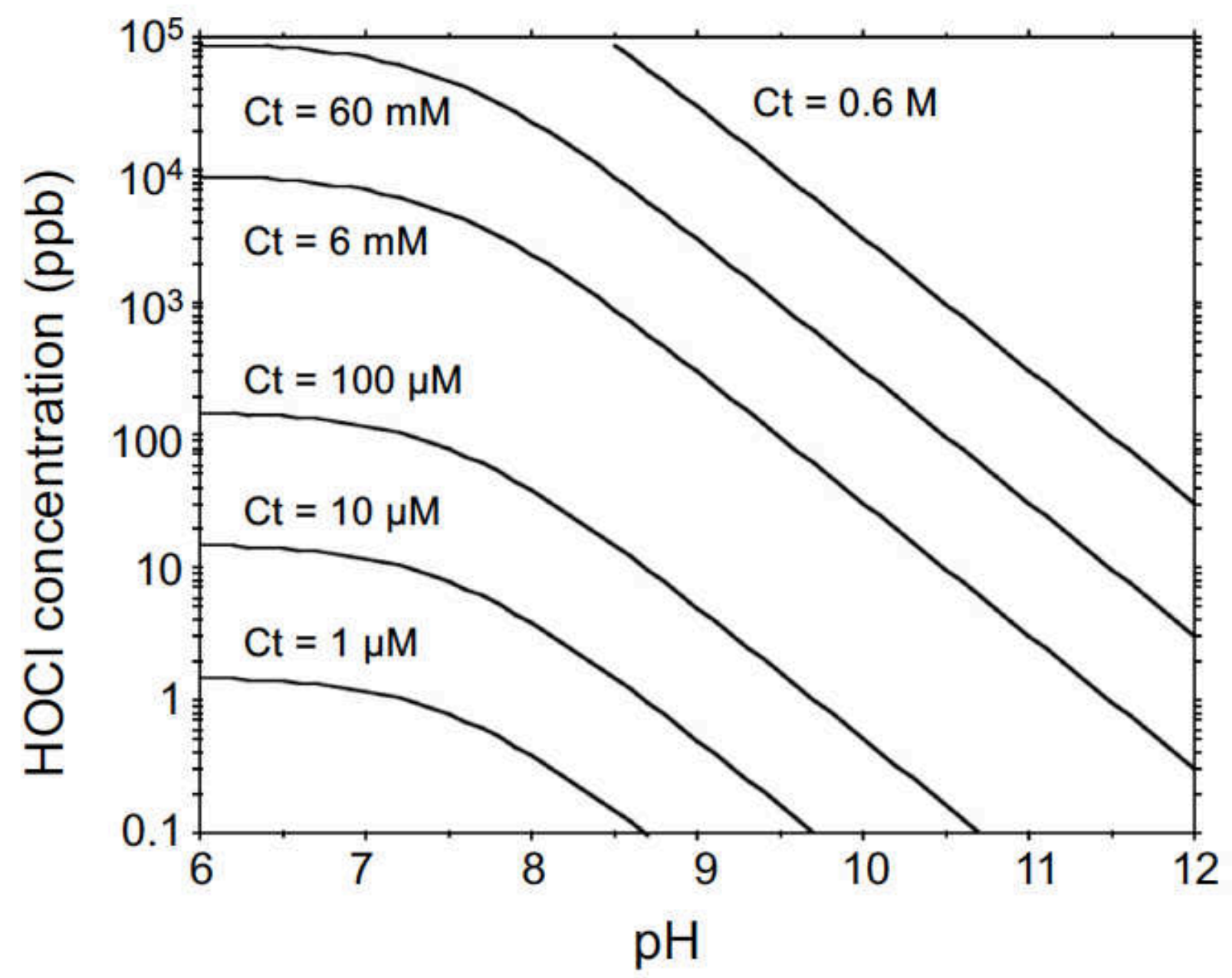

Figure 10. 
Formic acid

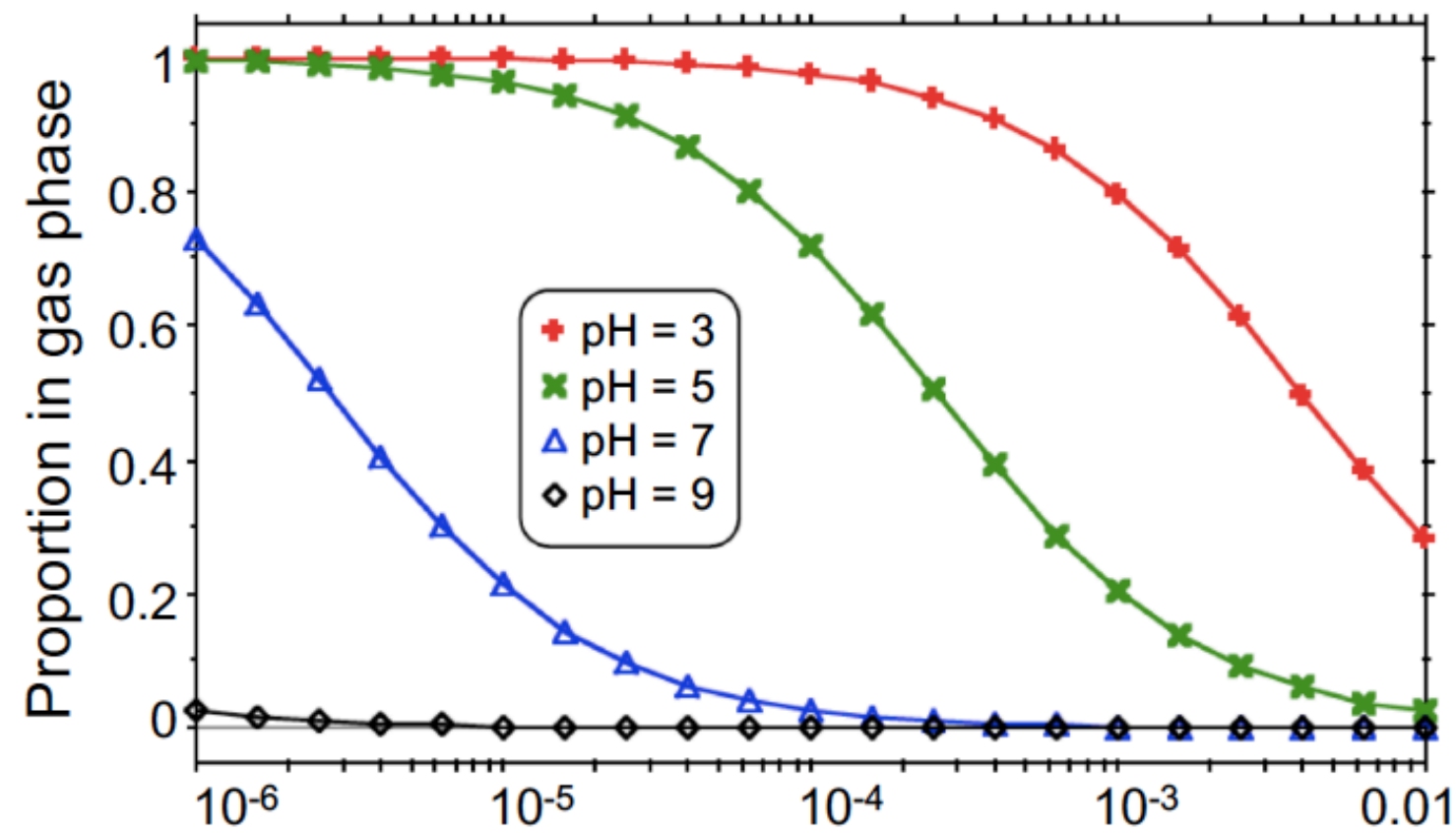

Liquid water volume fraction, $L^{*}\left(\mathrm{~L} \mathrm{~m}^{-3}\right)$

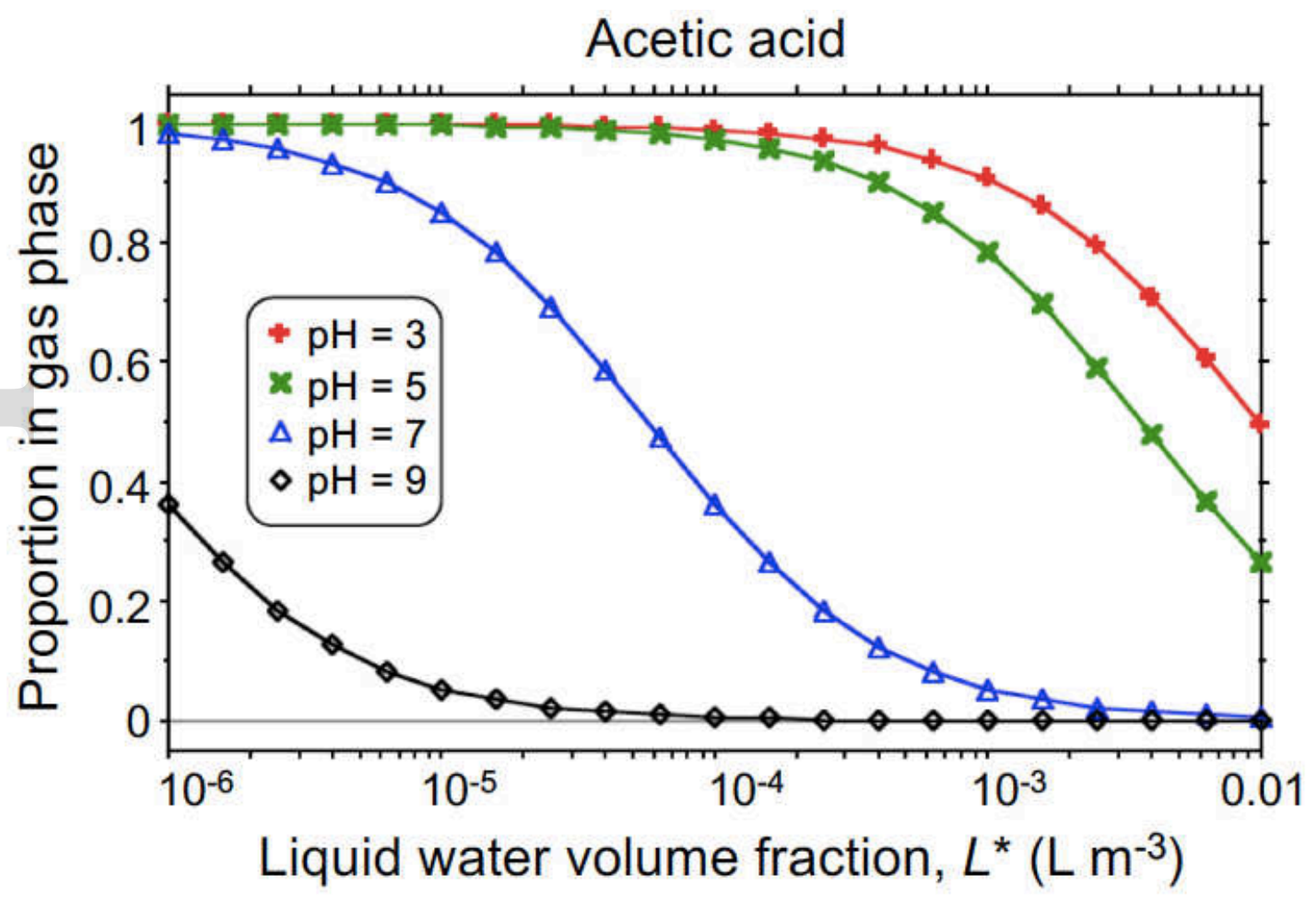

Figure 11. 


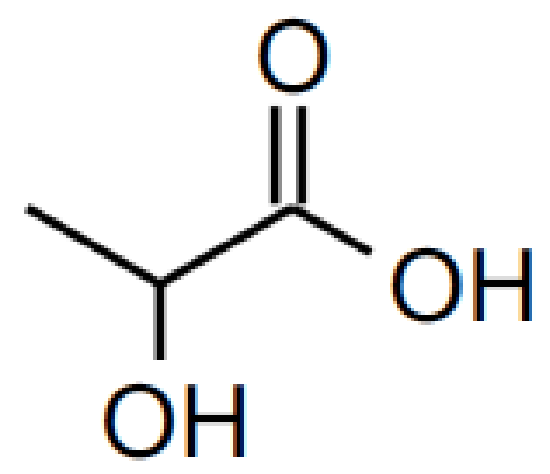

Figure 12.<smiles>O=C(O)CC(=O)O</smiles>

Oxalic acid
Malonic acid<smiles>O=C(O)CCC(=O)O</smiles>

Succinic acid

Figure 13.

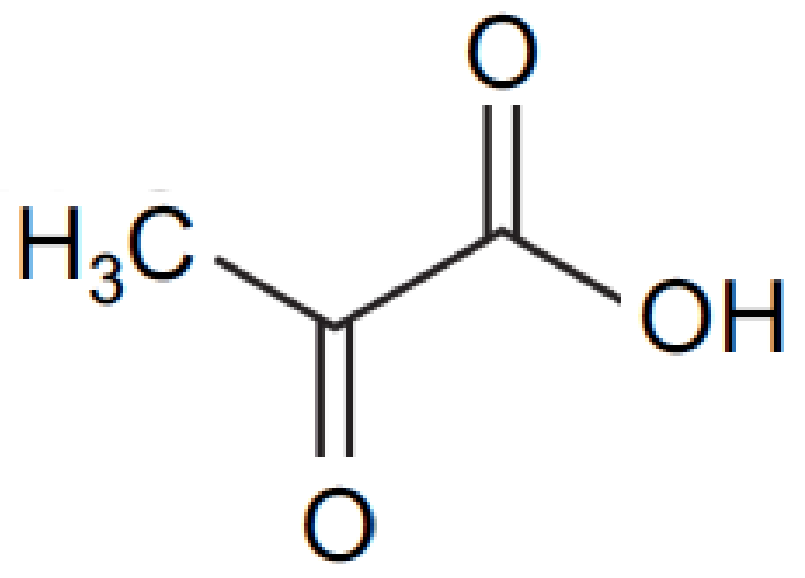

Figure 14. 


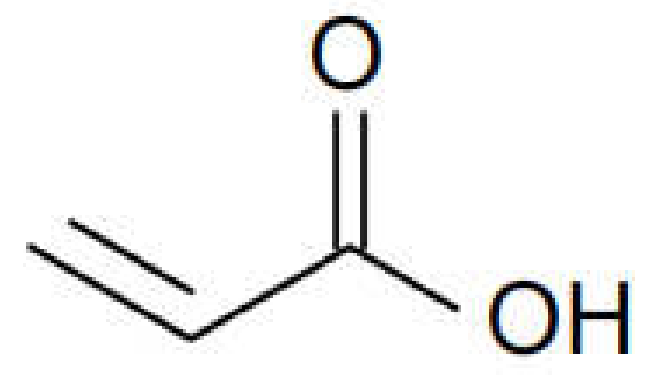

Figure 15.
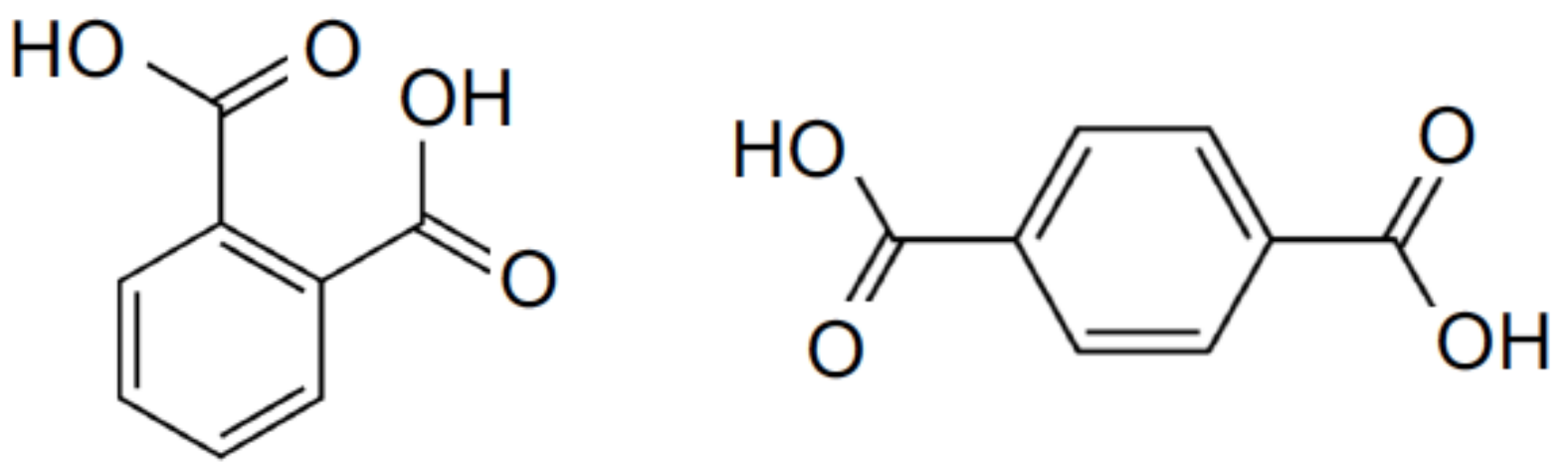

Phthalic acid

Terephthalic acid

Figure 16.

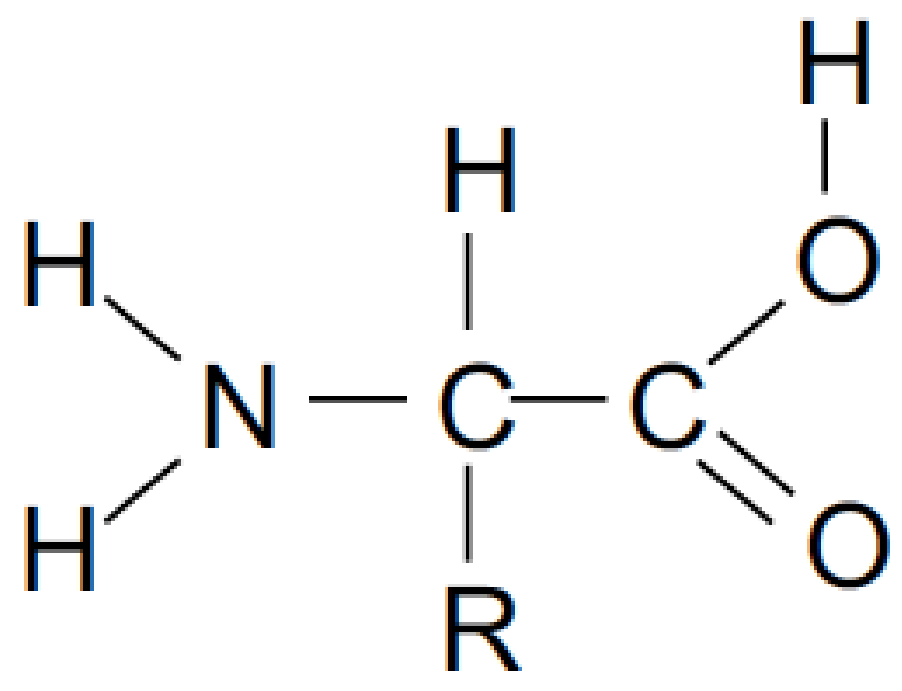

Figure 17. 


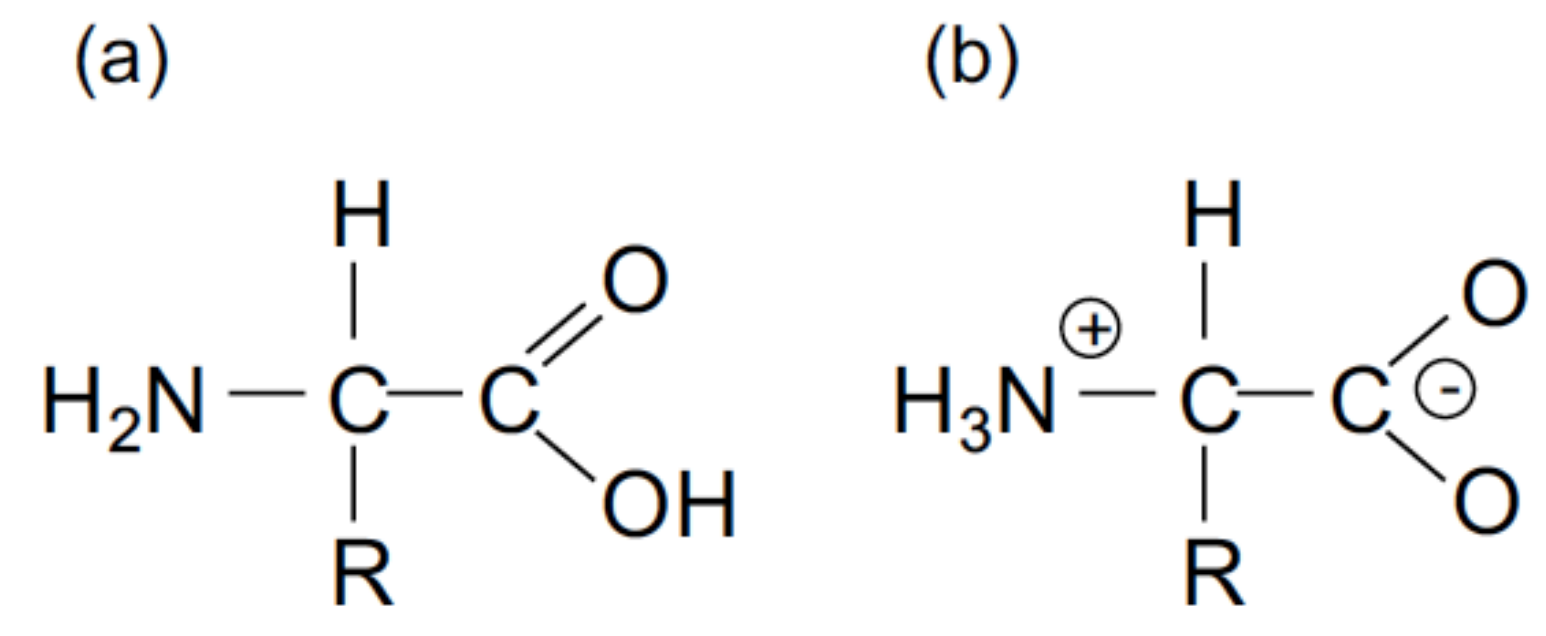

(b)

Figure 18.

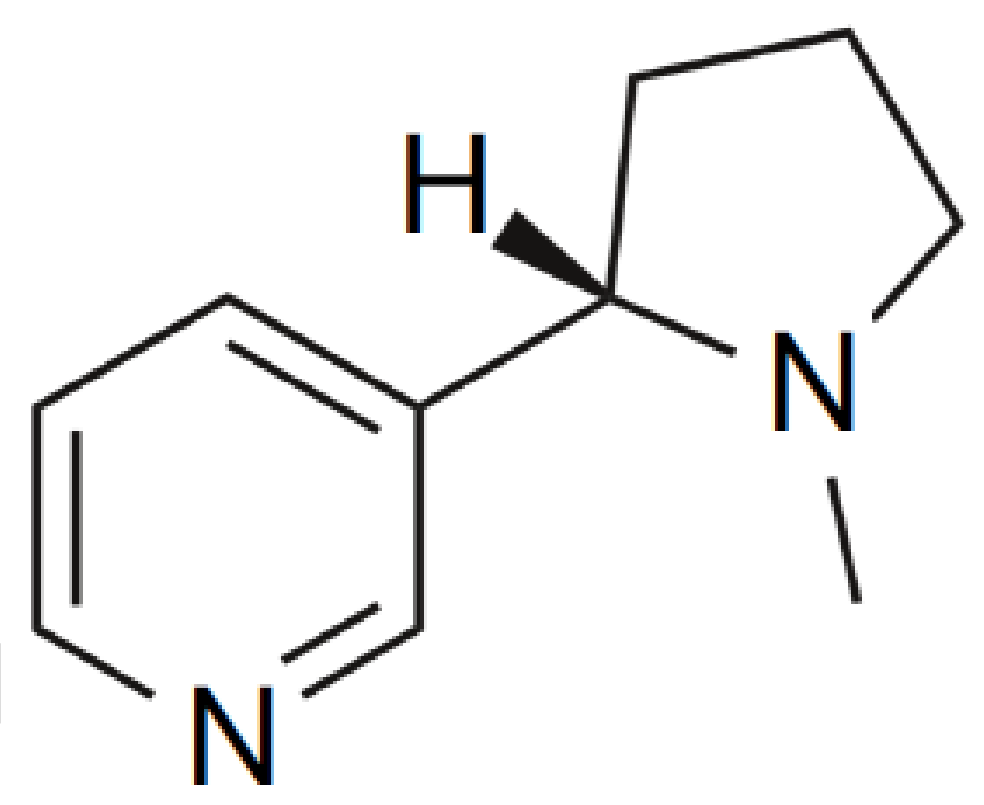

Figure 19. 


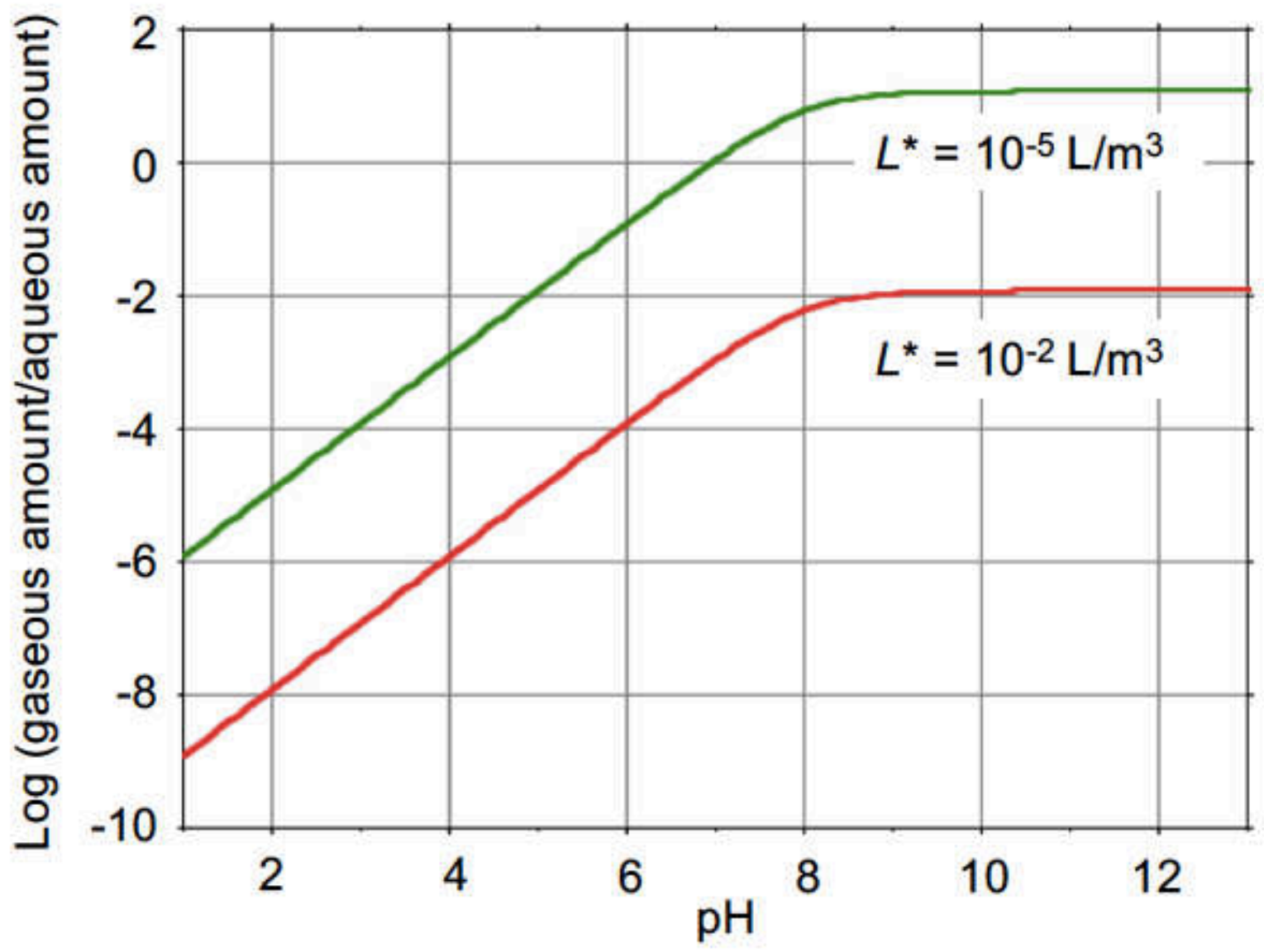

Figure 20. 
Particle phase

Case A

- Lower particle pH

- Higher proportion of $\mathrm{NicH}^{+}$in particles

- Lower proportion of $\mathrm{Nic}$ in gas phase

\section{Case B}

- Higher pH

- Lower proportion of $\mathrm{NicH}^{+}$in particles

- Higher proportion of Nic in gas phase

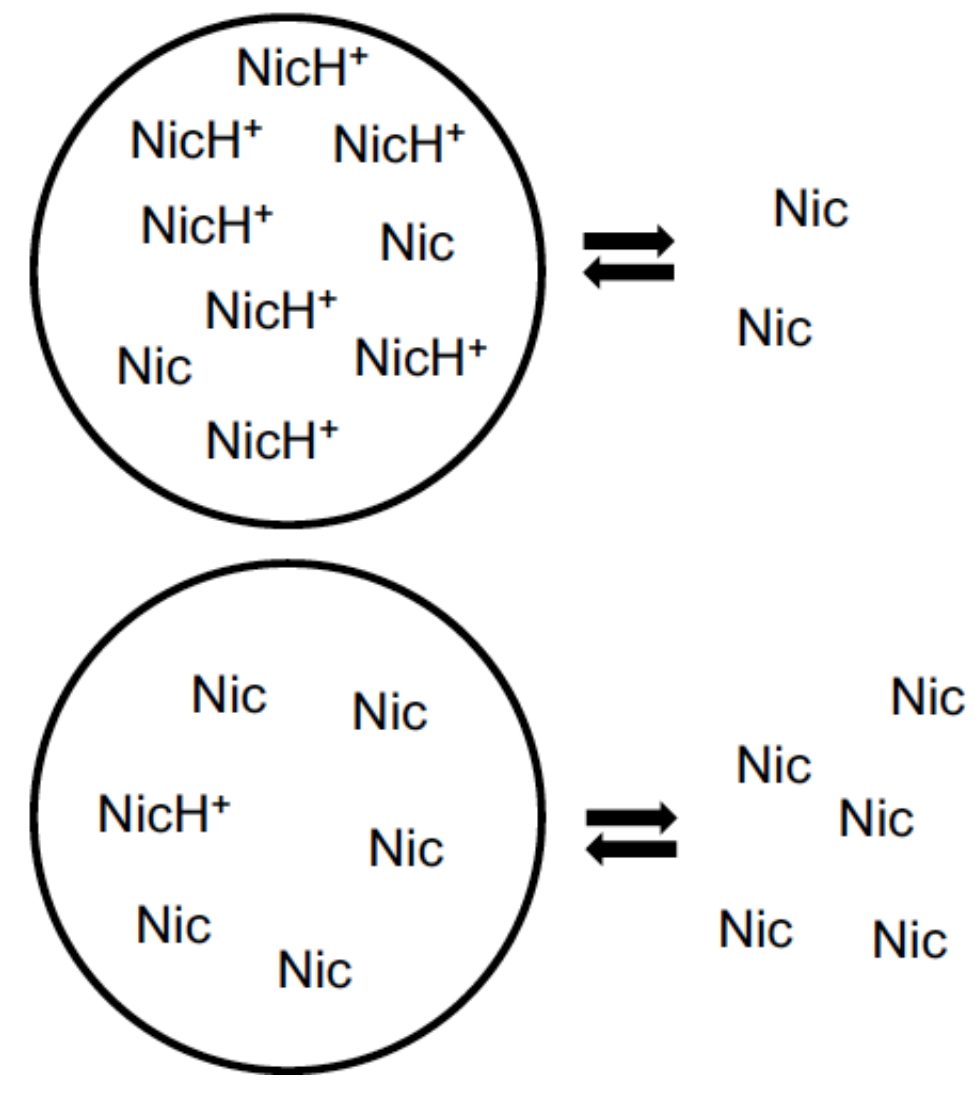

Figure 21. 